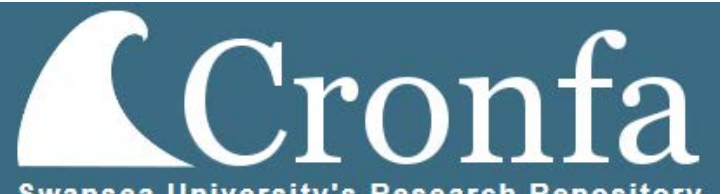

Swansea University's Research Repository

\title{
Brown trout in the Falkland Islands: invasion ecology, population structure and genetic diversity
}

\author{
Jessica F. Minett \\ College of Science \\ Swansea University
}

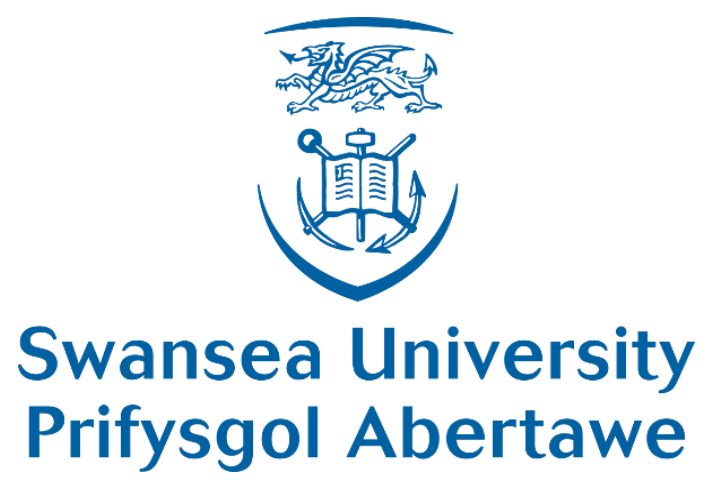

This thesis is submitted for the degree of

Doctor of Philosophy

2021 


\section{Summary}

Biological invasions are important causes of biodiversity loss, particularly in remote islands. Non-native salmonids, such as brown trout (Salmo trutta), have been widely introduced throughout the Southern Hemisphere, impacting endangered native fauna, particularly galaxiid fishes, through predation and competition. However, due to their importance for sport fishing and aquaculture, they are often protected, and any attempts to curtail their impacts are generally met with limited support, which poses a conservation conundrum. The best prospect of protecting native galaxiids is to predict where and how salmonids might disperse. This thesis aims to answer three main questions about brown trout in the Falkland Islands in order to provide resource managers with information to facilitate conservation planning to minimize the impacts of brown trout on native galaxiids. (1) determine the distribution of invasive brown trout and native zebra trout, Aplochiton zebra and Aplochiton taeniatus. (2) estimate patterns of movement and (3) assess the population structuring and estimate levels of gene flow between different rivers and populations of brown trout in the Falklands. To meet these aims, I used state-of-the-art methods, including SNP genotyping, stable isotope analysis, acoustic tagging, and environmental DNA (eDNA) analysis. The results of this thesis suggest that establishment success (calculated as the proportion of historical introductions where brown trout became established) was $\sim 88 \%$ and that brown trout are continuing to spread from their original sites of introduction. The native Aplochiton species have disappeared from most rivers invaded by brown trout. Four genetically distinct clusters of brown trout were identified, with high levels of gene flow indicating widespread dispersal of brown trout across the Falkland Islands. Without strong containment, brown trout are predicted to invaded nearly all suitable freshwater habitats in the Falklands within the next $\sim 70$ years, which might put native galaxiids at a high risk of extinction. 


\section{Declaration and Statements}

I, Jessica Minett, certify that this work has not previously been accepted in substance for any degree and is not being concurrently submitted in candidature for any degree.

Signed

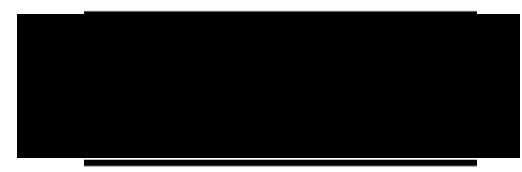

(candidate)

Date 17/07/2021

\section{STATEMENT 1}

This thesis is the result of my own investigations, except where otherwise stated. Where correction services have been used, the extent and nature of the correction is clearly marked in a footnote(s).

Other sources are acknowledged by footnotes giving explicit references. A bibliography is appended.

Signed

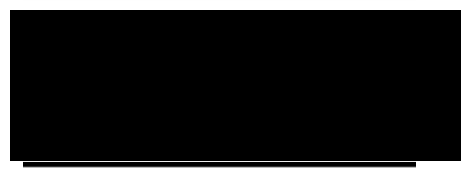

(candidate)

Date 17/07/2021

\section{STATEMENT 2}

I hereby give consent for my thesis, if accepted, to be available for photocopying and for inter-library loan, and for the title and summary to be made available to outside organisations.

Signed

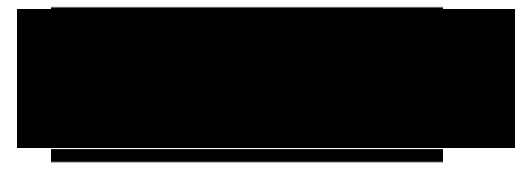

(candidate)

Date 17/07/2021 


\section{Authorship Declaration}

The following people and institutions contributed to the publication of work undertaken as part of this thesis:

\begin{tabular}{|c|c|c|c|}
\hline & Name & Institution & $\begin{array}{l}\text { Contribution } \\
\text { chapter }\end{array}$ \\
\hline Candidate & Jessica F. Minett & Swansea University & Chapter 2, 3 and 4 \\
\hline Author 1 & Sofia Consuegra & Swansea University & Chapter 2, 3 and 4 \\
\hline Author 2 & Carlos Garcia de Leaniz & Swansea University & Chapter 2, 3 and 4 \\
\hline \multirow[t]{2}{*}{ Author 3} & Paul Brickle & $\begin{array}{l}\text { South Atlantic Environmental } \\
\text { Research Institute }\end{array}$ & Chapter 2, 3 and 4 \\
\hline & & University of Aberdeen & \\
\hline Author 4 & Glenn T. Crossin & Dalhousie University & Chapter 3 and 4 \\
\hline Author 5 & Daniel M. Fowler & Swansea University & Chapter 3 \\
\hline Author 6 & Josh A. H. Jones & Swansea University & Chapter 3 \\
\hline Author 7 & Halina Sobolewska & Noahgene Ltd. & Chapter 4 \\
\hline
\end{tabular}


Author details and their roles:

Paper 1, A new high-resolution melt curve eDNA assay to monitor the simultaneous presence of invasive brown trout (Salmo trutta) and endangered galaxiids, Chapter 2.

Candidate contributed to the study idea, designed the methodology, carried out the sampling, laboratory work and analysis, and wrote the manuscript. Author 1 conceived the idea, aided with laboratory work and analysis, and wrote and contributed to the manuscript. Author 2 conceived the idea, secured funding, and contributed critically to the drafts and final version of the manuscript. Author 3 conceived the idea, secured funding, and contributed critically to the drafts and final version of the manuscript.

Paper 2, Conservation of endangered galaxiid fishes in the Falkland Islands requires urgent action on invasive brown trout, included in Chapter 3.

Candidate contributed to the study idea, collected and curated the data, designed the methodology, wrote the scripts, ran the models and analysed the data, interpreted the outputs and wrote the first draft. Author 1 conceived the idea and contributed critically to the drafts and final version of the manuscript. Author 2 conceived the idea, aided with the design of the methodology and interpretation of the results, and wrote and contributed to the manuscript. Author 3 conceived the idea and contributed critically to the drafts and final version of the manuscript. Author 4 conceived the idea and contributed critically to the drafts and final version of the manuscript. Author 5 contributed to data collection, carried out sampling and contributed critically to the drafts and final version of the manuscript. Author 6 designed the methodology, wrote the scripts, aided in the analysis and interpretation of outputs, and contributed critically to the drafts and final version of the manuscript.

Paper 3, SNP analysis and acoustic tagging reveal multiple origins and widespread dispersal of invasive brown trout in the Falkland Islands, Chapter 4.

Candidate contributed to the study idea, designed methodology, carried out sampling and analysis, and wrote the manuscript. Author 1 conceived the idea, aided with analysis, and wrote and contributed to the manuscript. Author 2 conceived the idea, secured funding, and contributed critically to the drafts and final version of the manuscript. Author 3 conceived the idea, secured funding, and contributed critically to the drafts and final version of the manuscript. Author 4 conceived the idea, secured funding, designed methodology and contributed critically to the drafts and final version of the manuscript. Author 7 designed 
methodology, carried laboratory work, and contributed critically to the drafts and final version of the manuscript.

We the undersigned agree with the above stated proportion of work undertaken for each of the above submitted peer-reviewed manuscripts contributing to this thesis:

Candidate

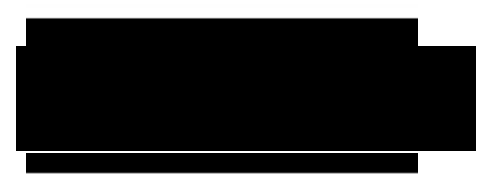

Author 1

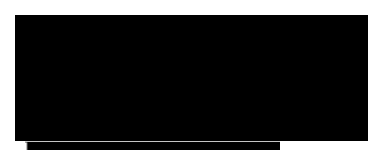

Author 2

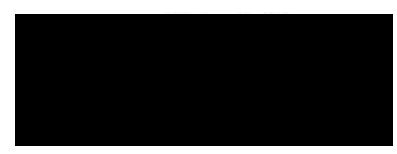

Author 4

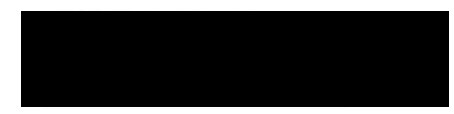

Author 5

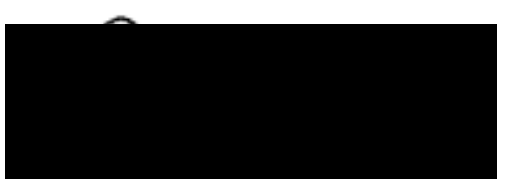

Author 6



Author 7

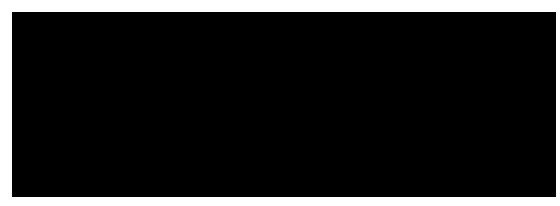




\section{Contents}

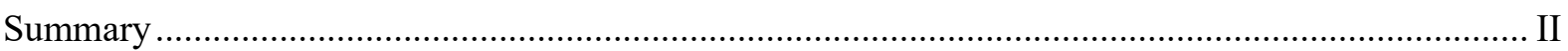

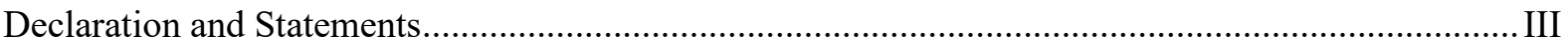

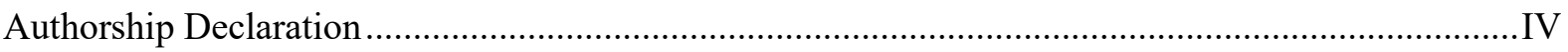

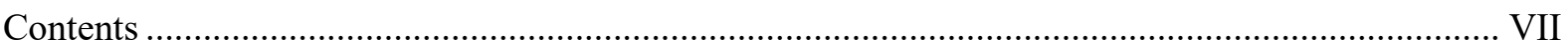

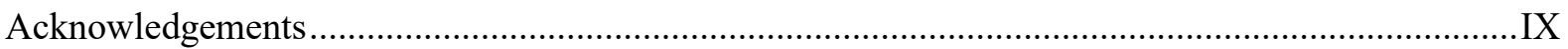

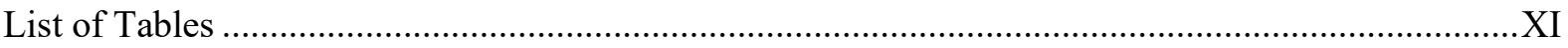

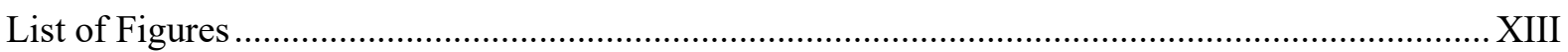

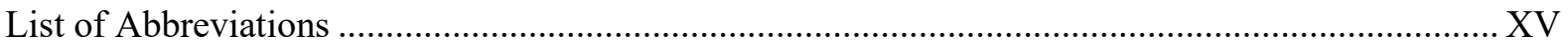

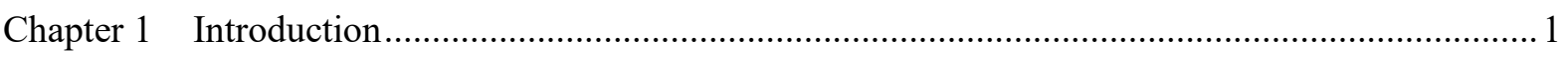

1.1 Freshwater Ecosystems and Invasive Species................................................................... 1

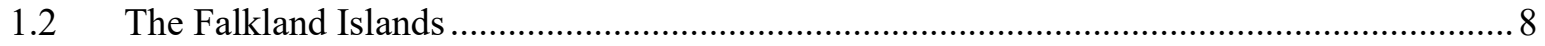

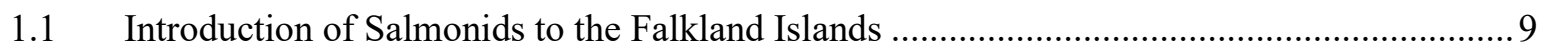

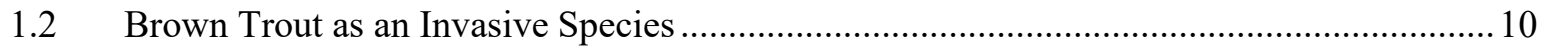

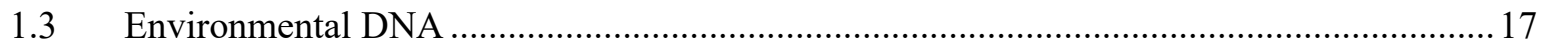

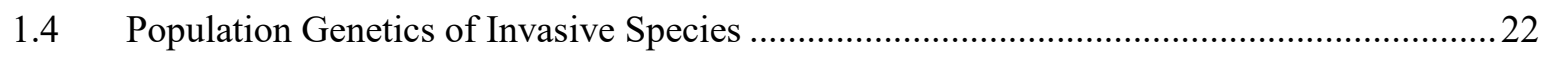

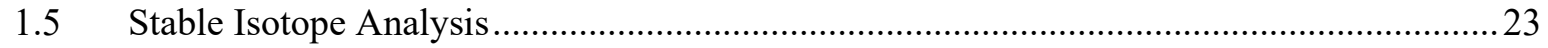

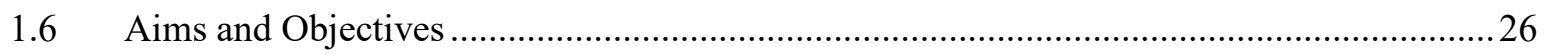

Chapter 2 A new high-resolution melt curve eDNA assay to monitor the simultaneous presence of invasive brown trout (Salmo trutta) and endangered galaxiids .......................................................2 27

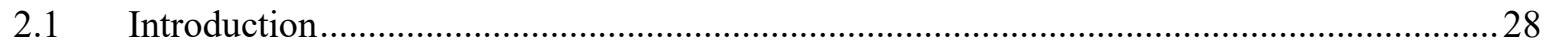

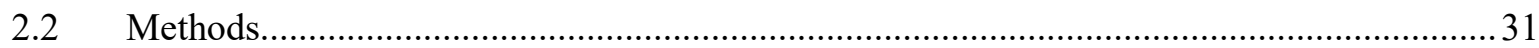

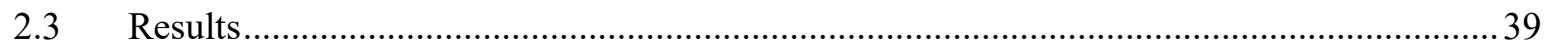

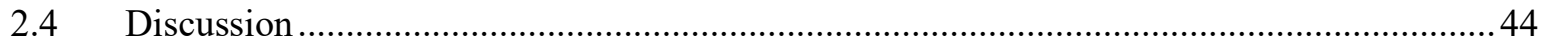

Chapter 3 Conservation of endangered galaxiid fishes in the Falkland Islands required urgent action on invasive brown trout

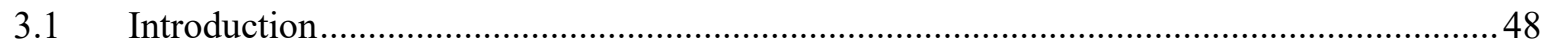

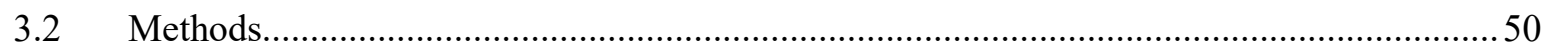




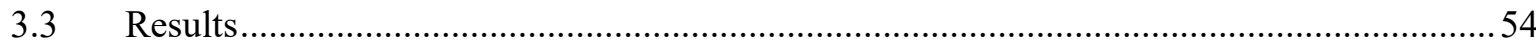

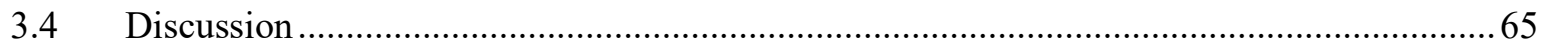

Chapter 4 SNP analysis and acoustic tagging reveal multiple origins and widespread dispersal of invasive brown trout in the Falkland Islands



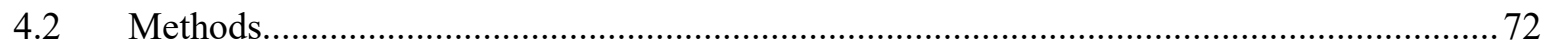

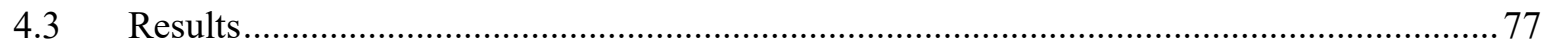

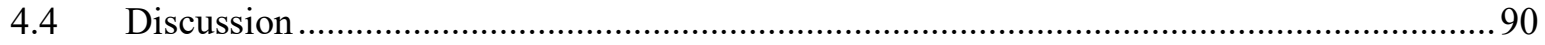

Chapter 5 Stable isotope analysis reveals multiple life history strategies and the extent of migratory brown trout in the Falkland Islands................................................................................... 93

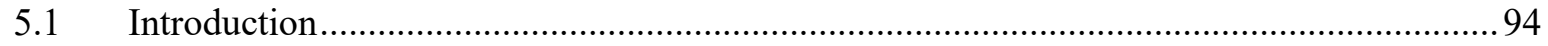

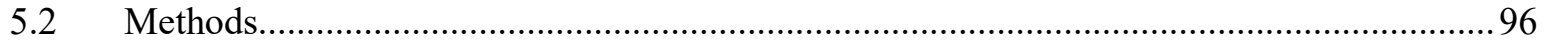

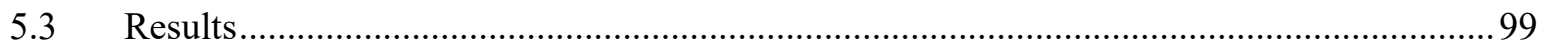

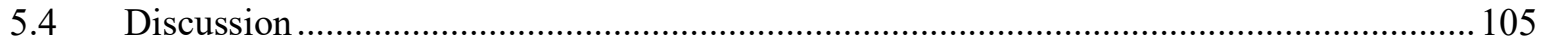

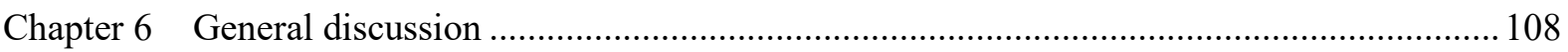

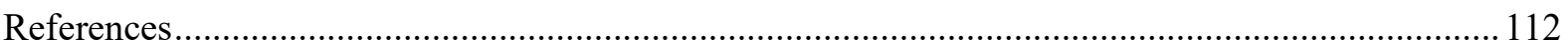

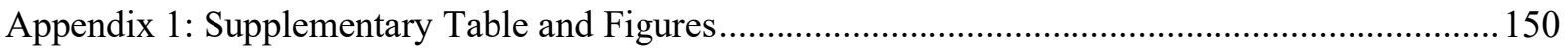

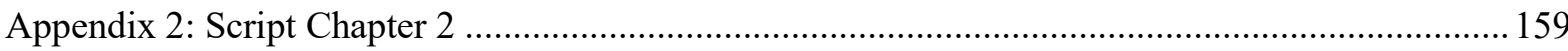

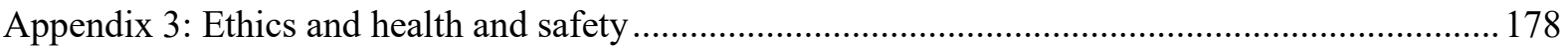




\section{Acknowledgements}

Firstly, I wish to thank my supervisors Professor Carlos Garcia de Leaniz, Professor Sonia Consuegra and Dr Paul Brickle for giving me the opportunity to undertake this project and to become part of their research groups both in Swansea University and at the South Atlantic Environmental Research Institute (SAERI) in the Falklands Islands. It has been a privilege to develop both as a person and a researcher within your groups, and thank you for your continued enthusiasm, guidance, and support.

This project would not have been possible without the support and funding from Fortuna Ltd. Thank you for funding my research for three and a half years and allowing me to undertake this exciting and fascinating project!

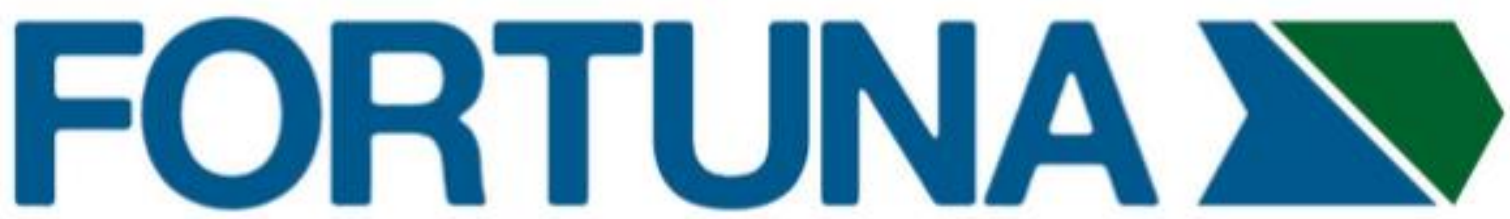

I am grateful to SAERI and all of their staff who have supported me throughout this project, in particular Paul Brewin who hosted me during my fieldwork and assisted with acoustic receiver deployment and retrieval. I am also extremely thankful to Steve Cartwright and Shallow Marine Surveys Group for all of their help and without who I would not have been able to deploy and retrieve the acoustic receivers.

I also wish to thank Dr Glenn Crossin for his support, guidance, and for answering my endless list of question on tagging and acoustic tracking. Thank you to the Ocean Tracking Network for lending me 10 acoustic receivers.

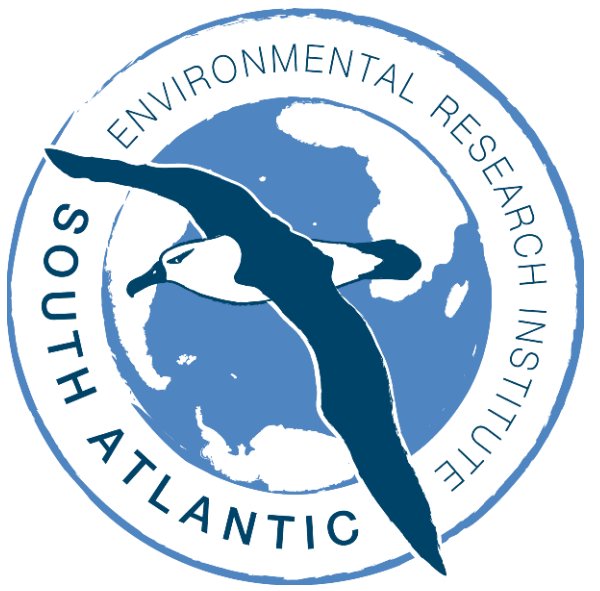

I would also like to thank all of the landowners that allowed me to sample of their land, and I am extremely grateful for all those who assisted with sampling: Nickolas Bonner, Amy Guest, Daniel Fowler, Megan Boldenow, Peter Nightingale, Will Goss, Luke Davies, John 
Henry, Lee Ferriby, Cian Derbyshire, Martin Carey, Marcello Cazzola, Connor McLeod, Mike Evans, Katherine Ross, Emma Phillips, Denise Blake and Fraser Gould, without who I would not have been able to conduct my research. Thanks to Chloe Robinson for assisting with sampling design, Tamsyn Uren Webster for providing support with primer design and testing, and William P. Kay for providing R code to calculate distance around the coast. For the acoustic tracking component of this study a big thanks the Ocean Tracking Network at Dalhousie University, Halifax, NS, Canada for an equipment loan, and to Glenn Crossin for all of your assistance and answering my many questions!

Thanks to all the FishBEE lab and all the PGR students at Swansea (particularly those in 037 !), I couldn't have done this without you, thank you for looking after me and creating an amazing working environment! I am eternally grateful to all my friends and family for the unconditional and continued support and encouragement. A special thanks to my Grandad, Alistair Bell, who continuously encouraged me and provided me with so many amazing experiences, if it wasn't for you taking me sailing and on so many trips to the beach and rockpools I don't think I would be where I am today! Lastly, a massive thank you to Ryan, I am forever grateful for your continued love and support!

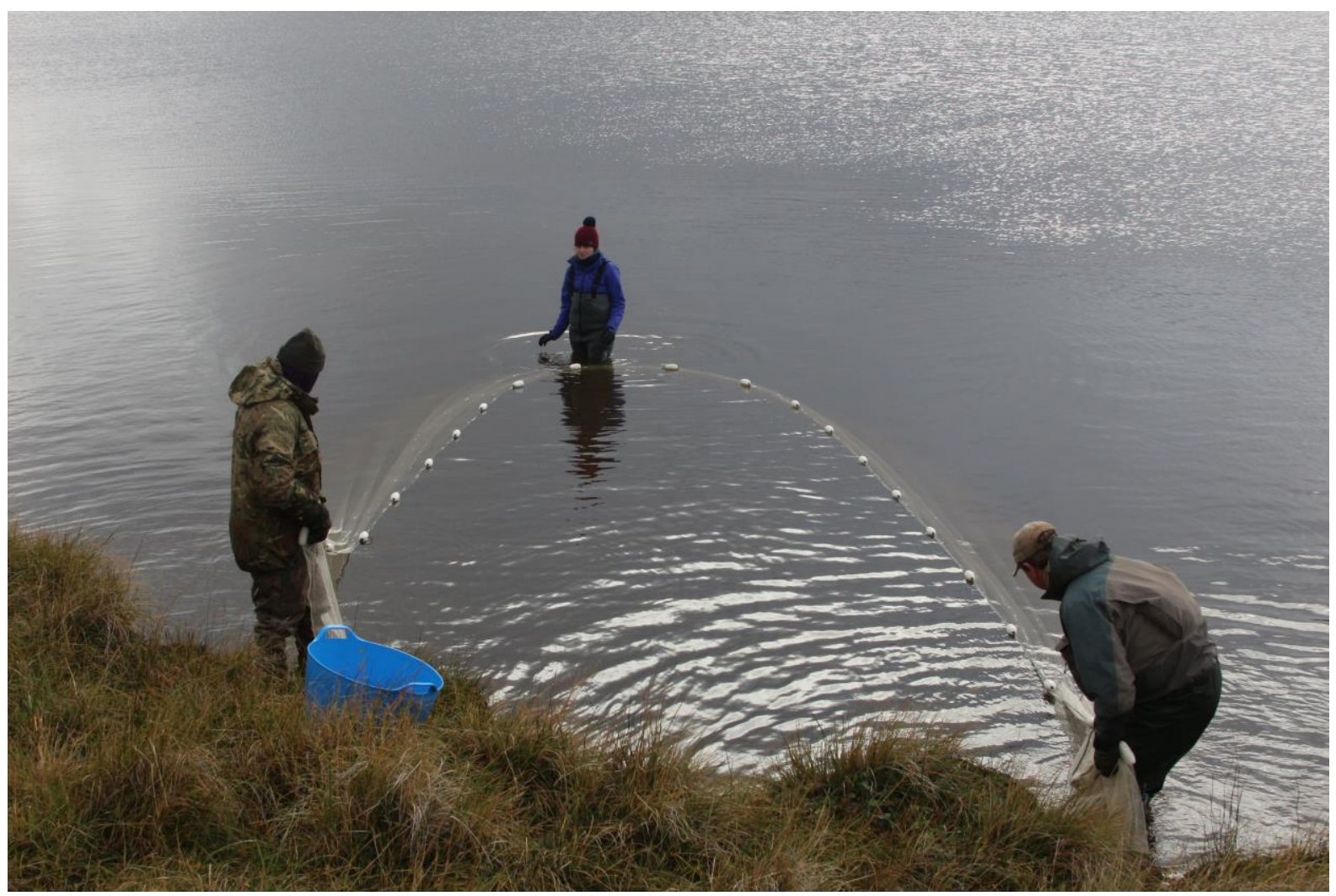




\section{List of Tables}

Table 1.1. Main threats faced by Freshwater ecosystems. 7

Table 2.1. Locations and environmental data for eDNA sampling sites, including latitude and longitude, temperature $\left({ }^{\circ} \mathrm{C}\right)$, shade cover (0-3), river width, $\mathrm{pH}$, total dissolved solids (TDS), electrical conductivity (EC) and total volume filtered.

Table 2.2. Species that could be cross amplified with AzebAtaeCytb and StruttaCytb primers, in silico cross amplification checks conducted using Primer-BLAST. None of the species are present in the Falkland Islands and in all cases the region sequenced has at least one base pair difference with the target species.

Table 2.3. Previous and current presence/absence data for the three study species at all sampling sites based on previous sampling using electrofishing and on current sampling using eDNA. Y $=$ species present, $\mathrm{N}=$ Species not present/detected. * zebra trout seen during eDNA sampling; ** brown trout caught/seen during eDNA sampling period. 41

Table 2.4. Total number of amplifications in waterbodies where brown trout or zebra trout were detected. 42

Table 2.5. Model output and AIC for all possible models used to determine if amplifications were affected by sampling conditions. Predictor variables included volume, shade, and season.

Table 3.1. Predictor variables used to generate species distribution model. Variables in bold had a VIF scores $<3$ (Kock and Lynn, 2012) and were included in the species distribution model. 53

Table 3.2. Sites of introductions of brown trout in the Falkland Islands 55

Table 3.3. Presence and absence of brown trout (St), Aplochiton spp. (Ap) and Galaxias maculatus $(\mathrm{Gm})$ in the Falkland Islands. Sites marked with an asterisk denote brown trout introduction sites (see Table 3.2). 58

Table 4.1. Details of sampling sites in the Falkland Islands and likely origin of the introduced stocks. Number in brackets corresponds to number of samples for Falklands-GB comparisons when number of samples differed from Falklands only analysis. Seine netting (SN), angling (A), and electrofishing (EF). Surrey trout farm (STF), Pentlands (P), German origin from Chile (G), and Middleton Hatchery $(\mathrm{MH})$. 76

Table 4.2. Estimates of genetic diversity (observed heterozygosity, Ho; observed gene diversity, Hs; $\mathrm{F}_{\mathrm{IS}}$, overall $\left.\mathrm{F}_{\mathrm{ST}}\right)$ and effective population size $\left(\mathrm{N}_{\mathrm{e}}\right)$ calculated according to linkage disequilibrium._ 78 
Table 4.3. Pairwise $\mathrm{F}_{\mathrm{ST}}$ values for Falkland Islands sample sites, calculated according to Weir and Cockerham.

Table 4.4. Pairwise $F_{\text {ST }}$ values for cluster $(K=4)$ of Falkland Islands samples, calculated according to Weir and Cockerham.

Table 4.5. Relative migration rates for Falkland Islands sample sites, migration rates calculated using $\mathrm{Nm}$.

Table 4.6. Pairwise $\mathrm{F}_{\mathrm{ST}}$ values for cluster $(\mathrm{K}=5)$ of Falkland Islands-GB comparisons, calculated according to Weir and Cockerham. 88

Table 4.7. Breakdown of acoustic receiver detection data in the Falklands Islands at three sites. 89

Table 5.1. Summary of samples collected from each site and sample size (N). Electrofishing (EF); seine netting (SN); angling (A). * Sites where invertebrate samples were also collected, ${ }^{+}$sites where Falklands minnows (Galaxias maculatus) were also found. 96

Table 5.2. Output for $\delta^{13} \mathrm{C}$ model 100

Table 5.3. Output for $\delta^{15} \mathrm{~N}$ model 100

Table 5.4. Life history strategies of Falkland Islands brown trout predicted through K-means cluster analysis based on $\delta^{13} \mathrm{C}$ and $\delta^{15} \mathrm{~N}$ values from adipose fin tissue from 14 sampling sites. 102

Table 5.5. Summary of brown trout stable isotope signatures for cluster 1, 2 and 3. Sample size $(\mathrm{N})$, mean Trophic level (TL)

Table S1. Model output and AIC for all possible models used to determine species distribution model. For information on predictor variables used see Table 3.1. 150

Table S2. Breakdown of fish acoustically tagged in the San Carlos River, Falkland Islands, including latitude and longitude, acoustic tag number, Length $(\mathrm{mm})$, and date tagged. 154

Table S3. Breakdown of invertebrate's present (1) and absent (0) at each sampling site, number of samples for sample isotope analysis $(\mathrm{N})$ and mean and standard error for Carbon and Nitrogen stable isotopes. 155

Table S4. Stable isotope and sample data for fish from each sample site assigned to each cluster. 156 


\section{List of Figures}

Figure 1.1. Global distribution of brown trout (Salmo trutta), data source: FishBase. This map does not indicate the countrywide presence, but that brown trout is categorized as an introduced species within that country. 11

Figure 1.2. Brown trout life cycle, images obtained from RiverLife and produced in BioRender. 13

Figure 1.3. Examples of brown trout (A and B) and zebra trout (C) caught in the Falkland Islands, image (C) kindly provided by Sonia Consuegra and Carlos Garcia de Leaniz. 14

Figure 1.4. Environmental DNA sample process flow chart, created in BioRender. 21

Figure 2.1. qPCR product melt curve profile for ratios of A. zebra:A. taeniatus DNA, red and blue peaks corresponds to positive $A$. zebra and A. taeniatus tissue samples respectively, whilst green peak is from a 50:50 A. zebra:A. taeniatus mix and orange and pink peaks correspond to 70:30 and 30:70 A. zebra and A. taeniatus mixes respectively. 32

Figure 2.2. qPCR product melt curve profile for positive tissue controls for Aplochiton zebra and Aplochiton taeniatus and eDNA sample amplifications. Red and blue peaks corresponds to positive A. zebra and A. taeniatus tissue samples respectively, the black peak is from an eDNA sample amplifying both $A$. zebra and $A$. taeniatus simultaneously, and orange and pink peaks correspond to eDNA samples amplifying $A$. zebra and A. taeniatus respectively. 33

Figure 2.3. eDNA sampling locations in the Falkland Islands. Current eDNA sampling locations (black circles), previously sampled sites where only zebra trout were present (white circles) and previously sampled sites with zebra trout and brown trout present (white triangle), previous sampled data obtained from McDowall et al (2001), Ross (2009) and Fowler (2012).

Figure 3.1. Map of the Falkland Islands showing (A) sites of the historical introductions of brown trout during 1944-1962 (details given in Table 3.2) and (B) presence/absence of brown trout and native Aplochiton species based on 1999-2012 surveys (detailed in Table 3.3) with six additional sites sampled in 2018-2019.

Figure 3.2. Frequency of occurrence ( $\%$ and binomial upper $95 \mathrm{CI})$ of native galaxiids (Aplochiton spp. and Galaxias maculatus $)$ in streams invaded $(\mathrm{N}=62)$ and in those uninvaded $(\mathrm{N}=72)$ by brown trout.

Figure 3.3. Risk map showing probabilities of brown trout invasion based on species distribution modelling. Aplochiton refugia at high risk of brown trout invasion are shown in zoomed insets. 63 
Figure 3.4. Modelled expansion of brown trout in the Falkland Islands under three different management scenarios.

Figure 4.1. Sampling locations for this study in the Falkland Islands (black circles) and sites where brown trout had been previously detected (white triangles) from McDowall et al. (2001), Ross (2009), and Fowler (2013). Sites where acoustic receivers deployed (red diamonds). 75

Figure 4.2. Cluster dendrogram of Falkland Islands sites, based on Nei's distance. 80

Figure 4.3. Bayesian Information Criterion (BIC) values for the different number of clusters in (A) Falkland Islands only data (optimal $\mathrm{K}=4$ ) and (B) Falkland Islands GB comparisons (optimal $\mathrm{K}=5$ ). 81

Figure 4.4. Discriminant Analysis of Principle Components (DAPC) analysis of population structure for (A) Falkland Islands brown trout based on 477 SNPs and K $=4$ and (B) Falkland Islands and GB brown trout based on $592 \mathrm{SNPs}$ and $\mathrm{K}=5$. Each bar corresponds to an individual and colours represent genetic clusters. $\left(^{*}\right)$ Indicate GB sites. 82

Figure 4.5. Discriminant Analysis of Principle Components (DAPC) for (A) Falkland Islands brown trout based on 477 SNPs and $\mathrm{K}=4$ and (B) Falkland Islands and GB brown trout based on 592 SNPs and $\mathrm{K}=5$. Dots represent individuals and colours represent genetic clusters. 85

Figure 4.6. Population structure of Falkland Islands brown trout when F1 hybrids and F2 backcrosses are accounted for. Hybridisation analysed between (A) cluster 1 and 4, (B) cluster 2 and 4, and (C) cluster 3 and 4. Bars represent individuals and colours represent cluster and hybrid group. 86

Figure 4.7. Relative migration network among Falkland Islands sampled rivers/lakes, migration rates calculated using $\mathrm{Nm}$, threshold set to 0.35 . 87

Figure 5.1. Map of sampling locations in the Falkland Islands 97

Figure 5.2. Relationship between length and $\delta^{13} \mathrm{C}(\mathrm{A})$ and $\delta^{15} \mathrm{~N}(\mathrm{~B})$, grouped by clusters determined from K-means clustering analysis. Mean and 95\% confidence intervals (whiskers) of length $(\mathrm{C}), \delta^{13} \mathrm{C}$ (D) and $\delta^{15} \mathrm{~N}$ (E) for each cluster. Stable isotope values obtained from adipose fin clips collected from brown trout in the Falkland Islands. 101

Figure 5.3. Scatter plot of results of $\mathrm{K}$-means cluster analysis using $\delta^{13} \mathrm{C}$ and $\delta^{15} \mathrm{~N}$ stable isotopes found in adipose fin clips of brown trout in the Falkland Islands. 103

Figure 5.4. Examples of brown trout from cluster 1 (A), cluster 3 (B), and cluster 2 (C). Brown trout from Head of the Bay, Camilla Creek, and San Carlos, respectively. 104

Figure S1. Population structure for Falkland Islands (A) and Falkland Islands GB comparison (B) when SNPs that significantly deviate from Hardy-Weinberg equilibrium are removed. A total of eight and nine SNPs were removed from Falkland Islands only and Falklands-GB comparisons, respectively. 153 


\section{List of Abbreviations}

\begin{tabular}{|c|c|}
\hline Abbreviation & Definition \\
\hline A & Angling \\
\hline $\mathrm{AIC}$ & Akaike Information Criterion \\
\hline AUC & Area Under the Curve \\
\hline $\mathrm{BIC}$ & Bayesian Information Criterion \\
\hline $\mathrm{bp}$ & Base pair \\
\hline $\mathrm{CI}$ & Confidence Intervals \\
\hline DAPC & Discriminant Analysis of Principle Components \\
\hline df & Degrees of freedom \\
\hline DNA & Deoxyribonucleic acid \\
\hline$E$ & Estimate \\
\hline $\mathrm{EC}$ & Electrical conductivity \\
\hline eDNA & Environmental DNA \\
\hline eDNA-HRM & Environmental DNA-high-resolution melt \\
\hline $\mathrm{EF}$ & Electrofishing \\
\hline $\mathrm{F}$ & F-statistic \\
\hline FIG & Falkland Islands Government \\
\hline $\mathrm{F}_{\text {IS }}$ & Inbreeding coefficient \\
\hline $\mathrm{F}_{\mathrm{ST}}$ & Proportion of the total genetic variance \\
\hline $\mathrm{g}$ & Grams \\
\hline GB & Great Britain \\
\hline Ho & Heterozygosity \\
\hline HRM & High-resolution melt \\
\hline hrs & Hours \\
\hline Hs & Gene diversity \\
\hline $\mathrm{Hz}$ & Hertz \\
\hline IBD & Isolation By Distance \\
\hline $\mathrm{k}$ & Thousand \\
\hline $\mathrm{K}$ & Number of centroids \\
\hline $\mathrm{Km}$ & Kilometres \\
\hline $\mathrm{Km}^{2}$ & Kilometres squared \\
\hline $\mathrm{L}$ & Litre \\
\hline LOD & Limit of detection \\
\hline LOOCV & Leave One Out Cross Validation \\
\hline LOQ & Limit of quantification \\
\hline LRT & Likelihood ratio test \\
\hline MAF & Minor Allele Frequency \\
\hline $\min$ & Minutes \\
\hline $\mathrm{ml}$ & Millilitre \\
\hline $\mathrm{mg}$ & Milligrams \\
\hline $\mathrm{MH}$ & Middleton Hatchery \\
\hline $\mathrm{mm}$ & Millimetre \\
\hline $\mathrm{mt}$ & Mitochondrial \\
\hline $\mathrm{N}$ & Number \\
\hline $\mathrm{N}_{\mathrm{e}}$ & Effective population size \\
\hline $\mathrm{Nm}$ & $\begin{array}{l}\text { Gene flow parameter - product of effective population number and rate of } \\
\text { migration }\end{array}$ \\
\hline
\end{tabular}




\begin{tabular}{|c|c|}
\hline ng & Nanograms \\
\hline No. & Number \\
\hline$p$ & P-value \\
\hline PCR & Polymerase chain reaction \\
\hline PES & Polyethersulfone \\
\hline $\mathrm{r}$ & Correlation coefficient \\
\hline SE & Standard error \\
\hline $\mathrm{Sec}$ & Seconds \\
\hline SIA & Stable isotope analysis \\
\hline SN & Seine netting \\
\hline SNP & Single Nucleotide Polymorphism \\
\hline Spp. & Species \\
\hline$t$ & Test statistic \\
\hline TDS & Total dissolved solids \\
\hline TL & Trophic level \\
\hline $\operatorname{tm}$ & Melt temperature \\
\hline$\mu 1$ & Microliter \\
\hline$\mu \mathrm{m}$ & Micrometre \\
\hline$\mu \mathrm{M}$ & Micromolar \\
\hline USGS & United States Geological Survey \\
\hline UV & Ultraviolet \\
\hline qPCR & Quantitative PCR \\
\hline $\mathrm{V}$ & volt \\
\hline VIF & Variance Inflation Factor \\
\hline$\chi^{2}$ & Chi-squared statistic \\
\hline$\%$ & Parts per thousand \\
\hline${ }^{\circ} \mathrm{C}$ & Degrees Celsius \\
\hline$\%$ & Percentage \\
\hline$\sim$ & Approximately \\
\hline$\delta$ & Delta \\
\hline$\%$ & Parts per thousand \\
\hline
\end{tabular}




\section{Chapter 1 Introduction}

\subsection{Freshwater Ecosystems and Invasive Species}

Freshwater ecosystems contain only $0.01 \%$ of the world's water and cover $5-7 \%$ of the Earth's surface. Yet, they are home to one-third of all vertebrate species, including almost $50 \%$ of global fish diversity, over 14,736 species (Lundberg et al., 2000; Lehner and Do, 2004; Balian et al., 2008; Vega and Wiens, 2012). Despite such species richness freshwater ecosystems are experiencing declines in biodiversity at a far greater rate than any terrestrial ecosystems. In 2016 the Living Planet Index reported that freshwater vertebrates declined by $81 \%$ between 1970 and 2012, representing an annual decline of 3.9\%. In contrast, land and sea vertebrates declined by $38 \%$ and $36 \%$ respectively (Collen et al., 2009; World Wildlife Foundation, 2016). Therefore, freshwater ecosystems could be classified as the most endangered ecosystem in the world (Sala et al., 2000; Dudgeon et al., 2006). Previous work by Dudgeon et al. (2006) identified five main challenges to freshwater ecosystems; however, a more recent study by Reid et al. (2019) named 12 emerging threats to freshwater biodiversity; amongst both was the introduction of invasive species, Table 1.1 (Dudgeon et al., 2006; Reid et al., 2019). Without appropriate measures, freshwater ecosystems which provide critical ecosystem services, essential to humanity and freshwater biodiversity will be endangered (Sala et al., 2000; Rockström and Karlberg, 2010).

Strong human dependence on freshwaters has resulted in widespread water pollution, habitat degradation and biodiversity loss due to changes in land use, the introduction of invasive species and flow modification (Malmqvist and Rundle, 2002; Dudgeon et al., 2006; Reid et $a l ., 2019)$. Due to the expanding human population requiring more urban and agricultural zones, the demand for freshwater resources is increasing (Martinuzzi et al., 2014). Additional agricultural zones are required to meet a growing need for food production. However, this can lead to increased levels of sediment, pesticides and nutrients entering freshwaters (Schaller et al., 2004), consequently resulting in changes to the water chemistry, causing eutrophication and harmful algal blooms (Heisler et al., 2008; Moss, 2008). Endocrinedisrupting chemicals and antimicrobials have also been found entering freshwater from urban wastewater. Synthetic hormones can result in the development of intersex in male fishes which can have transgenerational effects and reduced species fitness and abundance (Jobling et al., 2002; Harris et al., 2011; Schwindt et al., 2014). Changes in land use can also alter stream flows and diminish flood pulses through flow modification in order to support 
agricultural systems, consequently decreasing stream-channel and riparian habitats, biodiversity, and reducing native fish movement (Schlosser, 1995; Poff et al., 1997; Roy et al., 2003; Scanlon et al., 2007; King et al., 2011).

The flow of freshwater systems can be modified through instream infrastructure and impact many aspects of an ecosystem, for example, dams, weirs, and culverts can affect species movement, alter water chemistry and sediment dynamics, and create discontinuities in temperature (Andersson et al., 2000; Stanley and Doyle, 2002; Mueller et al., 2011; Pépino et al., 2012; McIntyre et al., 2015; Oele et al., 2019). The development of instream infrastructure is increasing at unprecedented rates with 11 small hydropower plants for every large dam globally (Couto and Olden, 2018). However, low head structures $(<1 \mathrm{~m})$ are often overlooked and missing from records, with field surveys indicating that barrier density is underestimated by over 60\% in current databases (Jones et al., 2019; Belletti et al., 2020). Thus $<1 \%$ of catchments are free of artificial barriers in the UK (Jones et al., 2019), and only $37 \%$ of rivers $>1000 \mathrm{~km}$ remain free-flowing globally (Grill et al., 2019).

Overexploitation is another major cause of freshwater biodiversity loss, although it predominantly impacts fishes, some reptiles and amphibians, certain aquatic invertebrates and mammals can also be affected. Despite primarily only being considered a problem with marine fisheries, overexploitation also widely affects freshwater ecosystems (Raby et al., 2011), especially in poorer and remote countries where freshwater species provide a critical source of protein (Allan et al., 2005; Welcomme et al., 2010; He et al., 2017). Overexploitation can contribute to species declines through targeted harvest, for example, sturgeon and paddlefish are being pushed to the brink of extinction due to intense fishing pressure for caviar, resulting in many fisheries crashing 7-20 years after launching and decreasing harvests, putting the survival of these species in the wild at risk (Pikitch et al., 2005), or through by-catch, as observed in the Yangtze River dolphin (Lipotes vexillifer), which was the first recorded extinction of a cetacean species due to human activity. Declines in the Yangtze River dolphin populations were mainly attributed to by-catch in local fisheries where electrofishing, gill and fyke nets, and rolling hooks were used, with $40 \%$ of Yangtze River dolphin mortality recorded during the 1990s attributed to electrofishing alone (Turvey et al., 2007).

Climate change is likely to exacerbate and magnify many of the other threats and challenges faced by freshwater ecosystems, as well as increasing water temperatures, creating changes in 
flow and water discharge, and shifts in species distribution. Extreme events (i.e., storm events, floods, and droughts) are likely to become more prevalent, with rising temperatures modifying species distributions and disease outbreaks. For example, cold-water species may experience a reduction in range (Meisner, 1990; Rahel, 2002; Xenopoulos et al., 2005), whereas temperate- and warm-water species may experience range expansions (Chu et al., 2005; Buisson et al., 2008). However, such range expansions may severely impact fish communities already inhabiting those watersheds, especially when invading species are top predators (Chu et al., 2005; Rahel and Olden, 2008). Climate change can impact population dynamics and community composition. For brook trout (Salvelinus fontinalis) increases in mean stream temperature have been shown to reduce the survival of the youngest age class, thus, decreasing overall population size (Bassar et al., 2016). Changes in population dynamics can have knock-on ecological impacts for communities, as observed in Rio Grande, New Mexico, where the onset of spawning advanced by 4-28 days between 2008-2010 compared to 1995. Therefore, decreasing the resource partitioning between species and altering the species composition (Krabbenhoft et al., 2014), similar effects have also been observed in aquatic insect communities (Thompson, 2016). In addition to warming temperatures, cold shock events, such as the rapid decrease in water temperature in Bolivia in 2010 that caused the mass mortality of fishes in the Amazon, are likely to become more widespread (Szekeres et al., 2016). Species in the tropics are more susceptible due to little seasonal variation, ensuing species are less adapted to fluctuations in temperature (Szekeres et al., 2014; Gutiérrez-Pesquara et al., 2016). Global temperature rises have resulted in a shift in the oviposition date of the Chinese alligator (Alligator sinensis) by 10 days between 19872005 (Zhang et al., 2009). Indicating the potential and substantial effects climate change can have on species phenology. Furthermore, rising temperatures can also impact species demographics by altering sex ratios (Thompson, 2016), in fishes the sex ratio can be significantly changed from 1:1 (males: females) to 3:1 (males: females) by an increase of only $1-2^{\circ} \mathrm{C}$ (Piferrer, 2008).

A wide range of species have been introduced to freshwaters around the world through accidental introductions, whereby species hitchhike on ships/planes transporting people and/or goods, or intentional introductions, where species are the commodity and, therefore, deliberately transported/released (Hulme, 2009). Many freshwater fish have been introduced for recreational purposes (e.g., angling) or as a result of aquaculture activities (Savini et al., 2010). For example, in Chile and Argentina it is commonplace to stock salmonids, mainly 
rainbow trout (Oncorhynchus mykiss) and brown trout (Salmo trutta) (Pascual et al., 2007). In addition, Chile became the second-largest producer of salmon in the 1990s and now generates $25 \%$ of global salmon production (Asche et al., 2013; Iversen et al., 2020). Yet, as salmon production in Chile increased, so did escapes from aquaculture net pens, leading to fish straying into rivers in Chile and Argentina and forming self-sustaining populations (Pascual et al., 2007; Arismendi et al., 2009; Di Prinzio and Pascual, 2009). As global trade and e-commerce has grown so has the intentional introduction of species to novel environments through exotic pet trade (Padilla and Williams, 2004; Keller and Lodge, 2007). Exotic plants and animals are now sold internationally via the internet and online auctions (Kay and Hoyle, 2001; Humair et al., 2015), resulting in species becoming established and invasive through accidental escapes and intentional releases (Lockwood et al., 2019). Seven to eight percent of pet owners have admitted to intentionally releasing pets into the wild due to excessive growth, aggressive behaviour, lack of space or rapid reproduction (Gertzen et al., 2014; Banha et al., 2019). Such introductions have resulted in $84 \%$ of the non-native amphibians and reptiles introduced to Florida arriving as a result of pet trade (Krysko et al., 2011), and over 10,000 fishes estimated to be released every year in Montréal, Canada (Gertzen et al., 2014). The trade of live bait has also contributed to the introduction of invasive species as anglers accidently or intentionally release unused bait, which can contain multiple non-target, and possibly invasive, species into waterbodies (Mahon et al., 2014; Nathan et al., 2014). Over 50\% of anglers have released live unused bait in the United States (Litvak and Mandrak, 1993; Kilian et al., 2012) with approximately 5\% of bait samples containing at least one target invasive fish species (Nathan et al., 2014), such releases have resulted in the known introduction of 47 freshwater species to the Mid-Atlantic slope region of the United States (Kilian et al., 2012).

Biological invasions are frequently thought of as a staged process (Richardson et al., 2000; Colautti and MacIsaac, 2004). Although often not linear, they are seen to be divided by barriers or ecological filters that species must pass before progressing to the next stage (Richardson et al., 2000; Colautti and MacIsaac, 2004; Mitchell et al., 2006). With the number of species reaching each stage diminishing due to the process (Williamson, 1993; Williamson and Fitter, 1996; Levine et al., 2004). Viewing invasion in such a way allows ecologists to conceptualise factors that may enable species to move from one stage to the next, guiding research and management actions. For example, Williamson's rule of ten states that 1 in 10 will pass from one stage to the next, with the stages being importation, 
introduction, establishment, and pest (Williamson and Fitter, 1996). However, biological invasions are a complicated process composed of many steps and drivers (e.g., propagule pressure and various biotic and abiotic factors), and the contribution of these different mechanisms to invasion success is unknown and likely varies depending on the invading species, time, and space (Pyšek and Richardson, 2006; Catford et al., 2009).

Although not all introduced species become invasive, those that do have been observed to have dramatic impacts on native species and ecosystems (Gallardo et al., 2016). Aquatic invasive species directly impact native populations through predation (McIntosh et al., 1994; Kats and Ferrer, 2003; Habit et al., 2010), competition (Jackson, 2002; Martin et al., 2010; Richter-Boix et al., 2013), and hybridization (Perry et al., 2002; Dufresnes et al., 2016), or indirectly through habitat modification (Jackson, 2002; Matsuzaki et al., 2009; EmeryButcher et al., 2020) and the spread on of novel diseases (Miaud et al., 2016; Martín-Torrijos et al., 2019). In addition, the introduction of invasive species can have impacts of local communities as observed in Guangdong Province, China where the introduction of Nile tilapia (Oreochromis niloticus) reduced the growth, density, and abundance of native mud carp leading to socio-economic impacts due to a reduction in income for local fishermen $(\mathrm{Gu}$ et al., 2015).

The transport of species around the world has resulted in biotic homogenization, the widespread introduction of species outside of their native range and the loss of native and endemic species, reducing regional biodiversity and distinctiveness (Mckinney and Lockwood, 1999; Rahel, 2000). More than 600 freshwater fish species had been introduced outside of their native range for fishing, aquaculture, and ornamental reasons by the end of the $20^{\text {th }}$ century, many of which tend to dominate the communities and ecosystems they invade (Rahel, 2007; Gozlan, 2008; Gozlan et al., 2010). However, only a few introduced species contribute to worldwide homogenization (Toussaint et al., 2016). Increasing homogenization is of critical importance as it can result in the extinction of endemic species, and the loss of species diversity and geographic uniqueness as species become common, and communities become more uniform in geographically distinct and distant areas (Taylor, 2004). For instance, widespread introductions to enhance food and sport fisheries across the United States resulted in an average similarity increase of 7.2\% (Rahel, 2000). The introduction of invasive species has direct effects on native ecosystems, by reducing the abundance and distribution of native fauna and flora, but can also indirectly affect ecosystems, for example, decreasing the availability of host species for obligate parasitic 
Introduction

freshwater mussels which could potentially result in evolutionary and demographic consequences, particularly if host specificity is critical (Douda et al., 2013; Huber and Geist, 2019). 
Table 1.1. Main threats faced by Freshwater ecosystems.

\begin{tabular}{|c|c|c|}
\hline Threat & Impact & Reference \\
\hline Water pollution & $\begin{array}{l}\text { Change water quality (eutrophication, sedimentation, and harmful algal blooms); } \\
\text { cause developmental and reproductive abnormalities affecting species fitness and } \\
\text { abundance through endocrine disruption }\end{array}$ & $\begin{array}{l}\text { (Guillette } \text { et al., 1994; Heisler et al., 2008; Moss, } \\
\text { 2008; Schwindt et al., 2014) }\end{array}$ \\
\hline $\begin{array}{l}\text { Instream } \\
\text { infrastructure }\end{array}$ & $\begin{array}{l}\text { Alter movement of species; reduce access to upstream spawning ground; fragment } \\
\text { populations; alter the natural flow, diminish flood pulses, and create thermal } \\
\text { discontinuities; decrease channel and riparian habitats; modify water chemistry and } \\
\text { sediment dynamics; increase the prevalence of water-related diseases }\end{array}$ & $\begin{array}{l}\text { (Andersson et al., 2000; Stanley and Doyle, 2002; } \\
\text { Roy et al., 2003; Steinmann et al., 2006; Pépino } \\
\text { et al., 2012; Ong et al., 2016; Oele et al., 2019) }\end{array}$ \\
\hline Overexploitation & $\begin{array}{l}\text { Declines in the abundance of species and local populations; increased mortality and } \\
\text { risk of extinction due to targeted harvest and by-catch. }\end{array}$ & $\begin{array}{l}\text { (Pikitch et al., 2005; Turvey et al., 2007; Raby et } \\
\text { al., 2011) }\end{array}$ \\
\hline Climate change & $\begin{array}{l}\text { Changes in species distribution and survival; disease outbreaks; rising } \\
\text { temperatures; the increased prevalence of extreme events (storm events, drought, } \\
\text { floods, cold shock); alterations in annual precipitation potential impact on } \\
\text { population demographics in reptiles; interactions with other stressors/threats }\end{array}$ & $\begin{array}{l}\text { (Chu et al., 2005; Piferrer, 2008; Zhang et al., } \\
\text { 2009; Krabbenhoft et al., 2014; Bassar et al., } \\
\text { 2016; Szekeres et al., 2016; Thompson, 2016) }\end{array}$ \\
\hline Invasive species & $\begin{array}{l}\text { Changes in species abundance and distribution through predation, competitive } \\
\text { exclusion and hybridization; introduction of diseases; habitat modification though } \\
\text { altering food web structure, water chemistry and sedimentation }\end{array}$ & $\begin{array}{l}\text { (McIntosh et al., 1994; Jackson, 2002; Richter- } \\
\text { Boix et al., 2013; Gallardo et al., 2016; David et } \\
\text { al., 2017; Martín-Torrijos et al., 2019) }\end{array}$ \\
\hline
\end{tabular}


Introduction

\subsection{The Falkland Islands}

The Falkland Islands are an archipelago in the South Atlantic located 500km off the mainland of South America. The islands cover an area of 12,200 $\mathrm{km}^{2}$ and are composed of two large main islands (East and West Falkland) surrounded by 780 smaller islands (McDowall et al., 2001; Broughton and McAdam, 2005; Fowler, 2013). The Falklands have a cool temperate oceanic climate with mean summer and winter temperatures of $9.4^{\circ} \mathrm{C}$ in January and $2.2^{\circ} \mathrm{C}$ in July respectively, low levels of precipitation (mean annual rainfall of $640 \mathrm{~mm}$ for Stanley between 1944-1978) and an average wind speed of approximately 16 knots (Poncet et al., 2011). The landscape is generally hilly, with Mt. Usborne on East Falkland being the tallest mountain at $705 \mathrm{~m}$ high (Broughton and McAdam, 2005). Although the islands were uninhabited until 1764, they were likely exposed to invasive rats (Rattus norvegicus and Rattus rattus) and mice (Mus musculus) through passing whaling and sealing vessels (Poncet et al., 2011). There are now many introduced species on the islands including 192 non-native plants (Broughton and McAdam, 2005; Lewis and Gardens, 2014), a number of invertebrates, and many vertebrates including feral cats (Felis catus), the domestic goose (Anser anser) and brown trout (Salmo trutta) (Rendell, 2011).

The Falkland Islands are home to three species of native freshwater fish, two species of zebra trout, Aplochiton zebra and Aplochiton taeniatus, and the Falklands minnow, Galaxias maculatus (McDowall et al., 2001; Vanhaecke et al., 2012b). Other species, such as Galaxias platei and the pouched lamprey, Geotria australis, have also been reported although these reports have never been substantiated, due to only one specimen of G. platei ever recorded in 1905, and there is debate over the origin of the specimen (McDowall, 2005). Although the pouched lamprey has been recorded sporadically in the islands, these occurrences are believed to result from individuals migrating from South America and South Georgia, with the last known occurrence in 2016. The family Galaxiidae are one of the most threatened and endangered families of fish (Helfman, 2007; McIntosh et al., 2010), with declines of native galaxiid fishes in New Zealand (Townsend and Crowl, 1991; Townsend, 1996; McDowall, 2003; McDowall, 2006) and South America (Arismendi et al., 2009; Young et al., 2009; Habit et al., 2010; Young et al., 2010; Elgueta et al., 2013) associated with the introduction of salmonids (Garcia de Leaniz et al., 2010). 


\subsection{Introduction of Salmonids to the Falkland Islands}

Brown trout were introduced to the Falkland Islands between 1947-1962 from Chile and the UK. Over this 18-year period, approximately 113,000 brown trout ova were imported and introduced to 29 watersheds across the Falklands (Stewart, 1973; Stewart, 1980; Fowler, 2013; Minett et al., 2021a). Subsequently, the once abundant Aplochiton spp. is now limited to uninvaded refugia in the south if the islands and classified as threatened in the Falkland Islands (McDowall et al., 2001; Ross, 2009). For more information on the introduction of brown trout, see Chapter 2.

Several other salmonid species have been introduced to the Falklands. In 1944 small quantities of rainbow trout (Oncorhynchus mykiss) and brook trout (Salvelinus fontinalis) were shipped from Chile (Crawford and Muir, 2008; MacCrimmon, 2011; Monzón-Argüello et al., 2014b). Atlantic salmon (Salmo salar) was introduced from the UK in 1960-1964; yet only brown trout have survived and formed self-sustaining populations (Arrowsmith and Pentelow, 1965). Rainbow and brook trout were introduced in small quantities; therefore, their lack of survival and establishment is likely due to their low propagule pressure (number and frequency of introductions) (Lockwood et al., 2005; García-Díaz et al., 2015). However, Atlantic salmon were introduced in similar quantities to those of brown trout (approximately 104,000 and 113,000 respectively). Although Atlantic salmon were reported to survive well in rivers, they have never been recorded returning from sea and spawning in the islands. Similar disappearances of introduced Atlantic salmon have also been observed in other Southern Hemisphere locations. Atlantic salmon were introduced to the Kerguelen Islands, a French sub-Antarctic archipelago in the Southern Ocean, in the 1970s, however, they failed to establish anadromous populations (Lecomte et al., 2013).

Two small scale fish farms have been set up in the Falklands, one in 1986 farming Atlantic salmon in Fox Bay, West Falkland, the second in 2013 farming brown trout in Fitzroy sound, East Falkland (Fowler, 2013; Bridson, 2018). The Atlantic salmon farm was a small-scale project which imported 28,500 eggs to the Falklands, from which at least 2000 salmon were transported to sea cages. However, this project was deemed unsuccessful and shut down in 1990 (Fowler, 2013). Escapes from sea cages are not uncommon in salmon farming and are the main source of introduction for invasive salmonids in the Southern Hemisphere (Arismendi et al., 2009; Consuegra et al., 2011). Although no salmon were reported to escape it is possible that some may have, though Atlantic salmon have never established breeding populations in the Falklands. The farming of brown trout started with the transfer of 10,000 
Introduction

sea trout smolts from local broodstock into sea cages in Fitzroy Harbour, today brown trout are still farmed in the islands at a freshwater hatchery at Moody Brook, and sea cages in Fitzroy Harbour. All farmed brown trout originated from local broodstock, except for fish from 2014/2015 where eggs were imported to the islands from Howietoun hatchery, UK. The level of escape from the sea cages and the possible impacts on the wild brown trout populations is unknown.

Despite Atlantic salmon never returning from sea and forming self-sustaining populations in the Falklands local fishermen have occasionally reported catching a 'salmon'. These reports are, however, likely to be unusual sea trout, due to their highly plastic phenotype. In 2011 and 2019 a chinook salmon (Oncorhynchus tshawytscha) (Fowler, 2013) and a coho salmon (Oncorhynchus kisutch) were caught, respectively, these salmon possibly originated from escaped farmed fish from Patagonia (Ciancio et al., 2005; Correa and Gross, 2008), demonstrating that the Falklands are not completely isolated and there is the potential for future invasions by other salmonid species.

\subsection{Brown Trout as an Invasive Species}

The native range of brown trout extends from Iceland and the northern coasts of Europe to North Africa and towards the northern slopes of the Himalayas (MacCrimmon and Marshall, 1968). Brown trout were first introduced beyond their native range in 1864, when 300 ova from the Wey and river Itchen, UK were introduced to the Plenty River, Tasmania (MacCrimmon and Marshall, 1968). Subsequently, brown trout have been introduced to rivers and lakes on every continent except Antarctica (Figure 1.1). Despite little information on the state of local fauna in the Southern Hemisphere before their introduction (Morgan et al., 2004; Pascual et al., 2007), brown trout have been linked to declines in native species and are now classified as one of the 100 world's worst invasive species (MacCrimmon and Marshall, 1968; Lowe et al., 2000; Cambray, 2003). The invasion biology and impacts of brown trout on native fauna and ecosystems has been studied around the world, but extensively in New Zealand and South America where brown trout have been associated with the decline in native galaxiid fishes, one of the most endangered fish families in the world (McIntosh et al., 2010). Negative relationships have been observed between the abundance of native fishes and salmonids in Chile (Soto et al., 2006), Patagonia (Arismendi et al., 2009) and New Zealand (Townsend, 1996) rivers, with predation and competition considered the main cause for these declines. 


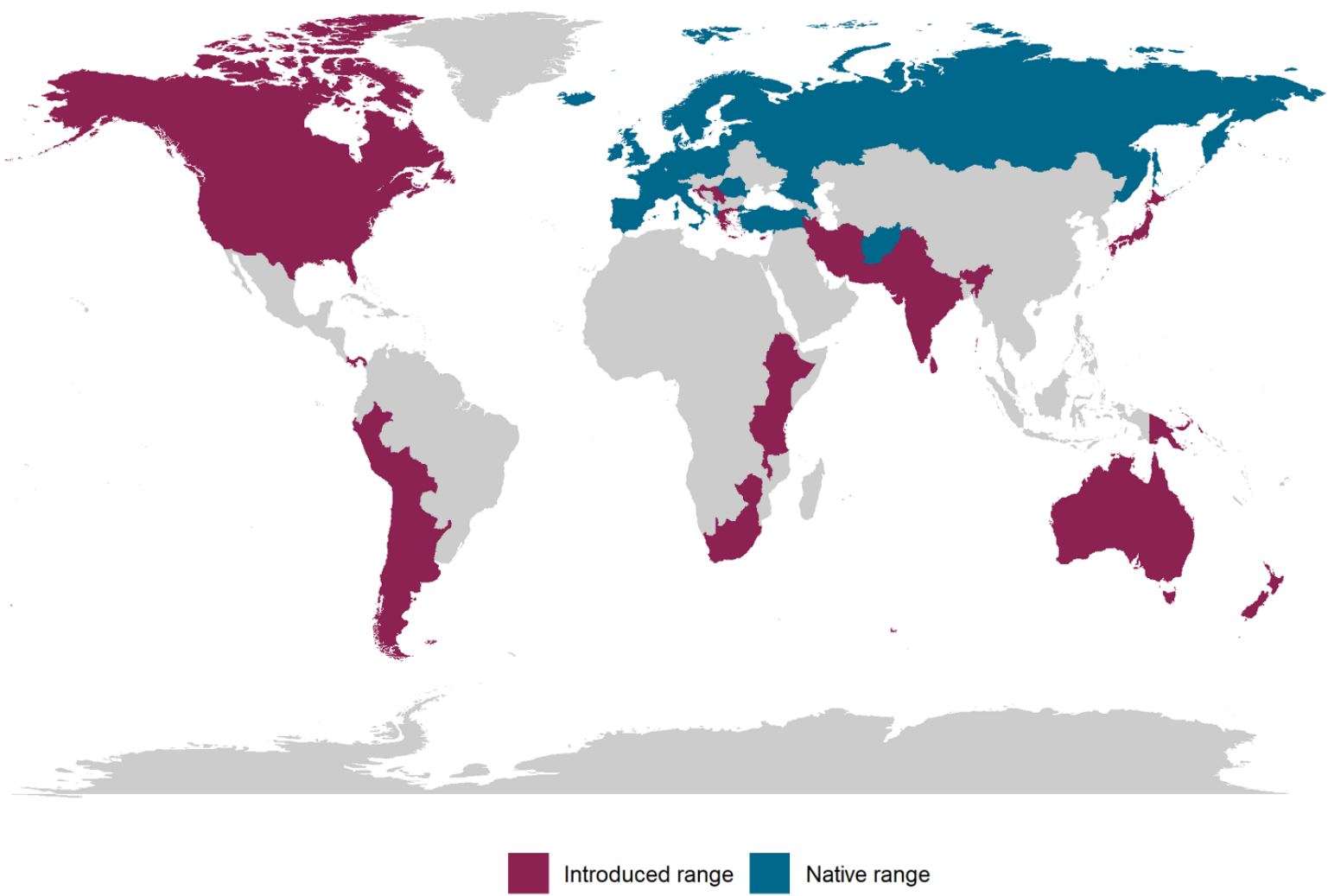

Figure 1.1. Global distribution of brown trout (Salmo trutta), data source: FishBase. This map does not indicate the countrywide presence, but that brown trout is categorized as an introduced species within that country.

Brown trout are a highly plastic species that possess a wide range of life history strategies and traits. The life history strategies utilised by brown trout can vary between individuals and populations, and are influenced by environmental, genetic, and physiological processes (Birnie-Gauvin et al., 2021). Brown trout exploit both freshwater and marine environments, while some fish will migrate to brackish, or saltwater's others will remain resident (Figure 1.2 and Figure 1.3). In their native range brown trout reproduce in Autumn/Winter on gravel bottom streams where they dig their nest and bury their eggs, in the Falkland Islands brown trout have been observed to start breeding in late May (Autumn/Winter in the Southern hemisphere), coinciding with native spawning periods (pers comms., Nick Bonner). Depending on water temperature, eggs are incubated for one to several months in the gravel before hatching in Spring (Wild Trout Trust, 2021), with longer incubation periods required at lower temperatures (Klemetsen et al., 2003). Fry and parr are territorial and will intensively compete for resources, with the dominance hierarchy determining foraging status, for example, dominant fish will feed at dusk, the most beneficial feeding time (Alanärä et al., 2001; Lahti et al., 2001). Habitat use by brown trout is flexible and typically dependant on 
habitat availability and time of day (Greenberg et al., 2001; Heggnes et al., 2002). During their first-year young brown trout tend to inhabit shallow, fast flowing areas along the riverbank, whereas they typically prefer deeper and slow flowing areas as adults (Roussel and Bardonnet, 1999; Heggenes, 2002; Wild Trout Trust, 2021). Where brown trout have access to the sea, they typically form anadromous populations (Klemetsen et al., 2003). Often individuals migrating to the marine environment are found in shallow coastal areas close to the mouth of their home river, however, some individuals have been shown to migrate further out to sea (Bendall et al., 2005; Birnie-Gauvin et al., 2019; Davidsen et al., 2021). The time spent in the marine environment can also vary between individuals, with some fish only spending a summer and others remaining in the sea for many years (Jonsson and Jonsson, 2002; Birnie-Gauvin et al., 2019).

Although, brown trout are among the most studied fish species, a lot is still unknown about the variation in their migration and life history strategies. The lifecycle of brown trout was assumed to be relatively fixed, however, research has shown that many aspects are flexible and have been overlooked (Figure 1.2) (Limburg et al., 2001; Birnie-Gauvin et al., 2019). For example, migrating parr have been shown to enter the marine environment, resident fish may migrate and undergo late smoltification, autumn migrants may represent up to $40 \%$ of the spring smolt class, and migrating smolts may assume residency through desmoltification (Taal et al., 2014; Winter et al., 2016; Aarestrup et al., 2018; Birnie-Gauvin et al., 2019; Birnie-Gauvin and Aarestrup, 2019). 


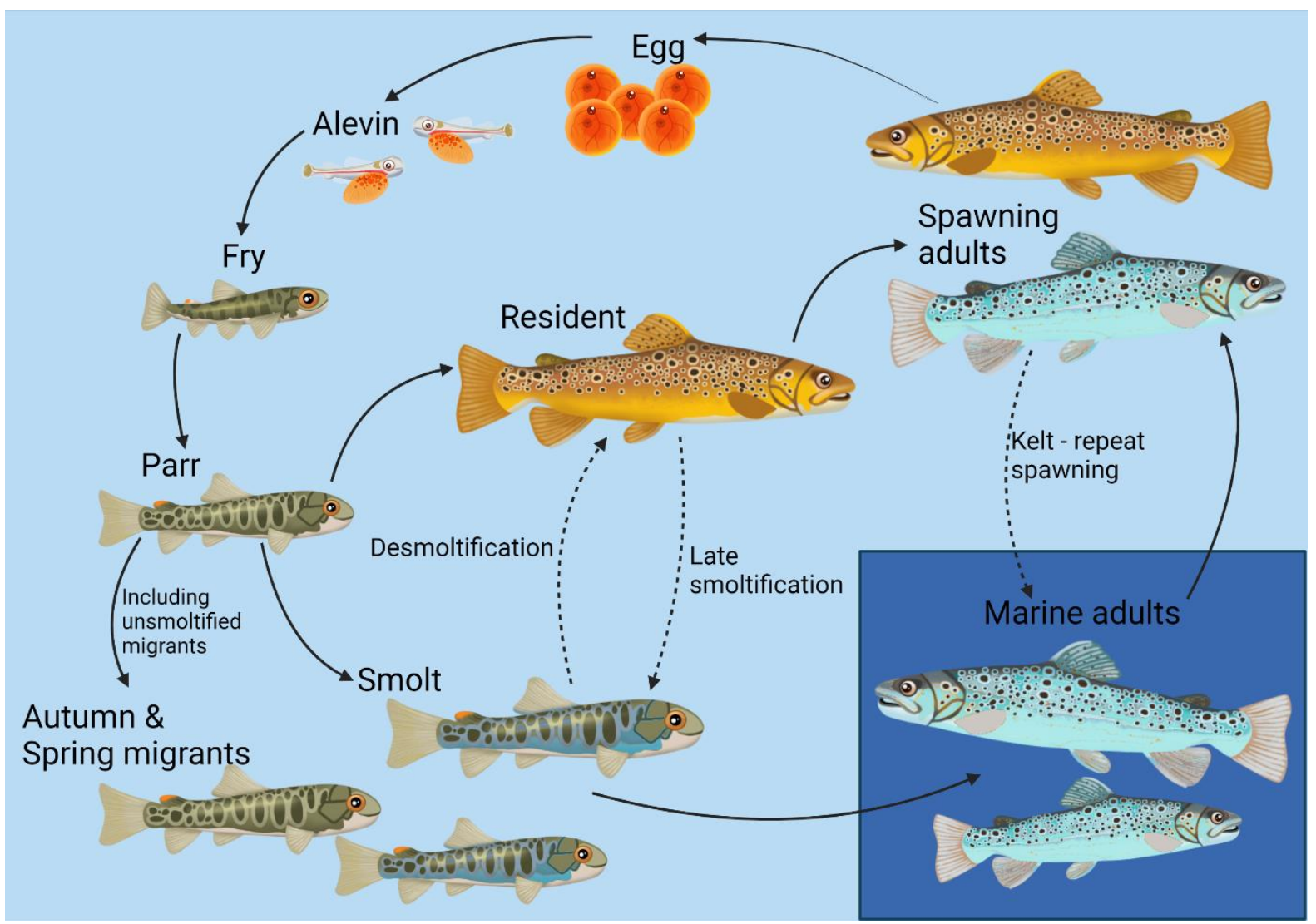

Figure 1.2. Brown trout life cycle, images obtained from RiverLife and produced in BioRender.

The wide-ranging life history tactics possessed by brown trout can also contribute to and assist with invasion success, thus, allow them to thrive in many ecological settings (Arismendi et al., 2014; Sloat et al., 2014). For example, the ability to migrate into the marine environment is likely to contribute to successful establishment and rapid spread. Straying, visiting, or inhabiting a watershed other than the one the fish was born in, is not uncommon in brown trout (Euzenat et al., 1999; Birnie-Gauvin et al., 2019). Studies around Norway and Scotland have recaptured individuals in non-native rivers (Pratten and Shearer, 1983; Berg and Berg, 1987), with one study in the Baltic Sea finding 16\% of recaptures were a result of fish being caught in non-natal rivers (Degerman et al., 2012). In the Falkland Islands migratory ecotypes of brown trout have been present since 1956 and have, therefore, likely aided in the spread of brown trout throughout the Islands (Salmon and Trout Association, 2012).

In comparison very little is known about the life history strategies of Aplochiton spp., and their ecology and conservation status remain poorly understood (Young et al., 2010; Alò et al., 2013). Morphological similarities between the A. zebra and A. taeniatus have led to high levels of misidentification, further complicating their conservation (Figure 1.3). In addition, 
further confusion surrounds their life history strategies as zebra trout were believed to have a marine living larval stage (McDowall et al., 2001; McDowall, 2006), although, research by Alò et al (2013) found no evidence of diadromy in either A. zebra or A. taeniatus. In Chile, both Aplochiton spp. are considered in danger of extinction due to the impacts of introduced salmonids, while in the Falklands the species are considered seriously threatened and have been protected since 1999 (Falkland Islands Government, 1999; McDowall et al., 2001; Alò et al., 2013). Neither species has been evaluated for the IUCN red list of threatened species as little information is available regarding their abundance and distribution (World Conservation Monitoring Centre, 1996).

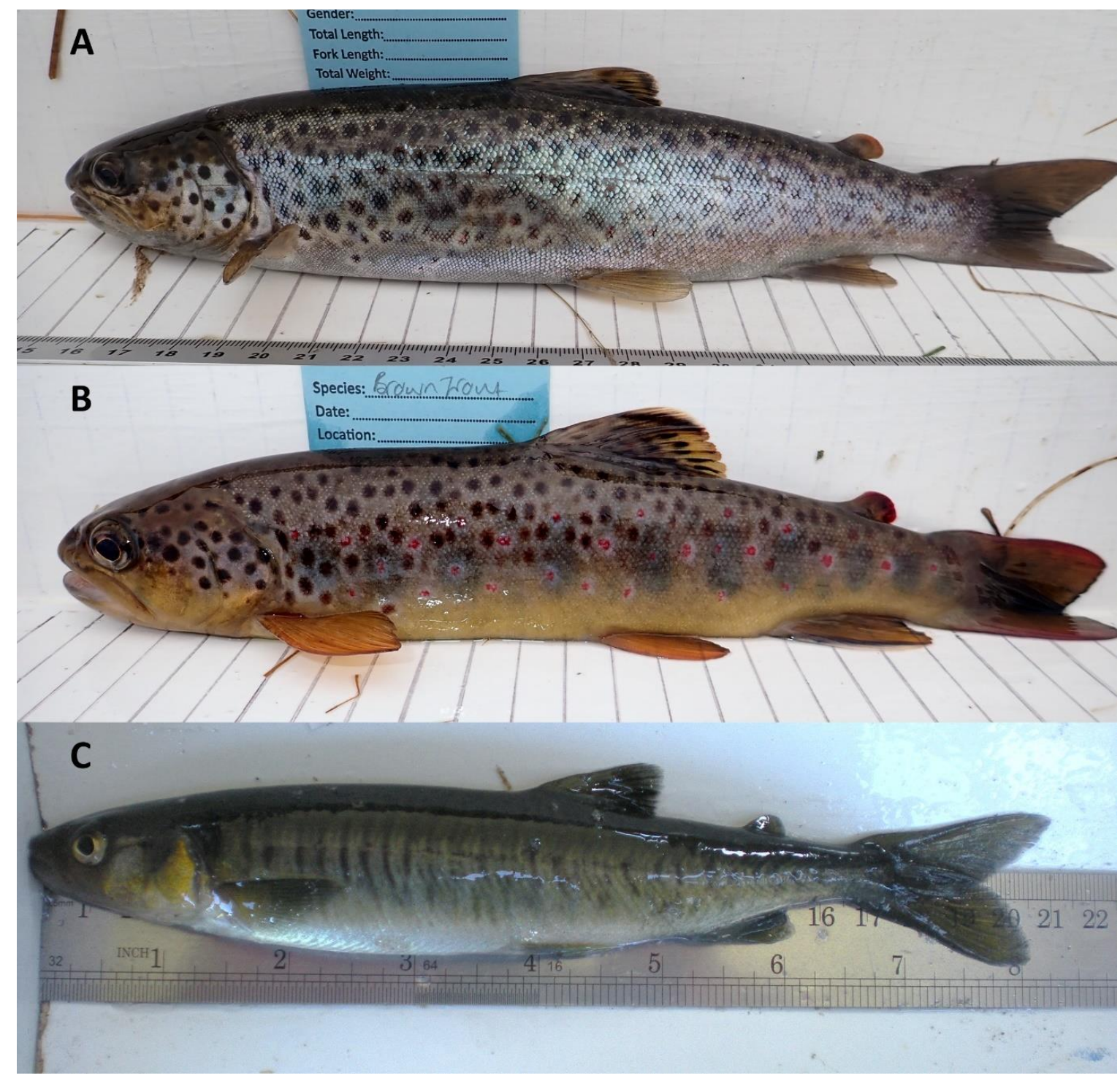

Figure 1.3. Examples of brown trout (A and B) and zebra trout $(\mathrm{C})$ caught in the Falkland Islands, image (C) kindly provided by Sonia Consuegra and Carlos Garcia de Leaniz. 
Size-specific predation is evident in New Zealand where medium-sized brown trout (100120mm) prey heavily on small galaxiids (McIntosh et al., 1994; Macchi et al., 2007; Habit et al., 2010), resulting in reduced abundance, or disappearance of galaxiid species and/or size classes (McIntosh, 2000; Glova, 2003; McIntosh et al., 2010). Both Aplochiton spp. (A. zebra and A. taeniatus) present in the Falkland Islands commonly reach sizes of $110-170 \mathrm{~mm}$ and are, therefore, vulnerable to predation from brown trout at all life stages (McDowall, 1971; Pascual et al., 2007; McIntosh et al., 2010). Galaxiids are particularly susceptible to brown trout predation as fry. Although galaxiids and brown trout generally spawn at the same time of year, brown trout tend to hatch earlier and, therefore, have a size advantage allowing even trout fry to consume galaxiid fry (Crowl et al., 1992). Hence, in areas where brown trout and galaxiids are present trout can have major impacts on galaxiid fry survival and recruitment (McIntosh et al., 2010).

Brown trout can impact native species not only through direct predation, but also by interference competition, altering their behaviour, and by feeding on the same prey items. Brown trout can feed on very diverse prey within a stream, including smaller fish and terrestrial prey (Huryn, 1996). Therefore, they can strongly influence stream invertebrate communities by altering species composition (Nyström and McIntosh, 2003), total biomass (Flecker and Townsend, 1994), and invertebrate behaviour (Flecker, 1992; McIntosh and Townsend, 1995; McIntosh and Townsend, 1996) leading to changes in nutrient dynamics (Simon et al., 2004). For example, in the presence of trout, invertebrates evolved an adaptive response to heavier predation and altered their behaviour to become more cryptic and spend more time beneath cobblestones (McIntosh and Townsend, 1998; McIntosh, 2000) or switch to a nocturnal feeding pattern to avoid predation (Flecker, 1992; Cowan and Peckarsky, 1994). These changes in behaviour can have knock-on effects and result in a reduction in the number of insects and other invertebrates on exposed surfaces, decreasing grazing pressure on periphyton and leading to its increased abundance (Flecker and Townsend, 1994; McIntosh and Townsend, 1996; Biggs et al., 2000; McDowall, 2003).

The feeding strategies of brown trout and galaxiids are similar (Glova et al., 1992; Glova and Sagar, 1993), which can result in habitat overlap. Trout can displace native galaxiids from optimal foraging locations or prevent foraging through competition, termed competitive exclusion/displacement (McIntosh et al., 1992; Edge et al., 1993; McDowall, 2003). In Chile, A. zebra were observed to shift their foraging behaviour to consume less winged Diptera (Brown et al., 2006) in order to avoid predation from brown trout, causing a reduction in 
trophic position which significantly reduced their condition factor. Although this shift in diet reduced their predation risk, it may have also increased competition between these two species, as the diet of A. zebra and brown trout become more similar (Elgueta et al., 2013). Furthermore, significant changes in condition factor have previously been inversely correlated with population abundance (Arismendi et al., 2011); thus, the presence of brown trout may result in a reduction in population size for $A$. zebra. Therefore, these substantial impacts exerted on the trophic ecology of native galaxiids may have disastrous effects on their abundance (Elgueta et al., 2013).

Although brown trout and invasive salmonids are known to impact native ecosystems and cause declines in native species, they are classified as naturalised in some areas of the Southern Hemisphere due to where, when, and why they were introduced, and the economic benefit they provide (Rowe, 2001; Iriarte et al., 2005; Valiente et al., 2010b). Therefore, conservation managers are tasked with a conservation oxymoron, to protect native species and habitats, as well as the invasive species that have caused their decline (Garcia de Leaniz et al., 2010). For example, in Patagonia, National Parks were set up to increase conservation and forestry management resources; however, they have restrictions on economic activities and do not protect native species but instead protect invasive trout species and sport fishing (Pascual et al., 2007). Due to the cultural and economic value of brown trout in the Falkland Islands they have been conferred a protected status since 1999 despite the declines in abundance and distribution observed in the native Aplochiton species following their introduction (McDowall et al., 2001; Ross, 2009). This protected status prevents brown trout from being captured outside the fishing season, while during the fishing season $\left(1^{\text {st }}\right.$ September $-30^{\text {th }}$ April) fishermen are restricted to a daily limit of six trout per day per person on most rivers (catch limit on the Murrell River is reduced to three) (Falkland Islands Government, 1999; Otley et al., 2008).

Three presence and absence surveys have been conducted following the introduction of brown trout to the Falklands: in 1999, 2008-09, and 2011-12 by McDowall et al. (2001), Ross (2009) and Fowler (2013), respectively. Although no surveys were conducted before their introduction, locals have reported the disappearance of the native zebra trout following the arrival of brown trout (McDowall et al., 2001). The first survey in 1999, 37 years after introductions had ceased, revealed that brown trout had formed self-sustaining populations and were now widespread throughout East and West Falkland. With the first sea-run brown trout reported in 1956 (Salmon and Trout Association, 2012), their spread throughout the 
Falklands was presumably aided by their anadromous lifestyle allowing individuals to migrate to new rivers and streams through the sea. However, some secondary translocations have occurred as brown trout are also found in landlocked areas not believed to be initial introduction sites (McDowall et al., 2001). Due to the reduction in the abundance and distribution of zebra trout, they were regarded as 'severely threatened' following McDowall's 1999 survey and were included as a protected species under the 1999 Conservation of Wildlife and Nature Ordinance (Falkland Islands Government, 1999). However, before 2012 only one species of zebra trout was thought to be present in the Falklands with A. taeniatus misidentified as A. zebra due to their morphological and ecological similarities which may have confounded their identification (Vanhaecke et al., 2012b). The study by Vanhaecke et al. (2012) determined that A. zebra was less widespread than previously thought, further complicating its conservation (McDowall, 2006; Vanhaecke et al., 2012b).

\subsection{Environmental DNA}

The distribution and impacts of invasive species are traditionally monitored through visual detection and counting, such sampling relies on practical and taxonomic expertise and often requires the physical capture (i.e., through trapping and netting) of individuals which can cause stress, injury, and even mortality (Hopkins and Freckleton, 2002; Miranda and Kidwell, 2010; Panek and Densmore, 2011). Analysing DNA obtained from environmental samples (environmental DNA), i.e., water, soil, or air, offers a non-invasive alternative approach to physical capture of individuals (Ficetola et al., 2008; Goldberg et al., 2011; Taberlet et al., 2012a; Wilson and Wright, 2016), and can increase the data available regarding the occurrence of rare or endangered species, the detection of invasive species, alongside estimating biodiversity (Goldberg et al., 2016).

DNA is released into the environment through faeces, urine, skin, mucus, and blood. Detection of environmental DNA (eDNA) provides a method to assess and monitor biodiversity in variety of settings including sediments, ice cores, lakes, and rivers, from both present-day and ancient samples (Willerslev et al., 2007; Haile et al., 2009; Jerde et al., 2011; Jørgensen et al., 2012; Thomsen et al., 2012; Xie et al., 2018; Duyke et al., 2019; Hellström et al., 2019; Holman et al., 2019). With evidence of a correlation between eDNA concentration and species abundance, there is now the potential to assess and estimate species abundance without the need for traditional methods such as mark and recapture techniques or netting/electrofishing surveys which can be costly and time-consuming (Lacoursière-Roussel 
et al., 2016b; Lacoursière-Roussel et al., 2016a). Therefore, sampling eDNA can further reduce field costs and time, allowing more sites to be sampled (Goldberg et al., 2011; Biggs et al., 2015; Evans et al., 2017).

To protect and conserve rare and threatened species and habitats, it is of utmost importance to detect and monitor species of direct interest, including invasive species. Riverine habitats are often difficult to sample due to their topography, poor access, and flow rate. In addition, many riverine species display cryptic colouration and are often found at low densities (Bayley and Peterson, 2001; Mehta et al., 2006). Sampling in such systems becomes increasingly complicated when sample sites are in remote areas. Traditional monitoring tools, such as netting and/or electrofishing, are only reliable indicators of species presence when target organisms are at moderate-to-high abundance due to their low capture and detection probabilities (Magnuson et al., 1994). Therefore, rare species can often be presumed absent when they are in fact present ( $\mathrm{Gu}$ and Swihart, 2004), and the only possible solution is to increase sampling effort, which is often unfeasible (Mcdonald, 2004). Environmental DNA analysis provides a way of assessing the distribution of rare and cryptic species or where sampling efforts could harm protected species (Beja-Pereira et al., 2009; Biggs et al., 2015; Doi et al., 2015; Doi et al., 2017; Robinson et al., 2019a), which is particularly useful in conservation and invasive species monitoring programs.

Analysis of eDNA can be completed using a targeted or general approach. A targeted approach, whereby the presence/absence of a single species is determined using speciesspecific primers and conventional PCR (PCR), quantitative PCR (qPCR) or digital droplet PCR (ddPCR), is typically used when detecting endangered or invasive species (Ficetola et al., 2008; Jerde et al., 2011; Thomsen et al., 2012; Doi et al., 2015; Capo et al., 2019). However, targeted approaches are limited to the detection of a single species and are, therefore, not efficient when whole communities need to be identified. In contrast, a general approach uses conserved primers, i.e., primers with binding sites that are shared across multiple taxa and flank a highly variable region that allows discrimination between taxa and species, and high-throughput sequencing (metabarcoding), enabling whole communities to be sequenced (Taberlet et al., 2012b; Valentini et al., 2016; Deiner et al., 2017). Metabarcoding is an attractive approach to analyse eDNA as it allows the simultaneous assessment of species diversity and distributions (Blackman et al., 2017; Elbrecht et al., 2017; Harper et al., 2019), although this can come with a reduction in accuracy and sensitivity as the more prevalent species are more likely to amplify and may mask the detection of rarer species (Kelly et al., 
2014; Brandon-Mong et al., 2015). This makes metabarcoding less suitable than targeted eDNA for the detections of rare species or when distribution data are required (Evans et al., 2016; Bylemans et al., 2019). In such cases, a targeted approach may be more appropriate to map species distribution accurately and quantify eDNA abundance to provide an indicator of species abundance (Takahara et al., 2012; Takahara et al., 2013; Sigsgaard et al., 2015; Bylemans et al., 2016; Lacoursière-Roussel et al., 2016a; Doi et al., 2017).

Although eDNA analysis has been shown to be as reliable as traditional sampling methods (Seymour et al., 2020; Boivin-Delisle et al., 2021; Seymour et al., 2021), species detection using eDNA is affected by extraction efficiency, assay sensitivity, sample interference, and the ecology of the target organism (Goldberg et al., 2016). Each step in the methodology (Figure 1.4) needs to be optimized and requires clean and consistent field and laboratory protocols, which are essential to minimize the risk of contamination. Negative controls in the form of clean water processed using the same equipment/protocols as the field samples should be included at all stages, including sample collection, extraction, and amplification to detect potential sources of contamination. To avoid cross-contamination between sites and samples, it is also necessary to decontaminate all equipment and use single-use disposable supplies. Where equipment is to be reused, it must be thoroughly cleaned and decontaminated beforehand. Samples should be stored and handled in dedicated areas/rooms separate from areas where high-quality DNA and PCR products are processed (Taberlet et al., 1999; Goldberg et al., 2016). Immediately after shedding, eDNA starts to decay due to microbial activity, chemical reactions, and mechanical forces (Lindahl, 1993; Nielsen et al., 2007; Thomsen et al., 2012) and hence samples should be preserved as soon as possible.

Environmental DNA can be concentrated in water samples through precipitation or filtration. Precipitation involves preserving small volumes of water (e.g., 15ml) with salt (e.g., sodium acetate) and absolute ethanol, then storing the sample at $-20^{\circ} \mathrm{C}$ (Ficetola et al., 2008; Turner et al., 2015). Greater volumes of water $(200 \mathrm{ml}$ to $>100 \mathrm{~L})$ can be processed with filtration (Hinlo et al., 2017; Sepulveda et al., 2019; Schabacker et al., 2020). Water can be filtered onsite, which preserves samples immediately and may be critical when working in remote locations, or they can be filtered in a laboratory, allowing for multiple samples to be filtered simultaneously, reducing field and processing time (Goldberg et al., 2016). DNA from filtered samples can be preserved through freezing, immersion in ethanol or cell lysis buffer, or drying filters (Hinlo et al., 2017; Spens et al., 2017). Final detection rates can vary with eDNA concentration process (filtration or precipitation), filter volume, filter material and 
Introduction

pore size, and DNA extraction method (Deiner et al., 2015; Renshaw et al., 2015; Goldberg et al., 2016). Sensitivity and specificity of single species detection can be further improved using a species-specific probe (Kutyavin et al., 2000; Pilliod et al., 2013; Wilcox et al., 2013; Amberg et al., 2015). Without probes, positive samples will require subsequent confirmation through sequencing to rule out false positives due to cross-contamination. 


\section{Sampling}
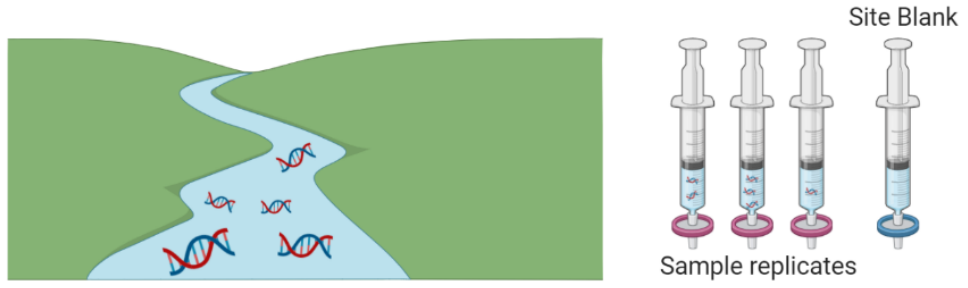

\section{DNA extraction}



DNA Amplification

qPCR
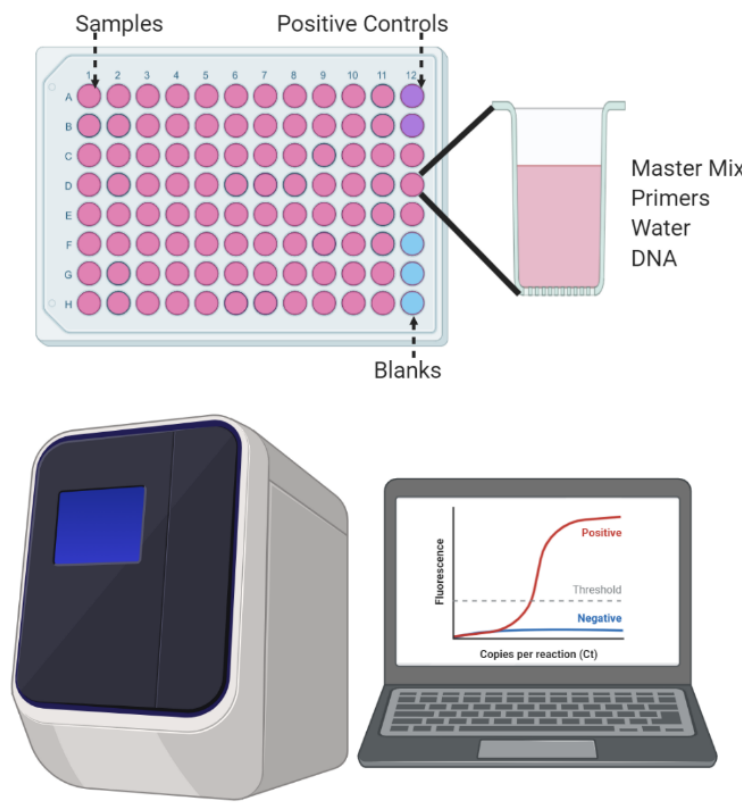

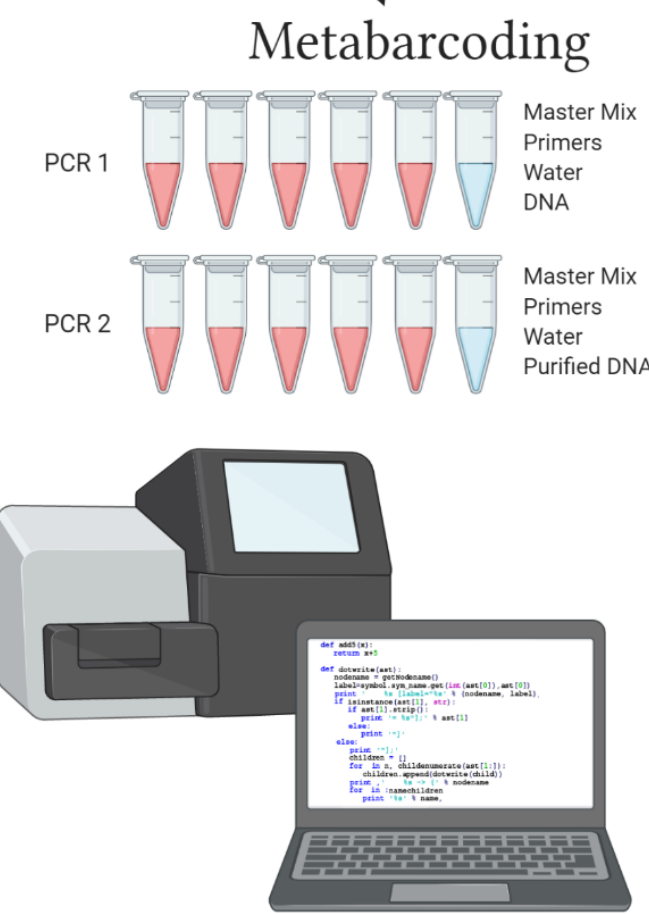

Figure 1.4. Environmental DNA sample process flow chart, created in BioRender. 


\subsection{Population Genetics of Invasive Species}

Population genetics focuses on the distribution and amount of genetic variation within and between populations. Genetic variation arises through mutations, i.e., base pair changes (single nucleotide polymorphisms), insertions/deletions, and rearrangement of DNA fragments. Over time these mutations accumulate, and subsequently different occurrences of each mutation will be present in the population, thus characterising their genetic variation (Le Roux and Wieczorek, 2009). Such genetic variation can be monitored through a variety of molecular markers, including Single Nucleotide Polymorphisms (SNPs).

SNPs are single base changes in the genome that differ across species and/or populations under study, they occur as a result of mutations which create base-pair differences among sequences. Due to their high abundance and widespread distribution throughout the genome they are a useful source of information regarding genetic variation and have been used to study population structure, adaption, and evolution (Brumfield et al., 2003; Morin et al., 2004; Leaché and Oaks, 2017). Previously, microsatellite markers were commonly used, however, the use of SNPs is becoming more commonplace as they are typically more efficient, do not require standardization across detection platforms and can be replicated between laboratories, enabling results to be directly compared (Coates et al., 2009; Seeb et al., 2011).

Molecular markers can be applied in a variety of ways to gain a better understanding of invasive species populations facilitating the implementation of management and control measures (Sakai et al., 2001; Resh et al., 2018; Du et al., 2021; Resh et al., 2021). To effectively manage invasive populations, it is essential to correctly identify species. However, this can be difficult for various reasons such as cryptic taxa or high diversity (Stepien and Tumeo, 2006; Le Roux and Wieczorek, 2009). Taxonomic misidentification can prevent early detection of cryptic invasive taxa or result in ineffective management strategies, particularly when utilizing biological controls, as they may only be efficient against a particular species or variant (May and Marsden, 1992; Stepien and Tumeo, 2006). Molecular markers can also be used to detect hybridisation between populations and species (Vanhaecke et al., 2012b; Deines et al., 2014; Sušnik Bajec et al., 2015). For example, the implementation of species diagnostic SNP markers in southern Africa determined the distribution of invasive largemouth bass (Micropterus salmoides), Florida bass (Micropterus floridanus) and their hybrids, revealing widespread introgression between these two invasive species, resulting in populations dominated by hybrids (Hargrove et al., 2019). Hybridisation 
can strongly influence invasive and native species fitness, resulting in the masking of deleterious alleles, increasing the fitness of invasive species (Abbott, 1992; Le Roux and Wieczorek, 2009). However, hybridisation can also severely threaten native populations by impacting their genetic integrity. Hybridisation between introduced sheepshead minnow (Cyprinodon variegatus) and native pupfish (Cyprinodon bovinus) in Dexter, New Mexico has resulted genetic introgression of the entire wild population.

Spread of invasive species can be limited through the implementation of targeted management strategies, however, such strategies require knowledge of invasive potential, movement pathways and sources of introduction (Sakai et al., 2001; Le Roux and Wieczorek, 2009; Resh et al., 2018; Du et al., 2021; Resh et al., 2021). This information can be obtained through SNP genotyping and assessing the population structure of introduced species. Previous studies examining invasive populations of Northern snakehead in the United States revealed the presence of more genetic populations than previously estimated, and by assessing population sizes, researchers were able to demonstrate their invasive potential (Resh et al., 2018). In addition, analysis of SNPs enabled these invasive populations to be traced back to their original sources in the Yangtse river, China, thus providing valuable information to managers which can be used to prevent future introductions and further spread of the species in the United States (Resh et al., 2018; Resh et al., 2021). SNPs also provide an opportunity to estimate migration rates and gene flow between sites and populations, therefore, enabling possible dispersal pathways to be assessed (Mamoozadeh et al., 2020).

\subsection{Stable Isotope Analysis}

Naturally occurring stable isotopes can be used to study and detect animal movement. Although movement is typically studied through marking and recapturing individuals with visible or electronic markers, stable isotope analysis can provide information regarding individual movements due to assimilated site-specific signatures (Rubenstein and Hobson, 2004; Cunjak et al., 2005). Many elements including carbon and nitrogen possess multiple stable isotopes, these isotopes are present in different proportions and their composition can change predictably through natural geochemical and biochemical processes. Variations in these proportions can be measured as isotopic differences compared to international standards and are reported in delta $(\delta)$ values as parts per thousand (\%o) (Peterson and Fry, 1987). Isotopic signatures can vary spatially between food webs or environments and these signatures can be assimilated and passed on through feeding where information is retained in 
tissues (Grey, 2001; Fry et al., 2003). Spatial and temporal movement patterns can then be inferred from these signatures when individuals move between isotopically distinct resources (Rubenstein and Hobson, 2004; Durbec et al., 2010). However, retention of isotopic signatures will vary depending on tissue and elemental turnover rates (Tieszen et al., 1983; Heady and Moore, 2013).

Different tissue can be analysed to determine isotopic signatures depending on the research question and the timeframe studied. Metabolically inert tissues such as bones and otoliths in fish reflect the isotopic record at the location where the tissue was formed, whereas metabolically active tissues reflect the isotopic signature over time depending on the turnover rate of the tissue selected (Tieszen et al., 1983; Campana and Neilson, 1985; Tzadik et al., 2017). Liver and blood plasma can provide information in days, while muscle tissue typically reflects changes in weeks to months, and longer-term information can be obtained from otoliths and scales (Perga and Gerdeaux, 2005; Ramsay et al., 2011). Obtaining muscle tissue and otoliths requires lethal sampling which is often not appropriate when working with threatened, endanger, or protected species (Barnett et al., 2010; Jardine et al., 2011). However, studies are increasingly using non-lethally sampled tissues, including scales, fins (both adipose and rayed), and mucus (Fincel et al., 2012; Graham et al., 2013; Heady and Moore, 2013; Winter et al., 2019). Carbon and nitrogen stable isotope values obtained from fins and muscle tissue are strongly correlated, therefore, fin tissue presents a non-lethal alternative (Kelly et al., 2006; Sanderson et al., 2009; Hanisch et al., 2010; Jardine et al., 2011; Graham et al., 2013).

Stable isotopes have been successfully used to investigate movement in a wide range of taxa and ecosystems (Fry et al., 2003; Rubenstein and Hobson, 2004; Hobson, 2008; Durbec et al., 2010; Steenweg et al., 2017). Carbon $\left(\delta^{13} \mathrm{C}\right)$ and nitrogen $\left(\delta^{15} \mathrm{~N}\right)$ stable isotopes have been analysed in a variety of metabolically inert and active tissue to estimate carbon flow in food webs and trophic levels (Rounick and Winterbourn, 1986; Post, 2002). Typically, $\delta^{15} \mathrm{~N}$ values are enriched by $3-4 \%$ as nitrogen moves through the food web, thus enabling consumer trophic levels to be estimated. In comparison, $\delta^{13} \mathrm{C}$ tends to be unaffected as carbon moves through the food web, however, $\delta^{13} \mathrm{C}$ provides information regarding the initial source of carbon and facilitates differentiation of isotopic signatures when sources change (Deniro and Epstein, 1981; Minagawa and Wada, 1984; Rounick and Winterbourn, 1986; Peterson and Fry, 1987; France and Peters, 1997). Individuals reflect the stable isotope signatures of a 
particular site as they feed, assimilate isotopic signatures, and assume equilibrium with their diet, enabling movement patterns to be discerned when individuals move to or from a new feeding site (Fry et al., 2003). However, turnover time of tissues needs to be accounted for when assessing this movement (Tieszen et al., 1983; Heady and Moore, 2013). Analysis of $\delta^{13} \mathrm{C}$ enabled feeding habitats for juvenile fish to be distinguished in Chwaka Bay, Zanzibar, as carbon values differed between mangroves, mud and sand flats and seagrass habitats, thus revealing the importance of feeding areas for different species, while intermediate values between feeding habitats established movement and connectivity between sites (Lugendo et al., 2006).

Movement patterns have been described at a range of spatial scales using stable isotopes (Rubenstein and Hobson, 2004; Hobson, 2008). Large scale migrations such as those conducted by monarch butterflies have been tracked back to their natal origins (Hobson et al., 1999). In comparison, relatively fine scales have also been studied, for example where movement of fish species has been estimated within a river or estuary (Haas et al., 2009; Rasmussen et al., 2009). 


\subsection{Aims and Objectives}

This thesis explores the invasion ecology of brown trout in the Falkland Islands with the aim to facilitate conservation planning and minimise the impacts of brown trout on native galaxiids. SNP genotyping, stable isotope analysis, acoustic tracking, and environmental DNA analysis were used to determine the distribution of invasive brown trout and its potential impacts on native endangered Aplochiton spp. in the Falklands. The following main objectives were addressed in four data chapters:

- Chapter 2. To determine the distribution of brown trout and native galaxiids in the Falkland Islands using environmental DNA. This chapter was published as Minett, J.F., Garcia de Leaniz, D., Brickle, P. \& Consuegra, S. (2020) A new high-resolution melt curve eDNA assay to monitor the simultaneous presence of invasive brown trout (Salmo trutta) and endangered galaxiids. Environmental DNA, 3, 561-572. https://doi.org/10.1002/edn3.151

- Chapter 3. To reconstruct the introduction and colonization of brown trout in the Falklands and model their dispersal. This chapter is under review in Biological Invasions.

- Chapter 4. To assess the population structure and likely origin of brown trout in the Falklands and evaluate the level gene flow between populations using SNPs. This chapter is published in Evolutionary Applications as Minett, J.F., Garcia de Leaniz, D., Sobolewska, H., Brickle, P., Crossin, G. T. \& Consuegra, S. (2021) SNP analysis and acoustic tagging reveal multiple origins and widespread dispersal of invasive brown trout in the Falkland Islands. Evolutionary Applications, 11-1. https://doi.org/10.1111/eva.13274

- Chapter 5. To examine the life history strategies of brown trout in the Falklands and determine the incidence of anadromy using SIA. This chapter is in preparation as Stable isotope analysis reveals multiple life history strategies and the extent of migratory brown trout in the Falkland Islands. 
A new high-resolution melt curve eDNA assay to monitor the simultaneous presence of invasive brown trout (Salmo trutta) and endangered galaxiids

\section{Chapter 2 A new high-resolution melt curve eDNA} assay to monitor the simultaneous presence of invasive brown trout (Salmo trutta) and endangered galaxiids

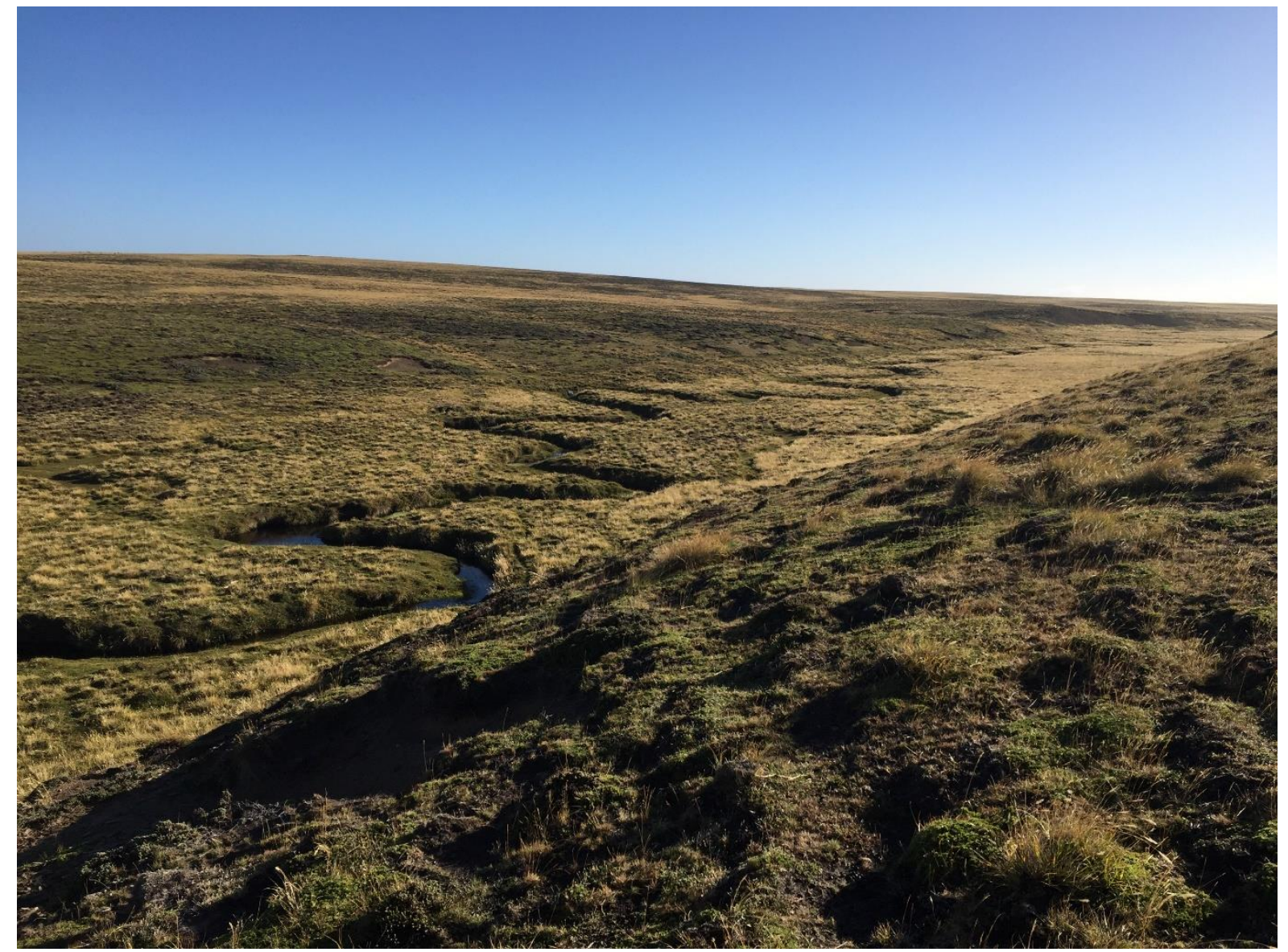

This work was published as:

Minett, J. F., Garcia de Leaniz, C., Brickle, P., \& Consuegra, S. (2020) A new high-resolution melt curve eDNA assay to monitor the simultaneous presence of invasive brown trout (Salmo trutta) and endangered galaxiids. Environmental DNA. 3, 561-572. 
A new high-resolution melt curve eDNA assay to monitor the simultaneous presence of invasive brown trout (Salmo trutta) and endangered galaxiids

\subsection{Introduction}

Understanding species' niche characteristics is essential to predict the consequences of biological invasions (Korsu et al., 2007), but requires being able to accurately identify particular species and their distributions (Darling and Blum, 2007). Species identification can be difficult if they are threatened, at low densities (Jerde et al., 2011) and/or morphologically cryptic (Bickford et al., 2006). This is important because the establishment and dispersal of non-native species often impact native fauna through increased predation, competition for resources and disease transmission (Gozlan et al., 2010; Ellender and Weyl, 2014). Competition for resources and/or predation can result in the displacement of native species and introgression/hybridisation with introduced species, potentially leading to their decline, extirpation or extinction (Huxel, 1999). These negative impacts can be particularly severe for endemic species, especially those found in low abundance and having limited geographic range (Burlakova et al., 2011; Hobbs et al., 2011), and particularly in freshwater ecosystems where invasive species are one of the main drivers of biodiversity loss (Dudgeon et al., 2006; Reid et al., 2019).

The introduction and spread of non-native fishes in freshwater ecosystems has often been attributed to aquaculture and recreational fishing, particularly in the case of salmonid fishes (Garcia de Leaniz et al., 2010), one of the most widespread groups of introduced fishes (Rahel, 2007). Although, few species are known to have become extinct due to the effects of introduced salmonids, declines in abundance and distribution of native and endemic fishes are evident in many countries (Woodford and Impson, 2004; Habit et al., 2010; McIntosh et al., 2010; Young et al., 2010; Kadye et al., 2013). In New Zealand for example, the extinction of the native grayling Prototroctes oxyrhynchus has been attributed in part to the introduction of brown trout Salmo trutta (McDowall, 2006). Galaxiid fishes, endemic of the Southern Hemisphere, constitute one of the freshwater fish families most seriously threatened by salmonid expansions (Garcia de Leaniz et al., 2010; Habit et al., 2010). Invasive salmonids exert strong selection pressure upon native galaxiids across their ranges, including New Zealand (McIntosh et al., 2010), Chile (Habit et al., 2010), and Australia (Hardie et al., 2006), mainly through predation and competition (Soto et al., 2006; Macchi et al., 2007; Arismendi et al., 2009; Penaluna et al., 2009).

In Chile and the Falkland Islands, the distribution of galaxiids (Aplochiton spp.) is determined by historical colonisation but also shows strong population structuring, isolation, 
A new high-resolution melt curve eDNA assay to monitor the simultaneous presence of invasive brown trout (Salmo trutta) and endangered galaxiids

and reduced genetic diversity in areas affected by salmonids (Vanhaecke et al., 2015). In particular, brown trout have caused widespread ecological damage to areas they have been introduced, and as a result, they have been classified as one of the '100 of the world's worst invasive species' (Lowe et al., 2000). In the Falkland Islands, since its introduction in 19471962, brown trout has spread around East and West Falkland (Arrowsmith and Pentelow, 1965; Stewart, 1973), resulting in the once-common native galaxiid, zebra trout (Aplochiton zebra) to be classed as threatened, and limited to refuges uninvaded by brown trout south of the islands (McDowall et al., 2001; Ross, 2009). Conservation of Aplochiton spp. is complicated because the two known species (A. zebra and A. taeniatus) are ecologically and morphologically similar and include resident and migratory ecotypes that may confound identification (McDowall, 2006). In fact, until recently both species had been misidentified as A. zebra in the Falklands (Vanhaecke et al., 2012b). The small sizes of A. zebra and $A$. taeniatus juveniles makes them particularly susceptible to salmonid predation and displacement (Macchi et al., 2007; Arismendi et al., 2009), which also potentially increases inbreeding and hybridisation as a result of population reductions and limited suitable habitat uninvaded by brown trout (Wolf et al., 2001; Vanhaecke et al., 2012b). In contrast, the abundance of salmonids seems to be related to propagule pressure (Consuegra et al., 2011) and habitat connectivity (Habit et al., 2012). Previous studies conducted 10 and 20 years ago to assess the distribution of brown trout and native galaxiids in the Falklands (McDowall et al., 2001; Ross, 2009; Fowler, 2013) showed marked reduction in the abundance and distribution of zebra trout since the introduction of brown trout. However, traditional monitoring exercises based on electrofishing are limited by their cost and by the protected and rare nature of Aplochiton spp. Electrofishing of rare species often requires increased effort, possibly reducing the number of reaches that can be sampled (Reynolds et al., 2003) and increasing the cost of sampling each reach (Evans et al., 2017). In addition, electrofishing can reduce survival in embryos (Bohl et al., 2009) as well as cause stress, injury and mortality (Miranda and Kidwell, 2010; Panek and Densmore, 2011), which could impact rare and threatened populations.

Environmental DNA (eDNA) released from organisms through blood, urine, skin, mucus and faeces, increasingly is used to detect aquatic species that are difficult to locate, identify and/or are in low abundance, and is particularly useful for conservation programs (Biggs et al., 2015; Robinson et al., 2019a). Whilst eDNA metabarcoding is used to target multiple species and often to assess the biodiversity of a system (Deiner et al., 2015; Lacoursière-Roussel et 
A new high-resolution melt curve eDNA assay to monitor the simultaneous presence of invasive brown trout (Salmo trutta) and endangered galaxiids

al., 2018), quantitative PCR (qPCR) targets single species and constitutes a reliable method for detecting endangered and invasive species when combined with in vitro controls and amplicon sequencing (Díaz-Ferguson et al., 2014; Carlsson et al., 2017). qPCR in combination with high-resolution melt (HRM) curve analysis allows single-base variations in DNA sequences to be detected based on the DNA product melt temperature in water samples (Wittwer, 2009; Ramón-Laca et al., 2014; Robinson et al., 2018), and has been used with environmental DNA as a sensitive method to detect individual or multiple species, including fishes (Behrens-Chapuis et al., 2018; Robinson et al., 2019b), invertebrates (Robinson et al., 2018; Robinson et al., 2019a), sea turtles (Harper et al., 2020), and plants (Emenyeonu et al., 2018). Here, I developed eDNA-HRM curve analysis assays to map the current distribution of brown trout and both Aplochiton species in the Falkland Islands in a non-destructive way, to identify refuges for zebra trout, which then can be prioritised for conservation.

Here, the main aims were to develop an eDNA-HRM curve analysis assay to detect the presence of both Aplochiton species. Develop and eDNA-HRM curve analysis assay to detect the presence of brown trout and map the current distribution of brown trout and both Aplochiton species and identify refuges for zebra trout. 
A new high-resolution melt curve eDNA assay to monitor the simultaneous presence of invasive brown trout (Salmo trutta) and endangered galaxiids

\subsection{Methods}

qPCR primer design and optimisation

Aplochiton zebra and A. taeniatus qPCR primers (AzebAtaeCytbF: 5'ATGAAATTTTGGCTCTCT-3' and AzebAtaeCytbR: 5'-GAAATATCGGAGGTGTAG-3') were designed to amplify an $89 \mathrm{bp}$ fragment of the cytochrome $b$ region of the mitochondrial (mt) genome (product melt temperature $77.8^{\circ} \mathrm{C}$ and $79.2^{\circ} \mathrm{C}$ for $A$. zebra and A. taeniatus respectively). Species-specific qPCR primers (StruttaCytbF: 5'TATCCTCCATACCTCTAA-3' and StruttaCytbR: 5'-GACCGATGATAATGAATG-3') were designed for Salmo trutta to amplify a 139 bp fragment of the mitochondrial cytochrome $b$ region. Both sets of primers were designed using OligoArchitect Primer and Probe Design online software and checked in silico for cross-amplification using NCBI Primer-BLAST (Ye et al., 2012). Both AzebAtaeCytb- and StruttaCytb-qPCR primers were tested in vitro for non-specific amplification against all freshwater fishes present in the Falklands (A. zebra, A. taeniatus, Galaxias maculatus and S. trutta, except Geotria australis that may occur intermittently) (McDowall et al., 2001; Vanhaecke et al., 2012b).

Primers were assessed using positive tissue controls (fin clips and muscle tissue) from 12 different $A$. zebra and A. taeniatus individuals. DNA was extracted using Qiagen DNeasy Blood and Tissue Kit (Qiagen, UK). A 10-fold dilution series using pools of DNA from each species (consisting of DNA from six A. zebra and six A. taeniatus) ranging from $19.7 \mathrm{ng} / \mu 1$ to $1.97 \times 10^{-4} \mathrm{ng} / \mu 1$ and $14.8 \mathrm{ng} / \mu 1$ to $1.48 \times 10^{-4} \mathrm{ng} / \mu 1$ respectively was conducted in order to determine the limit of detection (LOD) and the limit of quantification (LOQ) as in Robinson et al., (2018). Amplification efficiency, also estimated from the dilution curve, was $79.5 \%$ for A. zebra and $84.6 \%$ for A. taeniatus (Bio-Rad, 2013). The annealing temperature for AzebAtaeCytb primers was optimised at $61.5^{\circ} \mathrm{C}$. The AzebAtaeCytb-qPCR protocol began with a two min denaturation step at $95^{\circ} \mathrm{C}$, followed by 45 cycles of $95^{\circ} \mathrm{C}$ for $10 \mathrm{~s}$ and $61.5^{\circ} \mathrm{C}$ for 30 s. A HRM step was applied at the end of the real-time PCR reaction, ranging from $65^{\circ} \mathrm{C}$ to $95^{\circ} \mathrm{C}$ in $0.1^{\circ} \mathrm{C}$ increments to test the consistency of amplicon melt temperatures $(\mathrm{tm})$ for each species. To account for any potential intraspecific variation in qPCR product tm, six individuals from five A. zebra populations and six from three A. taeniatus populations were used for HRM analysis. To assess the ability to detect A. zebra and A. taeniatus in the same reaction, equal volumes of both species' DNA were pooled from six different individuals of 
A new high-resolution melt curve eDNA assay to monitor the simultaneous presence of invasive brown trout (Salmo trutta) and endangered galaxiids

both species at various concentration ratios ranging from 10:90 to 50:50 (e.g. 30:70 dilutions represented in Figure 2.1).

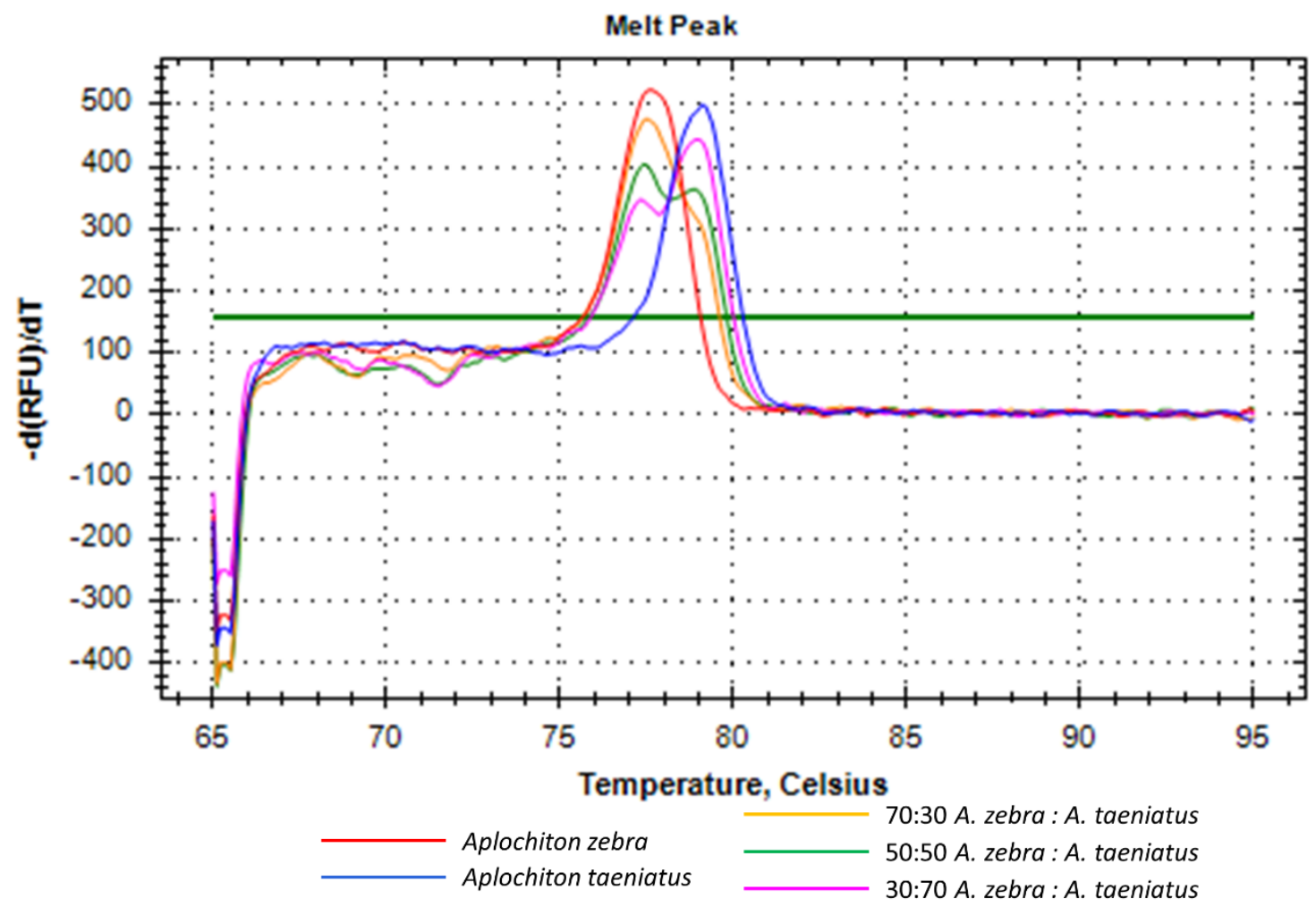

Figure 2.1. qPCR product melt curve profile for ratios of A. zebra: A. taeniatus DNA, red and blue peaks corresponds to positive $A$. zebra and A. taeniatus tissue samples respectively, whilst green peak is from a 50:50 A. zebra: A. taeniatus mix and orange and pink peaks correspond to 70:30 and 30:70 A. zebra and A. taeniatus mixes respectively.

StruttaCytb-qPCR primers were assessed in vitro using positive tissue controls (fin clips) from nine individual brown trout from a range of populations. DNA was extracted using the Qiagen Blood and Tissue Kit (Qiagen, UK), and amplified in real-time PCR-HRM analysis using the following StruttaCytb protocol: $95^{\circ} \mathrm{C}$ for $3 \mathrm{~min}$, followed by 40 cycles of $95^{\circ} \mathrm{C}$ for $10 \mathrm{sec}$ and $60^{\circ} \mathrm{C}$ for $30 \mathrm{sec}$, a HRM step was applied to the end of the real-time PCR reaction, ranging from $65^{\circ} \mathrm{C}$ to $95^{\circ} \mathrm{C}$ in $0.1^{\circ} \mathrm{C}$ increments. The annealing temperature for the StruttaCytb primers was optimised at $60^{\circ} \mathrm{C}$ resulting in an efficiency of $89.4 \%$. A 10 -fold dilution series was also carried out ranging from $35.4 \mathrm{ng} / \mu \mathrm{l}$ to $3.54 \times 10^{-4} \mathrm{ng} / \mu \mathrm{l}$ to determine the LOD and LOQ. 
A new high-resolution melt curve eDNA assay to monitor the simultaneous presence of invasive brown trout (Salmo trutta) and endangered galaxiids

AzebAtaeCytb and StruttaCytb primers also were tested using positive eDNA controls (sites where species had been seen during the sampling period) to ensure that the primers would amplify environmental DNA (Figure 2.2). eDNA samples (nine samples from three different sites $\times$ three technical PCR replicates) were spiked with positive control DNA $(1 \mu 1$ of $A$. zebra DNA from six individuals, $9.85 \mathrm{ng} / \mu \mathrm{l}$ ) to test for possible inhibition in separate reactions.

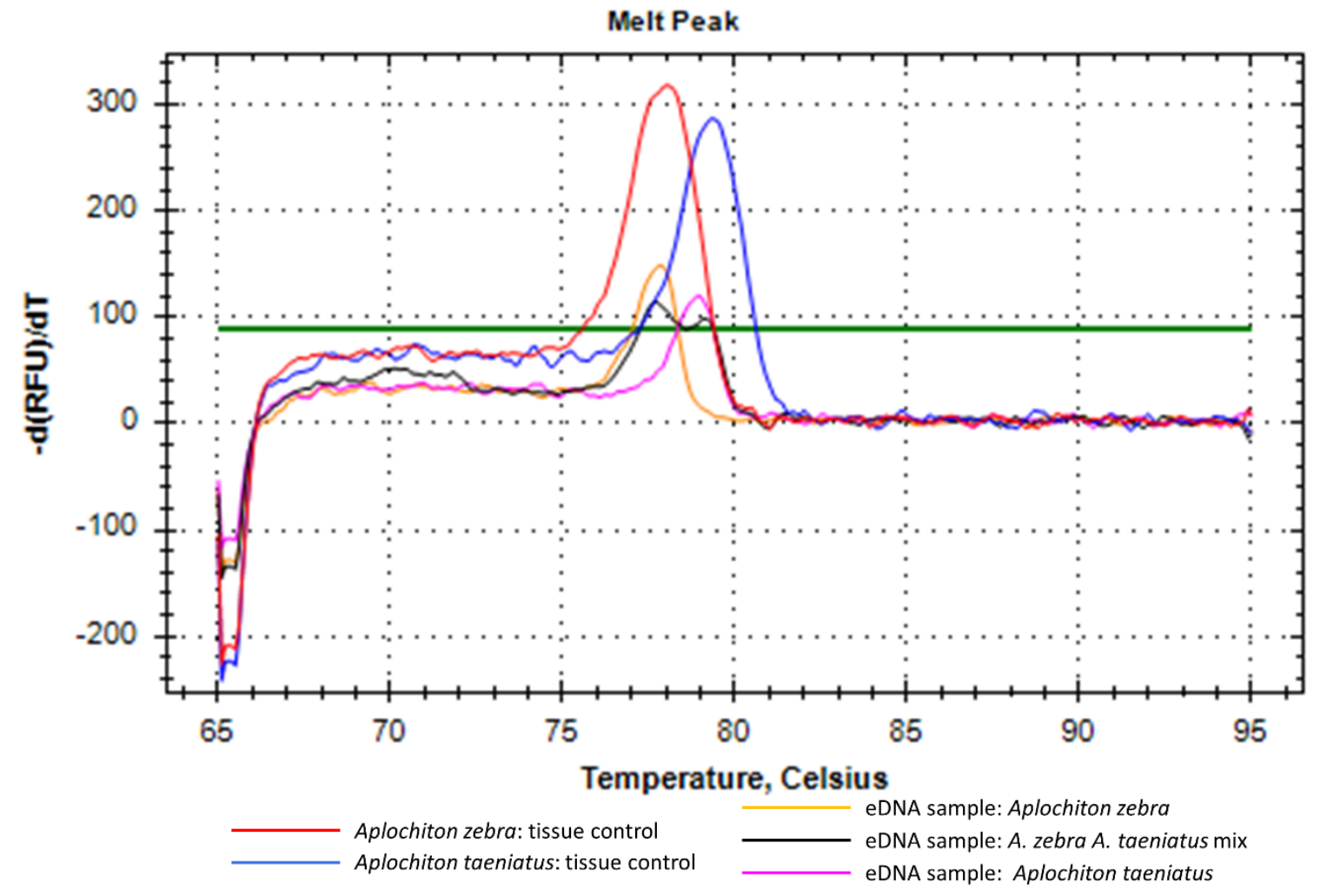

Figure 2.2. qPCR product melt curve profile for positive tissue controls for Aplochiton zebra and Aplochiton taeniatus and eDNA sample amplifications. Red and blue peaks corresponds to positive A. zebra and $A$. taeniatus tissue samples respectively, the black peak is from an eDNA sample amplifying both $A$. zebra and $A$. taeniatus simultaneously, and orange and pink peaks correspond to eDNA samples amplifying $A$. zebra and A. taeniatus respectively.

Study populations and eDNA sample collection

Nineteen rivers and ponds were sampled across the Falkland Islands (Figure 2.3), eight on East Falkland (five in the North and three in the South), and 11 on West Falkland (five in the North and six in the South). Locations were chosen based on information from monitoring studies conducted 10 and 20 years ago (McDowall et al., 2001; Ross, 2009; Fowler, 2013). Zebra trout had previously been detected at seven of the 19 locations, co-occurring with 
A new high-resolution melt curve eDNA assay to monitor the simultaneous presence of invasive brown trout (Salmo trutta) and endangered galaxiids

brown trout at only two locations. Six locations solely supported brown trout populations. The remaining seven rivers had not been surveyed previously $(\mathrm{N}=5)$ or were rivers that had been surveyed but where zebra trout or brown trout had not been recorded.

Two sites per river/pond were sampled except for R19 Neil Clark Nature Reserve where three sites were sampled; at each site, two water samples were collected from the surface of the water in areas of low flow near the bank of the river, taking precautions to avoid contamination following Robinson, Garcia de Leaniz, Rolla, et al. (2019). Three water replicates of $100-200 \mathrm{ml}$ (the final volume depending on the level of particulate organic matter present in the waterbody) were filtered at each site (Table 2.1). Water was pushed through a syringe filter containing a polyethersulfone (PES) filter membrane with a $0.45 \mu \mathrm{m}$ pore size using a sterile $50 \mathrm{ml}$ disposable syringe. Filters were then dried by pushing through air before being preserved in $95 \%$ ethanol and stored at $-20^{\circ} \mathrm{C}$ until further analyses. To prevent contamination, water sampling bags, syringes and gloves were disposed of between sites. Negative controls consisting of autoclaved or ultrapure water were filtered instead of river/pond water before sampling at each site. River width, temperature, shade cover, $\mathrm{pH}$, total dissolved solids, and electrical conductivity were measured at each sampling site where possible (Table 2.1). Due to time and weather constraints, sampling was conducted over two field seasons April-May (Autumn) and September-October (Spring) in 2018, three additional waterbodies were sampled by local citizens, two in May (Autumn) 2019 and a final site sampled in December 2019 (Table 2.1). 
A new high-resolution melt curve eDNA assay to monitor the simultaneous presence of invasive brown trout (Salmo trutta) and endangered galaxiids

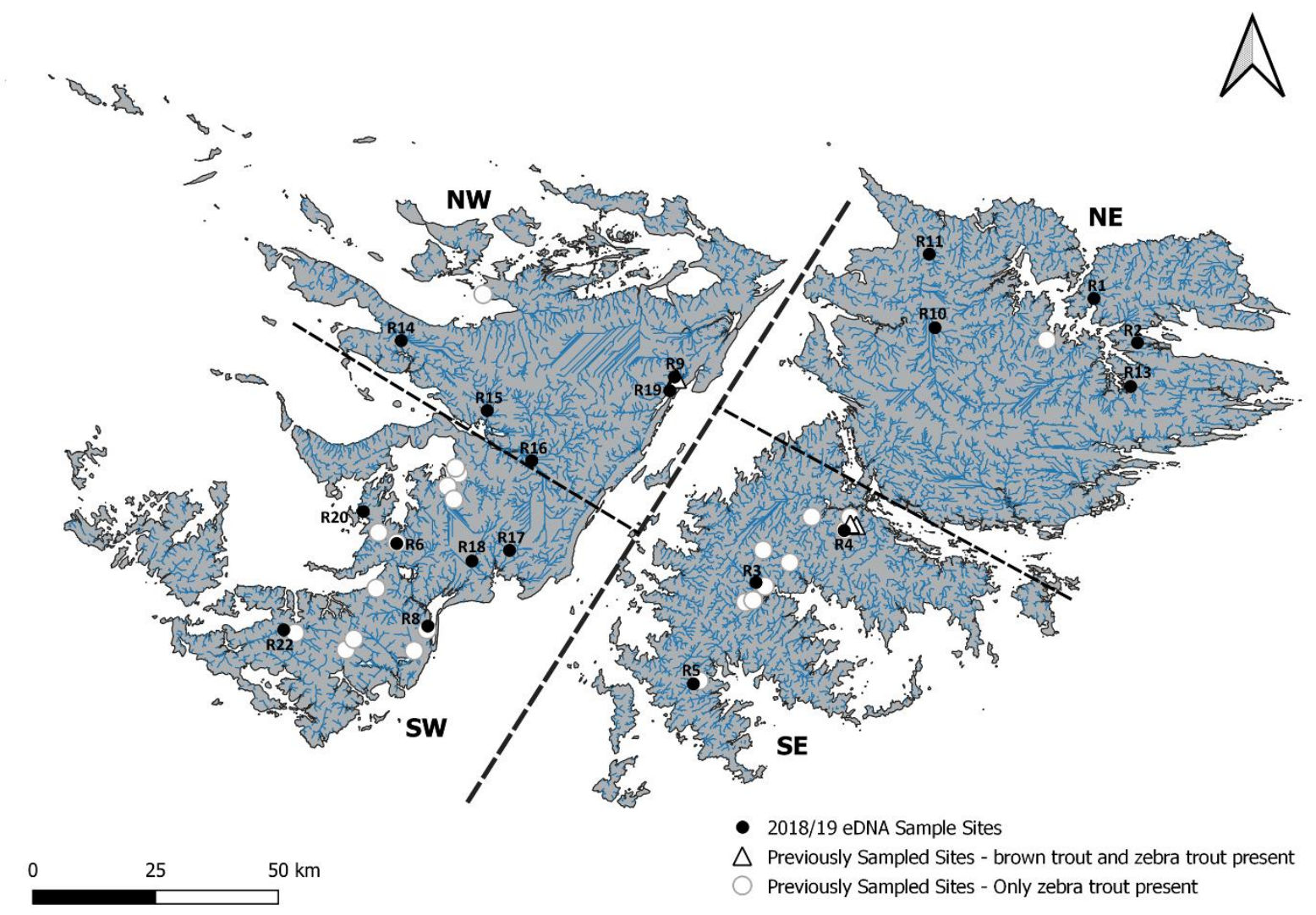

Figure 2.3. eDNA sampling locations in the Falkland Islands. Current eDNA sampling locations (black circles), previously sampled sites where only zebra trout were present (white circles) and previously sampled sites with zebra trout and brown trout present (white triangle), previous sampled data obtained from McDowall et al (2001), Ross (2009) and Fowler (2012).

eDNA extraction and amplification

eDNA was extracted from 273 field samples (19 waterbodies, 39 sites $\times$ two water samples $\times$ three replicates and one blank per site, Table 2.1) using the Qiagen DNeasy PowerSoil Kit (Qiagen, UK), following the manufacturer's instructions. DNA extractions took place in a dedicated eDNA area within an extraction cabinet equipped with a flow-through air system and UV light to minimise the risk of contamination. Extracted DNA was quantified with a Qubit 3.0 fluorometer. Six technical PCR replicates of each sample were amplified in a BioRad CFX96 Touch Real-Time PCR Detection System (Bio-Rad, UK), in 10 $\mu 1$ reaction consisting of $5 \mu 1$ of iTaq Universal SYBR Green Supermix (Bio-Rad, UK), 0.25 $\mu 1(10 \mu \mathrm{M})$ of each AzebAtaeCytbF and AzebAtaeCytbR, $2.5 \mu 1$ of ultrapure water and $2 \mu 1$ of extracted DNA. Amplifications were carried out using the standard AzebAtaeCytb-qPCR protocol as described above, only samples which consistently amplified in at least two technical PCR replicates per site at the target DNA product tm (either $77.8^{\circ} \mathrm{C} \pm 0.2$ or $79.2^{\circ} \mathrm{C} \pm 0.2$ ) were 
A new high-resolution melt curve eDNA assay to monitor the simultaneous presence of invasive brown trout (Salmo trutta) and endangered galaxiids

considered to be a positive result. Reactions of $10 \mu \mathrm{l}$ also were carried out using the StruttaCytb primers consisting of $5 \mu 1$ of iTaq Universal SYBR Green Supermix (Bio-Rad, $\mathrm{UK}), 0.25 \mu \mathrm{l}(10 \mu \mathrm{M})$ of each forward and reverse primer, $1.5 \mu 1$ of ultrapure water, and $3 \mu 1$ of DNA. Amplification was carried out using the standard StruttaCytb-qPCR protocol (described above) and only samples that amplified consistently in at least two technical PCR replicates per site at the target DNA product tm $\left(78.7^{\circ} \mathrm{C} \pm 0.1\right)$ were considered a positive result. qPCR reactions were carried out in a dedicated eDNA area; reaction mix was loaded in a DNA free PCR hood with a flow-through air system and UV light before being transferred to a separate PCR hood to load DNA. Once all eDNA samples had been loaded and sealed two positive controls (one for each species) and a negative control consisting of brown trout or Galaxias maculatus DNA also were loaded to control for false positives. Negative filter and extraction controls were run throughout the process. Three additional negative amplification controls consisting of ultrapure water were also added to test for contamination during the entire process (both with eDNA and positive control samples). To confirm primer specificity, a subset of eDNA samples ( $\mathrm{N}=4$ brown trout and $\mathrm{N}=9$ Aplochiton spp.) was amplified with the qPCR primers using end-point PCR and cloned into a pCR 4-TOPO plasmid cloning vector (TOPO TA Cloning Kit for Sequencing, Invitrogen). In total, 10-25 clones were sequenced per sample using T3 and T7 primers. All samples were cleaned using a sodium acetate/EtOH solution, resuspended in 10 $\mu 1$ HiDi Formamide (Applied Biosystems) and analysed using Sanger Sequencing on an ABI 3730 DNA Analyser (Applied Biosystems). Resulting sequences were aligned in BioEdit (v 7.2.5) (Hall, 1999), and input to BLAST (Ye et al., 2006) to confirm species identity.

To determine if sampling conditions (volume filtered, season, temperature, and shade, Table 2.1) affected amplifications, a generalised linear model using binomial error family was performed in R3.5.3. Using the dropl function, individual predictors were dropped from the model until the optimal model based on AIC was obtained. 
Table 2.1. Locations and environmental data for eDNA sampling sites, including latitude and longitude, temperature $\left({ }^{\circ} \mathrm{C}\right)$, shade cover $(0-3)$, river width, $\mathrm{pH}$, total dissolved solids (TDS), electrical conductivity (EC) and total volume filtered.

\begin{tabular}{|c|c|c|c|c|c|c|c|c|c|c|c|c|c|}
\hline $\begin{array}{l}\text { Sampling } \\
\text { Date }\end{array}$ & $\begin{array}{l}\text { Site } \\
\text { No. }\end{array}$ & Waterbody & $\begin{array}{l}\text { Previously } \\
\text { Sampled }\end{array}$ & Fish Status & Latitude & Longitude & $\begin{array}{l}\text { Temp } \\
\left({ }^{\circ} \mathrm{C}\right)\end{array}$ & $\begin{array}{l}\text { Shade } \\
\text { Cover }\end{array}$ & $\begin{array}{l}\text { Width } \\
\text { (m) }\end{array}$ & pH & $\begin{array}{l}\text { TDS } \\
(\mathrm{ppm})\end{array}$ & $\begin{array}{l}\text { EC } \\
(\mathrm{S} / \mathrm{m})\end{array}$ & $\begin{array}{l}\text { Total } \\
\text { Volume } \\
\text { Filtered } \\
\text { (ml) }\end{array}$ \\
\hline $04 / 04 / 18$ & R1a & Johns Brook & NA & Unknown & -51.48339 & -58.29203 & 5.6 & 0 & 1.5 & 4.5 & 92 & 46 & 872 \\
\hline $04 / 04 / 18$ & $\mathrm{R} 1 \mathrm{~b}$ & & NA & & -51.48137 & -58.29257 & 6.0 & 0 & 5 & 4.9 & 102 & 51 & 823 \\
\hline $04 / 04 / 18$ & $\mathrm{R} 2 \mathrm{a}$ & Monty Deans Creek & 1999 & & -51.56585 & -58.16645 & 5.0 & 0 & 2 & 6.1 & 240 & 120 & 850 \\
\hline $04 / 04 / 18$ & $\mathrm{R} 2 \mathrm{~b}$ & & 1999 & & -51.56715 & -58.15749 & 5.0 & 0 & 2 & 6.7 & 240 & 120 & 650 \\
\hline $09 / 04 / 18$ & $\mathrm{R} 3 \mathrm{a}$ & Spots Arroyo & 2009 & Zebra trout & -51.9902 & -59.30946 & 5.0 & 0 & 3 & 6.9 & 364 & 182 & 900 \\
\hline $09 / 04 / 18$ & $\mathrm{R} 3 \mathrm{~b}$ & & 2009 & & -51.9896 & -59.28561 & 6.8 & 0 & 3 & 7.3 & 370 & 185 & 1200 \\
\hline $18 / 04 / 18$ & $\mathrm{R} 4 \mathrm{a}$ & Findley Creek Stream & 2011 & Brown trout & -51.89972 & -59.04361 & 6.8 & 0 & $<1$ & 7.3 & 240 & 120 & 1200 \\
\hline $18 / 04 / 18$ & $\mathrm{R} 4 \mathrm{~b}$ & & 2011 & $\begin{array}{l}\& \text { zebra } \\
\text { trout }\end{array}$ & -51.93139 & -59.06011 & 7.4 & 0 & $<1$ & 7.5 & 288 & 144 & 1200 \\
\hline $19 / 04 / 18$ & $\mathrm{R} 5 \mathrm{a}$ & Northwest Arm House & 2012 & Zebra trout & -52.17283 & -59.50553 & 9.4 & 0 & 2 & 6.8 & 482 & 234 & 1200 \\
\hline $19 / 04 / 18$ & $\mathrm{R} 5 \mathrm{~b}$ & Stream & 2012 & & -52.16641 & -59.49236 & 11.6 & 0 & 3 & 7.1 & 479 & 239 & 1108 \\
\hline $01 / 05 / 18$ & R6a & Fish Creek (2) & 2012 & Zebra trout & -51.89306 & -60.36861 & 4.0 & 1 & 1 & 5.5 & 508 & 254 & 1200 \\
\hline $01 / 05 / 18$ & $\mathrm{R} 6 \mathrm{~b}$ & & 2012 & & -51.89306 & -60.36861 & 4.0 & 0 & 3 & 6.7 & 382 & 191 & 1200 \\
\hline $02 / 05 / 18$ & $\mathrm{R} 8 \mathrm{a}$ & Fish Creek (1) & 2012 & Zebra trout & -52.05583 & -60.29111 & 4.2 & 1 & 2 & 4.5 & 240 & 120 & 635 \\
\hline $02 / 05 / 18$ & $\mathrm{R} 8 \mathrm{~b}$ & & 2012 & & -52.04722 & -60.28778 & 4.2 & 0 & 5 & 4.6 & 242 & 121 & 650 \\
\hline $03 / 05 / 18$ & R9a & House Creek & 1999 & Brown trout & -51.6075 & -59.52972 & 4.2 & 0 & 3 & 4.8 & 56 & 28 & 1100 \\
\hline $03 / 05 / 18$ & $\mathrm{R} 9 \mathrm{~b}$ & & 1999 & $\begin{array}{l}\text { \& zebra } \\
\text { trout }\end{array}$ & -51.61111 & -59.52333 & 4.2 & 0 & 3 & 4.9 & 58 & 29 & 950 \\
\hline $22 / 09 / 18$ & $\mathrm{R} 10 \mathrm{a}$ & San Carlos & 1999 & Brown trout & -51.5095 & -58.822 & 1.6 & 0 & 20 & 3.9 & 70 & 35 & 1200 \\
\hline $30 / 09 / 18$ & $\mathrm{R} 10 \mathrm{~b}$ & & 1999 & & -51.531111 & -58.760278 & NA & 0 & 15 & NA & NA & $\mathrm{NA}$ & 1200 \\
\hline
\end{tabular}




\begin{tabular}{|c|c|c|c|c|c|c|c|c|c|c|c|c|c|}
\hline $03 / 10 / 18$ & R11a & $\begin{array}{l}\text { Elephant Beach Pond } \\
\text { Stream }\end{array}$ & 1999 & Brown trout & -51.395556 & -58.771944 & 2.6 & 0 & 5 & 4.5 & 92 & 46 & 1200 \\
\hline 03/10/18 & $\mathrm{R} 11 \mathrm{~b}$ & & 1999 & & -51.434444 & -58.773611 & 5.8 & 1 & 2 & 4.7 & 94 & 47 & 1200 \\
\hline 03/10/18 & $\mathrm{R} 13 \mathrm{a}$ & Estancia Creek & 2008 & Brown trout & -51.6475 & -58.195833 & 5.4 & 2 & $<1$ & 5.3 & 92 & 46 & 1200 \\
\hline $03 / 10 / 18$ & $\mathrm{R} 13 \mathrm{~b}$ & & 2008 & & -51.646389 & -58.188611 & 5.4 & 0 & 15 & 5.6 & 704 & 4352 & 1200 \\
\hline 08/10/18 & $\mathrm{R} 14 \mathrm{a}$ & Herbert Stream & 1999 & Brown trout & -51.5208333 & -60.3277778 & 5.8 & 0 & 10 & NA & 288 & 148 & 900 \\
\hline 08/10/18 & $\mathrm{R} 14 \mathrm{~b}$ & & 1999 & & -51.5308333 & -60.2427778 & 6.2 & 1 & 5 & NA & 226 & 110 & 1200 \\
\hline 08/10/18 & $\mathrm{R} 15 \mathrm{a}$ & Teal House River & NA & Unknown & -51.6194444 & -60.1102778 & 5.2 & 1 & 3 & NA & 72 & 36 & 1200 \\
\hline 08/10/18 & $\mathrm{R} 15 \mathrm{~b}$ & & NA & & -51.6561111 & -60.0841667 & 6.8 & 2 & 4 & NA & 90 & 45 & 1200 \\
\hline 08/10/18 & $\mathrm{R} 16 \mathrm{a}$ & Chartres River & 1999 & Brown trout & -51.7516667 & -59.9594444 & 7.8 & 1 & 25 & NA & 92 & 46 & 1192 \\
\hline 09/10/18 & $\mathrm{R} 16 \mathrm{~b}$ & & 1999 & & -51.8366667 & -59.9611111 & 4.6 & 1 & 3 & NA & 304 & 152 & 600 \\
\hline 09/10/18 & $\mathrm{R} 17 \mathrm{a}$ & Doctors Creek & 2012 & Brown trout & -51.9411111 & -60.0522222 & 4.0 & 1 & 3 & NA & 364 & 182 & 1200 \\
\hline 09/10/18 & $\mathrm{R} 17 \mathrm{~b}$ & & 2012 & & -51.9147222 & -60.0358333 & 3.6 & 2 & $<1$ & NA & 246 & 123 & 1200 \\
\hline 09/10/18 & $\mathrm{R} 18 \mathrm{a}$ & Malo Arroyo & NA & Unknown & -51.9313889 & -60.1483333 & 4.0 & 0 & 4 & NA & 364 & 182 & 614 \\
\hline $11 / 10 / 18$ & $\mathrm{R} 18 \mathrm{~b}$ & & NA & & -51.9597222 & -60.1569444 & 1.4 & 0 & 7 & NA & 328 & 164 & 600 \\
\hline $29 / 10 / 18$ & $\mathrm{R} 19 \mathrm{a}$ & Neil Clark Nature & NA & Unknown & -51.632444 & -59.54519 & NA & NA & NA & NA & NA & NA & 1200 \\
\hline 09/10/18 & $\mathrm{R} 19 \mathrm{~b}$ & Reserve & NA & & -51.9411111 & -60.0522222 & 3.0 & 0 & 50 & NA & 1660 & 830 & 1200 \\
\hline $14 / 12 / 19$ & $\mathrm{R} 19 \mathrm{c}$ & & NA & & -51.632222 & -59.545556 & NA & 2 & $<1$ & NA & NA & NA & 1150 \\
\hline 06/05/19 & $\mathrm{R} 20 \mathrm{a}$ & Spring Point & NA & Unknown & -51.8314 & -60.4628 & NA & 2 & 1 & NA & NA & NA & 900 \\
\hline 06/05/19 & $\mathrm{R} 20 \mathrm{~b}$ & & NA & & -51.823 & -60.4454 & $\mathrm{NA}$ & 2 & 2 & NA & NA & NA & 1000 \\
\hline 06/05/19 & $\mathrm{R} 22 \mathrm{a}$ & Whiskey Creek & 2009 & Zebra trout & -52.0542 & -60.7891 & NA & 2 & 2 & NA & NA & NA & 900 \\
\hline 06/05/19 & $\mathrm{R} 22 \mathrm{~b}$ & & 2009 & & -52.0416 & -60.7155 & NA & 2 & 3 & NA & NA & NA & 900 \\
\hline
\end{tabular}


A new high-resolution melt curve eDNA assay to monitor the simultaneous presence of invasive brown trout (Salmo trutta) and endangered galaxiids

\subsection{Results}

AzebAtaeCytb and StruttaCytb assays were tested in silico for cross-amplification using NCBI Primer-BLAST (Ye et al., 2012) (Table 2.2), I found no cross amplifications with any species present in the Falkland Islands. Primers were also tested in vitro against S. trutta and G. maculatus, and both species of zebra trout and G. maculatus respectively; no cross amplifications were detected. A 10-fold dilution series of positive control A. taeniatus and A. zebra DNA (from six individuals respectively) revealed that for A. taeniatus the limit of detection (LOD) was $1.97 \times 10^{-4} \mathrm{ng} / \mu 1$ and for $A$. zebra the LOD was $1.48 \times 10^{-4} \mathrm{ng} / \mu 1$. The detection threshold for both species of zebra trout at the lowest LOD was 42 cycles and the product melting temperatures $(\mathrm{tm})$ were consistent throughout the dilution series. qPCR product tm showed no overlap between the two species of zebra trout $\left(77.8^{\circ} \mathrm{C}\right.$ and $79.2^{\circ} \mathrm{C} \pm$ 0.2 for A. zebra and A. taeniatus respectively; these might vary in zebra trout from different regions, if there were polymorphisms in the amplified region). Using the diagnostic melt curve produced it was possible to detect the presence of both species when combining varying ratios of pooled DNA (Figure 2.2). Results from a 10-fold dilution series revealed that the LOD for brown trout was $3.54 \times 10^{-4} \mathrm{ng} / \mu 1$ for the $S$. trutta qPCR assay with a detection threshold of 37 cycles. The nine eDNA samples spiked with positive control $A$. zebra DNA amplified with qPCR product tm at $77.8^{\circ} \mathrm{C}$, indicating no signs of inhibition. 
A new high-resolution melt curve eDNA assay to monitor the simultaneous presence of invasive brown trout (Salmo trutta) and endangered galaxiids

Table 2.2. Species that could be cross amplified with AzebAtaeCytb and StruttaCytb primers, in silico cross amplification checks conducted using Primer-BLAST. None of the species are present in the Falkland Islands and in all cases the region sequenced has at least one base pair difference with the target species.

\begin{tabular}{|c|c|c|}
\hline \multicolumn{2}{|c|}{ AzebAtaeCytb Primers } & \multirow{2}{*}{$\frac{\text { StruttaCytb Primers }}{\text { Atherinomorus endrachtensis }}$} \\
\hline Astatotilapia burtoni & Kryptolebias marmoratus & \\
\hline Acantopsis dialuzona & Lobocheilos melanotaenia & Barilius bendelisis \\
\hline Acrossocheilus yunnanensis & Lobocheilos spp. & Salmo akairos \\
\hline Allodontichthys tamazulae & Luciogobius pallidus & Salmo marmoratus \\
\hline Argyrops spp. & Lutjanus adetii & Salmo munzuricus \\
\hline Barbus balcanicus & Mastacembelus ansorgii & Salmo obtusirostris \\
\hline Barbus barbus & Micropoecilia bifurca & Salmo ohridanus \\
\hline Barbus biharicus & Mystus singaringan & Salmo platycephalus \\
\hline Barbus caninus & Neoheterandria cana & Salmo salar \\
\hline Barbus peloponnesius & Olyra longicaudatus & Salmo tigridis \\
\hline Barbus petenyi & Orthodon microlepidotus & \\
\hline Barbus plebejus & Paracanthobrama guichenoti & \\
\hline Barbus plebejus spp. & Pethia longicauda & \\
\hline Betta simplex & Pethia sahit & \\
\hline Brachyrhaphis hartwegi & Pimelodus pictus & \\
\hline Brachyrhaphis roseni & Plotosus canius & \\
\hline Channa quinquefasciata & Poeciliopsis retropinna & \\
\hline Chiloglanis brevibarbis & Pseudomystus siamensis & \\
\hline Crenuchus spilurus & Pterolebias peruensis & \\
\hline Distoechodon hupeinensis & Rhodeus amurensis & \\
\hline Galaxias zebratus & Rhodeus atremius & \\
\hline Galaxiella pusilla & Rhodeus sinensis & \\
\hline Galaxiella toourtkoourt & Rhodeus uyekii & \\
\hline Gambusia eurystoma & Risor ruber & \\
\hline Gambusia sexradiata & Rivulus marmoratus & \\
\hline Gymnothorax margaritophorus & Rivulus santensis & \\
\hline Gymnothorax niphostigmus & Scarus flavipectoralis & \\
\hline Haplochromis burtoni & Tanakia limbate & \\
\hline Hara jerdoni & Thamnaconus modestus & \\
\hline Henicorhynchus lineatus & Trigonectes cf. & \\
\hline Ichthyoelephas longirostris & Xenocypris hupeinensis & \\
\hline
\end{tabular}

273 eDNA samples were extracted from 19 rivers and ponds in the Falklands retrieving DNA concentrations between 0 and $15 \mathrm{ng} / \mu \mathrm{l}$ across all sites (57 samples had no detectable DNA). Zebra trout DNA was successfully detected in three of the 19 rivers sampled (Table 2.3 and Table 2.4), Aplochiton zebra in two rivers and Aplochiton taeniatus in three, whereas brown trout DNA was detected in six out of 19 rivers (Table 2.3 and Table 2.4), three of being the first time. Previously, brown trout and zebra trout had been found together in two of the rivers, R4 (Findley Creek Stream) and R9 (House Creek); however, no indication of either species was found in those rivers. Brown trout and zebra trout DNA was detected at sites 
A new high-resolution melt curve eDNA assay to monitor the simultaneous presence of invasive brown trout (Salmo trutta) and endangered galaxiids

where they had been previously found ( $\mathrm{N}=3$ in each case) and also at sites where there was visual confirmation eDNA collection (Table 2.3), supporting the effectiveness of these assays in the field. All negative controls (sampling blanks, extraction blanks and PCR blanks) failed to amplify for both zebra trout species and brown trout.

Table 2.3. Previous and current presence/absence data for the three study species at all sampling sites based on previous sampling using electrofishing and on current sampling using eDNA. Y $=$ species present, $\mathrm{N}=$ Species not present/detected. * zebra trout seen during eDNA sampling; ** brown trout caught/seen during eDNA sampling period.

\begin{tabular}{|c|c|c|c|c|c|c|c|}
\hline \multirow[t]{2}{*}{ Waterbody } & \multirow[t]{2}{*}{$\begin{array}{l}\text { Site } \\
\text { No. }\end{array}$} & \multirow[t]{2}{*}{$\begin{array}{l}\text { Previously } \\
\text { sampled }\end{array}$} & \multirow{2}{*}{$\begin{array}{l}\text { Zebra } \\
\text { trout } \\
\text { previously } \\
\text { present }\end{array}$} & \multicolumn{2}{|c|}{$\begin{array}{l}\text { Zebra trout current } \\
\text { presence }\end{array}$} & \multirow{2}{*}{$\begin{array}{l}\text { Salmo } \\
\text { trutta } \\
\text { previously } \\
\text { present }\end{array}$} & \multirow{2}{*}{$\begin{array}{l}\text { Salmo } \\
\text { trutta } \\
\text { current } \\
\text { presence }\end{array}$} \\
\hline & & & & A. zebra & A. taeniatus & & \\
\hline Johns Brook & R1 & NA & NA & $\mathrm{N}$ & $\mathrm{N}$ & NA & $\mathrm{Y}$ \\
\hline Monty Deans Creek & $\mathrm{R} 2$ & 1999 & $\mathrm{~N}$ & $\mathrm{~N}$ & $\mathrm{~N}$ & $\mathrm{~N}$ & $\mathrm{~N}$ \\
\hline Spots Arroyo & R3 & 2009 & $\mathrm{Y}$ & $\mathrm{N}$ & $\mathrm{Y}$ & $\mathrm{N}$ & $\mathrm{N}$ \\
\hline Findley Creek Stream & R4 & 2011 & $\mathrm{Y}$ & $\mathrm{N}$ & $\mathrm{N}$ & $\mathrm{Y}$ & $\mathrm{N}$ \\
\hline $\begin{array}{l}\text { North West Arm House } \\
\text { Stream * }\end{array}$ & R5 & 2012 & $\mathrm{Y}$ & Y & Y & $\mathrm{N}$ & $\mathrm{N}$ \\
\hline Fish Creek (2) & R6 & 2012 & $\mathrm{Y}$ & $\mathrm{Y}$ & $\mathrm{Y}$ & $\mathrm{N}$ & $\mathrm{N}$ \\
\hline Fish Creek (1) & R8 & 2012 & $\mathrm{Y}$ & $\mathrm{N}$ & $\mathrm{N}$ & $\mathrm{N}$ & $\mathrm{N}$ \\
\hline House Creek & R9 & 1999 & $\mathrm{Y}$ & $\mathrm{N}$ & $\mathrm{N}$ & $\mathrm{Y}$ & $\mathrm{N}$ \\
\hline San Carlos ** & $\mathrm{R} 10$ & 1999 & $\mathrm{~N}$ & $\mathrm{~N}$ & $\mathrm{~N}$ & $\mathrm{Y}$ & $\mathrm{Y}$ \\
\hline $\begin{array}{l}\text { Elephant Beach Pond } \\
\text { Stream }\end{array}$ & $\mathrm{R} 11$ & 1999 & $\mathrm{~N}$ & $\mathrm{~N}$ & $\mathrm{~N}$ & $\mathrm{Y}$ & $\mathrm{Y}$ \\
\hline Estancia Creek & R13 & 2008 & $\mathrm{~N}$ & $\mathrm{~N}$ & $\mathrm{~N}$ & $\mathrm{Y}$ & $\mathrm{N}$ \\
\hline Herbert Stream ** & R14 & 1999 & $\mathrm{~N}$ & $\mathrm{~N}$ & $\mathrm{~N}$ & $\mathrm{Y}$ & $\mathrm{N}$ \\
\hline Teal House River & R15 & NA & NA & $\mathrm{N}$ & $\mathrm{N}$ & NA & $\mathrm{Y}$ \\
\hline Chartres River & R16 & 1999 & $\mathrm{~N}$ & $\mathrm{~N}$ & $\mathrm{~N}$ & $\mathrm{Y}$ & $\mathrm{N}$ \\
\hline Doctors Creek** & $\mathrm{R} 17$ & 2012 & $\mathrm{~N}$ & $\mathrm{~N}$ & $\mathrm{~N}$ & $\mathrm{Y}$ & $\mathrm{Y}$ \\
\hline Malo Arroyo ** & $\mathrm{R} 18$ & NA & NA & $\mathrm{N}$ & $\mathrm{N}$ & NA & $\mathrm{N}$ \\
\hline $\begin{array}{l}\text { Neil Clark Nature } \\
\text { Reserve }\end{array}$ & R19 & NA & NA & $\mathrm{N}$ & $\mathrm{N}$ & NA & $\mathrm{Y}$ \\
\hline Spring Point & $\mathrm{R} 20$ & NA & NA & $\mathrm{N}$ & $\mathrm{N}$ & NA & $\mathrm{N}$ \\
\hline Whiskey Creek Stream & $\mathrm{R} 22$ & 2009 & $\mathrm{Y}$ & $\mathrm{N}$ & $\mathrm{N}$ & $\mathrm{N}$ & $\mathrm{N}$ \\
\hline
\end{tabular}


A new high-resolution melt curve eDNA assay to monitor the simultaneous presence of invasive brown trout (Salmo trutta) and endangered galaxiids

Table 2.4. Total number of amplifications in waterbodies where brown trout or zebra trout were detected.

\begin{tabular}{llllll}
\hline Waterbody & $\begin{array}{l}\text { Site } \\
\text { No. }\end{array}$ & Total Volume & \multicolumn{2}{l}{$\begin{array}{l}\text { No. Zebra Trout } \\
\text { Smplifications }\end{array}$} & $\begin{array}{l}\text { No. Brown Trout } \\
\text { Amplifications }\end{array}$ \\
& & & A. zebra & A. taeniatus & \\
\hline Johns Brook & $\mathrm{R} 1.1$ & 872 & $0 / 36$ & $0 / 36$ & $4 / 36$ \\
& $\mathrm{R} 1.3$ & 823 & $0 / 36$ & $0 / 36$ & $2 / 36$ \\
Spots Arroyo & $\mathrm{R} 3.1$ & 900 & $0 / 36$ & $2 / 36$ & $0 / 36$ \\
North West Arm House & $\mathrm{R} 3.3$ & 1200 & $0 / 36$ & $4 / 36$ & $0 / 36$ \\
Stream & $\mathrm{R} 5.1$ & 1200 & $6 / 36$ & $5 / 36$ & $0 / 36$ \\
& & & & & \\
Fish Creek (2) & $\mathrm{R} 5.3$ & 1108 & $34 / 36$ & $0 / 36$ & $0 / 36$ \\
& $\mathrm{R} 6.1$ & 1200 & $0 / 36$ & $0 / 36$ & $0 / 36$ \\
San Carlos & $\mathrm{R} 6.3$ & 1200 & $9 / 36$ & $5 / 36$ & $0 / 36$ \\
& $\mathrm{R} 10.1$ & 1200 & $0 / 36$ & $0 / 36$ & $12 / 36$ \\
Elephant Beach Pond Stream & $\mathrm{R} 10.2$ & 1200 & $0 / 36$ & $0 / 36$ & $21 / 36$ \\
& $\mathrm{R} 11.1$ & 1200 & $0 / 36$ & $0 / 36$ & $19 / 36$ \\
Teal House River & $\mathrm{R} 11.3$ & 1200 & $0 / 36$ & $0 / 36$ & $6 / 36$ \\
& $\mathrm{R} 15.1$ & 1200 & $0 / 36$ & $0 / 36$ & $13 / 36$ \\
Doctors Creek & $\mathrm{R} 15.2$ & 1200 & $0 / 36$ & $0 / 36$ & $12 / 36$ \\
\multirow{2}{*}{ Neil Clark Nature Reserve } & $\mathrm{R} 17.1$ & 1200 & $0 / 36$ & $0 / 36$ & $19 / 36$ \\
& $\mathrm{R} 17.2$ & 1200 & $0 / 36$ & $0 / 36$ & $1 / 36$ \\
& $\mathrm{R} 19.1$ & 1200 & $0 / 36$ & $0 / 36$ & $0 / 36$ \\
& $\mathrm{R} 19.3$ & 1200 & $0 / 36$ & $0 / 36$ & $5 / 36$ \\
& $\mathrm{R} 19.5$ & 1150 & $0 / 36$ & $0 / 36$ & $0 / 36$ \\
\hline
\end{tabular}

Cloning of four brown trout samples resulted in 58 successfully transformed clones whose sequences matched $97.89-100 \%$ S. trutta sequences in BLAST (Ye et al., 2006). Aplochiton spp. cloning resulted in the successful transformation of 84 clones from nine eDNA samples ( $\mathrm{N}=2$ A. zebra, $\mathrm{N}=3$ A. taeniatus, and $\mathrm{N}=2$ mixed samples), 78 matching $89.66-100 \% A$. zebra, and six matching $91.67-100 \%$ A. taeniatus in BLAST, confirming the species identity of the peaks at each of the melting temperatures. Only A. zebra sequences were identified in the mixed samples and non-specific amplification was observed in the remaining clones.

To determine if amplifications were affected by sampling conditions (volume filtered, season, and shade, Table 2.1) a generalised linear model using binomial error family was performed. Individual predictors were dropped from the model until the optimal model based on AIC was obtained. Starting model contained volume (estimate $=0.005, \mathrm{SE}=0.002, t=2.384, p=$ 0.017 ), season (estimate $=0.485, \mathrm{SE}=0.853, t=0.569, p=0.570$ ), and shade (estimate $=$ $0.894, \mathrm{SE}=0.549, t=-1.628, p=0.106$ ) as predictor variables. Following the dropl function season was removed first, followed by shade (Table 2.5). In the final model total water volume sampled was the sole significant predictor (estimate $=0.005, \mathrm{SE}=0.002, t=2.293, p$ 
A new high-resolution melt curve eDNA assay to monitor the simultaneous presence of invasive brown trout (Salmo trutta) and endangered galaxiids

$=0.022$, AIC $=47.773$ ), indicating that larger volumes of water were more likely to yield successful amplifications.

Table 2.5. Model output and AIC for all possible models used to determine if amplifications were affected by sampling conditions. Predictor variables included volume, shade, and season.

\begin{tabular}{lllll}
\hline Model & Volume & Shade & Season & AIC \\
\hline Starting model & $\mathrm{E}=0.005$ & $\mathrm{E}=-0.894$ & $\mathrm{E}=0.485$ & 48.622 \\
& $\mathrm{SE}=0.002$ & $\mathrm{SE}=0.549$ & $\mathrm{SE}=0.853$ & \\
& $t=2.384$ & $t=-1.628$ & $t=0.569$ & \\
Intermediate model & $p=0.017$ & $p=0.106$ & $p=0.570$ & \\
& $\mathrm{E}=0.005$ & $\mathrm{E}=-0.793$ & & 46.946 \\
& $\mathrm{SE}=0.002$ & $\mathrm{SE}=0.500$ & & \\
& $t=2.530$ & $t=-1.588$ & & \\
Final Model & $p=0.011$ & $p=0.112$ & & 47.773 \\
& $\mathrm{E}=0.005$ & & & \\
& $\mathrm{SE}=0.002$ & & & \\
& $t=2.293$ & & & \\
& $p=0.022$ & & & \\
\hline
\end{tabular}


A new high-resolution melt curve eDNA assay to monitor the simultaneous presence of invasive brown trout (Salmo trutta) and endangered galaxiids

\subsection{Discussion}

The application of the novel AzebAtaeCytb assay allowed the detection of two threatened galaxiids, which coexisted in some of the sampling locations, and confirmed their presence at three rivers where they had previously been detected with conventional sampling. In addition, using the StruttaCytb assay, brown trout DNA was detected in six rivers, including three where they had not previously been sampled. The assays were validated by sequencing and visual identification.

Zebra trout were not detected in three rivers where they had previously been identified, including two where the species previously were found to coexist with brown trout. This failure to detect coexistence could be due to brown trout outcompeting native zebra trout, as seen in other streams throughout the Falklands and other counties (Garcia de Leaniz et al., 2010; Valiente et al., 2010a). It is possible that the trout caught in Findley Creek Stream and House Creek were new invaders into these areas during the first sampling and, therefore, coexistence between these species may have been short-lived. However, failure to detect brown trout and zebra trout at rivers where they had previously been found using traditional methods also could be due to low filtration volume, as filtering larger volumes of water increases eDNA capture (Deiner et al., 2015; Muha et al., 2019) and may facilitate detection of rare species and populations (Turner et al., 2014). Although all target species were detected using relatively small volumes of water $(100-200 \mathrm{ml}$ per replicate), which were previously shown to be sensitive enough to detect rare species (Robinson et al., 2019b), the analysis indicated that amplifications were affected by the total volume filtered, with detections being more likely with higher volumes (Turner et al., 2014; Schultz and Lance, 2015; Egeter et al., 2018). Therefore, I suggest filtering larger water volumes, at least $1 \mathrm{~L}$ per replicate, to maximise detection of rarer target species (Mächler et al., 2016; Capo et al., 2019).

Weather conditions might also have played a role in the detection rates, as sampling was carried out across two field seasons, the first April-May 2018 (Autumn) and the second September-October 2018 (Spring), coinciding with high volume of rain and snowmelt, resulting in more water and faster flowing rivers than in the first sampling season. These high/fast flowing conditions could have led to DNA being flushed out/downstream more quickly, potentially reducing the probability of detecting target species' DNA (Pilliod et al., 2014; Laramie et al., 2015). In addition, seasonal changes in eDNA concentration can occur with breeding, whereby DNA is released into the environment with gametes (Buxton et al., 2017; Doi et al., 2017). Environmental factors such as temperature also can have seasonal 
A new high-resolution melt curve eDNA assay to monitor the simultaneous presence of invasive brown trout (Salmo trutta) and endangered galaxiids

impacts, with temperature not only influencing the release of DNA through increased activity, but also impacting its degradation rates (Lacoursière-Roussel et al., 2016b; Buxton et al., 2017). However, statistical analyses indicated that season had no effect on amplification, so sampling in two different seasons did not seem to have affected the detection probability in this case. In addition, the spatial distribution, and densities of individuals in a river could affect the detection of target DNA, if animals congregated in a specific area and water movement resulted in the clumping of DNA (Furlan et al., 2016). Finally, it is possible that the presence of brown trout and zebra trout in some streams could not be detected as they no longer inhabited those areas.

The analyses distinguished between the morphologically similar A. zebra and A. taeniatus, enabling the determination of species assemblages when either or both species are present, highlighting the sensitivity of qPCR-based methods over traditional approaches (Wilcox et al., 2013; Evans et al., 2017). Previously, morphological identification was mainly based on stomach size and length, and dorsal spots; however, individuals can lack colour patterns especially when small and this colouration should be interpreted with caution (Alò et al., 2013). In addition, identifying species through stomach size and length (Mcdowall and Nakaya, 1988) requires destructive sampling, which is not ideal when working with a threatened species (Barnett et al., 2010; Jardine et al., 2011). Although it is possible to identify Aplochiton spp. though DNA barcoding of tissue samples (e.g., fin clips and muscle), this type of sampling could increase mortality as it requires capturing and handling individuals (Vanhaecke et al., 2012b), it is more time consuming than collecting water, particularly for rare species such as zebra trout (Reynolds et al., 2003), and is not appropriate endangered species (Falkland Islands Government, 1999; Sanderson et al., 2009).

The introduction of brown trout to the Falkland Islands has posed many risks to the native galaxiids, and the impacts can be seen in all three native species (Galaxias maculatus and both Aplochiton species) (McDowall et al., 2001; Ross, 2009). Since the introduction of brown trout, zebra trout abundance and distribution has shown a marked decline that resulted in the species being considered threatened in the Falklands (Falkland Islands Government, 1999; McDowall et al., 2001; Ross, 2009). Although, I did not detect any coexistence of brown trout and zebra trout in this study, their co-occurrence had been previously observed in the Falkland Islands (McDowall et al., 2001) and in Patagonia, where brown trout has caused dietary changes and decreased body condition in both species of zebra trout (Elgueta et al., 2013). 
A new high-resolution melt curve eDNA assay to monitor the simultaneous presence of invasive brown trout (Salmo trutta) and endangered galaxiids

eDNA from both Aplochiton species was also found in two locations where their coexistence had not been previously observed (Vanhaecke et al., 2012b). Such species mixing could lead to increased hybridisation, known to occur at very low frequencies (Vanhaecke et al., 2012b), potentially resulting in outbreeding depression, demographic swamping, and/or genetic assimilation (Esa et al., 2000; Wolf et al., 2001). Hybridisation effects of invasions have been observed in pupfish (Cyprinodon bovinus) in Texas and Mozambique tilapia (Oreochromis mossambicus) in southern Africa where native and invasive species are hybridizing (Echelle and Echelle, 1997; Firmat et al., 2013), and also in New Zealand where introgression between two species of native galaxiid (Galaxias depressiceps and Galaxias sp D) has been human induced (Esa et al., 2000). It is unknown whether hybrids between A. zebra and $A$. taeniatus would be viable, but further research on the potential risks is needed.

To protect the native galaxiids in the Southern Hemisphere it is important to determine their current distribution and that of invasive salmonids, for which eDNA provides an efficient and cost-effective non-invasive tool, as in many recent conservation and monitoring programs (Jerde et al., 2011; Rees et al., 2014). This is particularly valuable in remote/inaccessible areas (Lacoursière-Roussel et al., 2018), such as the Falklands, where it can be very difficult and costly to access and sample using traditional methods due to the limited road network. Information on remaining refugia for galaxiids can be used to prioritise sites for conservation (McGeoch et al., 2016), for example in designating nature reserves and/or Ramsar sites, implementing semi-permeable fish barriers that allow movement of only small native fishes or physically removing brown trout from galaxiid refuges (Chadderton, 2001).

In summary, using newly developed non-destructive eDNA assays, I identified brown trout in locations where it had previously been undetected, suggesting potential expansion of the species in the Falklands, and also detected the coexistence of both Aplochiton species. With further optimisation, such as using synthetic genes at known concentrations (Wilcox et al., 2013), it may be possible to gain relative estimates of species abundance using qPCR (Lodge et al., 2012; Lacoursière-Roussel et al., 2016a), although the results indicate that water volume is critical for the detection sensitivity. These tools can be used to monitor both threatened galaxiids and invasive brown trout and have the potential to inform conservation managers on their range expansion or contraction to better target areas for intervention (Rees et al., 2014). 


\section{Chapter 3 Conservation of endangered galaxiid fishes in the Falkland Islands required urgent action on invasive brown trout}
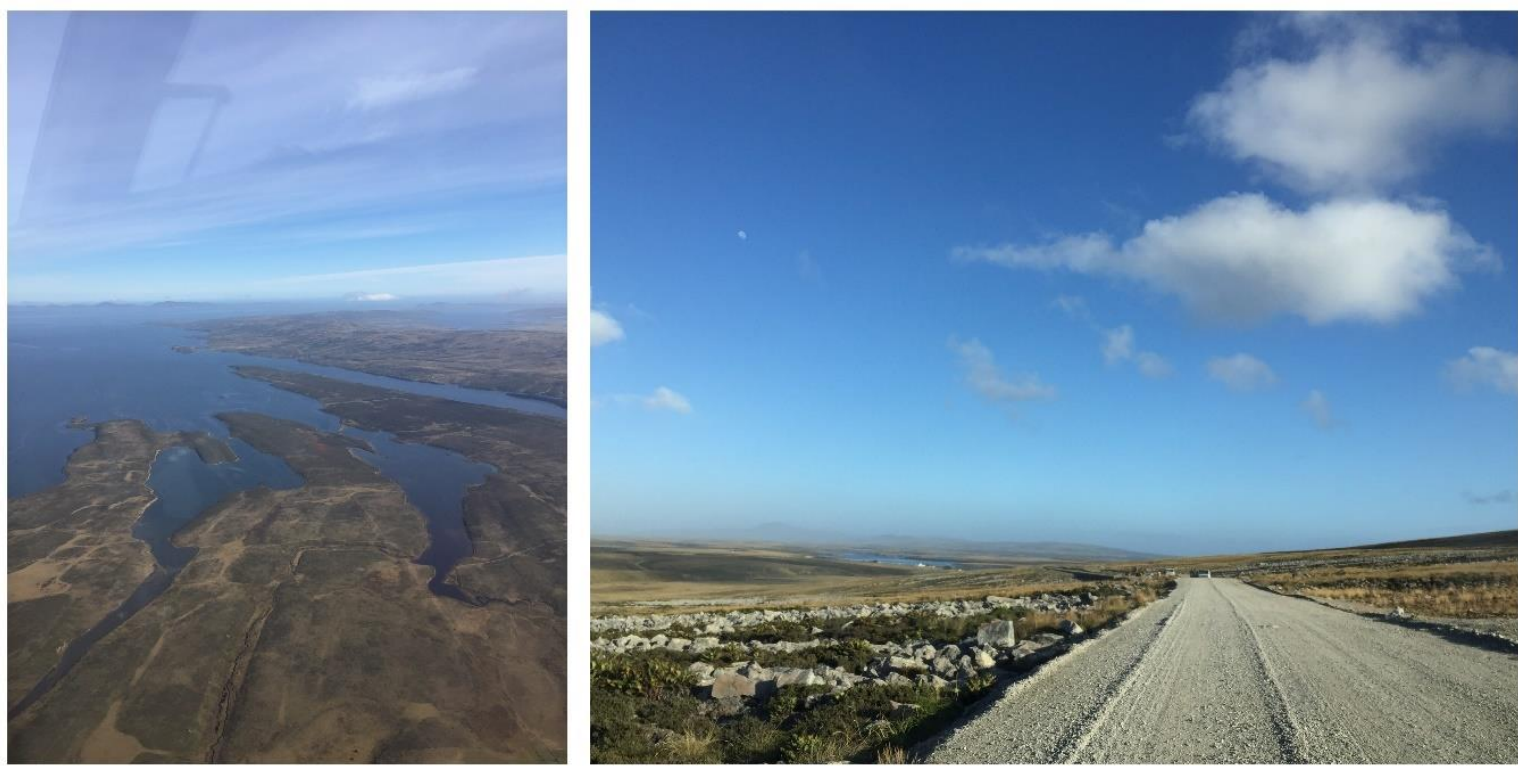

This work has been submitted to Biological Invasions as:

Minett, J. F., Fowler, D. M., Jones, J. A. H., Brickle, P., Crossin, G. T., Consuegra, S. \& Garcia de Leaniz, C. (2021) Conservation of endangered galaxiid fishes in the Falkland Islands requires urgent action on invasive brown trout. Biological Invasions (Under Review). 
Conservation of endangered galaxiid fishes in the Falkland Islands required urgent action on invasive brown trout

\subsection{Introduction}

Invasive species represent one of the major threats to freshwater biodiversity, and yet their introduction has in many cases been intentional. For example, salmonids have been deliberated translocated all over the world to provide fishing and aquaculture opportunities since the 19th century (McDowall, 2006), despite being responsible for the demise of native fish fauna (Garcia de Leaniz et al., 2010; Young et al., 2010).

Human activities have not only been responsible for the introduction of invasive species but have also helped in many cases with their expansion (Hulme, 2015). Yet, the importance of human assisted dispersal of non-native species is often difficult to assess due to lack of accurate introduction records and confounding environmental factors (Tabak et al., 2017). Islands provide ideal scenarios to examine the dispersal of invasive species as the date and location of introductions are typically well known, and there is often baseline information on the status of native species before the invasion (Ewel and Högberg, 1995).

Brown trout (Salmo trutta) is one of the most successful freshwater invaders and has been included as one of the ' 100 of the world's worst invasive alien species' (Lowe et al., 2000) due to its widespread ecological damage. The species has been implicated in the decline of native galaxiid fishes in many parts of the Southern Hemisphere (McDowall, 2006), most notably in South America (Young et al., 2010; Elgueta et al., 2013), New Zealand (McDowall, 2003), and the Falkland Islands, where it has benefitted from protected status (Falkland Islands Government, 1964; Falkland Islands Government, 1999; McDowall et al., 2001). This has created a conservation conundrum as protecting non-native salmonids to boost sport fishing may have put native fish at risk (Garcia de Leaniz et al., 2010).

Three surveys, conducted 10-20 years ago, concluded that brown trout had severely impacted two of the three native galaxiids, Aplochiton zebra and Aplochiton taeniatus (McDowall et al., 2001; Ross, 2009; Fowler, 2013), which appear to have contracted their range and are threatened by secondary releases (i.e., invasions following the initial introductions). However, little is known about the current distribution of the endangered galaxiids, or the roles that natural and human-mediated dispersal may have played in the dispersal of brown trout following the initial introductions.

Here, the main aims were to reconstruct the introduction and establishment of brown trout in the Falkland Islands using historical records. Model the dispersal of brown trout using anthropogenic and bioclimatic variables to derive risk maps which could be used to prioritise 
Conservation of endangered galaxiid fishes in the Falkland Islands required urgent action on invasive brown trout

conservation of native galaxiid populations. In addition to predicting the invasion of brown trout in the Falklands under different management scenarios. 
Conservation of endangered galaxiid fishes in the Falkland Islands required urgent action on invasive brown trout

\subsection{Methods}

Reconstructing the introductions of brown trout

Historical records on the introduction of brown trout in the Falkland Islands were obtained from Arrowsmith and Pentelow (1962), Stewart (1973, 1980) and Chilean sources, Basulto (2003) and Faundez et al. (1997). This information was supplemented with angler accounts, newspaper, magazine, and blog articles (Arrowsmith and Pentelow, 1965; Salmon and Trout Association, 2012), Master's thesis (Fowler, 2013) and grey literature (Stewart, 1973) to reconstruct the origin of brown trout introductions, due to a paucity of published literature.

A database of presence/absence records of the four species of freshwater fish present in the Falklands (three native galaxiids, A. zebra, A. taeniatus and G. maculatus) was compiled using records from McDowall et al. (2001), Ross (2009) and Fowler (2013). McDowall's (McDowall et al., 2001) first survey of the Falkland Islands (2001) employed seine, gill and fyke netting, spotlighting at night and electrofishing. Electrofishing was mostly conducted on $50 \mathrm{~m}$ stretches of river and survey sites were primarily located around the road network to optimize the number of sites that could be sampled. Ross (Ross, 2009) also utilized electrofishing, seine netting and visual checks, primarily focused on Aplochiton spp. but also to expand the presence/absence database of freshwater fish across the Falklands. Fowler (Fowler, 2013) used single-pass electrofishing (Smith-Root ELBP2), seine netting and visual surveys in 2011/2012 sampling seasons. Active fishing effort varied between 159 and 1800 seconds depending on location.

\section{Species distribution modelling}

The Falklands were divided into $8,8131 \times 1 \mathrm{~km}^{2}$ grid cells, excluding those with less than $70 \%$ land and those which contained no rivers (Rodríguez-Rey et al., 2019). Brown trout presence was modelled using a generalised linear model and presence/absence records from 134 sites obtained from McDowall et al. (2001), Ross (2009) and Fowler (2013) were used to train and test the model (Figure 3.1). The model employed 12 anthropogenic and 9 bioclimatic predictors (Table 3.1) for which mean values or values from the centre of the grid cells were extracted using zonal statistics and sample raster value tools in QGIS 3.4 (QGIS Development Team, 2020). To examine human-mediated range expansion, Euclidean distance to closest settlement and road as indicators of human pressure and accessibility was included. Euclidean distance to the nearest river-road crossing and number of river-road crossings in the watershed was calculated to account for factors which may have contained 
Conservation of endangered galaxiid fishes in the Falkland Islands required urgent action on invasive brown trout

the spread of brown trout, as well barrier free length (fragment length between consecutive barriers) and barrier-free length share (proportion of total river length free of culverts) (Jones et al., 2019). Bioclimatic predictors included slope, altitude, minimum winter temperature, annual rainfall, and land cover type, in addition to river density (total river length per watershed) and flow accumulation (accumulation of flow downstream from the grid cell). To examine marine dispersal, flow accumulation was included as a proxy for distance to the river mouth as sites with low flow accumulation are further from the mouth of the river and, therefore, less likely to become invaded by anadromous dispersal. Aplochiton spp. could act as a potential food source for brown trout, therefore, their presence/absence was included as a variable. East/West was also included as a variable to determine if there were any differences in the invasion of brown trout between the two main islands. In addition, introduction site (whether the grid cell contained an introduction site), and introduction basin (does the drainage basin contained an introduction site) were included as if the drainage basin contained an introduction site other sites within the same drainage basin would be more likely to become invaded. Euclidean distance to the nearest invaded and introduction sites was included to account for human translocation of fish, whereas; the distance to the nearest invaded and introduction sites around the coast was included to account for natural marinemediated colonization. Euclidean distances were calculated using the distance matrix tool from the centroid of the grid to the point of interest (e.g., introduction sites) in QGIS. Distances around the coast were calculated using a purpose-built function (pers comms., William P. Kay) in R3.5.3 (R Core Team, 2019) using rgdal, sp, raster, gdistance, dplyr and tidyverse packages.

The Variance Inflation Factor (VIF) was calculated using the corvif function in R (Zuur et $a l ., 2009$ ) and predictors with a VIF $<3$ were retained to reduce bias due to collinearity (Kock and Lynn, 2012). On this basis, three variables (basin introduction, river density and distance to the nearest culvert, Table 3.1) were excluded, resulting in 10 anthropogenic and eight bioclimatic variables being retained. Equal numbers of presence and absence records were randomly divided into training and testing datasets with an 80:20 split. Species distribution was predicted using a generalised linear model and Leave One Out Cross Validation (LOOCV), see Appendix 2 for details (Rennie et al., 2005; Hooten and Hobbs, 2015). The dropl function from the lme4 package (Bates et al., 2015) was used to test the significance of individual predictors and arrive at the best model based on the lowest AIC value (see Table S1 for a breakdown of models). Model performance was assessed using the evaluate function 
Conservation of endangered galaxiid fishes in the Falkland Islands required urgent action on invasive brown trout

in dismo to examine the area under the curve (AUC) criterion (Fielding and Bell, 1997), and compared against a null model of all variables built using the same testing and training datasets as used for the real model (Rodríguez-Rey et al., 2019). The final and null models were compared using parametric bootstrapping (1000 simulations) methods in R3.5.3 (R Core Team, 2019) using PBmodcomp in pbkrtest (Halekoh and Højsgaard, 2014). Risk maps were generated in QGIS 3.10.3 using the predicted probability of invasion calculated using LOOCV for all 8,813 grid cells.

\section{Establishment success}

To calculate establishment success, the proportion of introduction sites that still had brown trout $\sim 50$ years later were compared against the random 50\% expectation using a binomial test. Presence/absence data for brown trout and the three native galaxiids was used to assess how the presence of brown trout influenced the presence of native galaxiids by calculating relative risks.

\section{Predictive modelling of brown trout invasions under different management scenarios}

The future dispersal of brown trout over a 130-year period from 1947 onwards was modelled and predicted considering three different management scenarios: (1) No containment, (2) moderate containment (a 10\% reduction in the probability of invasion at each cell), and (3) strong containment (a 30\% reduction in the probability of invasion at each cell). All scenarios were modelled using the invasion probabilities calculated with the brown trout occurrence model and LOOCV. For scenarios 2 and 3 the probability of invasion was reduced by $10 \%$ and $30 \%$, respectively. Grid cells with an original probability of $\geq 0.8$ remained the same as they would not be targeted for management due to their high invasion risk. Using these probabilities, the invasion status, invaded or not-invaded, was estimated using a random binomial distribution generator with the rbinom function in $\mathrm{R}$ version 3.5.3 ( $\mathrm{R}$ Core Team, 2019). As not every instance of invasion is successful (Sax and Brown, 2000), sites that became invaded were randomly selected using rbinom to remain invaded or return to a notinvaded status. As grid cells were found to be more likely to become invaded if they were close to invaded sites (see results) Euclidean distance to the nearest invaded site was calculated using the $s f$ version 0.9-6 (Pebesma, 2018) and geodist version 0.0.6 packages (Padgham and Sumner, 2020). Invasion probabilities were then updated at each iteration under the three scenarios outlined above. To obtain a mean percentage occupancy and $97.5 \%$ confidence intervals each scenario was run for over 300 iterations (Vose, 2008). The 
Conservation of endangered galaxiid fishes in the Falkland Islands required urgent action on invasive brown trout

observed rate of expansion ( $0.9 \%$ increase in occupancy/year since 1950$)$ was used to calibrate the model and convert the number of model iterations into calendar years (one iteration $=\sim 24$ years or $\sim 4$ generations), see supplementary material for details.

Table 3.1. Predictor variables used to generate species distribution model. Variables in bold had a VIF scores $<3$ (Kock and Lynn, 2012) and were included in the species distribution model.

\begin{tabular}{|c|c|c|}
\hline Predictor & Description & Source \\
\hline \multicolumn{3}{|c|}{ Anthropogenic predictors } \\
\hline Eucl_dist_inv & $\begin{array}{l}\text { Euclidean distance to the nearest invaded } \\
\text { site in a straight line }(\mathrm{km})\end{array}$ & Own creation \\
\hline Coast_dist_inv & $\begin{array}{l}\text { Distance to the nearest invaded site around } \\
\text { the coast }(\mathrm{km})\end{array}$ & $\begin{array}{l}\text { Own creation using modified R script } \\
\text { from William P. Kay and processed using } \\
\text { the sunbird cluster from Supercomputing } \\
\text { Wales }\end{array}$ \\
\hline Eucl_dist_intro & $\begin{array}{l}\text { Euclidean distance to the nearest } \\
\text { introduction site in a straight line }(\mathrm{km})\end{array}$ & Own Creation \\
\hline Coast_dist_intro & $\begin{array}{l}\text { Distance to the nearest introduction site } \\
\text { around the coast }(\mathrm{km})\end{array}$ & $\begin{array}{l}\text { Own creation using modified R script } \\
\text { from William P. Kay and processed using } \\
\text { the sunbird cluster from Supercomputing } \\
\text { Wales }\end{array}$ \\
\hline Intro_site & Introduction site $(\mathrm{y} / \mathrm{n})$ & Table 3.2 \\
\hline Intro_basin & Introduction basin $(\mathrm{y} / \mathrm{n})$ & Table 3.2 \\
\hline Settle_dist & Distance to the nearest settlement $(\mathrm{km})$ & Own creation, FIG IMS-GIS Centre \\
\hline Road_dist & Distance to the nearest road $(\mathrm{km})$ & Own creation, FIG IMS-GIS Centre \\
\hline Road_cross_No & $\begin{array}{l}\text { Number of river-road crossings in the river } \\
\text { basin }\end{array}$ & Own creation, FIG IMS-GIS Centre \\
\hline Road_cross_dist & $\begin{array}{l}\text { Distance to nearest river-road crossing } \\
(\mathrm{km})\end{array}$ & Own creation \\
\hline BFL & $\begin{array}{l}\text { Barrier Free Length, length of river } \\
\text { between consecutive river-road crossings } \\
(\mathrm{km})\end{array}$ & Own creation \\
\hline BFL_share & $\begin{array}{l}\text { Proportion of total river length free from } \\
\text { river-road crossings }\end{array}$ & Own creation \\
\hline \multicolumn{3}{|c|}{ Bioclimatic predictors } \\
\hline Ap & $\begin{array}{l}\text { Presence of Aplochiton spp. }(\mathrm{y} / \mathrm{n}) \text {; coded } \\
\text { no if unknown }\end{array}$ & Table 3.3 \\
\hline $\mathbf{E W}$ & East or West Island & Own creation \\
\hline Slope & Mean slope of each grid cell & USGS \\
\hline Alt & Mean altitude of each grid cell & USGS \\
\hline River_dens & River network in the basin $(\mathrm{km})$ & $\begin{array}{l}\text { Own creation, SAERI/FIG IMS-GIS } \\
\text { Centre }\end{array}$ \\
\hline Flow_accum & $\begin{array}{l}\text { Mean flow accumulation scaled by max } \\
\text { flow accumulation in basin }\end{array}$ & $\begin{array}{l}\text { Own creation, SAERI/FIG IMS-GIS } \\
\text { Centre }\end{array}$ \\
\hline Min_winter_temp & Minimum winter temperature $\left({ }^{\circ} \mathrm{C}\right)$ & SAERI/FIG IMS-GIS Centre \\
\hline Rain & Annual precipitation & SAERI/FIG IMS-GIS Centre \\
\hline $\mathbf{L C}$ & Land cover/substrate type & $\begin{array}{l}\text { SAERI/FIG IMS-GIS Centre, DPLUS065 } \\
\text { Project }\end{array}$ \\
\hline
\end{tabular}


Conservation of endangered galaxiid fishes in the Falkland Islands required urgent action on invasive brown trout

\subsection{Results}

Introduction and dispersal of brown trout

Approximately 113,000 brown trout eggs were dispatched to the Falkland Islands on eight separate occasions over an 18-year period (1944-1962, Table 3.2; Figure 3.1) (Arrowsmith and Pentelow, 1965). Although original records are missing, many consignments were described as arriving in 'excellent condition' (Stewart, 1973). The first introductions took place in Moody Brook during 1944, but due to missing records, their origin is unclear. However, these first introductions likely came from Chile as 30,000 eggs from the Lautaro hatchery (River Cautín, Chile) were sent to the Falklands three years later in 1947 (Arrowsmith and Pentelow, 1965; MacCrimmon and Marshall, 1968). Eggs from the Lautaro hatchery were primarily sourced from Germany from non-anadromous parents (Faundez et al., 1997; Basulto, 2003). Subsequent eggs came from three sources in the United Kingdom: Surrey, Pentlands and Lancashire. The Surrey and Pentlands fish were from non-anadromous parents, while the Lancashire trout were from sea-trout caught in the River Lune (Arrowsmith and Pentelow, 1965; Stewart, 1973). Thus, both anadromous and non-anadromous brown trout were introduced to the Falklands. The provenance of the Pentlands stock is unclear, but they may have originated from Cobbinshaw Loch (Arrowsmith and Pentelow, 1965; Stewart, 1973), Loch Leven (Fish Loch Leven, 2019), or the Howietoun Hatchery (Ross Gardiner, pers. comm.). The Howietoun hatchery had reared trout from Loch Leven and many other sources, however, no records were found of fish having ever been sent to the Falkland Islands.

In total 28 sites were stocked, but three rivers within a $25 \mathrm{~km}$ radius of the capital Stanley (Moody Brook, Murrell River and Malo River) received most of the introductions. Fish were transported around the islands in sea-planes, milk churns, on horseback in panniers and in Bren-gun carriers (Arrowsmith and Pentelow, 1965; Stewart, 1973; Salmon and Trout Association, 2012). Trout were reported to become quickly established and colonized new areas aided by marine dispersal, with the first sea-run trout detected in 1956-57 (Arrowsmith and Pentelow, 1965; Stewart, 1973; Salmon and Trout Association, 2012), four years before any anadromous trout were introduced (Table 3.2).

Of the 17 stocked sites for which there are fish survey data, 15 sites still had brown trout $\sim 50$ years later. Establishment success can therefore be estimated as $88 \%(95 \mathrm{CI}=62-98 \%)$, which is significantly better than chance $\left(\chi^{2}=8.47, \mathrm{df}=1, p=0.004\right)$. 
Conservation of endangered galaxiid fishes in the Falkland Islands required urgent action on invasive brown trout

Table 3.2. Sites of introductions of brown trout in the Falkland Islands

\begin{tabular}{|c|c|c|c|c|c|}
\hline Stock origin & Year & Quantity & Introduction Site & Latitude & Longitude \\
\hline \multicolumn{6}{|c|}{ Unknown (likely German stock via Chile; non-anadromous) } \\
\hline & \multirow[t]{3}{*}{1944} & \multirow[t]{3}{*}{ 'Small quantities' } & Unknown & Unknown & Unknown \\
\hline & & & Moody Brook & -51.6857 & -57.9222 \\
\hline & & & Moody Brook & -51.6857 & -57.9222 \\
\hline \multicolumn{6}{|c|}{ Lautaro Hatchery (Chile, German Stock; non-anadromous) } \\
\hline & \multirow[t]{3}{*}{1947} & \multirow[t]{3}{*}{30,000} & Moody Brook & -51.6857 & -57.9222 \\
\hline & & & Malo River & -51.6171 & -58.3018 \\
\hline & & & Murrell River & -51.6535 & -57.9951 \\
\hline \multicolumn{6}{|c|}{ Surrey Trout Farm (UK; non-anadromous) } \\
\hline & \multirow[t]{5}{*}{1948} & \multirow[t]{5}{*}{10,000} & Malo River & -51.6171 & -58.3018 \\
\hline & & & Murrell River & -51.6535 & -57.9951 \\
\hline & & & Hill Cove & -51.4736 & -59.9764 \\
\hline & & & Chartres River & -51.6428 & -59.9283 \\
\hline & & & Port Howard/Warrah River & -51.4554 & -59.6245 \\
\hline \multicolumn{6}{|c|}{ Surrey Trout Farm or Pentlands (UK; non-anadromous) } \\
\hline & \multirow[t]{12}{*}{1949} & \multirow[t]{12}{*}{15,000} & Port San Carlos & -51.5095 & -58.8220 \\
\hline & & & Elephant Beach Pond/Stream & -51.3807 & -58.7690 \\
\hline & & & Head of the Bay & -51.6061 & -59.0142 \\
\hline & & & Lorenzo Pond & -51.3593 & -58.6730 \\
\hline & & & Swan Inlet & -51.8239 & -58.6161 \\
\hline & & & Fitzroy River & -51.7546 & -58.3068 \\
\hline & & & Kidney Pond & -51.6251 & -57.7739 \\
\hline & & & Pebbly Pond & -51.7270 & -57.8740 \\
\hline & & & Johnsons Harbour & -51.4995 & -58.0044 \\
\hline & & & Fox Bay East & -51.9421 & -60.0500 \\
\hline & & & Fox Bay West & -51.9510 & -60.0897 \\
\hline & & & Hill Cove & -51.4736 & -59.9764 \\
\hline \multicolumn{6}{|c|}{ Surrey Trout Farm or Pentlands (UK; non-anadromous) } \\
\hline & \multirow[t]{9}{*}{1950} & \multirow[t]{9}{*}{10,000} & Darwin (Camilla Creek) & -51.7711 & -58.9457 \\
\hline & & & Malo River & -51.6171 & -58.3018 \\
\hline & & & Port San Carlos & -51.5095 & -58.8220 \\
\hline & & & Fitzroy River & -51.7546 & -58.3068 \\
\hline & & & Pebble Island & -51.3199 & -59.5741 \\
\hline & & & Chartres River & -51.6428 & -59.9283 \\
\hline & & & Hill Cove & -51.4736 & -59.9764 \\
\hline & & & Port Howard/Warrah River & -51.4554 & -59.6245 \\
\hline & & & Port Stephens & -52.0980 & -60.8321 \\
\hline \multicolumn{6}{|c|}{ Surrey Trout Farm or Pentlands (UK; non-anadromous) } \\
\hline & \multirow[t]{6}{*}{1951} & \multirow[t]{6}{*}{10,000} & Malo River & -51.6171 & -58.3018 \\
\hline & & & Swan Inlet & -51.8239 & -58.6161 \\
\hline & & & Darwin (Camilla Creek) & -51.7711 & -58.9457 \\
\hline & & & North Arm & -52.1291 & -59.3709 \\
\hline & & & Port San Carlos & -51.5095 & -58.8220 \\
\hline & & & Murrell River & -51.6535 & -57.9951 \\
\hline Surrey Trout I & $\mathrm{m}$ or $\mathrm{P}$ & tlands (UK; non-an & romous) & & \\
\hline & 1952 & 10,000 & Murrell River & -51.6535 & -57.9951 \\
\hline & & & Malo River & -51.6171 & -58.3018 \\
\hline & & & Johns Brook & -51.4865 & -58.2932 \\
\hline & & & Lorenzo Pond & -51.3593 & -58.6730 \\
\hline & & & Fitzroy River & -51.7546 & -58.3068 \\
\hline & & & Swan Inlet & -51.8239 & -58.6161 \\
\hline & & & North Arm & -52.1291 & -59.3709 \\
\hline & & & Pebbly Pond & -51.7270 & -57.8740 \\
\hline & & & Kidney Pond & -51.6251 & -57.7739 \\
\hline Middleton $\mathrm{Ha}$ & hery - I & ncashire Fisheries $\mathrm{F}$ & rd (UK; anadromous) & & \\
\hline & 1961 & 20,000 & Chartres River & -51.6428 & -59.9283 \\
\hline
\end{tabular}


Conservation of endangered galaxiid fishes in the Falkland Islands required urgent action on invasive brown trout

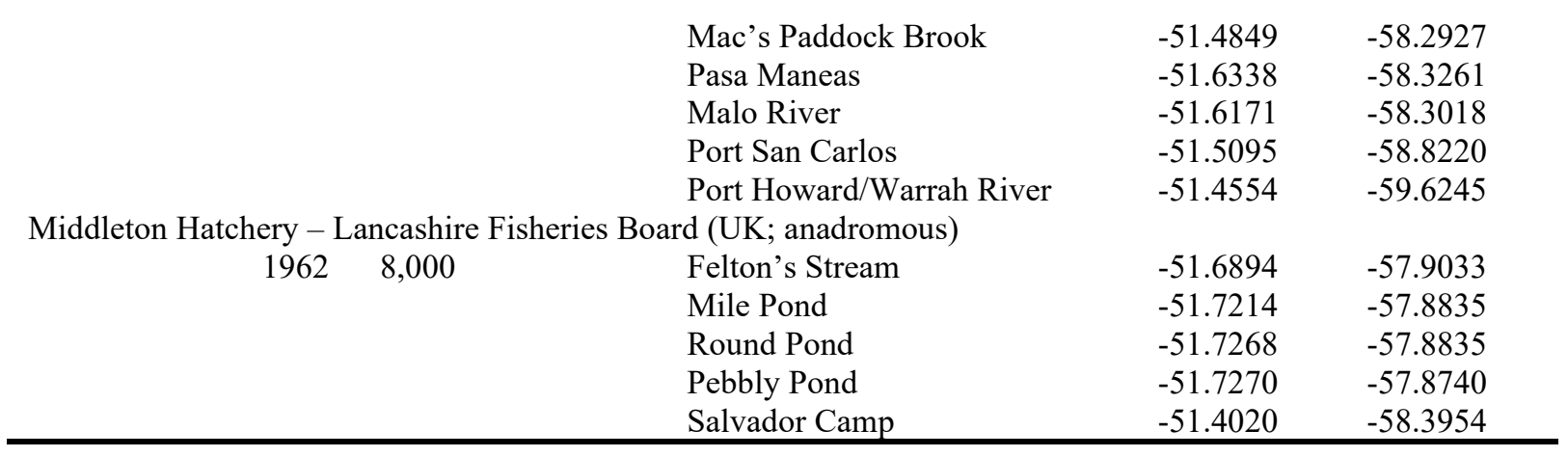

Farming of brown trout in the Falklands began in 2013 with the transfer of 10,000 sea trout smolts from local broodstock into sea cages at Fitzroy Sound, although ova were imported from Howietoun Hatchery UK in 2014 and 2015. Small quantities of fish have been translocated between river/ponds to form populations in new uncolonised areas or landlocked locations that would never be naturally colonized (McDowall et al., 2001). These rivers/ponds are not believed to be part of the initial introduction sites (Table 3.2), for example, trout found in the landlocked pond at Mary Hill Quarry are believed to be a result of such movements (Jay Moffatt, pers. comms.)

The three surveys conducted in 1999, 2009 and 2012 by McDowall et al. (2001), Ross (2009) and Fowler (2012) (see Table 3.3 for more information on sample sites) revealed a marked decline in the once abundant Aplochiton spp., which local previously described as widespread and found throughout East and West Falkland (McDowall et al., 2001). These native galaxiids now confined to the South of the Islands (Figure 3.1). At the time of the last survey (2012), brown trout occupied 54\% of all sampled sites, with Aplochiton spp. only occupying $18 \%$. 
Conservation of endangered galaxiid fishes in the Falkland Islands required urgent action on invasive brown trout

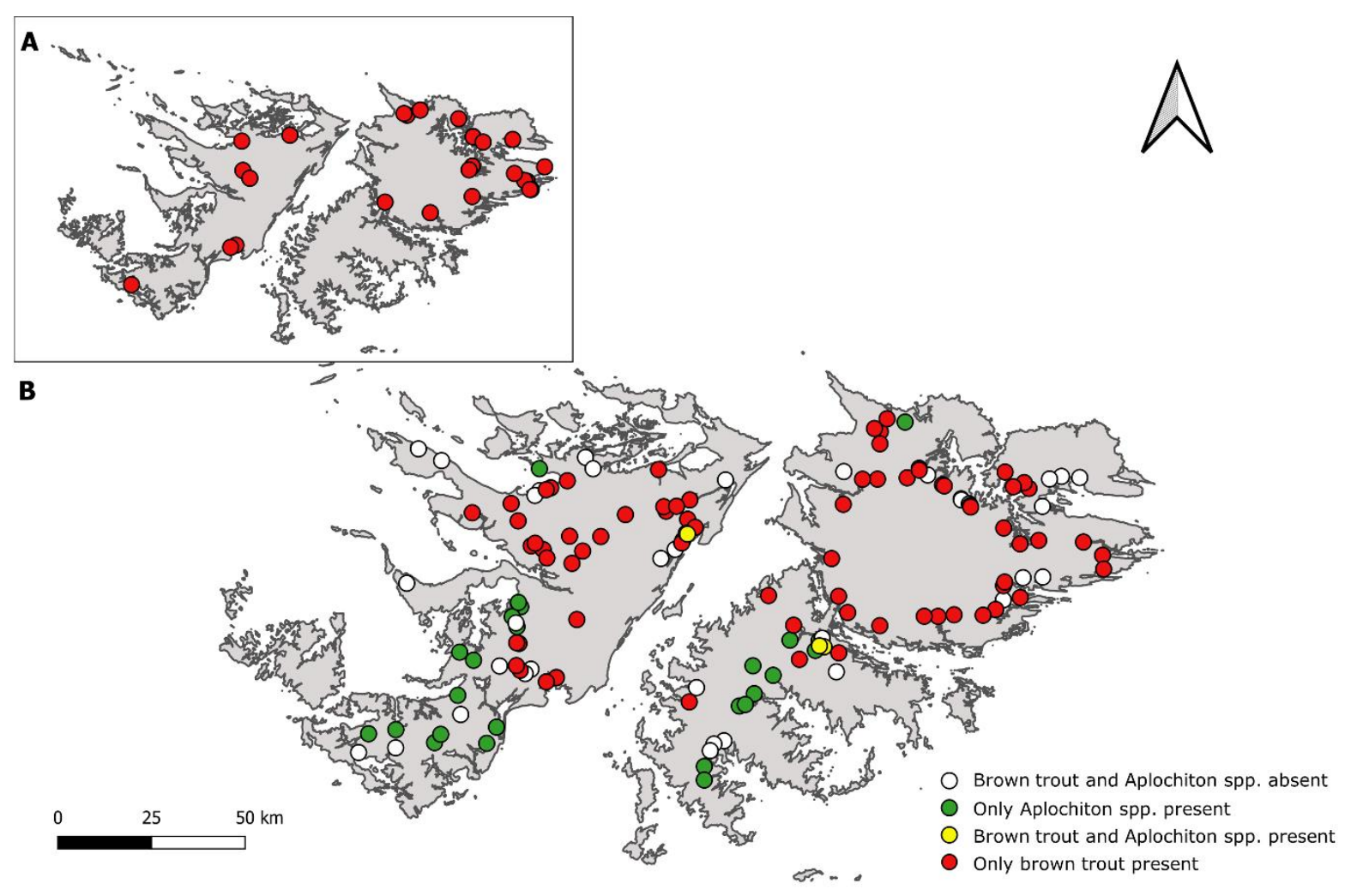

Figure 3.1. Map of the Falkland Islands showing (A) sites of the historical introductions of brown trout during 1944-1962 (details given in Table 3.2) and (B) presence/absence of brown trout and native Aplochiton species based on 1999-2012 surveys (detailed in Table 3.3) with six additional sites sampled in 2018-2019. 
Conservation of endangered galaxiid fishes in the Falkland Islands required urgent action on invasive brown trout

Table 3.3. Presence and absence of brown trout (St), Aplochiton spp. (Ap) and Galaxias maculatus $(\mathrm{Gm})$ in the Falkland Islands. Sites marked with an asterisk denote brown trout introduction sites (see Table 3.2).

\begin{tabular}{|c|c|c|c|c|c|c|c|c|}
\hline Sample Site & Island & $\begin{array}{l}\text { Date } \\
\text { Sampled }\end{array}$ & Latitude & Longitude & $S t$ & $A p$ & $G m$ & Reference \\
\hline Arrow Harbour Arroyo & East & 2011 & -51.9062 & -58.9508 & + & - & + & Fowler (2013) \\
\hline Arroyo Pedro & East & 1999 & -51.5111 & -58.5346 & + & - & - & $\begin{array}{l}\text { McDowall et al. } \\
(2001)\end{array}$ \\
\hline Big Pond & East & 2018 & -51.8433 & -51.7522 & + & - & + & Minett (unpubl.) \\
\hline Bodie Creek & East & 2011 & -51.9191 & -59.1042 & + & - & + & Fowler (2013) \\
\hline Bull Pass Stream & East & 2011 & -51.8909 & -59.0074 & + & + & + & Fowler (2013) \\
\hline Clay Ditch & East & 1999 & -51.4925 & -58.6700 & + & - & - & $\begin{array}{l}\text { McDowall et al. } \\
(2001)\end{array}$ \\
\hline Colorado Pond & East & 2018 & -51.7136 & -58.4717 & + & - & - & Minett et al. (2021) \\
\hline Comoda Ditch & East & 1999 & -51.8219 & -58.5003 & + & - & - & $\begin{array}{l}\text { McDowall et al. } \\
(2001)\end{array}$ \\
\hline Congo Ponds Area & East & 2009 & -51.9787 & -59.5072 & - & - & - & Ross (2009) \\
\hline Dan's Shanty Stream & East & 1999 & -51.5236 & -58.2020 & + & - & + & $\begin{array}{l}\text { McDowall et al. } \\
(2001)\end{array}$ \\
\hline Darwin (Camilla Creek) * & East & 1999 & -51.7711 & -58.9457 & + & - & - & $\begin{array}{l}\text { McDowall et al. } \\
(2001)\end{array}$ \\
\hline Deep Arroyo & East & 2011 & -51.9553 & -59.2080 & - & + & + & Fowler (2013) \\
\hline Ditches into New Haven & East & 2009 & -51.7646 & -59.2166 & + & - & + & Ross (2009) \\
\hline Duffins Bridge Stream & East & 2009 & -52.1078 & -59.4073 & - & - & + & Ross (2009) \\
\hline Elephant Beach Pond* & East & 1999 & -51.3807 & -58.7690 & + & - & + & $\begin{array}{l}\text { McDowall et al. } \\
(2001)\end{array}$ \\
\hline Elmer's Ditch Tributary & East & 1999 & -51.4939 & -58.7840 & + & - & - & $\begin{array}{l}\text { McDowall et al. } \\
(2001)\end{array}$ \\
\hline Estancia Brook & East & 2008 & -51.6480 & -58.1678 & + & - & - & Fowler (2013) \\
\hline Felton Stream* & East & NA & -51.6894 & -57.9033 & NA & NA & NA & Not sampled \\
\hline Findley Creek Stream & East & 2011 & -51.8882 & -59.0250 & + & + & + & Fowler (2013) \\
\hline $\begin{array}{l}\text { Findlay Harbour (Wreck } \\
\text { House) }\end{array}$ & East & 2009 & -52.0122 & -59.5375 & + & - & - & Fowler (2013) \\
\hline Fitzroy River* & East & 2012 & -51.7546 & -58.3068 & + & NA & NA & Angler \\
\hline Frying Pan & East & 2011 & -51.8111 & -58.3387 & + & - & - & Fowler (2013) \\
\hline Gonzales Arroyo & East & 2009 & -51.9513 & -58.9621 & - & - & + & Ross (2009) \\
\hline $\begin{array}{l}\text { Green Pass Brook } \\
\text { Tributary }\end{array}$ & East & 1999 & -51.4098 & -58.7715 & + & - & - & $\begin{array}{l}\text { McDowall et al. } \\
(2001)\end{array}$ \\
\hline Head of the Bay* & East & 2012 & -51.6061 & -59.9764 & + & NA & NA & Angler \\
\hline Head of the Creek Stream & East & 1999 & -51.4961 & -58.0763 & - & - & + & $\begin{array}{l}\text { McDowall et al. } \\
(2001)\end{array}$ \\
\hline Hunter's Arroyo & East & 1999 & -52.1147 & -59.4470 & - & - & + & $\begin{array}{l}\text { McDowall et al. } \\
(2001)\end{array}$ \\
\hline John's Brook* & East & 2018 & -51.4834 & -58.2930 & + & - & NA & Minett et al. (2020) \\
\hline Johnsons Harbour* & East & NA & -51.4995 & -58.0044 & NA & NA & NA & Not sampled \\
\hline Kidney Pond* & East & NA & -51.6251 & -57.7739 & NA & NA & NA & Not sampled \\
\hline Laguna Isla & East & 2011 & -51.8439 & -58.7890 & + & - & - & Fowler (2013) \\
\hline L'Antioja Stream & East & 2012 & -51.8249 & -58.5627 & + & - & - & Fowler (2013) \\
\hline Little Creek Stream & East & 1999 & -51.3504 & -58.7418 & + & - & - & $\begin{array}{l}\text { McDowall et al. } \\
(2001)\end{array}$ \\
\hline Lorenzo Pond* & East & 1973 & -51.3593 & -58.6730 & - & + & + & Stewart (1973) \\
\hline Mac's Paddock Brook* & East & NA & -51.4849 & -58.2927 & NA & NA & NA & Not sampled \\
\hline Magellan Pond & East & 1999 & -51.4995 & -58.0062 & - & - & + & $\begin{array}{l}\text { McDowall et al. } \\
(2001)\end{array}$ \\
\hline Malo River* & East & 1999 & -51.6171 & -58.3018 & + & - & + & $\begin{array}{l}\text { McDowall et al. } \\
(2001)\end{array}$ \\
\hline Mary Hill Quarry & East & 2018 & -51.6844 & -57.7894 & + & NA & NA & Minett (unpubl.) \\
\hline Mile Pond* & East & NA & -51.7214 & -57.8835 & NA & NA & NA & Not sampled \\
\hline Moody Brook* & East & 2012 & -51.6857 & -57.9222 & + & - & - & Fowler (2013) \\
\hline Mullet Creek & East & 1999 & -51.7187 & -57.9185 & + & - & + & $\begin{array}{l}\text { McDowall et al. } \\
(2001)\end{array}$ \\
\hline Murrell River* & East & 2013 & -51.6535 & -57.9951 & + & - & - & Fowler (2013) \\
\hline North Arm* & East & 2011 & -52.1291 & -29.3709 & - & - & + & Fowler (2013) \\
\hline Northwest Arm House & East & $2012 / 18$ & -52.1674 & -59.4874 & - & + & + & Fowler (2013), \\
\hline
\end{tabular}


Conservation of endangered galaxiid fishes in the Falkland Islands required urgent action on invasive brown trout

\begin{tabular}{|c|c|c|c|c|c|c|c|c|}
\hline $\begin{array}{l}\text { Stream } \\
\text { Northern Stream }\end{array}$ & East & 1999 & -51.5018 & -58.1223 & - & - & + & $\begin{array}{l}\text { Minett et al. (2020) } \\
\text { McDowall et al. } \\
(2001)\end{array}$ \\
\hline Orequta Arroyo & East & 2011 & -51.8373 & -59.1229 & + & - & - & Fowler (2013) \\
\hline Pasa Maneas* & East & NA & -51.6338 & -58.3261 & NA & NA & NA & Not sampled \\
\hline Pebbly Pond* & East & NA & -51.7270 & -57.8740 & NA & NA & NA & Not sampled \\
\hline Round Pond* & East & NA & -51.7268 & -57.8835 & NA & NA & NA & Not sampled \\
\hline Rumford Brook & East & 2011 & -51.6557 & -58.2399 & + & - & - & Fowler (2013) \\
\hline Salvador Camp* & East & NA & -51.4020 & -58.3954 & NA & NA & NA & Not sampled \\
\hline San Carlos River at Ford* & East & $\begin{array}{l}1999 / \\
2018\end{array}$ & -51.5095 & -58.220 & + & - & - & $\begin{array}{l}\text { McDowall et al. } \\
\text { (2001), Minett et } \\
\text { al. (2020) }\end{array}$ \\
\hline Shepherds Brook & East & 1999 & -51.6808 & -58.9688 & + & - & + & $\begin{array}{l}\text { McDowall et al. } \\
\text { (2001) }\end{array}$ \\
\hline Spots Arroyo & East & $2009 / 18$ & -52.0260 & -59.3432 & - & + & + & $\begin{array}{l}\text { Ross (2009), } \\
\text { Minett et al. (2020) }\end{array}$ \\
\hline Stream at Colorado Pass & East & 2009 & -51.8702 & -59.0137 & - & - & + & Ross (2009) \\
\hline Stream at Gibraltar Gate & East & 1999 & -51.4933 & -58.8417 & + & - & - & $\begin{array}{l}\text { McDowall et al. } \\
\text { (2001) }\end{array}$ \\
\hline $\begin{array}{l}\text { Stream near Hunter } \\
\text { Arroyo }\end{array}$ & East & 1999 & -52.1303 & -59.4622 & - & - & + & $\begin{array}{l}\text { McDowall et al. } \\
\text { (2001) }\end{array}$ \\
\hline Stream, Caneja Creek & East & 1999 & -51.5190 & -58.2621 & + & - & - & $\begin{array}{l}\text { McDowall et al. } \\
\text { (2001) }\end{array}$ \\
\hline Stream, at Fitzroy & East & 1999 & -51.7838 & -58.2425 & + & - & + & $\begin{array}{l}\text { McDowall et al. } \\
\text { (2001) }\end{array}$ \\
\hline Stream, Douglas Creek & East & 1999 & -51.4704 & -58.6229 & + & - & - & $\begin{array}{l}\text { McDowall et al. } \\
\text { (2001) }\end{array}$ \\
\hline $\begin{array}{l}\text { Stream, Elephant Beach } \\
\text { Pond* }\end{array}$ & East & $\begin{array}{l}1999 / \\
2018\end{array}$ & -51.3731 & -58.7911 & + & - & + & $\begin{array}{l}\text { McDowall et al. } \\
\text { (2001), Minett et } \\
\text { al. (2020) }\end{array}$ \\
\hline Stream, Fitzroy & East & 1999 & -51.7887 & -58.3085 & - & - & - & $\begin{array}{l}\text { McDowall et al. } \\
\text { (2001) }\end{array}$ \\
\hline $\begin{array}{l}\text { Stream, Monty Dean's } \\
\text { Creek }\end{array}$ & East & 1999 & -51.5669 & -58.1515 & - & - & + & $\begin{array}{l}\text { McDowall et al. } \\
\text { (2001) }\end{array}$ \\
\hline Stream, Mount Pleasant & East & 1999 & -51.8243 & -58.3878 & + & - & - & $\begin{array}{l}\text { McDowall et al. } \\
\text { (2001) }\end{array}$ \\
\hline Stream, NW of Teal Inlet & East & 1999 & -51.5456 & -58.4638 & - & - & + & $\begin{array}{l}\text { McDowall et al. } \\
\text { (2001) }\end{array}$ \\
\hline Stream NW of Teal Inlet & East & 1999 & -51.5481 & -58.4629 & - & - & + & $\begin{array}{l}\text { McDowall et al. } \\
\text { (2001) }\end{array}$ \\
\hline Stream, Salt House Creek & East & 2009 & -52.1997 & -59.4894 & - & + & + & Ross (2009) \\
\hline Stream, SE of Teal Inlet & East & 1999 & -51.5580 & -58.4330 & - & - & - & $\begin{array}{l}\text { McDowall et al. } \\
\text { (2001) }\end{array}$ \\
\hline Stream, Smylie's Brook & East & 1999 & -51.4738 & -58.9129 & - & - & - & $\begin{array}{l}\text { McDowall et al. } \\
\text { (2001) }\end{array}$ \\
\hline Stream, Teal Inlet & East & 1999 & -51.5654 & -58.4278 & + & - & - & $\begin{array}{l}\text { McDowall et al. } \\
\text { (2001) }\end{array}$ \\
\hline Stream, SE of Teal Inlet & East & 1999 & -51.5622 & -58.4294 & - & - & + & $\begin{array}{l}\text { McDowall et al. } \\
\text { (2001) }\end{array}$ \\
\hline Swan Inlet* & East & 2012 & -51.8239 & -58.6161 & + & NA & NA & Angler \\
\hline Teal Creek Arroyo & East & 2009 & -51.8106 & -58.9121 & + & - & + & Ross (2009) \\
\hline Third Corral Brook & East & 1999 & -51.5520 & -58.9182 & + & - & - & $\begin{array}{l}\text { McDowall et al. } \\
(2001))\end{array}$ \\
\hline $\begin{array}{l}\text { Trib., Halfway House } \\
\text { Arroyo }\end{array}$ & East & 2011 & -51.9977 & -59.2836 & - & + & + & Fowler (2013) \\
\hline Turners Stream & East & 1999 & -51.5137 & -58.5277 & + & - & - & $\begin{array}{l}\text { McDowall et al. } \\
\text { (2001) }\end{array}$ \\
\hline Unnamed Stream & East & 1999 & -51.8726 & -59.1386 & - & + & + & $\begin{array}{l}\text { McDowall et al. } \\
\text { (2001) }\end{array}$ \\
\hline Unnamed Stream & East & 1999 & -51.9311 & -59.2855 & - & + & + & $\begin{array}{l}\text { McDowall et al. } \\
\text { (2001) }\end{array}$ \\
\hline Unnamed Stream & East & 1999 & -51.4869 & -58.5905 & - & - & - & $\begin{array}{l}\text { McDowall et al. } \\
\text { (2001) }\end{array}$ \\
\hline Unnamed Stream & East & 1999 & -52.0228 & -59.3197 & - & + & + & $\begin{array}{l}\text { McDowall et al. } \\
\text { (2001) }\end{array}$ \\
\hline Unnamed Stream & East & 1999 & -51.8987 & -59.0414 & - & + & + & $\begin{array}{l}\text { McDowall et al. } \\
\text { (2001) }\end{array}$ \\
\hline
\end{tabular}


Conservation of endangered galaxiid fishes in the Falkland Islands required urgent action on invasive brown trout

\begin{tabular}{|c|c|c|c|c|c|c|c|c|}
\hline Unnamed Stream & East & 1999 & -51.8753 & -59.0254 & - & + & + & $\begin{array}{l}\text { McDowall et al. } \\
\text { (2001) }\end{array}$ \\
\hline Unnamed Stream & East & 1999 & -51.7461 & -58.3020 & + & - & - & $\begin{array}{l}\text { McDowall et al. } \\
\text { (2001) }\end{array}$ \\
\hline Unnamed Stream & East & 1999 & -51.7366 & -58.2306 & - & - & + & $\begin{array}{l}\text { McDowall et al. } \\
\text { (2001) }\end{array}$ \\
\hline Unnamed Stream & East & 1999 & -51.7357 & -58.1542 & - & - & - & $\begin{array}{l}\text { McDowall et al. } \\
\text { (2001) }\end{array}$ \\
\hline Unnamed Stream & East & 1999 & -51.4747 & -58.6230 & + & - & - & $\begin{array}{l}\text { McDowall et al. } \\
(2001)\end{array}$ \\
\hline Pebble Island* & Pebble & NA & -51.3199 & $-59-5741$ & NA & NA & NA & Not sampled \\
\hline $1^{\text {st }}$ Arroyo & West & 2009 & -52.0838 & -60.5346 & - & + & - & Ross (2009) \\
\hline $2^{\text {nd }}$ Pass Stream & West & 1999 & -51.6253 & -60.1260 & + & - & - & $\begin{array}{l}\text { McDowall et al. } \\
\text { (2001) }\end{array}$ \\
\hline $2^{\text {nd }}$ Arroyo & West & 2009 & -52.0647 & -60.5092 & - & + & + & Ross (2009) \\
\hline Arroyo Chico & West & 1999 & -51.9208 & -60.1891 & + & - & - & $\begin{array}{l}\text { McDowall et al. } \\
\text { (2001) }\end{array}$ \\
\hline Arroyo Malo & West & 1999 & -51.9194 & -60.1471 & - & - & - & $\begin{array}{l}\text { McDowall et al. } \\
\text { (2001) }\end{array}$ \\
\hline Ballan Stream & West & 2009 & -51.6471 & -59.5714 & - & - & + & Ross (2009) \\
\hline Beach Stream & West & 1999 & -51.6258 & -59.5402 & + & - & + & $\begin{array}{l}\text { McDowall et al. } \\
\text { (2001) }\end{array}$ \\
\hline Bull Hill Stream & West & 1999 & -51.5764 & -59.5194 & + & - & - & $\begin{array}{l}\text { McDowall et al. } \\
\text { (2001) }\end{array}$ \\
\hline Bull Stream & West & 1999 & -51.4888 & -60.0413 & + & - & - & $\begin{array}{l}\text { McDowall et al. } \\
\text { (2001) }\end{array}$ \\
\hline Campbell Creek Stream & West & 2009 & -52.0197 & -60.4278 & - & - & + & Ross (2009) \\
\hline Cemetery Creek Estuary & West & 1999 & -51.5961 & -59.4913 & + & - & + & $\begin{array}{l}\text { McDowall et al. } \\
\text { (2001) }\end{array}$ \\
\hline Chartres River* & West & 1999 & -51.6428 & -59.9283 & + & - & - & $\begin{array}{l}\text { McDowall et al. } \\
\text { (2001) }\end{array}$ \\
\hline Daddy's Ditch & West & 2009 & -51.4195 & -59.9033 & - & - & + & Ross (2009) \\
\hline Dean's River & West & 2009 & -52.0914 & -60.6869 & - & - & + & Ross (2009) \\
\hline $\begin{array}{l}\text { Dirty Ditch at the High } \\
\text { Tide }\end{array}$ & West & 1999 & -51.5401 & -60.3470 & + & - & + & $\begin{array}{l}\text { McDowall et al. } \\
\text { (2001) }\end{array}$ \\
\hline Double Stream & West & 2009 & -51.6677 & -59.6277 & - & - & + & Ross (2009) \\
\hline Doyle River Tributary & West & 1999 & -51.7695 & -60.1764 & - & + & + & $\begin{array}{l}\text { McDowall et al. } \\
\text { (2001) }\end{array}$ \\
\hline Dunbar Creek & West & 2009 & -51.4124 & -60.4556 & - & - & + & Ross (2009) \\
\hline Edye Creek & West & 2012 & -51.8711 & -60.4206 & - & + & + & Fowler (2013) \\
\hline Fish Creek 1 & West & 2012 & -52.0538 & -60.2908 & - & + & + & Fowler (2013) \\
\hline Fish Creek 2 & West & $\begin{array}{l}2012 / \\
2018\end{array}$ & -51.8918 & -60.3681 & - & + & + & $\begin{array}{l}\text { Fowler (2013), } \\
\text { Minett et al. (2020) }\end{array}$ \\
\hline $\begin{array}{l}\text { Fox Bay East* (Doctors } \\
\text { Creek) }\end{array}$ & West & $2012 / 18$ & -51.9421 & -60.0500 & + & - & NA & Minett et al. (2020) \\
\hline Fox Bay West* & West & 2012 & -51.9510 & -60.0897 & + & NA & $\mathrm{NA}$ & Angler \\
\hline Gibraltar Stream & West & 2009 & -52.0913 & -60.3318 & - & + & + & Ross (2009) \\
\hline Green Hill Stream & West & 2009 & -51.5552 & -59.6012 & + & - & - & Ross (2009) \\
\hline Herbert Stream & West & 1999 & -51.5222 & -60.1959 & + & - & - & $\begin{array}{l}\text { McDowall et al. } \\
\text { (2001) }\end{array}$ \\
\hline Hawk's Nest Stream & West & 1999 & -51.8055 & -59.9614 & + & - & - & $\begin{array}{l}\text { McDowall et al. } \\
(2001)\end{array}$ \\
\hline Hill Cove* & West & 2008 & -51.4736 & -59.9764 & + & - & - & Fowler (2013) \\
\hline House Creek & West & 1999 & -51.6097 & -59.5267 & + & + & + & $\begin{array}{l}\text { McDowall et al. } \\
\text { (2001) }\end{array}$ \\
\hline House Stream & West & 2012 & -51.6116 & -59.5221 & + & + & + & Fowler (2013) \\
\hline Lake Sulivan, Outflow & West & 2009 & -51.7922 & -60.2111 & - & + & + & Ross (2009) \\
\hline Lake Sulivan North & West & 2011 & -51.8167 & -60.1941 & - & + & + & Fowler (2013) \\
\hline $\begin{array}{l}\text { Lake Sulivan North } \\
\text { Outflow }\end{array}$ & West & 1999 & -51.8073 & -60.1976 & - & - & + & $\begin{array}{l}\text { McDowall et al. } \\
\text { (2001) }\end{array}$ \\
\hline Lake Sulivan South & West & 2011 & -51.8567 & -60.1891 & + & - & + & Fowler (2013) \\
\hline Larger Stream, Hill Cove & West & 1999 & -51.4945 & -60.0843 & - & - & + & $\begin{array}{l}\text { McDowall et al. } \\
\text { (2001) }\end{array}$ \\
\hline Leicester Stream & West & 2009 & -51.9084 & -60.2682 & - & - & + & Ross (2009) \\
\hline Main Point Creek & West & 2009 & -51.4474 & -59.8757 & - & - & + & Ross (2009) \\
\hline Many Branches Stream & West & 1999 & -51.5303 & -59.5083 & + & - & + & $\begin{array}{l}\text { McDowall et al. } \\
\text { (2001) }\end{array}$ \\
\hline
\end{tabular}


Conservation of endangered galaxiid fishes in the Falkland Islands required urgent action on invasive brown trout

\begin{tabular}{|c|c|c|c|c|c|c|c|c|}
\hline Mickey Doolan's Ditch & West & 1999 & -51.9292 & -60.1703 & - & - & + & $\begin{array}{l}\text { McDowall et al. } \\
\text { (2001) }\end{array}$ \\
\hline Mt Adam Stream & West & 1999 & -51.6355 & -60.0802 & + & - & - & $\begin{array}{l}\text { McDowall et al. } \\
\text { (2001) }\end{array}$ \\
\hline Mt Donald Pond Inflow & West & 1999 & -51.5643 & -60.1720 & + & - & - & $\begin{array}{l}\text { McDowall et al. } \\
\text { (2001) }\end{array}$ \\
\hline $\begin{array}{l}\text { Neil Clark Nature } \\
\text { Reserve }\end{array}$ & West & 2018 & -51.6324 & -59.5452 & + & - & NA & Minett et al. (2020) \\
\hline Poncho Valley Stream & West & 2012 & -51.9736 & -60.4357 & - & + & + & Fowler (2013) \\
\hline Port Howard/Warrah* & West & 1999 & -51.4554 & -59.6245 & + & - & - & $\begin{array}{l}\text { McDowall et al. } \\
\text { (2001) }\end{array}$ \\
\hline Port Stephens* & West & 2009 & -52.0980 & -60.8321 & - & - & + & Ross (2009) \\
\hline River Doyle & West & 2009 & -51.7588 & -60.1845 & - & + & + & Ross (2009) \\
\hline Rous Creek Stream & West & 2009 & -51.7006 & -60.6122 & - & - & + & Ross (2009) \\
\hline Skull Pass Stream & West & 1999 & -51.5444 & -59.6095 & + & - & - & $\begin{array}{l}\text { McDowall et al. } \\
\text { (2001) }\end{array}$ \\
\hline Stewart's Brook & West & 2009 & -52.0482 & -60.6826 & - & + & + & Ross (2009) \\
\hline $\begin{array}{l}\text { Stream by Mt Rosalie } \\
\text { House }\end{array}$ & West & 2009 & -51.4856 & -59.3685 & - & - & + & Ross (2009) \\
\hline Stud Paddock Stream & West & 1999 & -51.9416 & -60.0497 & - & - & + & $\begin{array}{l}\text { McDowall et al. } \\
\text { (2001) }\end{array}$ \\
\hline Teal House River & West & 2018 & -51.6194 & -60.1103 & + & - & NA & Minett et al. (2020) \\
\hline $\begin{array}{l}\text { Teal Ponds and Waterfall } \\
\text { Stream }\end{array}$ & West & 1999 & -51.6557 & -60.0672 & + & - & + & $\begin{array}{l}\text { McDowall et al. } \\
\text { (2001) }\end{array}$ \\
\hline Top Hog Ground Stream & West & 1999 & -51.6711 & -59.9714 & + & - & - & $\begin{array}{l}\text { McDowall et al. } \\
\text { (2001) }\end{array}$ \\
\hline Unnamed Stream & West & 1999 & -51.5443 & -59.5602 & + & - & - & $\begin{array}{l}\text { McDowall et al. } \\
\text { (2001) }\end{array}$ \\
\hline Unnamed Stream & West & 1999 & -51.9092 & -60.2030 & + & - & - & $\begin{array}{l}\text { McDowall et al. } \\
\text { (2001) }\end{array}$ \\
\hline Unnamed Stream & West & 2012 & -51.6098 & -59.8563 & + & - & - & Fowler (2013) \\
\hline $\begin{array}{l}\text { Unnamed Stream, Hill } \\
\text { Cove }\end{array}$ & West & 1999 & -51.5053 & -60.1034 & - & - & + & $\begin{array}{l}\text { McDowall et al. } \\
\text { (2001) }\end{array}$ \\
\hline $\begin{array}{l}\text { Unnamed Stream, Hill } \\
\text { Cove }\end{array}$ & West & 1999 & -51.4928 & -60.0587 & + & - & - & $\begin{array}{l}\text { McDowall et al. } \\
\text { (2001) }\end{array}$ \\
\hline Warrah River & West & 1999 & -51.5598 & -59.7581 & + & - & - & $\begin{array}{l}\text { McDowall et al. } \\
\text { (2001) }\end{array}$ \\
\hline Waterfall Stream & West & 2009 & -51.3817 & -60.5421 & - & - & + & Ross (2009) \\
\hline Weedy Outlet & West & 1999 & -51.8548 & -60.1980 & + & - & + & $\begin{array}{l}\text { McDowall et al. } \\
\text { (2001) }\end{array}$ \\
\hline West Lagoons & West & 2013 & -51.4421 & -60.0817 & - & + & + & Fowler (2013) \\
\hline Whisky Creek & West & 2009 & -52.0546 & -60.7896 & - & + & - & Ross (2009) \\
\hline
\end{tabular}

\section{Modelling of brown trout occurrence}

The most plausible model of brown trout occurrence contained only three predictors, Euclidean distance to nearest invaded site (estimate $=-0.238, \mathrm{SE}=0.067, t=-3.56, p=$ 0.0004), presence of Aplochiton spp. (estimate $=-1.57, \mathrm{SE}=0.769, t=-2.04, p=0.041$ ) and number of river-road crossings in the drainage basin (estimate $=0.156, \mathrm{SE}=0.066, t=2.37$, $p=0.018$ ). This model explained the occurrence of brown trout significantly better than chance $(\operatorname{LRT}(3)=52.17, p=<0.0001, \mathrm{AUC}=0.85)$. 
Conservation of endangered galaxiid fishes in the Falkland Islands required urgent action on invasive brown trout

\section{Impact of brown trout on native galaxiids}

Native galaxiids were less likely to occur in streams invaded by brown trout than in uninvaded ones (Figure 3.2), but the impact of invasive brown trout was more pronounced in the case of Aplochiton spp. Calculation of relative risk indicated that Aplochiton spp. was 4.5 times less likely to persist in streams invaded by brown trout than in uninvaded streams (95CI $=1.8-11.2, p<0.001)$. For Galaxias maculatus, the presence of brown trout decreased the probability of occurrence 2.9 -fold $(95 \mathrm{CI}=2.0-4.2, p<0.001)$.

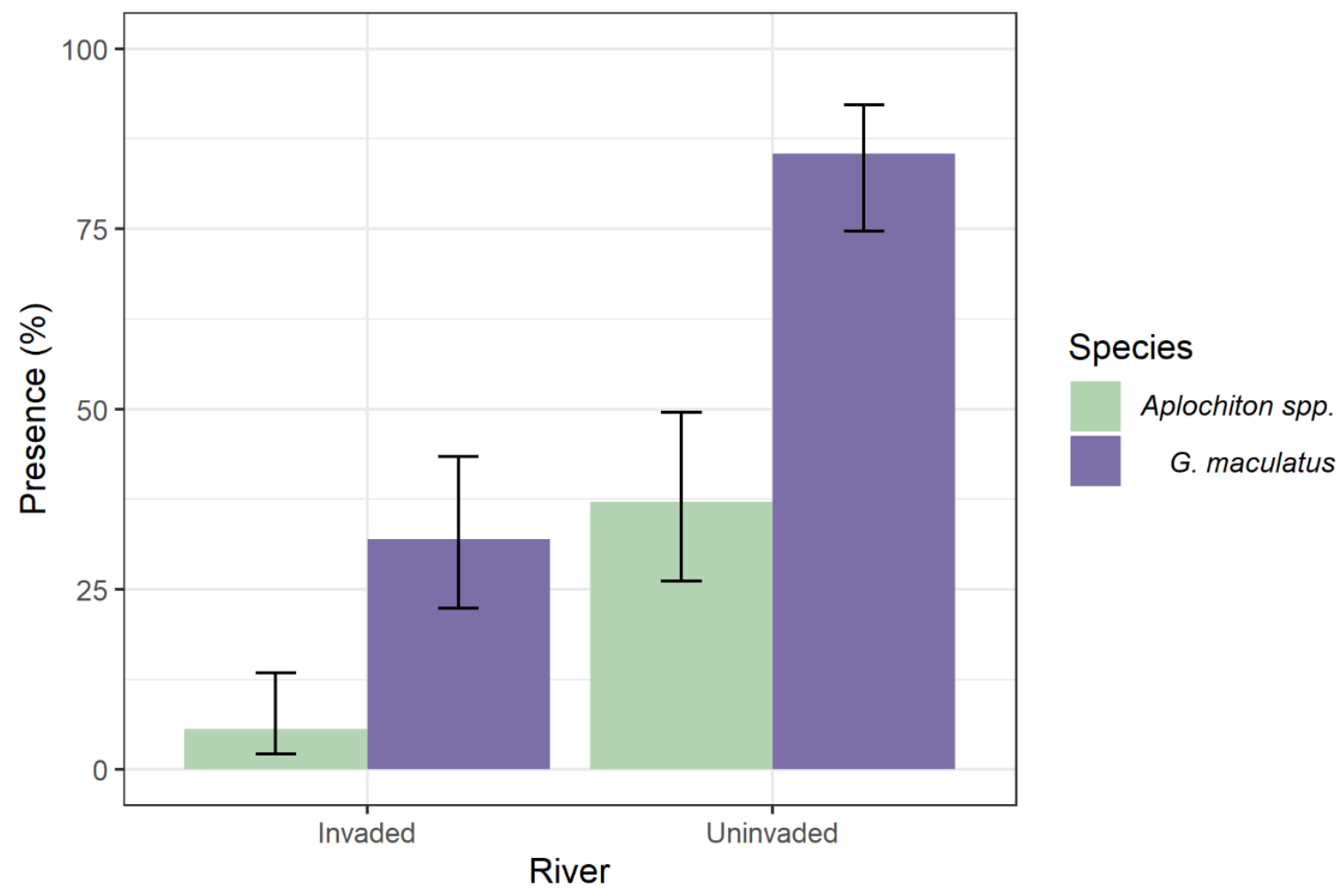

Figure 3.2. Frequency of occurrence (\% and binomial upper 95CI) of native galaxiids (Aplochiton spp. and Galaxias maculatus) in streams invaded $(\mathrm{N}=62)$ and in those uninvaded $(\mathrm{N}=72)$ by brown trout. 
Conservation of endangered galaxiid fishes in the Falkland Islands required urgent action on invasive brown trout

\section{Risk of invasions}

A risk map generated from the LOOCV probabilities identified $21 \%$ of cells with a very high risk of invasion ( $\geq 0.75$ ), with a further $24 \%$ at high risk of invasion $(\geq 0.5$ to $<0.75)$, and the remaining $17 \%$ and $40 \%$ being at medium $(\geq 0.25$ to $<0.5)$ and low risk $(<0.25)$ respectively (Figure 3.3). Overlaying Aplochiton spp. presence identified 10 high or very high-risk areas for native species where preventative measures should be prioritised to exclude brown trout and protect native freshwater fish (Figure 3.3).

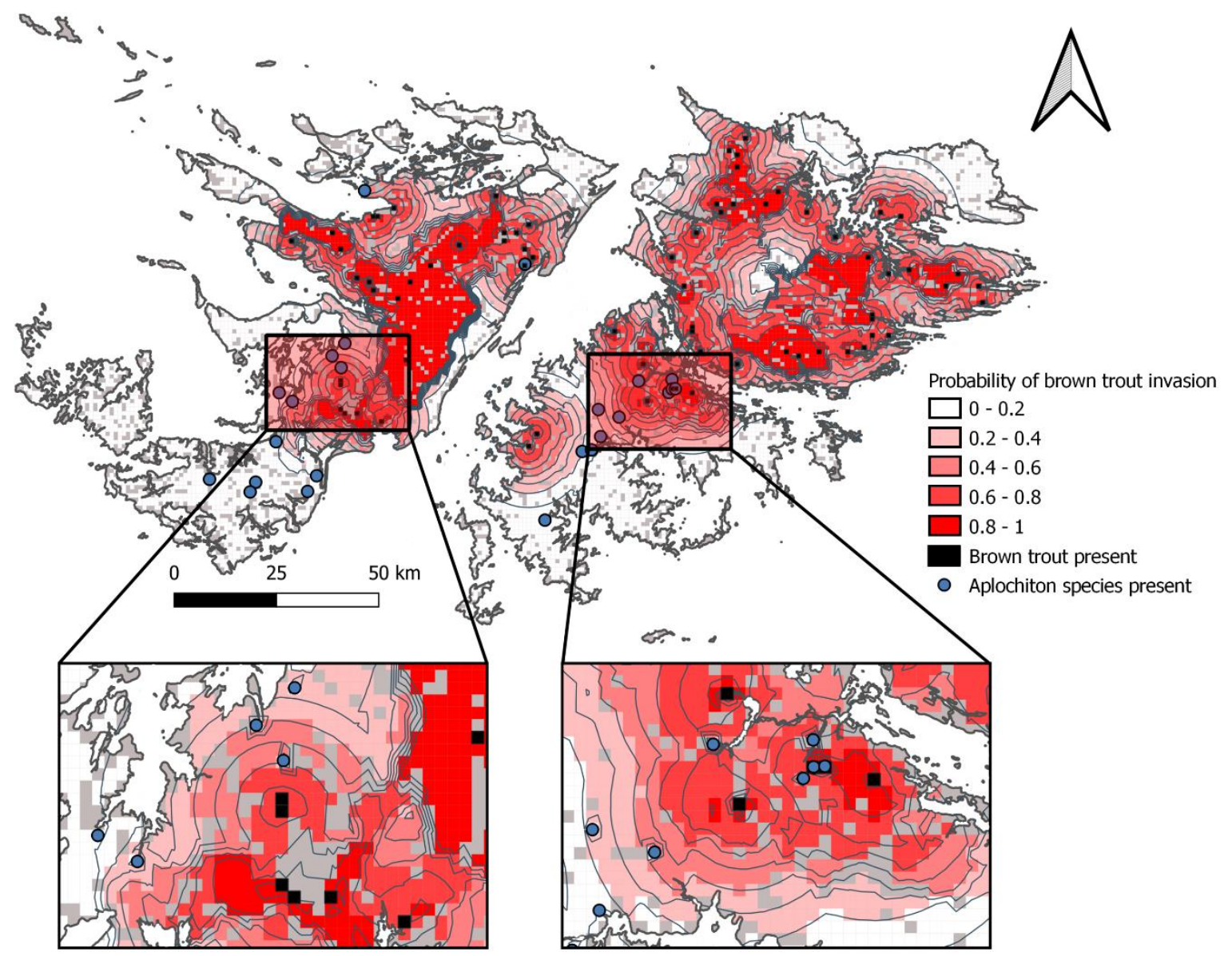

Figure 3.3. Risk map showing probabilities of brown trout invasion based on species distribution modelling. Aplochiton refugia at high risk of brown trout invasion are shown in zoomed insets. 
Conservation of endangered galaxiid fishes in the Falkland Islands required urgent action on invasive brown trout

\section{Management scenarios}

The simulation of brown trout invasion probabilities under three management scenarios indicated that if nothing is done (scenario 1: no containment) brown trout will likely increase their occupancy from $54 \%$ to $93 \%$ within the next 70 years $(97.5 \mathrm{CI}=70-99 \%)$. Under scenario 2 (moderate containment) occupancy is predicted to increase to $86 \%(97.5 \mathrm{CI}=59$ $94 \%$ ) and to $69 \%(97.5 \mathrm{CI}=47-81 \%)$ with strong containment (scenario 3, Figure 3.4). Thus, occupancy is predicted to increase under all three scenarios, but only with strong containment can current Aplochiton refugia likely be protected from trout invasions.

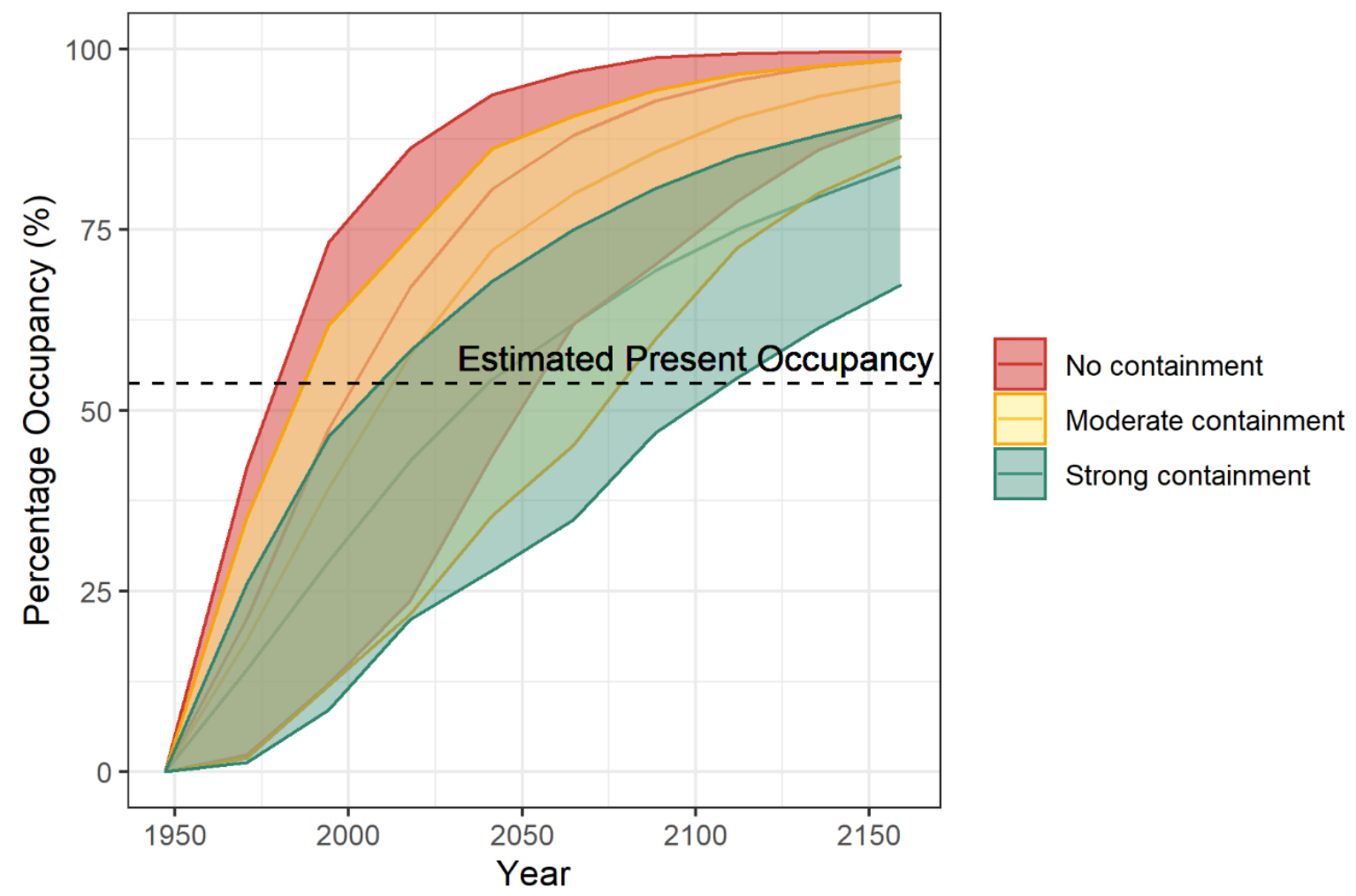

Figure 3.4. Modelled expansion of brown trout in the Falkland Islands under three different management scenarios. 
Conservation of endangered galaxiid fishes in the Falkland Islands required urgent action on invasive brown trout

\subsection{Discussion}

This study indicates that brown trout have already invaded $54 \%$ of the streams in the Falkland Islands since they were introduced in 1944-1962 and are impacting on native freshwater fish. Streams invaded by brown trout were significantly less likely to harbour native galaxiids than uninvaded streams, suggesting that the impacts are substantial. This finding is consistent with competitive exclusion of native galaxiids by invasive brown trout (Young et al., 2009; Garcia de Leaniz et al., 2010), exacerbated by predation and trophic interference (Elgueta et al., 2013; Arismendi et al., 2014). These simulations suggest that unless more stringent measures are put in place, brown trout will likely invade nearly all the suitable freshwater habitats in the Falklands within the next $\sim 70$ years. Given that endangered Aplochiton spp. only occupy $\sim 18 \%$ of the area, mostly confined to southern part of the Islands, this could drive the species to extinction.

The establishment success of brown trout in the Falkland Islands was very high (88\%), as seen elsewhere in the Southern Hemisphere (Young et al., 2010; Lecomte et al., 2013; Arismendi et al., 2014; Davidsen et al., 2021), and remarkably, in Argentina, no failed introduction of brown trout was ever reported (Baigún and Quirós, 1985). Several factors may help explain this. Firstly, this study shows that brown trout introduced into the Falkland Islands originated from at least four different origins with two life history strategies (anadromous, non-anadromous), which resulted in genetic admixture (Minett et al., 2021b). Multiple origins and genetic admixture can increase genetic diversity and facilitate adaptation to novel conditions (Consuegra et al., 2011), which along with repeated introductions may increase invasion success. Establishment success may have also been facilitated by phenotypic plasticity and marine dispersal, as demonstrated recently by acoustic tracking (Minett et al., 2021b).

However, marine dispersal alone cannot explain the current distribution of brown trout in the Falklands; secondary translocations must have also taken place because the species is now found in land-locked sites, where it could not have reached without human intervention. Transporting brown trout has been illegal in the Falklands since 1999, but some translocations must have taken place (McDowall et al., 2001). Indeed, these results indicate that brown trout presence was predicted by proximity to other invaded sites (overland, but not around the coast) and by the density of river-road crossings, which is consistent with secondary translocations facilitated by the road network, as seen in many other aquatic 
Conservation of endangered galaxiid fishes in the Falkland Islands required urgent action on invasive brown trout

invasive species. For example, roads facilitated the expansion of smallmouth bass (Micropterus dolomieu) in remote lakes in Canada (Kaufman et al., 2009) and of bluegill (Lepomis macrochirus) in Japan (Kizuka et al., 2014). The Falklands has $\sim 800 \mathrm{~km}$ of roads that crisscross a dense river network, most of which were built over the last three decades (Fowler and Garcia de Leaniz 2012), and it is likely that this may have facilitated the expansion of brown trout. Recent eDNA analysis of water samples (Minett et al., 2020) has revealed the presence of brown trout in additional streams since the last survey, suggesting that the species is expanding at a rate of $\sim 0.9 \% / y e a r$. The data used to build the invasion risk model was derived from studies conducted 10-20 years ago (Fowler, 2013; McDowall et al, 2001; Ross, 2009). Thus, it is possible that if this model were to be rerun with new up to data information on the distribution of brown trout in the Falklands, which could be obtained from eDNA analysis, other predictor variables could have a larger influence.

Invasion risk was modelled using a GLM. GLMs are commonly used to model species distribution and are user friendly, however, they are not always the most appropriate method to use as they only implement linear (straight-line) functions (Austin, 2007; Breiner et al., 2015). Therefore, it is important to consider model accuracy and test model performance against null models (Rodríguez-Rey et al., 2019), as was done here (see methods and results).

Other invasive salmonids are also threatening the native fish fauna of the Falklands. For example, both chinook salmon (Oncorhynchus tshawytscha) (Fowler, 2013) and coho salmon (Oncorhynchus kisutch) are increasingly being caught off West Falkland, most likely originating from Chile or Argentina, highlighting the potential for further salmonid invasions. Similarly, the recent development of sea trout farming in open-net cages in the Falklands in 2013 poses a risk of escapees, which could further compromise the survival of native galaxiids, as seen in Patagonia (Consuegra et al., 2011; Vanhaecke et al., 2012a), particularly if sea cages are located close to Aplochiton refugia. Given the widespread ecological damage caused by invasive salmonids, being able to identify areas at high risk of invasion is critical for managing and curtailing their expansion. In this sense, these risk maps (Figure 3.3) may aid conservation officers tasked with the protection of native fish fauna to monitor high risk areas and develop an integrated management strategy for invasive salmonids in the Falkland Islands. 
Conservation of endangered galaxiid fishes in the Falkland Islands required urgent action on invasive brown trout

\section{Conclusions \& Recommendations}

Galaxiids rank among the most severely threatened fish in the world due to the introduction of invasive salmonids (McDowall, 2006; Garcia de Leaniz et al., 2010). This modelling suggests that without containment and strict measures brown trout will likely invade all remaining suitable freshwater bodies in the Falklands before the end of the century, putting the endangered native freshwater fish at high risk of extinction.

Existing legislation makes it illegal to transport or propagate brown trout in the Falkland Islands (Falkland Islands Government, 1964), but this seems insufficient as the species is also afforded a protected status (Falkland Islands Government, 1999), and fishing for trout is widely promoted (Falkland Islands Government, 2015), which may facilitate its spread. The road network appears to be a main route of human-assisted translocations and it is therefore essential that more stringent measures are put in place. This may involve making people more aware of the impacts of salmonid invasions and passing more stringent legislation. Exclusion barriers could also be deployed around galaxiid refugia to reduce the risk of salmonid invasions (Jones et al., 2021b), but care must be taken to ensure this does not impact on native galaxiids, which may pose a challenge as even small barriers can have negative impacts on weak swimmers (Jones et al., 2021a). Changes to angling regulations might also be useful. Currently, brown trout anglers are subject to a daily bag limit and a strict fishing season (Falkland Islands Government, 1999; Falkland Islands Government, 2015), lifting these restrictions may help slow down the invasion front in some places. Intensive fishing could be used to eradicate brown trout and establish buffer zones around Aplochiton spp. refugia although this may not be effective if there is compensatory density-dependent mortality (Saunders et al., 2015). Analysis of eDNA from water samples could be used to delineate galaxiid refugia (Minett et al., 2020), to serve as an early warning of brown trout invasions, and to establish whether containment or eradication measures have been successful.

Since McDowall's call for action 20 years ago (McDowall et al., 2001), brown trout has continued to expand while native galaxiids have continued to decline. Aplochiton spp. feature on a Falklands postal stamp while Galaxias maculatus is called 'Falklands minnow', testifying to their importance for local islanders, and their place in the natural and cultural heritage of the Falkland Islands. Brown trout has brought wealth and recreation opportunities 
Conservation of endangered galaxiid fishes in the Falkland Islands required urgent action on invasive brown trout

to the Falklands but has also caused the demise of native freshwater fish. This study shows that urgent protection measures are needed to safeguard their survival. 


\section{Chapter 4 SNP analysis and acoustic tagging reveal multiple origins and widespread dispersal of invasive brown trout in the Falkland Islands}

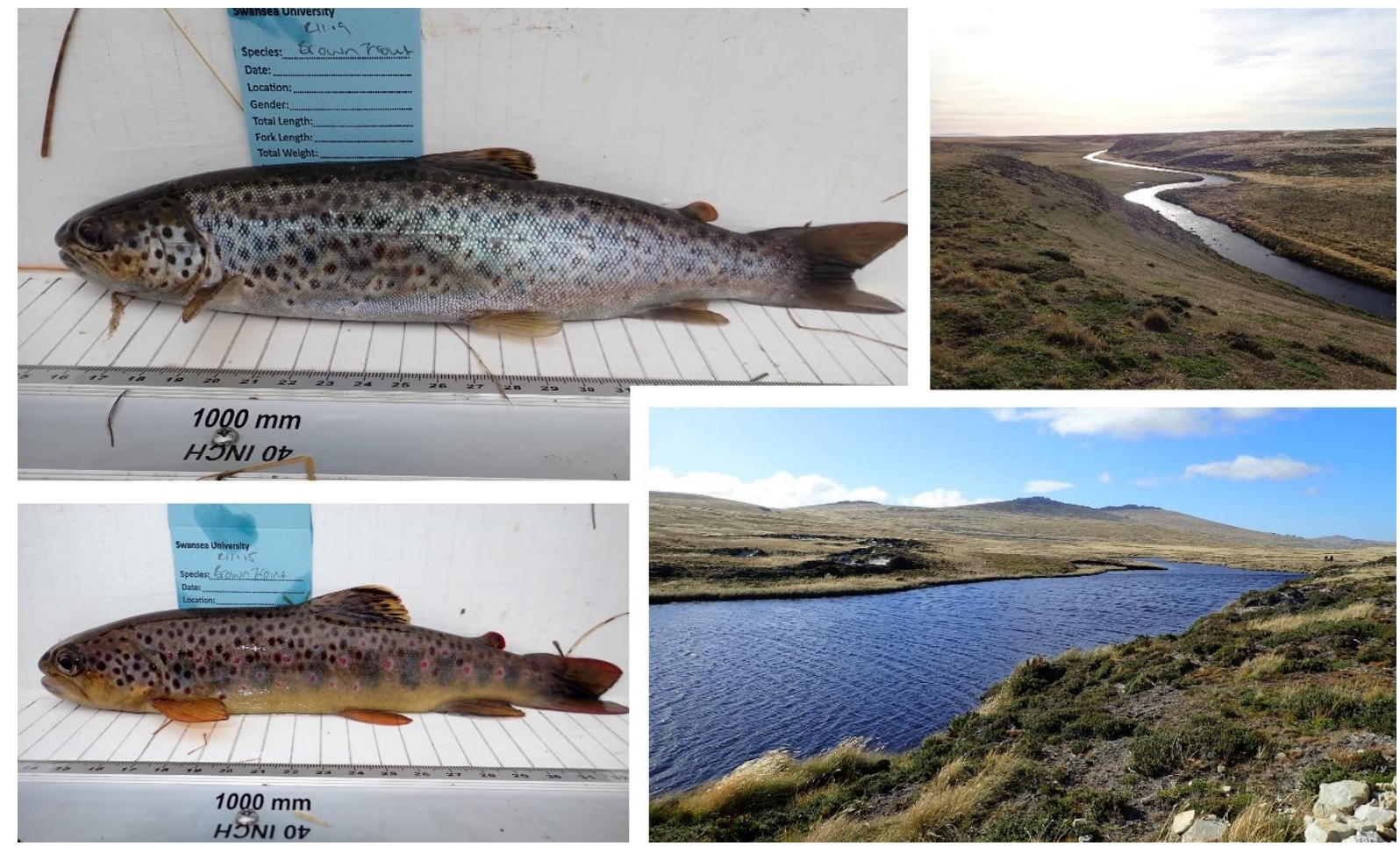

This work is published in Evolutionary Applications as:

Minett, J.F., Garcia de Leaniz, C., Sobolewska, H., Brickle, P., Crossin, G. T. \& Consuegra, S. (2021) SNP analysis and acoustic tagging reveal multiple origins and widespread dispersal of invasive brown trout in the Falkland Islands. Evolutionary Applications, 11-1. https://doi.org/10.1111/eva.13274. 
SNP analysis and acoustic tagging reveal multiple origins and widespread dispersal of invasive brown trout in the Falkland Islands

\subsection{Introduction}

The spread of invasive species can occur via accidental introduction, deliberate release and/or through natural processes. Controlling biological invasions is increasingly important because they impact native species and communities leading to loss of biodiversity and ecosystem functionality (Mills et al., 2003; Doherty et al., 2016; Mollot et al., 2017), particularly in remote islands with low native diversity (Moser et al., 2018). However, control measures can face social opposition, for example if the costs are high (Sheremet et al., 2017) or the introduced species has acquired socio-cultural importance (Lohr and Lepczyk, 2014; Roberts et al., 2018). Thus, in some cases, managing the damage caused by invaders can be the best option (Hanley and Roberts, 2019). Management of invasive species requires an understanding of propagule pressure (introduction effort), number of different origins (Du et al., 2021), and the pathways and patterns of dispersal (Sakai et al., 2001; Resh et al., 2018). However, unless introductions are deliberate and thorough records are kept, the number and routes of introductions are generally unknown. Molecular techniques, such as microsatellites and Single Nucleotide Polymorphisms (SNPs) can be used to assess the evolution and dispersal of invasive species and design targeted plans of containment or eradication (Le Roux and Wieczorek, 2009; Resh et al., 2021).

Brown trout (Salmo trutta) is native to Europe, Western Asia and Northern Africa, however, since 1864 it has been widely introduced outside of their native range and are currently found on all continents except Antarctica (MacCrimmon and Marshall, 1968). Such introductions have resulted in extensive ecological damage making brown trout one of the 100 world's worst invasive species (Lowe et al., 2000). Invasive brown trout have had strong negative impacts on native fishes in New Zealand (McIntosh et al., 1994; McIntosh, 2000; McDowall, 2006; McIntosh et al., 2010), Chile (Penaluna et al., 2009; Habit et al., 2010), North America (McHugh and Budy, 2006; Budy and Gaeta, 2018), and Japan (Kitano, 2004; Morita, 2018), causing severe decreases in native biodiversity and loss of ecosystem function though predation, competition and habitat modification (Macchi et al., 2007; Penaluna et al., 2009).

Brown trout from Great Britain (approximately 83,000) and Chile (approximately 30,000with a potential bridgehead effect (Bertelsmeier et al., 2018)) were introduced to the Falkland Islands nearly 80 years ago, over an 18-year period between 1944-1962, although much of the information regarding introduction sites and stocks has been lost. Chilean stocks from Lautaro hatchery were primarily sourced from Germany (Faundez et al., 1997; Basulto, 
SNP analysis and acoustic tagging reveal multiple origins and widespread dispersal of invasive brown trout in the Falkland Islands

2003), whereas trout from Great Britain originated from three sources: the Surrey trout farm, Pentlands (Scotland), and the Middleton hatchery in Lancashire (Arrowsmith and Pentelow, 1965; Stewart, 1973; Stewart, 1980), and included anadromous trout. The exact sources of the Pentlands stock are unknown but believed to originated from Cobbinshaw Loch or Loch Leven (Minett et al., 2021a).

Since their introduction, brown trout have widely spread throughout East and West Falkland (McDowall et al., 2001; Fowler, 2013; Minett et al., 2021a). Their dispersal has been facilitated by marine dispersal, as in other places (Jonsson, 1985; Nevoux et al., 2019), with anadromous brown trout (sea trout) having been documented in the Falklands since 1956 (Salmon and Trout Association, 2012). Additionally, brown trout have been moved intentionally amongst various locations (McDowall et al., 2001). The native fish community, mainly zebra trout (Aplochiton zebra and A. taeniatus) and the Falklands minnow (Galaxias maculatus), has been severely impacted by brown trout (McDowall et al., 2001), and zebra trout are currently regarded as seriously threatened and protected by law (Falkland Islands Government, 1999; McDowall et al., 2001; Ross, 2009). However, brown trout can be difficult and costly to eradicate once established (Bosch et al., 2019; Healy et al., 2020) and have become an important source of income through angling tourism in the Falklands (Ross, 2009). Therefore, to maintain a balance between trout fishing and the protection of native galaxiids, targeted management plans should be implemented to limit trout dispersal and prevent further invasion. These need geographical information (e.g., concave, and complex coastlines seem to favour brown trout invasion (Labonne et al., 2013)), as well as information on dispersal routes and population connectivity. Here I analysed the movement and genetic status of brown trout populations across the Falkland Islands to provide information that can be used for future management plans aimed at preventing further dispersal of the species.

Here, the main aims were to examine the population structure of brown trout in the Falkland Islands. Analyse levels of migration and gene flow between populations in order to establish their patterns of dispersal and to assess potential origins of current brown trout populations. 
SNP analysis and acoustic tagging reveal multiple origins and widespread dispersal of invasive brown trout in the Falkland Islands

\subsection{Methods}

\section{Sampling}

A total of 290 brown trout were non-lethally sampled from 14 rivers and ponds across the Falkland Islands, nine on East Falkland and five on West Falkland (Figure 4.1; Table 4.1), during two field seasons (April-May 2018 [autumn] and September-October 2018 [spring]). Sampling locations were chosen based on brown trout presence information from previous work conducted by McDowall et al (2001), Ross (2009) and Fowler (2013). Fish were captured using either seine netting, angling or backpack electrofishing (Model: Smith-Root LR-24, 160-280v and 50Hz). Adipose fin clips and scale samples were obtained from all fish greater than $50 \mathrm{~mm}$, and weight $(\mathrm{g})$ and fork length $(\mathrm{mm})$ were recorded. Fish were then returned alive to their location of capture. Adipose fin clips were stored in $90 \%$ ethanol at $20^{\circ} \mathrm{C}$ for subsequent genetic analysis.

\section{DNA extraction, SNP calling and filtering}

DNA from adipose fins was extracted using Qiagen DNeasy 96 plate tissue kits (Qiagen, UK) following the manufacturer's protocol. Concentration and QC parameters were determined using a NanoDrop 8000 spectrophotometer (ThermoFisher Scientific, UK) and samples normalised to $50 \mathrm{ng} / \mu \mathrm{l}$. SNP array analysis was completed by Neogen Europe (Ayr, UK), using a custom design 24k Salmo salar / Oncorhynchus mykiss Illumina Infinium beadchip array, under permission of Hendrix Genetics (Hendrix Genetics BV., Boxmeer, Netherlands). Data analysis was completed by Noahgene Ltd (Alloa, UK). Raw data was imported into the software package Genome Studio 2.0.4 (Illumina Inc., San Diego, Ca., USA) for cluster analysis and SNP calling. SNP calls were exported as a Genome Studio FR.txt files and imported into SNP Variation Suite 8.9.0 (Golden Helix Inc., Bozeman, Mt., USA). QC parameters threshold call rate $>0.85$ and $\mathrm{MAF}>0.025$ were applied and filtered SNP genotypes $(\mathrm{N}=14,195)$ exported to Microsoft Excel for downstream analysis. Invariant loci $(\mathrm{N}=12,233)$, SNPs with more than 3\% missing data overall, and any individuals with more than $10 \%$ missing data were removed.

\section{Genetic differentiation, isolation by distance and effective population size}

Heterozygosity (Ho), gene diversity (Hs) and $\mathrm{F}_{\text {IS }}$ were calculated for each sample site using the basic.stats function in R 3.5.3 (Goudet, 2005; R Core Team, 2019; Goudet and Jombart, 2020). Deviations from Hardy-Weinberg equilibrium were estimated using the hw.test (Guo 
SNP analysis and acoustic tagging reveal multiple origins and widespread dispersal of invasive brown trout in the Falkland Islands

and Thompson, 1992) function from the adegenet package. Genetic differentiation, between rivers and genetic clusters was calculated using the hierfstat 0.5-8 package. Weir and Cockerham pairwise $\mathrm{F}_{\mathrm{ST}}$ values were calculated using the pairwise.WCfst function and $97.5 \%$ confidence intervals were obtained by bootstrapping using the boot.ppfst function $(1,000$ permutations). Overall $\mathrm{F}_{\mathrm{ST}}$ estimates were calculated using the betas function (Weir and Cockerham, 1984). Nei's distance between populations (Nei, 1987) was calculated using the genet.dist function and used to produce a dendrogram of the population relationships. Effective population size $\left(\mathrm{N}_{\mathrm{e}}\right)$ was estimated using linkage disequilibrium method implemented in NeEstimator v2 (Hill, 1981; Do et al., 2014a).

To examine the extent of isolation by distance (IBD) a Mantel test between genetic distance (pairwise Weir and Cockerham FST values) and geographic distance matrix was conducted using 999 randomisations in the ade4 package in R (Mantel, 1967; Thioulouse et al., 2018). Two measures of geographic distance were used: pairwise distance between river mouths around the coast (to reflect marine dispersal), and shortest Euclidean distances between sampling sites (to reflect potential human-mediated translocation of fish). River mouth distances around the coast were calculated using rgdal (Bivand et al., 2019), sp (Pebesma and Bivand, 2005; Bivand et al., 2013), raster (Hijmans, 2020), and gdistance (van Etten, 2017) packages using a purpose-built function. Euclidean distances were calculated in QGIS v3.10.14 (QGIS Development Team, 2020). IBD was calculated for all sampling sites across the Falklands, as well as for East and West Falklands separately.

\section{Genetic cluster identification, admixture, and gene flow}

Genetic clusters of related individuals were identified through analysis of SNP genotypes using Discriminant Analysis of Principal Components (DAPC) using the adegenet 2.1.3 R package (Jombart, 2008; Jombart and Ahmed, 2011). The optimal number of genetically distinct clusters were determined by K-means cluster analysis based on the lowest associated Bayesian Information Criterion (BIC) value, with a maximum K of 14 (the total number of sites sampled in the Falklands), using the find.clusters function. To examine the genetic structure and describe diversity between clusters I preformed DAPC using the dapc function and the clusters defined by K-means. The number of principal components retained in DAPC was determined based on their alpha-scores using the optim.a.score function, resulting in the retention of 5 principle components (Jombart et al., 2010). The level of admixture was assessed through individual assignment to different clusters; assuming that an individual was 
SNP analysis and acoustic tagging reveal multiple origins and widespread dispersal of invasive brown trout in the Falkland Islands

admixed if it had less than $90 \%$ probability of belonging to a single cluster (Noble et al., 2010).

Admixture between clusters was also examined using the snapclust function in the adegenet $\mathrm{R}$ package. Using the clusters defined by K-means I simulated F1 and F2 backcrosses between pairs of clusters and snapclust was run to reassign individuals to one of six possible classes: parental 1, parental 2, F1 hybrid, or F2 backcross with either parental population.

Directional migration rates were calculated as a proxy for gene flow between sample sites using the divMigrate function in the diveRsity v1.9.90 R package using genetic diversity and differentiation statistics (Keenan et al., 2013; Sundqvist et al., 2016).

\section{Origin of brown trout introduced into the Falkland Islands}

The stocking history of brown trout in the Falkland Islands during 1948-1962 was reconstructed and the putative sources from the literature and historical records were identified (Minett et al., 2021a). Fresh or archived tissue samples were also obtained for genetic analysis from three of the putative sources in Great Britain (Table 4.1), the River Wey for the Surrey trout farm, $\mathrm{N}=12$; and Howietoun hatchery $(\mathrm{N}=6)$ and Loch Leven $(\mathrm{N}=14)$ representing the Pentlands. It was not possible to obtain samples from Cobbinshaw Loch (it was not a natural brown trout population and trout are no longer stocked in the loch) or Germany (the original stock is no longer cultured). DNA extraction and genotyping was carried out as above except for 10 samples obtained from Loch Leven whose DNA had already been extracted. SNP data from putative origins and the Falklands' samples were combined into a single database and analysed as above to examine genetic clustering and differentiation, using a maximum $\mathrm{K}$ of 17.

\section{Acoustic tracking}

To gain additional insight into brown trout movements and costal dispersal around the Falkland Islands, 25 putative sea trout with a size range between $175 \mathrm{~mm}$ and $545 \mathrm{~mm}$ were captured (by angling) and tagged from San Carlos River (see supplementary material Table S2 for a breakdown of the fish tagged). San Carlos was chosen as it was accessible and surrounded by East and West Falkland rivers with brown trout presence, allowing the movement between the two islands to be detected. All fish were tagged with 9mm ID-2LP9 acoustic transmitters (Thelma Biotel) inserted in the abdominal cavity, following standard surgical tagging procedures (Lacroix et al., 2005). Tags were programmed to transmit every 
SNP analysis and acoustic tagging reveal multiple origins and widespread dispersal of invasive brown trout in the Falkland Islands

180s for approximately 2.5 years, had an acoustic range of $\sim 450 \mathrm{~m}$ and a transmitter failure rate reported by manufacturers $<2 \%$ (Newton et al., 2016). Ten acoustic receivers (VR2W; Vemco Ltd) were deployed in five rivers (two receivers per river; Figure 4.1) configured to record directional movements for a maximum of 23 months, although two receivers were recovered after 11 months. To assess movement within and between islands, acoustic receivers were deployed in three sites on East Falkland and two sites on West Falkland, no range testing was conducted. Detection data was downloaded from all acoustic receivers, exported to Microsoft Excel, and visually examined to determine if any tagged fish had moved between sites, no statistical analysis was conducted.

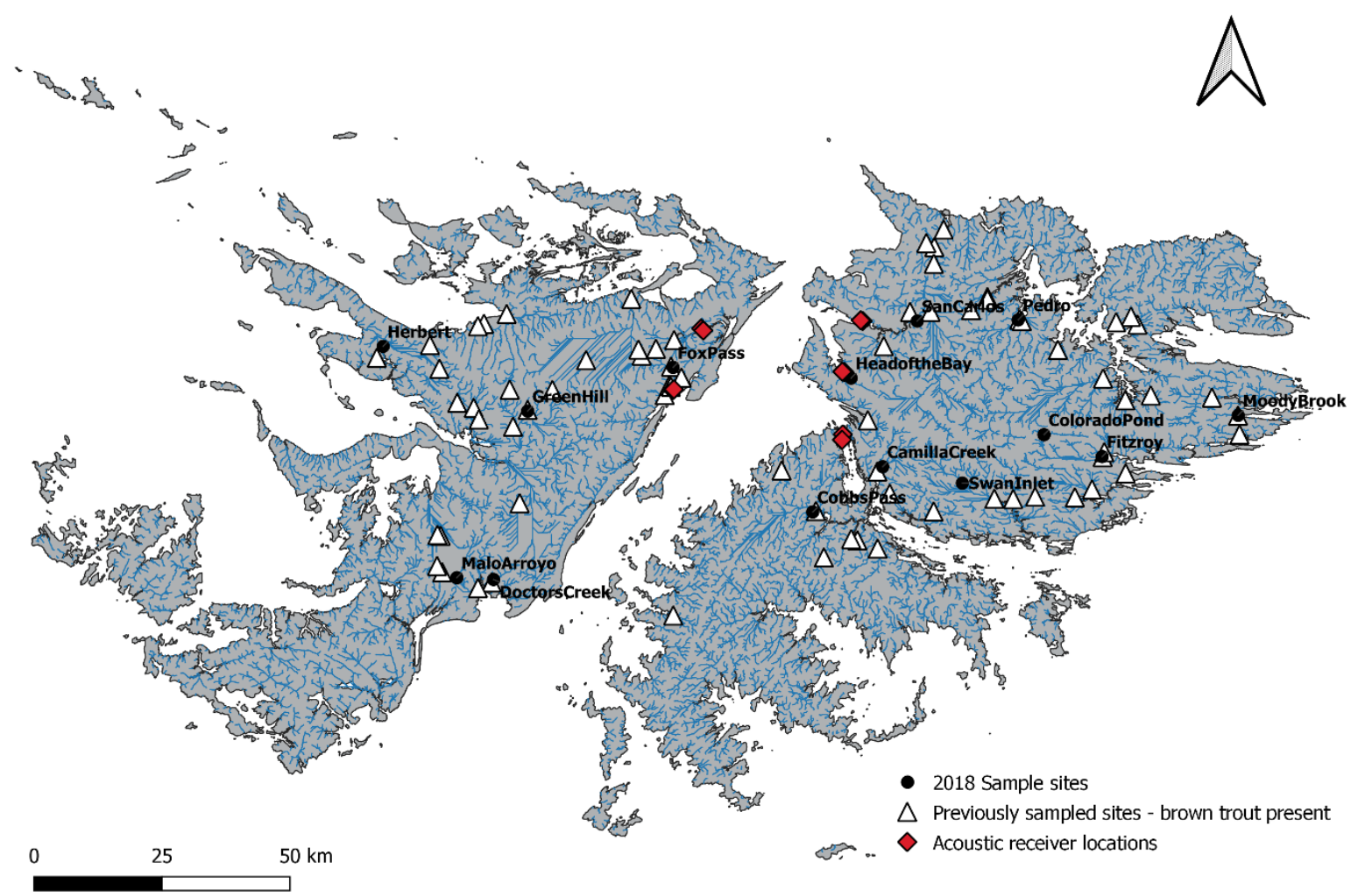

Figure 4.1. Sampling locations for this study in the Falkland Islands (black circles) and sites where brown trout had been previously detected (white triangles) from McDowall et al. (2001), Ross (2009), and Fowler (2013). Sites where acoustic receivers deployed (red diamonds). 
SNP analysis and acoustic tagging reveal multiple origins and widespread dispersal of invasive brown trout in the Falkland Islands

Table 4.1. Details of sampling sites in the Falkland Islands and likely origin of the introduced stocks. Number in brackets corresponds to number of samples for Falklands-GB comparisons when number of samples differed from Falklands only analysis. Seine netting (SN), angling (A), and electrofishing (EF). Surrey trout farm (STF), Pentlands (P), German origin from Chile (G), and Middleton Hatchery $(\mathrm{MH})$.

\begin{tabular}{llllll}
\hline River & $\begin{array}{l}\text { No. brown } \\
\text { trout }\end{array}$ & $\begin{array}{l}\text { No. samples } \\
\text { analysed }\end{array}$ & $\begin{array}{l}\text { Sampling } \\
\text { Method }\end{array}$ & Island & $\begin{array}{l}\text { Introduction } \\
\text { Stock }\end{array}$ \\
\hline Camilla Creek * & 25 & 12 & EF & East Falkland & STF/P \\
Cobbs Pass & 22 & 22 & SN & East Falkland & NA \\
Colorado Pond & 25 & 25 & SN \& A & East Falkland & NA \\
Doctors Creek $*$ & 24 & 24 & EF & West Falkland & STF/P \\
Fitzroy * & 16 & 16 & EF & East Falkland & STF/P \\
Fox Pass & 17 & 16 & EF & West Falkland & NA \\
Green Hill $*$ & 23 & $21(23)$ & EF & West Falkland & STF/P/MH \\
Head of the Bay $*$ & 25 & 25 & EF & East Falkland & STF/P \\
Herbert & 14 & 13 & EF & West Falkland & NA \\
Malo Arroyo & 9 & 9 & EF & West Falkland & NA \\
Moody Brook & 11 & 10 & EF & East Falkland & G \\
Pedro & 25 & 25 & EF & East Falkland & NA \\
San Carlos $*$ & 29 & 14 & A & East Falkland & STF/P/MH \\
Swan Inlet & 25 & 25 & EF \& A & East Falkland & STF/P \\
River Lune & 2 & $(0)$ & & UK & MH \\
River Wey & 12 & $(12)$ & & UK & STF \\
Loch Leven & 14 & $(12)$ & & UK & P \\
Howietoun & 6 & $(6)$ & UK & P \\
\hline
\end{tabular}


SNP analysis and acoustic tagging reveal multiple origins and widespread dispersal of invasive brown trout in the Falkland Islands

\subsection{Results}

Genomic data

Two hundred and sixty-five fish were successfully genotyped from 14 sites (Table 4.1) and 32 fish from three putative origins. After removing invariant SNPs and samples with missing data, 477 SNPs were available for the genetic analysis of 257 trout in the Falkland Islands and 592 SNPs for comparisons with three of the putative origins $(\mathrm{N}=289$ trout). the relatively low number of variable SNPs is likely the result of using an array designed for other salmonid species, possibly combined with the history of the introduced populations, that originated from limited number of stocks of hatchery/farm origin, as reflected in the current population structuring. Low intra-population genetic diversity and high structuring had also been observed in the Falklands brown trout analysed using microsatellites (MonzónArgüello et al., 2014a). Eight SNPs (Ax-87899852, AX-87986668, AX-880117788, AX88166365, omy19_28513692, omy22_31997564, omy22_39402264, omy_28375016) deviated significantly from Hardy-Weinberg equilibrium in four or more sites in the Falkland Islands but were retained as their exclusion did not change the genetic clustering of individuals (Appendix Figure S1a). For Falklands/GB comparisons, nine SNPs (the same as above in addition to AX-88095436) deviated significantly from Hardy-Weinberg equilibrium but were also retained as their exclusion did not affect clustering (Appendix Figure S1b).

\section{Genetic differentiation, isolation by distance and effective population size}

The inbreeding coefficient $\left(\mathrm{F}_{I S}\right)$ was negative for all sampling sites, indicating a small excess of heterozygotes (Table 4.2 and Table 4.3). Overall F FT for all Falklands sites was 0.090. The smallest pairwise genetic distance $\left(\mathrm{F}_{\mathrm{ST}}=0.011\right)$ was observed between Green Hill and Herbert, in contrast the largest pairwise genetic distance $\left(F_{\mathrm{ST}}=0.215\right)$ observed between Cobbs Pass and Colorado Pond (Table 4.3 and Figure 4.2).

Estimates of $\mathrm{N}_{\mathrm{e}}$ based on linkage disequilibrium, ranged from $11.5(95 \% \mathrm{CI}=3-965)$ at Moody Brook to 489 (95\% CI = 167-infinity) at Doctors Creek (Table 4.2).

No significant isolation by distance was found, using either geographic distance around the coast $(\mathrm{r}=0.085 ; p=0.272)$ or Euclidean distance $(\mathrm{r}=-0.042 ; p=0.593)$, for the Falklands together or for West Falkland (coastal distance $\mathrm{r}=-0.084 ; p=0.601$; Euclidean distance $\mathrm{r}=$ 0.144; $p=0.343)$. However, a significant correlation was observed for rivers in East Falkland 
SNP analysis and acoustic tagging reveal multiple origins and widespread dispersal of invasive brown trout in the Falkland Islands

between genetic and coastal distance $(\mathrm{r}=0.391 ; p=0.004)$ but not for Euclidean distance $(\mathrm{r}=$ $0.282 ; p=0.116$ ), suggesting a role for marine dispersal.

Table 4.2. Estimates of genetic diversity (observed heterozygosity, Ho; observed gene diversity, Hs; $\mathrm{F}_{\mathrm{IS}}$, overall $\left.\mathrm{F}_{\mathrm{ST}}\right)$ and effective population size $\left(\mathrm{N}_{\mathrm{e}}\right)$ calculated according to linkage disequilibrium.

\begin{tabular}{lllllll}
\hline Sample Site & Ho & $\mathbf{H s}$ & $\mathbf{F}_{\boldsymbol{I}}$ & $\mathbf{F}_{\text {ST }}$ & Sample size & $\mathbf{N}_{\mathbf{e}}$ \\
\hline Camilla Creek & 0.110 & 0.105 & -0.051 & 0.109 & 12 & inf (inf-inf) \\
Cobbs Pass & 0.106 & 0.095 & -0.126 & 0.254 & 22 & $20.0(10.3-55.9)$ \\
Colorado Pond & 0.095 & 0.088 & -0.080 & 0.195 & 25 & $45.6(27.4-105.3)$ \\
Doctors Creek & 0.125 & 0.116 & -0.078 & 0.009 & 24 & $489.0(167.4-$ inf) \\
Fitzroy & 0.115 & 0.104 & -0.106 & 0.116 & 16 & $221.5(47.2$-inf) \\
Fox pass & 0.121 & 0.109 & -0.116 & 0.073 & 16 & $41.1(10.6$-inf) \\
Green Hill & 0.116 & 0.110 & -0.055 & 0.064 & 21 & $149.0(52.8$-inf) \\
Head of the Bay & 0.115 & 0.105 & -0.098 & 0.108 & 25 & $70.6(36.5-357.7)$ \\
Herbert & 0.114 & 0.114 & -0.002 & 0.029 & 13 & inf $(112.6$-inf) \\
Malo Arroyo & 0.109 & 0.104 & -0.046 & 0.114 & 9 & inf $(265.9$-inf) \\
Moody Brook & 0.108 & 0.104 & -0.035 & 0.116 & 10 & $11.5(3.0-965.3)$ \\
Pedro & 0.120 & 0.114 & -0.050 & 0.028 & 25 & $130.7(69.4-698.0)$ \\
San Carlos & 0.129 & 0.121 & -0.061 & -0.032 & 14 & $16.3(7.1-80.5)$ \\
Swan Inlet & 0.112 & 0.109 & -0.033 & 0.077 & 25 & $111.9(60.3-521.4)$ \\
\hline
\end{tabular}


SNP analysis and acoustic tagging reveal multiple origins and widespread dispersal of invasive brown trout in the Falkland Islands

Table 4.3. Pairwise $\mathrm{F}_{\mathrm{ST}}$ values for Falkland Islands sample sites, calculated according to Weir and Cockerham.

\begin{tabular}{|c|c|c|c|c|c|c|c|c|c|c|c|c|c|}
\hline & $\begin{array}{l}\text { Camilla } \\
\text { Creek }\end{array}$ & $\begin{array}{l}\text { Cobbs } \\
\text { Pass }\end{array}$ & $\begin{array}{l}\text { Colorado } \\
\text { Pond }\end{array}$ & $\begin{array}{l}\text { Doctors } \\
\text { Creek }\end{array}$ & Fitzroy & $\begin{array}{l}\text { Fox } \\
\text { Pass }\end{array}$ & $\begin{array}{l}\text { Green } \\
\text { Hill }\end{array}$ & $\begin{array}{l}\text { Head of } \\
\text { the Bay }\end{array}$ & Herbert & $\begin{array}{l}\text { Malo } \\
\text { Arroyo }\end{array}$ & $\begin{array}{l}\text { Moody } \\
\text { Brook }\end{array}$ & Pedro & $\begin{array}{l}\text { San } \\
\text { Carlos }\end{array}$ \\
\hline Cobbs Pass & 0.133 & & & & & & & & & & & & \\
\hline Colorado Pond & 0.172 & 0.215 & & & & & & & & & & & \\
\hline Doctors Creek & 0.083 & 0.100 & 0.121 & & & & & & & & & & \\
\hline Fitzroy & 0.146 & 0.181 & 0.027 & 0.083 & & & & & & & & & \\
\hline Fox pass & 0.074 & 0.143 & 0.170 & 0.065 & 0.127 & & & & & & & & \\
\hline Green Hill & 0.069 & 0.103 & 0.126 & 0.025 & 0.095 & 0.072 & & & & & & & \\
\hline Head of the Bay & 0.101 & 0.136 & 0.172 & 0.075 & 0.137 & 0.055 & 0.083 & & & & & & \\
\hline Herbert & 0.049 & 0.105 & 0.115 & 0.020 & 0.080 & 0.066 & 0.011 & 0.069 & & & & & \\
\hline Malo Arroyo & 0.122 & 0.168 & 0.177 & 0.089 & 0.146 & 0.130 & 0.088 & 0.149 & 0.093 & & & & \\
\hline Moody Brook & 0.093 & 0.169 & 0.153 & 0.071 & 0.106 & 0.091 & 0.064 & 0.096 & 0.062 & 0.109 & & & \\
\hline Pedro & 0.067 & 0.109 & 0.132 & 0.050 & 0.092 & 0.078 & 0.031 & 0.088 & 0.027 & 0.086 & 0.044 & & \\
\hline San Carlos & 0.063 & 0.110 & 0.158 & 0.052 & 0.122 & 0.024 & 0.045 & 0.023 & 0.042 & 0.103 & 0.073 & 0.054 & \\
\hline Swan Inlet & 0.068 & 0.061 & 0.141 & 0.037 & 0.111 & 0.074 & 0.036 & 0.081 & 0.039 & 0.096 & 0.077 & 0.052 & 0.049 \\
\hline
\end{tabular}


SNP analysis and acoustic tagging reveal multiple origins and widespread dispersal of invasive brown trout in the Falkland Islands



Figure 4.2. Cluster dendrogram of Falkland Islands sites, based on Nei’s distance.

Genetic cluster identification, admixture, and gene flow

Results of the DAPC analysis support four genetically distinct genetic clusters of brown trout in the Falkland Islands $(\mathrm{K}=4 \mathrm{BIC}=1983.383$; Figure 4.3 and Figure 4.4a). Cobbs Pass largely formed its own cluster, cluster 1 , which contained 25 individuals including a few from Swan Inlet. One cluster (cluster 2) contained 41 individuals from Colorado Pond and Fitzroy and was well differentiated from the rest of the sampling sites (Table 4.4). Another cluster (cluster 3) consisted of 61 individuals primarily from Fox Pass, Head of the Bay and San Carlos. The remaining fish formed cluster 4, which contained 130 individuals from all sampling sites except Colorado Pond, Fox Pass and Head of the Bay. All clusters were clearly distinct (Figure 4.5a). The lowest pairwise distance was observed between cluster 1 and cluster 4 (F $F_{\text {ST }}$ of 0.081$)$, and the largest between cluster 1 and cluster 2 (FST of 0.202 , Table 4.4). 
SNP analysis and acoustic tagging reveal multiple origins and widespread dispersal of invasive brown trout in the Falkland Islands

A

Value of BIC versus number of clusters



B

Number of clusters

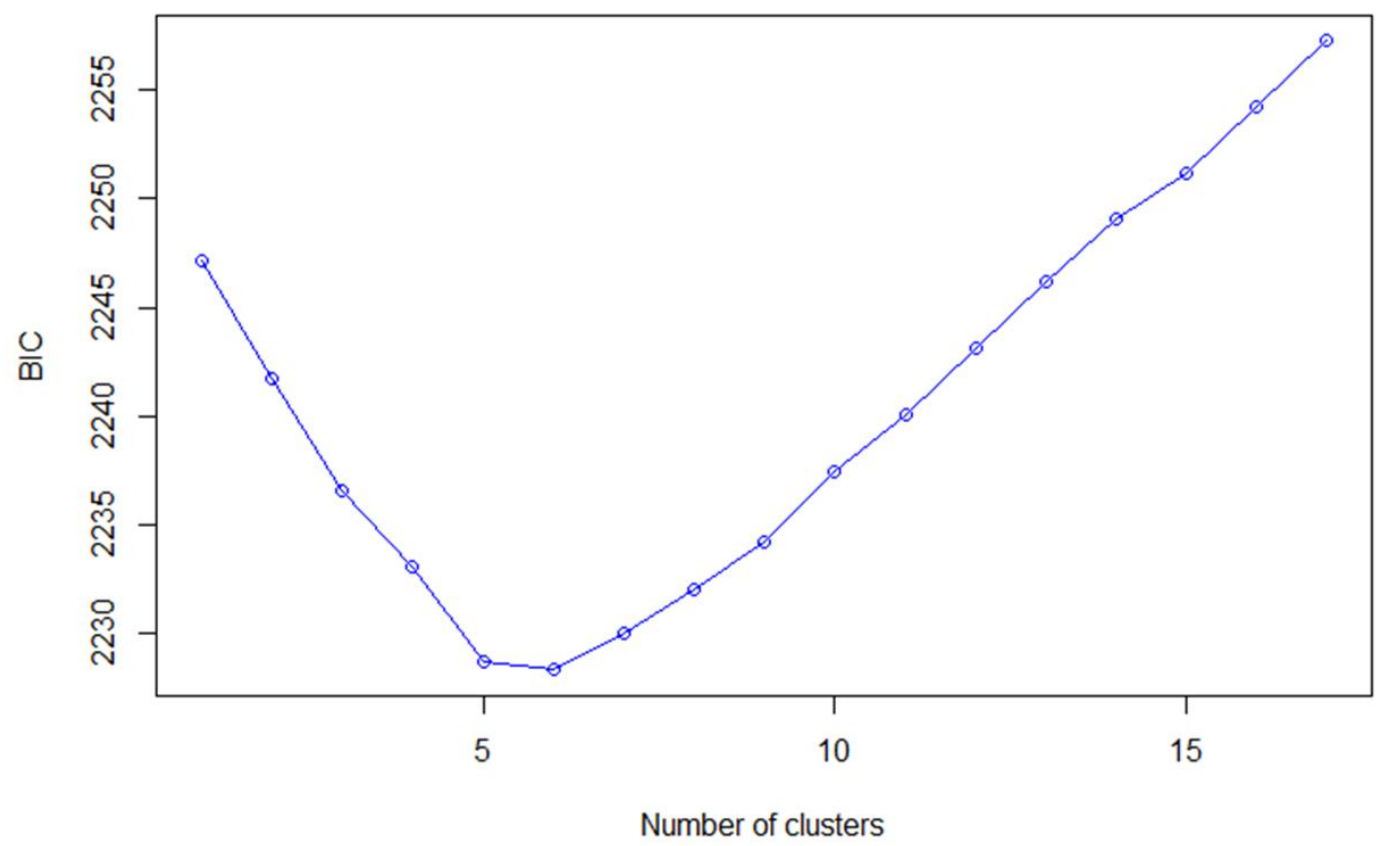

Figure 4.3. Bayesian Information Criterion (BIC) values for the different number of clusters in (A) Falkland Islands only data (optimal $\mathrm{K}=4$ ) and (B) Falkland Islands GB comparisons (optimal $\mathrm{K}=5$ ). 


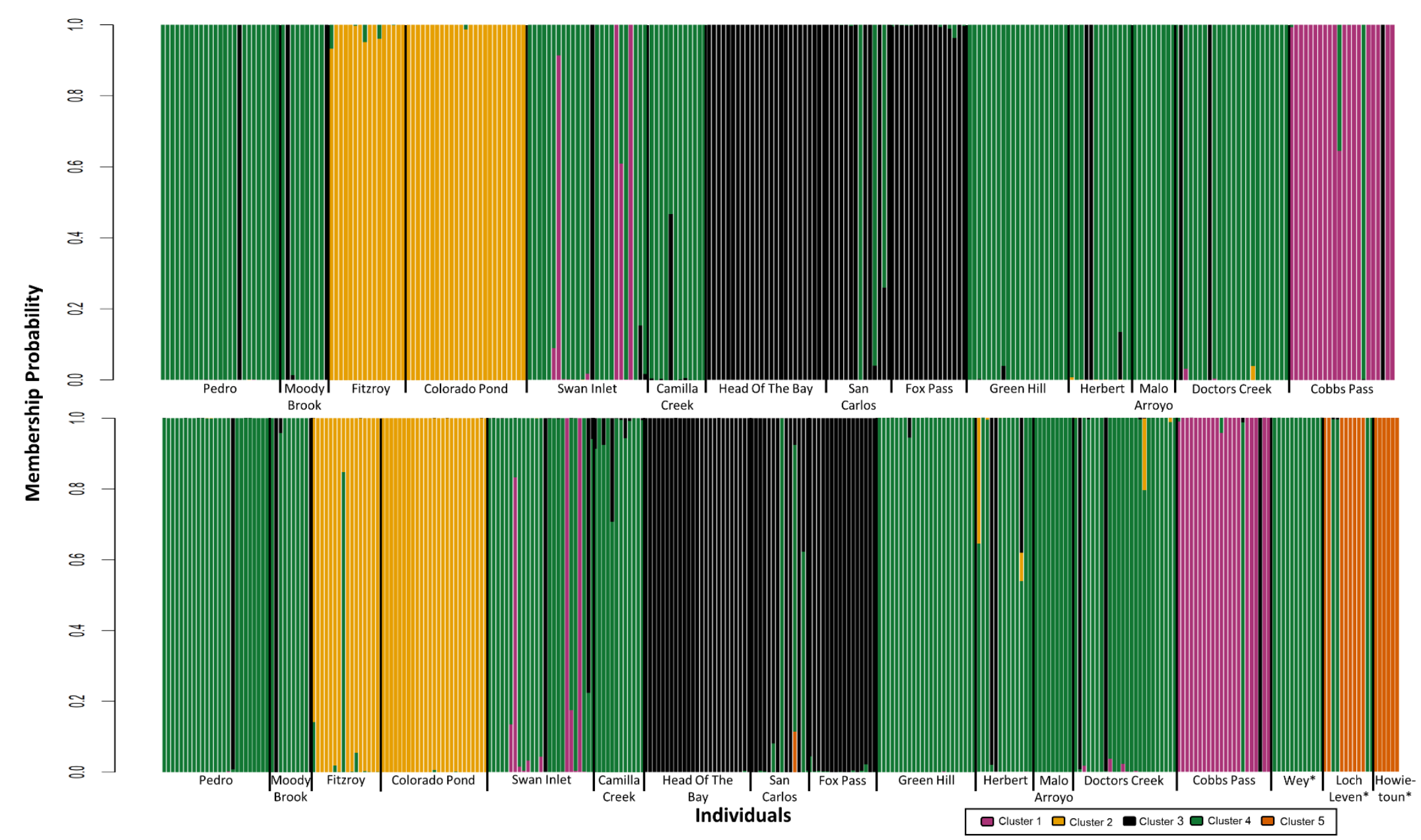

Figure 4.4. Discriminant Analysis of Principle Components (DAPC) analysis of population structure for (A) Falkland Islands brown trout based on 477 SNPs and $\mathrm{K}=4$ and (B) Falkland Islands and GB brown trout based on 592 SNPs and $\mathrm{K}=5$. Each bar corresponds to an individual and colours represent genetic clusters. (*) Indicate GB sites. 
SNP analysis and acoustic tagging reveal multiple origins and widespread dispersal of invasive brown trout in the Falkland Islands

Only six individuals from five sites displayed evidence of admixture between the distinct genetic backgrounds (clusters), mostly between clusters 3 and 4 and between clusters 1 and 4 , with the greatest number of admixed individuals being from Swan Inlet (Figure 4.4). Admixed individuals included 9\% F1 hybrids and 0.6\% - 28\% backcrosses (Figure 4.6).

Estimates of migration rates were consistent with the DAPC analysis (Table 4.5 and Figure 4.7). The greatest inferred gene flow was between Head of the Bay and San Carlos ( $\mathrm{Nm}=$ $1.00)$, while Malo Arroyo was the only clearly isolated site $(\mathrm{Nm} \leq 0.26)$.

Table 4.4. Pairwise $\mathrm{F}_{\mathrm{ST}}$ values for cluster $(\mathrm{K}=4)$ of Falkland Islands samples, calculated according to Weir and Cockerham.

\begin{tabular}{llll}
\hline & Cluster 1 & Cluster 2 & Cluster 3 \\
\hline Cluster 2 & 0.202 & & \\
Cluster 3 & 0.122 & 0.136 & \\
Cluster 4 & 0.081 & 0.088 & 0.046 \\
\hline
\end{tabular}


SNP analysis and acoustic tagging reveal multiple origins and widespread dispersal of invasive brown trout in the Falkland Islands

Table 4.5. Relative migration rates for Falkland Islands sample sites, migration rates calculated using Nm.

\begin{tabular}{|c|c|c|c|c|c|c|c|c|c|c|c|c|c|}
\hline & $\begin{array}{l}\text { Camilla } \\
\text { Creek }\end{array}$ & $\begin{array}{l}\text { Cobbs } \\
\text { Pass }\end{array}$ & $\begin{array}{l}\text { Colorado } \\
\text { Pond }\end{array}$ & $\begin{array}{l}\text { Doctors } \\
\text { Creek }\end{array}$ & Fitzroy & Fox Pass & $\begin{array}{l}\text { Green } \\
\text { Hill }\end{array}$ & $\begin{array}{l}\text { Head of } \\
\text { the Bay }\end{array}$ & Herbert & $\begin{array}{l}\text { Malo } \\
\text { Arroyo }\end{array}$ & $\begin{array}{l}\text { Moody } \\
\text { Brook }\end{array}$ & Pedro & $\begin{array}{l}\text { San } \\
\text { Carlos }\end{array}$ \\
\hline Cobbs Pass & & 0.19 & 0.12 & 0.29 & 0.14 & 0.27 & 0.28 & 0.24 & 0.38 & 0.16 & 0.18 & 0.34 & 0.32 \\
\hline Colorado Pond & 0.22 & & 0.12 & 0.30 & 0.14 & 0.17 & 0.25 & 0.20 & 0.25 & 0.13 & 0.14 & 0.29 & 0.23 \\
\hline Doctors Creek & 0.16 & 0.13 & & 0.25 & 0.81 & 0.15 & 0.27 & 0.17 & 0.27 & 0.14 & 0.16 & 0.24 & 0.17 \\
\hline Fitzroy & 0.29 & 0.26 & 0.22 & & 0.26 & 0.36 & 0.71 & 0.38 & 0.71 & 0.23 & 0.29 & 0.50 & 0.44 \\
\hline Fox pass & 0.18 & 0.15 & 0.74 & 0.32 & & 0.19 & 0.32 & 0.20 & 0.32 & 0.15 & 0.22 & 0.30 & 0.20 \\
\hline Green Hill & 0.32 & 0.21 & 0.15 & 0.40 & 0.17 & & 0.35 & 0.46 & 0.35 & 0.16 & 0.25 & 0.37 & 0.78 \\
\hline Head of the Bay & 0.35 & 0.27 & 0.21 & 0.89 & 0.25 & 0.33 & & 0.33 & 0.89 & 0.25 & 0.30 & 0.67 & 0.49 \\
\hline Herbert & 0.28 & 0.22 & 0.16 & 0.40 & 0.15 & 0.56 & 0.36 & & 0.37 & 0.14 & 0.28 & 0.36 & 1.00 \\
\hline Malo Arroyo & 0.43 & 0.28 & 0.23 & 0.84 & 0.26 & 0.36 & 0.95 & 0.40 & & 0.22 & 0.32 & 0.64 & 0.50 \\
\hline Moody Brook & 0.16 & 0.14 & 0.13 & 0.24 & 0.14 & 0.16 & 0.24 & 0.16 & 0.21 & & 0.17 & 0.26 & 0.20 \\
\hline Pedro & 0.22 & 0.15 & 0.17 & 0.25 & 0.19 & 0.22 & 0.31 & 0.23 & 0.28 & 0.17 & & 0.44 & 0.26 \\
\hline San Carlos & 0.36 & 0.25 & 0.20 & 0.54 & 0.26 & 0.31 & 0.68 & 0.32 & 0.62 & 0.24 & 0.36 & & 0.43 \\
\hline Swan Inlet & 0.25 & 0.23 & 0.15 & 0.35 & 0.17 & 0.48 & 0.34 & 0.49 & 0.35 & 0.16 & 0.25 & 0.37 & \\
\hline
\end{tabular}


SNP analysis and acoustic tagging reveal multiple origins and widespread dispersal of invasive brown trout in the Falkland Islands
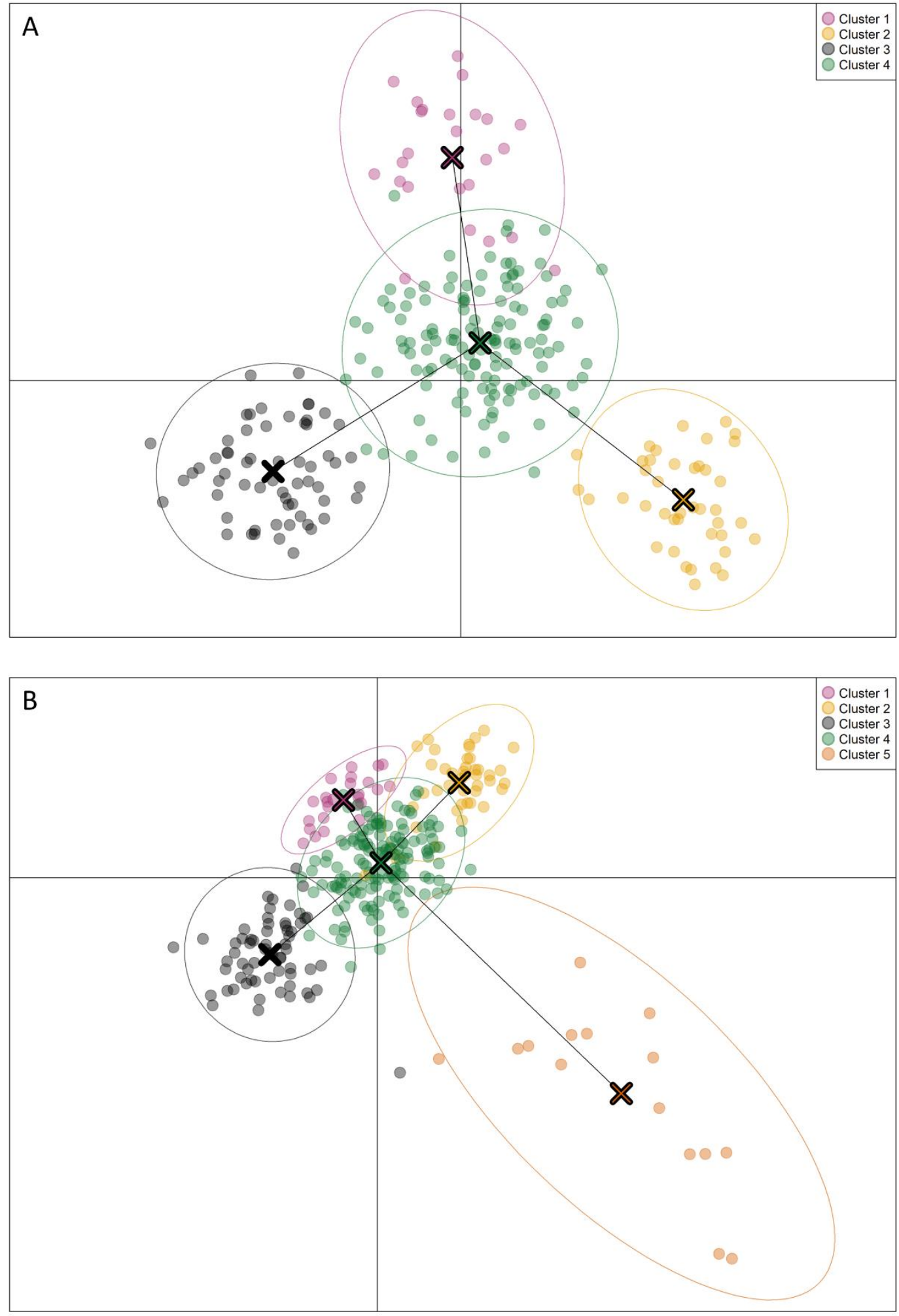

Figure 4.5. Discriminant Analysis of Principle Components (DAPC) for (A) Falkland Islands brown trout based on 477 SNPs and K $=4$ and (B) Falkland Islands and GB brown trout based on 592 SNPs and $\mathrm{K}=5$. Dots represent individuals and colours represent genetic clusters. 
SNP analysis and acoustic tagging reveal multiple origins and widespread dispersal of invasive brown trout in the Falkland Islands
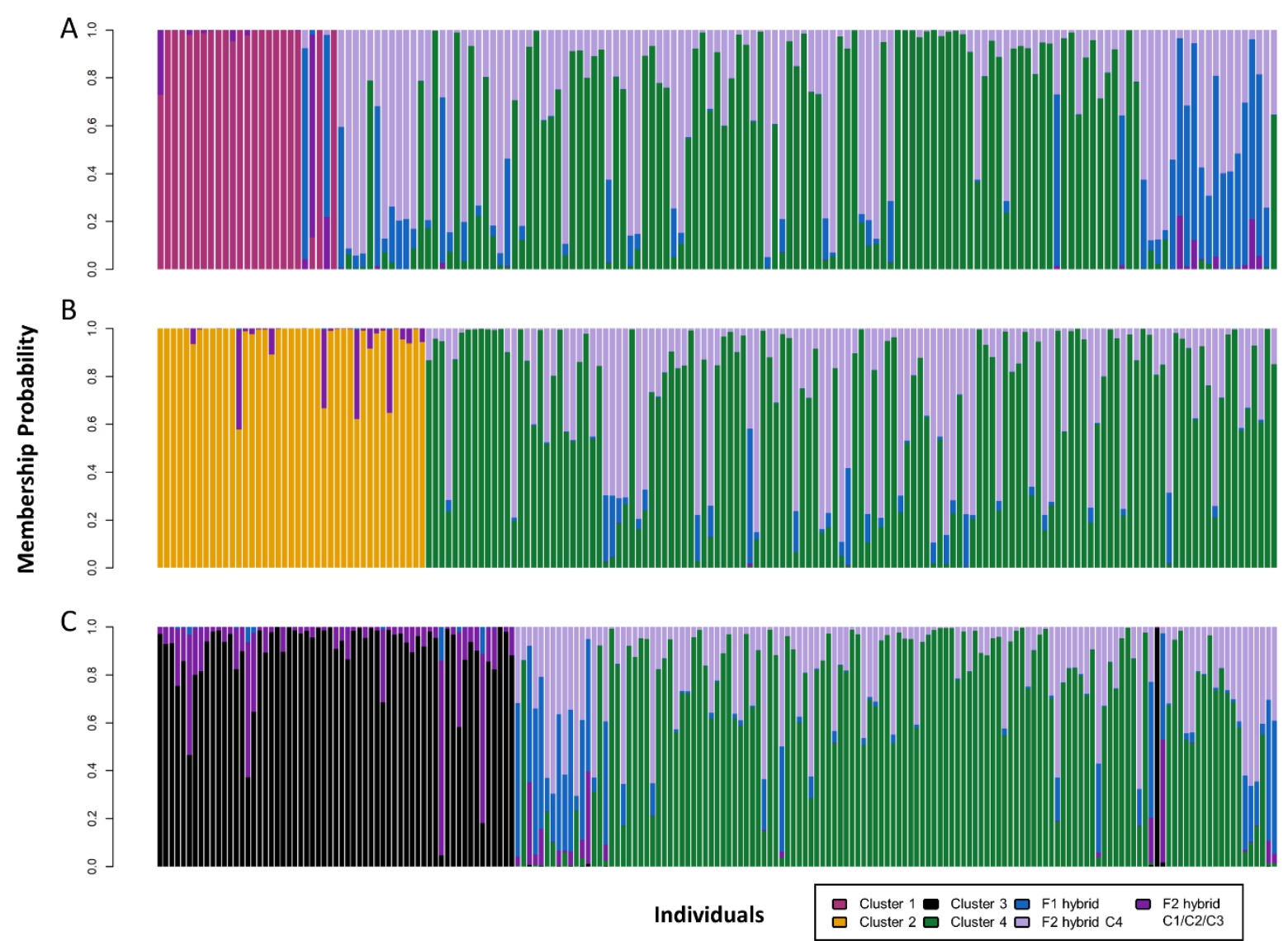

Figure 4.6. Population structure of Falkland Islands brown trout when F1 hybrids and F2 backcrosses are accounted for. Hybridisation analysed between (A) cluster 1 and 4, (B) cluster 2 and 4, and (C) cluster 3 and 4. Bars represent individuals and colours represent cluster and hybrid group. 
SNP analysis and acoustic tagging reveal multiple origins and widespread dispersal of invasive brown trout in the Falkland Islands

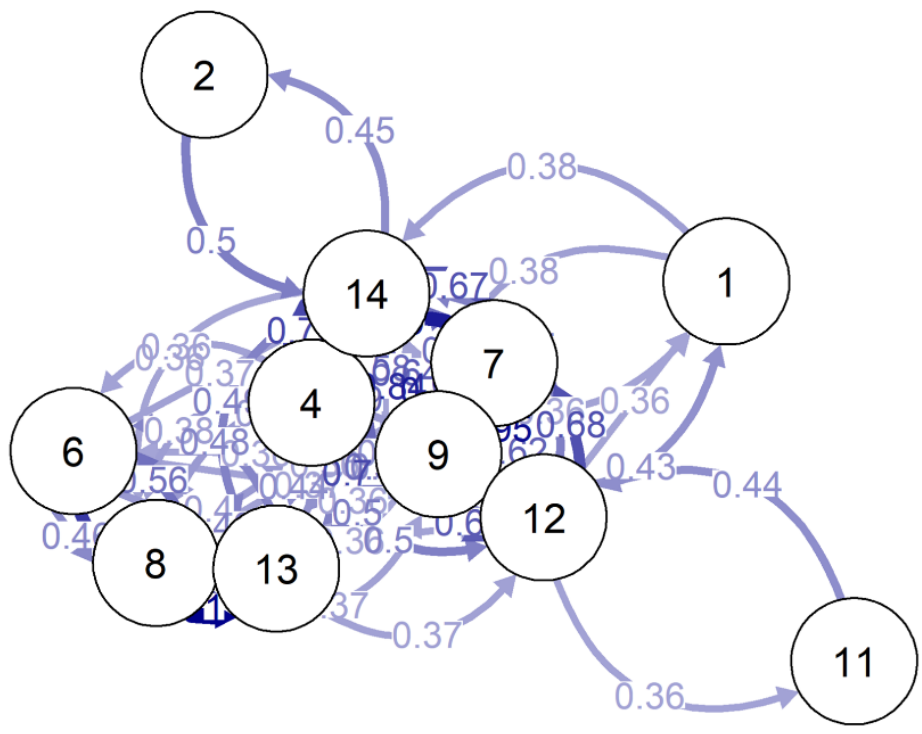

1: Camilla Creek

2: Cobbs Pass

3: Colorado Pond

4: Doctors Creek

5: Fitzroy

6: Fox Pass

7: Green Hill

8: Head of the Bay

9: Herbert

10: Malo Arroyo

11: Moody Brook

12: Pedro

13: San Carlos

14: Swan Inlet

10

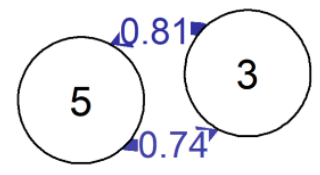

Figure 4.7. Relative migration network among Falkland Islands sampled rivers/lakes, migration rates calculated using Nm, threshold set to 0.35 .

\section{Genetic assignment to putative populations of origin}

The results of the DAPC analysis of samples from both the Falkland Islands and Great Britain indicated the existence of five genetically distinct clusters (Figure 4.4b and Figure 4.5b), the 4 clusters identified in Falklands-only analysis and one additional cluster (5), which consisted of individuals from Loch Leven and the Howietoun hatchery (Figure 4.4). Trout from the River Wey, representative of the Surrey trout farm, were included in cluster 4, suggesting that they could be the origin of the trout populations in Camilla Creek, Doctors Creek, Green Hill, Herbert, Malo Arroyo, Moody Brook, Pedro, and Swan Inlet. Despite Loch Leven samples forming part of cluster 5, four of the 12 individuals belonged to cluster 4, suggesting Loch Leven as another possible source of these populations. The smallest genetic distance was between cluster 2 and $4\left(\mathrm{~F}_{\mathrm{ST}}=0.047\right)$ and the greatest between cluster 1 (Falklands) and 5 (Great Britain) $\left(\mathrm{F}_{\mathrm{ST}}=0.205\right.$, Table 4.6). 
SNP analysis and acoustic tagging reveal multiple origins and widespread dispersal of invasive brown trout in the Falkland Islands

Table 4.6. Pairwise $F_{S T}$ values for cluster $(K=5)$ of Falkland Islands-GB comparisons, calculated according to Weir and Cockerham.

\begin{tabular}{lllll}
\hline & Cluster 1 & Cluster 2 & Cluster 3 & Cluster 4 \\
\hline Cluster 2 & 0.117 & & & \\
Cluster 3 & 0.193 & 0.131 & & \\
Cluster 4 & 0.079 & 0.047 & 0.082 & \\
Cluster 5 & 0.205 & 0.167 & 0.185 & 0.129 \\
\hline
\end{tabular}

\section{Acoustic tracking}

Movements of 12 fish (mean length 365mm) in San Carlos were detected (Table 4.7), three of which also moved to Head of the Bay (separated by $26 \mathrm{~km}$ around the coast), confirming the migration between different rivers through marine dispersal. The remaining 13 fish (mean length $367 \mathrm{~mm}$ ) were not detected on any of the acoustic receivers. Of the three fish that were detected in both San Carlos and Head of the Bay, two fish moved from San Carlos to Head of the Bay and back. A third fish moved between the two sites twice and was detected around Head of the Bay initially for 22 days before being detected in San Carlos 26 days later. 
SNP analysis and acoustic tagging reveal multiple origins and widespread dispersal of invasive brown trout in the Falkland Islands

Table 4.7. Breakdown of acoustic receiver detection data in the Falklands Islands at three sites.

\begin{tabular}{|c|c|c|c|c|c|c|c|}
\hline Receiver & River & Date range & Transmitter ID & No. of detections & Total No. of detections & Latitude & Longitude \\
\hline VR2W-132982 & San Carlos & $\begin{array}{l}18 / 02 / 19-12 / 11 / 20 \\
20 / 01 / 19-16 / 11 / 19 \\
20 / 02 / 19-25 / 02 / 19 \\
28 / 11 / 19-02 / 01 / 20 \\
29 / 12 / 19-03 / 01 / 20 \\
24 / 02 / 19-18 / 10 / 20 \\
20 / 01 / 19-17 / 02 / 19 \\
20 / 01 / 19-16 / 02 / 19 \\
08 / 03 / 19-12 / 12 / 19 \\
23 / 01 / 20 \\
12 / 11 / 19\end{array}$ & $\begin{array}{l}\text { A69-1303-4439 } \\
\text { A69-1303-4441 } \\
\text { A69-1303-4448 } \\
\text { A69-1303-4450 } \\
\text { A69-1303-4453 } \\
\text { A69-1303-4454 } \\
\text { A69-1303-4457 } \\
\text { A69-1303-4458 } \\
\text { A69-1303-4459 } \\
\text { A69-1303-4460 } \\
\text { A69-1303-4461 }\end{array}$ & $\begin{array}{l}4 \\
209 \\
635 \\
8 \\
115 \\
3 \\
97 \\
1488 \\
6 \\
1 \\
1\end{array}$ & 2567 & -51.5069 & -58.9757 \\
\hline VR2W-132983 & San Carlos & $\begin{array}{l}18 / 02 / 19 \\
20 / 01 / 19-17 / 11 / 19 \\
21 / 01 / 19-22 / 02 / 19 \\
28 / 11 / 19-03 / 01 / 20 \\
29 / 12 / 19-03 / 01 / 20 \\
27 / 01 / 19-01 / 02 / 19 \\
20 / 01 / 19-15 / 02 / 19 \\
01 / 02 / 19-12 / 12 / 19 \\
05 / 11 / 19-23 / 01 / 20 \\
12 / 11 / 19 \\
12 / 12 / 19\end{array}$ & $\begin{array}{l}\text { A69-1303-4439 } \\
\text { A69-1303-4441 } \\
\text { A69-1303-4448 } \\
\text { A69-1303-4450 } \\
\text { A69-1303-4453 } \\
\text { A69-1303-4457 } \\
\text { A69-1303-4458 } \\
\text { A69-1303-4459 } \\
\text { A69-1303-4460 } \\
\text { A69-1303-4461 } \\
\text { A69-1303-4466 }\end{array}$ & $\begin{array}{l}1 \\
51 \\
14 \\
6 \\
39 \\
29 \\
836 \\
4 \\
4 \\
1 \\
1\end{array}$ & 986 & -51.5057 & -58.9811 \\
\hline VR2W-132983 & Head of the Bay & $\begin{array}{l}10 / 11 / 19 \\
09 / 11 / 19 \\
04 / 12 / 19-09 / 11 / 20\end{array}$ & $\begin{array}{l}\text { A69-1303-4439 } \\
\text { A69-1303-4454 } \\
\text { A69-1303-4460 }\end{array}$ & $\begin{array}{l}2 \\
1 \\
25\end{array}$ & 28 & -51.5947 & -59.0370 \\
\hline
\end{tabular}


SNP analysis and acoustic tagging reveal multiple origins and widespread dispersal of invasive brown trout in the Falkland Islands

\subsection{Discussion}

This analysis revealed the presence of four genetically distinct clusters of invasive brown trout in the Falkland Islands, likely reflecting their different origins, although the effects of founder effects on the structuring cannot be discarded. The four clusters had high levels of genetic diversity and low levels of admixture, although high levels of gene flow were detected between rivers within each cluster. Relatively variable effective population sizes $\left(\mathrm{N}_{\mathrm{e}}\right.$ ranging from 12 to 489 ) were also observed, with high 95\% confidence intervals in several cases, potentially due to low sample sizes (Do et al., 2014b). These estimates were greater than those estimated by a previous study 10 years ago, for which $\mathrm{N}_{\mathrm{e}}$ ranged between 16-46 (Monzón-Argüello et al., 2014a). The difference in $\mathrm{N}_{\mathrm{e}}$ could reflect the expansion of brown trout in the Falklands, potentially aided by marine dispersal as evidenced from the estimates of the number of migrants, supported by acoustic tagging. However, this comparison must be treated with caution as there were differences in the molecular markers and methods used in both studies (microsatellites and maximum likelihood in 2014, SNPs and linkage disequilibrium method here), as well as in the target populations. Yet, both the current and previous analysis identified strong population structuring, lack of isolation by distance as well as the presence of anadromous trout (Monzón-Argüello et al., 2014a).

Putative F1 and backcrossed individuals were identified between two genetic clusters (cluster 2 and 4) that could have resulted from marine dispersal, but also from admixture with farmed escapees. One of the rivers in cluster 2 (Fitzroy) is close to the location where sea trout are being farmed in open net sea cages since 2013, initially with locally captured brood stock from Camilla Creek (cluster 4), and then with ova imported from Howietoun Hatchery UK in 2014 and 2015. Although I found no direct evidence of mixing between Fitzroy and Howietoun fish, escapes from sea pens are not uncommon in salmonid farming and are the main route of introduction of invasive salmonids in the Southern Hemisphere (Arismendi et al., 2009; Consuegra et al., 2011; Monzón-Argüello et al., 2014a). Thus, the presence of farmed fish in close proximity to naturalised populations could have resulted in admixture, as for rainbow trout in Chile (Consuegra et al., 2011; Monzón-Argüello et al., 2013), potentially increasing dispersal. Alterations in dispersal patterns can be expected by genetic admixture between wild (naturalised is this case) and captive-bred trout and could apply to this case (Saint-Pé et al., 2018), considering the anadromous nature of the farmed stock. 
SNP analysis and acoustic tagging reveal multiple origins and widespread dispersal of invasive brown trout in the Falkland Islands

The highest level of genetic diversity was observed in trout from the rivers San Carlos and Green Hill. These are the sites with the greatest number of documented introductions and the most diverse origins, including three sources from Great Britain (Arrowsmith and Pentelow, 1965; Stewart, 1973; Fowler, 2013). In comparison, lower genetic diversity was observed in Cobbs Pass, where no fish were stocked and where the population likely represents the result of secondary invasions and natural dispersal, as suggested by earlier studies in the Falkland Islands (Monzón-Argüello et al., 2014b; Monzón-Argüello et al., 2014a) and the Kerguelen Islands, where current genetic diversity largely reflects the pattern of historical introductions (Launey et al., 2010).

The analysis of some of the donor populations from Great Britain suggests that many trout in the Falklands must have originated from the River Wey (representative of the Surrey trout farm) as reported in the early literature (Arrowsmith and Pentelow, 1965; Stewart, 1973) and, to a lesser extent possibly from Loch Leven. Although I did not have samples from two other potential sources (Middleton hatchery or Cobbinshaw Loch), the results indicate that trout in the Falklands likely originate from four distinct sources, that can be used to trace new colonisation events. Migration between sampling sites could have been the result of human mediated translocations, as reported by McDowall et al (2001). However, strong sea runs of sea trout have been observed since 1956 (Salmon and Trout Association, 2012) indicating the ability of brown trout to colonize new rivers through marine dispersal (Launey et al., 2010; Westley and Fleming, 2011), a fact also supported by these results from acoustically tagged fish, which were detected moving between two rivers $\sim 26 \mathrm{~km}$ apart (San Carlos and Head of the Bay). A recent study using environmental DNA (eDNA) has detected brown trout in sites where the species had not previously been recorded, suggesting it is continuing to spread across the Falklands (Minett et al., 2020). Without containment measures in place, there is a risk that brown trout may invade the last remaining refuges for the native endangered Aplochiton spp.

Further examination of the movements from acoustically tagged fish in the Falklands is required and ongoing (acoustic receivers have been redeployed and additional fish tagged). Only three for the 25 individuals tagged were detected, this could be due to a variety of reasons, all the fish were tagged in the river and classified as putative sea trout based on their coloration, however, this is not a reliable method to determine if a fish is going to migrate to sea (Youngson et al., 1997; Birnie-Gauvin et al., 2019). In addition, it is possible that some of these fish could have been returning to the river and may have not re-entered the sea after 
SNP analysis and acoustic tagging reveal multiple origins and widespread dispersal of invasive brown trout in the Falkland Islands

tagging (Birnie-Gauvin et al., 2019). Due to time and weather constraints, there was also a delay between tagging the fish (September-October) and deploying the receivers (DecemberFebruary), therefore, some individuals may have travelled downstream and into the marine environment before receivers were deployed and, hence, were not detected.

The popularity of brown trout as a sport fish is common to other countries where it is also highly invasive, such as US or New Zealand (Jones and Closs, 2018), however, awareness of the negative impacts on the native ecosystems is increasing and plans for containment or eradication are starting to be implemented (Saunders et al., 2015; Budy and Gaeta, 2018). Mechanical removal of trout tends to increase the density of small fish (Meyer et al., 2006; Saunders et al., 2015) and is not appropriate management strategy, although they seem to be contained by beaver dams and natural competition at high densities of native fish (Budy and Gaeta, 2018). A combination of molecular markers, eDNA and acoustic tagging, as used here, can be employed to monitor the expansion of brown trout, and put measures in place to limit its dispersal, for example through the installation of selective barriers (Jones et al., 2021b). 


\section{Chapter 5 Stable isotope analysis reveals multiple life history strategies and the extent of migratory brown trout in the Falkland Islands}
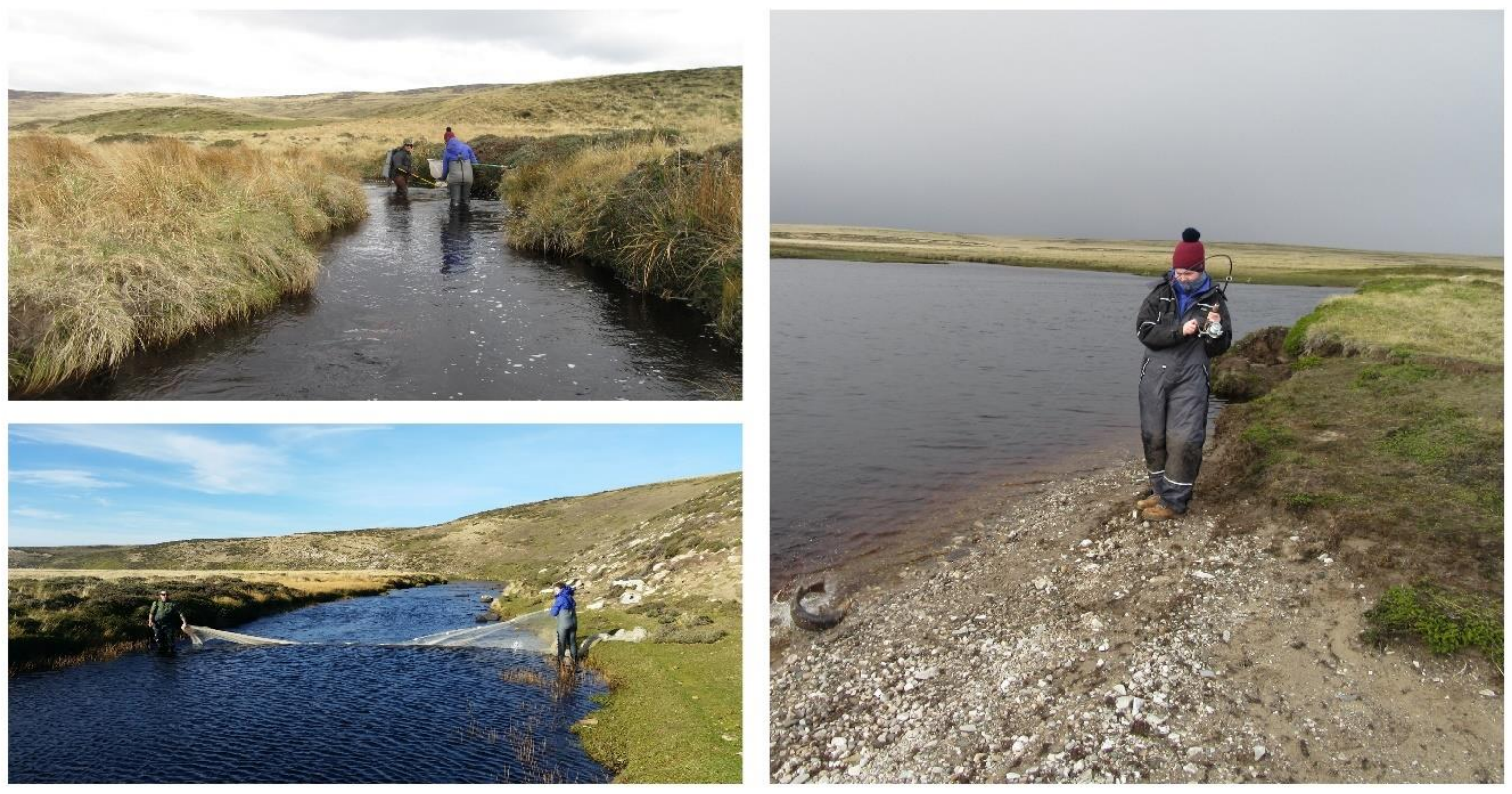

This work is in preparation for publication. 
Stable isotope analysis reveals multiple life history strategies and the extent of migratory brown trout in the Falkland Islands

\subsection{Introduction}

Brown trout possess flexible life history strategies owing to their facultative anadromous nature thus allowing individuals to choose to either complete their whole life cycle in freshwater (resident) or migrate to the marine environment (anadromous), termed partial migration (Ferguson et al., 2019; Marco-Rius et al., 2013). This enables individuals to benefit from better food and reach larger size and fecundity (Ferguson et al., 2016). This plasticity contributes to their resilience to environmental variability and facilitates their adaptability to new environments (Guiry et al., 2020), enabling brown trout to rapidly succeed in colonizing areas where they have been introduced outside of their native range. Hence, brown trout are now found on all continents except Antarctica (MacCrimmon and Marshall, 1968). Introductions of brown trout have caused extensive ecological damage, particularly in the Southern Hemisphere where they have exerted strong negative impacts on native fish and freshwater communities. In New Zealand, brown trout invasions have caused widespread reductions in the abundance and distribution of native galaxiids, mainly due to size-specific predation (McIntosh et al., 1994; McIntosh et al., 2010). In addition, strong predation pressure on invertebrates has caused shifts in community structure resulting in ecosystems dominated by algae (McIntosh and Townsend, 1996; Simon and Townsend, 2003; Townsend, 2003). Thus, due to their impacts on native communities' brown trout have been classified as one of the 100 world's worst invasive species (Lowe et al., 2000).

Brown trout were introduced to 29 watersheds in the Falkland Islands over an 18-year period between 1944-1962 (Arrowsmith and Pentelow, 1965; Stewart, 1973; Fowler, 2013; Minett et al., 2021a). Despite the reduced opportunity for growth in freshwaters in the Falklands due to poor abundance and diversity of invertebrates and low biological productivity brown trout are found in both resident and migratory ecotypes (Stewart, 1973; McDowall et al., 2001; Flower, 2005; Fowler, 2013). Trout have spread throughout East and West Falklands (McDowall et al., 2001; Fowler, 2013; Minett et al., 2021a), with their dispersal aided by marine migration, which has been documented in the Falklands since 1956, even though anadromous stock were only introduced in 1961 (Stewart, 1973; Salmon and Trout Association, 2012; Minett et al., 2021a). Severe impacts have been observed on the native fish community, composed of two Aplochiton spp. (Aplochiton zebra and Aplochiton taeniatus) and the Falklands minnow (Galaxias maculatus), following the introduction of brown trout (McDowall et al., 2001; Vanhaecke et al., 2012b). Aplochiton spp. were previously found in great abundance all over the islands, but they are now limited to a few 
Stable isotope analysis reveals multiple life history strategies and the extent of migratory brown trout in the Falkland Islands

refugia mainly in the south of the East and West Falkland and are now classified as seriously threatened and protected by law (Falkland Islands Government, 1999; McDowall et al., 2001; Ross, 2009). In order to protect these native species, it is imperative to manage brown trout populations in the Falklands, limit any future spread and prevent further invasions, particularly in areas that could be refuges for native Aplochiton spp.

To effectively manage populations, it is important to understand their life history strategies. Salmonids have previously been tracked using a variety of methods including genetics (Chapter 4), tagging and scale reading (Jonsson and Jonsson, 2002; Cunjak et al., 2005; Ferguson et al., 2016; Wollebaek et al., 2018; Ferguson et al., 2019). Although resident and migratory ecotypes can typically be distinguished based on colour, size and body form (i.e., resident fish are usually smaller and brownish whilst migratory fish tend to be silvery in colour and larger in size) identification can be problematic due to considerable overlap in phenotypes, especially as a result of unsmoltified migrants and desmoltification (Eek and Bohlin, 1997; Youngson et al., 1997; Birnie-Gauvin et al., 2019). However, differences between marine and freshwater environments can be detected through analysis of naturally occurring carbon and nitrogen stable isotopes (McCarthy and Waldron, 2000; Charles et al., 2004). Stable isotope analysis (SIA) is normally conducted using muscle tissue, otoliths, or scales, with the tissue chosen depending on the timeframe being analysed and sampling strategy. Whereas muscle tissue reflects shorter term changes, typically weeks to months, depending on the growth and turnover of the tissue, longer-term information can be obtained from otoliths and scales (Perga and Gerdeaux, 2005; Ramsay et al., 2011). However, obtaining muscle tissue and otoliths requires lethal sampling (Graham et al., 2013). Sampling a small fin clip of the adipose fin presents a non-lethal alternative to muscle tissue and has previously been shown to be provide comparable $\delta^{13} \mathrm{C}$ and $\delta^{15} \mathrm{~N}$ values at similar turnover rates (McCarthy and Waldron, 2000; Suzuki et al., 2005; Hanisch et al., 2010; Graham et al., 2013).

Here, the aims were to distinguish between resident and anadromous brown trout in the Falklands using carbon and nitrogen stable isotopes values obtained non-lethally from adipose fins clips, and to use this information to assess the incidence of different migratory ecotypes across the Falkland Islands. 
Stable isotope analysis reveals multiple life history strategies and the extent of migratory brown trout in the Falkland Islands

\subsection{Methods}

\section{Sampling}

A total of 156 brown trout were sampled across 14 rivers and ponds in the Falkland Islands, nine on East Falkland and five on West Falkland (Table 5.1; Figure 5.1). Sampling was conducted throughout two field seasons, April-May 2018 [Autumn] and September-October 2018 [Spring] and coincided with the start and the end of the fishing season (Falkland Islands Government, 1999). Fish were captured using seine netting, angling, or backpack electrofishing (Smith-Root LR-24, 160-280v and 50Hz). Fish were weighted (g) and the fork length $(\mathrm{mm})$ recorded, adipose fin clips and scales were obtained from all fish $>50 \mathrm{~mm}$ before releasing them alive at point of capture. Fin clips were stored in $90 \%$ ethanol and at $-20^{\circ} \mathrm{C}$ for subsequent analysis. In addition, the level of silvery (0-3) was recorded as a proxy for resident/anadromous trout, where $0=$ brown/yellowish colour typical of resident brown trout with no silvering and 3 = almost completely silvery (Dannewitz and Petersson, 2001; Thomson and Lyndon, 2018). Invertebrate samples were obtained for assessment of prey consumption $(\mathrm{N}=11$ sampling sites including Mary Hill Quarry where no trout were included sampled, Table 5.1) and prey items identified to class level (family level where possible) for processing and analysis.

Table 5.1. Summary of samples collected from each site and sample size (N). Electrofishing (EF); seine netting (SN); angling (A). * Sites where invertebrate samples were also collected, ${ }^{+}$sites where Falklands minnows (Galaxias maculatus) were also found.

\begin{tabular}{llll}
\hline Sample site & Date of collection & N & Sampling method \\
\hline Camilla Creek* & September & 12 & EF \\
Cobbs Pass & April/May & 11 & SN \\
Colorado Pond* & April & 25 & SN \& A \\
Doctors Creek* & October & $17^{+}$ & EF \\
Fitzroy* & May & $2^{+}$ & EF \\
Fox Pass & October & 2 & EF \\
Green Hill* & October & 7 & EF \\
Head of the Bay* & September & 17 & EF \\
Herbert* & October & 6 & EF \\
Malo Arroyo* & October & $6^{+}$ & EF \\
Moody Brook* & October & 6 & EF \\
Pedro & May & 4 & EF \\
San Carlos* & September/October & 20 & A \\
Swan Inlet & May/September & 20 & EF \& A \\
\hline
\end{tabular}


Stable isotope analysis reveals multiple life history strategies and the extent of migratory brown trout in the Falkland Islands

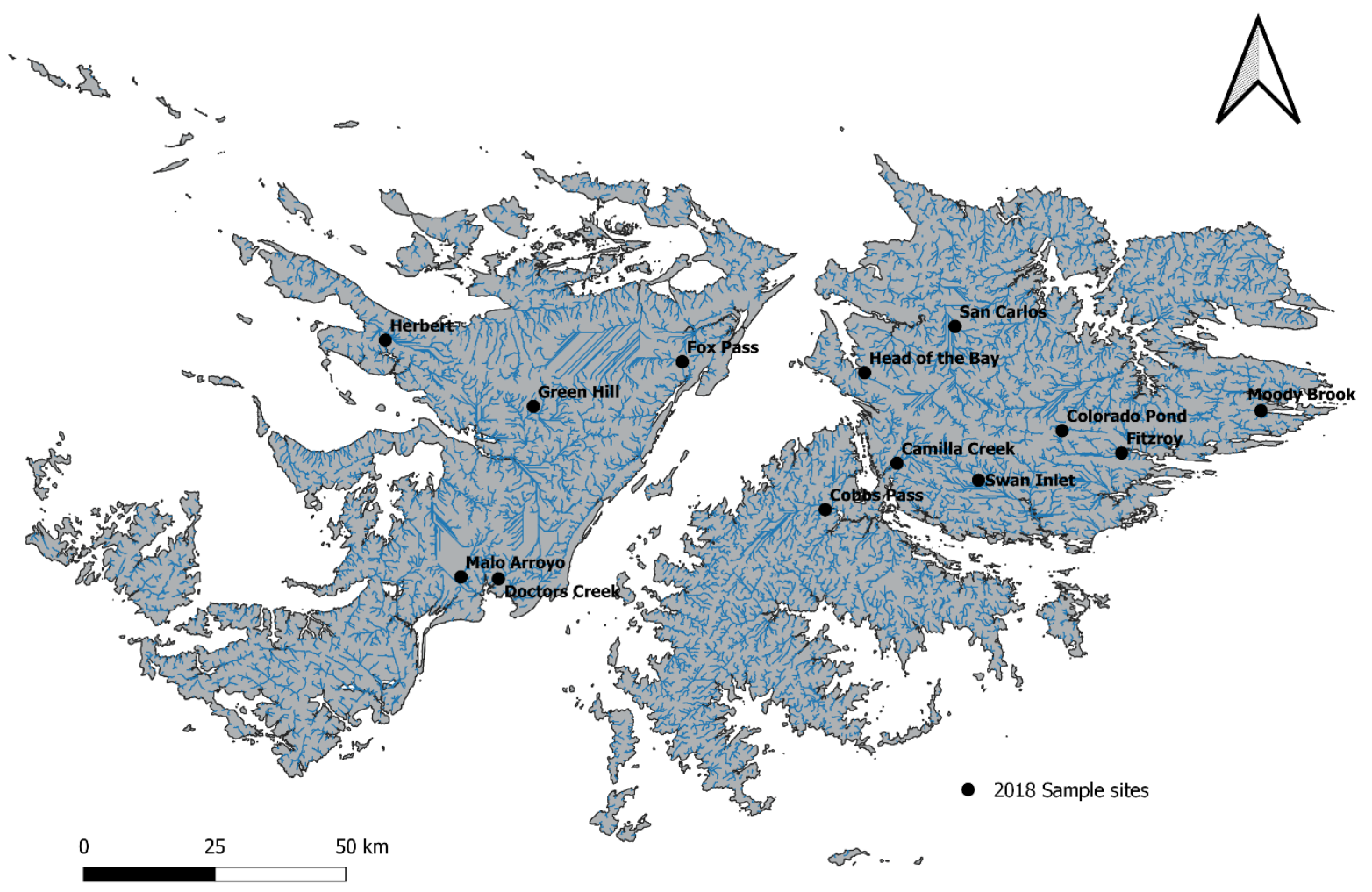

Figure 5.1. Map of sampling locations in the Falkland Islands

Laboratory Analysis

All samples (adipose fin clips and invertebrates) were oven dried at $50^{\circ} \mathrm{C}$ for $48 \mathrm{hrs}$ or until samples reached a constant weight. Dry samples were cut into fine pieces using scissors and ground using a pestle and mortar before weighing $0.5 \mathrm{mg}( \pm 0.05 \mathrm{mg})$ into tin capsules. A mix of invertebrate's present was produced for each sample site as well as a mix of individual invertebrate groups across all sample sites. Samples were combusted in excess oxygen over chrome oxide at $1000^{\circ} \mathrm{C}$ in an ANCA GSL Elemental Analyser interfaced with a Sercon 20/20 Mass Spectrometer (Swansea University) as per (McCarroll and Loader, 2004). Oxides of nitrogen were reduced over hot copper $\left(600^{\circ} \mathrm{C}\right)$ and any traces of water removed using a chemical water trap. Carbon and nitrogen isotope ratios, expressed in delta notation $(\delta)$ as parts per thousand (\%o), were calculated relative to the international standard for ${ }^{13} \mathrm{C}$, the Vienna Pee Dee Belemnite (VPDB) standard (Coplen, 1995), and the standard $\mathrm{N}_{2}$ of the atmosphere (Mariotti, 1983). Acetanilide references (Sigma-Aldrich Co., UK) were analysed between tissue samples to calibrate the machine and compensate for any machine drift. C:N ratios ranged from 2.82 to 3.79 in all brown trout samples. Adipose fin clip samples were not 
Stable isotope analysis reveals multiple life history strategies and the extent of migratory brown trout in the Falkland Islands

lipid normalised as $\mathrm{C}: \mathrm{N}$ ratios were only greater than 3.5 in four out of 156 samples. All $\mathrm{C}: \mathrm{N}$ ratios for invertebrate samples were greater than 3.5, therefore the following lipid normalisation equation was used to derive lipid corrected $\delta^{13} \mathrm{C}$ values as recommended by (Post et al., 2007) for aquatic organisms:

$\delta^{13} \mathrm{C}_{\text {corr. }}=\delta^{13} \mathrm{C}-3.32+0.99 \times \mathrm{C}: \mathrm{N}$

All $\delta^{13} \mathrm{C}$ values reported for invertebrates were lipid-corrected in this way. Recommendations for stable isotope terminology from (Fry, 2006) and (Coplen, 2011) were followed; the term 'enriched' refers to samples with higher $\delta$ values and 'depleted' to samples with lower $\delta$ values.

\section{Data Analysis}

All data analysis was conducted in R 3.5.3 (R Core Team, 2019). Separate linear models were run to compare carbon and nitrogen content, $\delta^{13} \mathrm{C}$ and $\delta^{15} \mathrm{~N}$, in brown trout adipose fin clips using sample site, fork length and level of silvery as predictors, due to the small sample sizes samples from Fitzroy and Fox Pass were excluded from analysis. Correlations between length and $\delta^{13} \mathrm{C}$ or $\delta^{15} \mathrm{~N}$ were also calculated using the cor.test function and spearman method (Best and Roberts, 1975).

To determine if there was any clustering based on the carbon and nitrogen SIA signatures a K-means cluster approach was undertaken using the factoextra and stats packages in $\mathrm{R}$ (Kassambara and Mindt, 2020). The optimal number of clusters (K) was calculated using the fviz_nbclust function using the total within sum of squares (WSS) method, and the clusters were determined with the kmeans function.

Trophic level was calculated for each cluster from $\delta^{13} \mathrm{C}$ and $\delta^{15} \mathrm{~N}$ values, using a one baseline model in the jagsBayesianModel and TPmodel functions in the tRophicPosition R package. These functions use a Markov Chain Monte Carlo Bayesian modelling framework through JAGS (Quezada-Romegialli et al., 2018) and utilise invertebrate samples as baseline values and trophic discrimination factors (Post, 2002). Kruskal-Wallis tests were conducted to compare length, $\delta^{13} \mathrm{C}$ and $\delta^{15} \mathrm{~N}$ values for all clusters using the Kruskal.test function. Where significant differences were found, a pairwise Wilcox test was performed to compare pairs of clusters using the pairwise.wilcox.test function and the $B H$ method to adjust p-values for false discovery (Benjamini and Hochberg, 2007). 
Stable isotope analysis reveals multiple life history strategies and the extent of migratory brown trout in the Falkland Islands

\subsection{Results}

Stable isotope data were successfully obtained for all brown trout samples; however, one sample was removed from analysis due to extremely low $\delta^{13} \mathrm{C}$ and $\delta^{15} \mathrm{~N}$ values. The size of brown trout ranged between 142 and $770 \mathrm{~mm}$ in fork length and stable isotope values ranged from -32 to -10 for $\delta^{13} \mathrm{C}$ and 7 to 20 for $\delta^{15} \mathrm{~N}$.

Twenty-three invertebrate samples were removed from analysis due to errors in analysis or strange $\delta^{13} \mathrm{C}$ and $\delta^{15} \mathrm{~N}$ values. All invertebrates identified had previously been found in the Falkland Islands (Flower, 2001). Invertebrates were identified from Amphipoda, Oligochaeta, Hirudinea, Diptera, Coleoptera, Gastropoda, Plecoptera and Tricoptera (Table S3 for breakdown of invertebrates found at each site).

Sampling site $\left(\delta^{13} \mathrm{C}: \mathrm{df}=11, \mathrm{~F}=39.634, p<0.001 ; \delta^{15} \mathrm{~N}: \mathrm{df}=11, \mathrm{~F}=31.300, p<0.001\right)$, length $\left(\delta^{13} \mathrm{C}: \mathrm{F}=36.634, p=<0.001 ; \delta^{15} \mathrm{~N}: \mathrm{F}=98.895, p<0.001\right)$, and level of silvery $\left(\delta^{13} \mathrm{C}: \mathrm{df}=3\right.$, $\left.\mathrm{F}=13.150, p<0.001 ; \delta^{15} \mathrm{~N}: \mathrm{df}=3, \mathrm{~F}=13.554, p=0.001\right)$ all influenced brown trout $\delta^{13} \mathrm{C}$ and $\delta^{15} \mathrm{~N}$ signatures (Table 5.2 and Table 5.3). A positive correlation was observed between both carbon and nitrogen isotopic signatures and length $\left(\delta^{13} \mathrm{C}\right.$ : rho $=0.63, p<0.001 ; \delta^{15} \mathrm{~N}$ : rho $=$ $0.70, p<0.001$, Figure 5.2a/b), and enriched $\delta^{13} \mathrm{C}$ and $\delta^{15} \mathrm{~N}$ signatures with and increasing level of silvery. 
Stable isotope analysis reveals multiple life history strategies and the extent of migratory brown trout in the Falkland Islands

Table 5.2. Output for $\delta^{13} \mathrm{C}$ model

\begin{tabular}{lllll}
\hline Variable & Estimate & Standard error & $\boldsymbol{t}$ value & $\boldsymbol{p}$ value \\
\hline Intercept & -25.343 & 1.052 & -24.087 & $<0.001$ \\
Cobbs Pass & 1.812 & 1.095 & 1.660 & 0.099 \\
Colorado Pond & -2.542 & 0.905 & -2.810 & 0.006 \\
Doctors Creek & -4.371 & 0.965 & -4.527 & $<0.001$ \\
Green Hill & -2.818 & 1.224 & -2.302 & 0.023 \\
Head of the Bay & 2.635 & 1.004 & 2.625 & 0.010 \\
Herbert & -1.183 & 1.280 & -0.924 & 0.357 \\
Malo Arroyo & -1.838 & 1.253 & -1.467 & 0.145 \\
Moody Brook & -1.313 & 1.263 & -1.039 & 0.301 \\
Pedro & 1.368 & 1.460 & 0.936 & 0.351 \\
San Carlos & 0.816 & 1.076 & 0.759 & 0.449 \\
Swan Inlet & 2.840 & 1.008 & 2.818 & 0.006 \\
Length & 0.010 & 0.003 & 3.704 & $<0.001$ \\
Silvery level 1 & 1.083 & 0.811 & 1.335 & 0.184 \\
Silvery level 2 & 4.278 & 0.791 & 5.410 & $<0.001$ \\
Silvery level 3 & 4.512 & 0.808 & 5.586 & $<0.001$ \\
\hline
\end{tabular}

Table 5.3. Output for $\delta^{15} \mathrm{~N}$ model

\begin{tabular}{lllll}
\hline Variable & Estimate & Standard error & $\boldsymbol{t}$ value & $\boldsymbol{p}$ value \\
\hline Intercept & 6.705 & 0.736 & 9.111 & $<0.001$ \\
Cobbs Pass & 1.347 & 0.766 & 1.771 & 0.079 \\
Colorado Pond & -0.592 & 0.633 & -0.935 & 0.352 \\
Doctors Creek & 0.528 & 0.675 & 0.782 & 0.435 \\
Green Hill & 1.311 & 0.856 & 1.531 & 0.128 \\
Head of the Bay & 2.464 & 0.702 & 3.510 & $<0.001$ \\
Herbert & 1.902 & 0.895 & 2.124 & 0.036 \\
Malo Arroyo & -1.841 & 0.876 & -2.101 & 0.038 \\
Moody Brook & 2.229 & 0.883 & 2.524 & 0.013 \\
Pedro & -0.400 & 1.021 & -0.392 & 0.696 \\
San Carlos & 1.365 & 0.752 & 1.815 & 0.072 \\
Swan Inlet & 1.314 & 0.705 & 1.864 & 0.065 \\
Length & 0.013 & 0.002 & 7.364 & $<0.001$ \\
Silvery level 1 & 1.179 & 0.567 & 2.077 & 0.040 \\
Silvery level 2 & 3.036 & 0.553 & 5.489 & $<0.001$ \\
Silvery level 3 & 3.234 & 0.565 & 5.725 & $<0.001$ \\
\hline
\end{tabular}


Stable isotope analysis reveals multiple life history strategies and the extent of migratory brown trout in the Falkland Islands
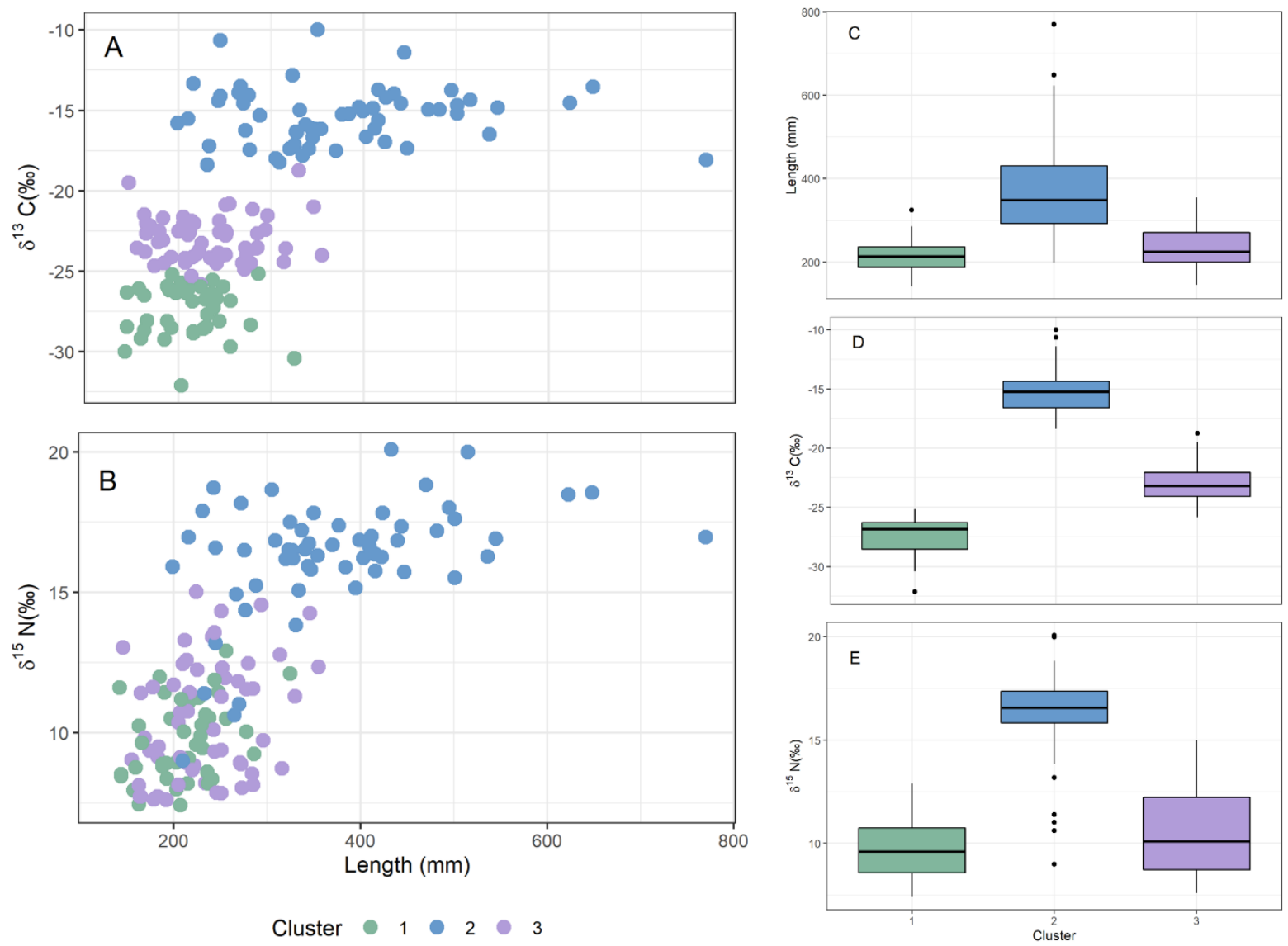

Figure 5.2. Relationship between length and $\delta^{13} \mathrm{C}(\mathrm{A})$ and $\delta^{15} \mathrm{~N}(\mathrm{~B})$, grouped by clusters determined from K-means clustering analysis. Mean and $95 \%$ confidence intervals (whiskers) of length $(\mathrm{C}), \delta^{13} \mathrm{C}$ (D) and $\delta^{15} \mathrm{~N}$ (E) for each cluster. Stable isotope values obtained from adipose fin clips collected from brown trout in the Falkland Islands.

Results of the K-means cluster analysis from adipose fin clips resulted in an optimal $\mathrm{K}$ of three (Table 5.4; Figure 5.3, K $=3$ WSS = 963.654). Cluster 1 contained a total of 40 individuals from six sites, with $78 \%$ of fish in cluster 1 originating from Colorado Pond and Doctors Creek, $43 \%$ and 35\%, respectively. Cluster 2 contained a total of 58 individuals from eight sites, including all individuals from Fitzroy, and San Carlos, with the majority of fish, $66 \%$, derived from Swan Inlet and Head of the Bay, 34\% and 31\% respectively. Cluster 3 contained 57 individuals from 12 sites and contained all individuals from Fox Pass, Malo Arroyo (Table 5.4).

All clusters were clearly distinct (Figure 5.3), with clusters $1\left(\delta^{13} \mathrm{C}=-27 ; \delta^{15} \mathrm{~N}=10\right)$ and 2 $\left(\delta^{13} \mathrm{C}=-15 ; \delta^{15} \mathrm{~N}=16\right)$ exhibiting isotopic signatures typical of freshwater and marine environments, respectively (McCarthy and Waldron, 2000; Ciancio et al., 2008a). Cluster 1 displayed depleted $\delta^{13} \mathrm{C}$ and $\delta^{15} \mathrm{~N}$ values compared to cluster 2, representative of a freshwater background, with cluster 3 exhibiting intermediate values $\left(\delta^{13} \mathrm{C}=-23 ; \delta^{15} \mathrm{~N}=10\right)$, therefore, 
Stable isotope analysis reveals multiple life history strategies and the extent of migratory brown trout in the Falkland Islands

likely reflecting intermediate fish (estuarine/slob trout) (Appendix Table S4). Based on stable isotope values, $26 \%$ and $37 \%$ of the fish sampled were classified as cluster 1 (freshwater resident) and cluster 2 (anadromous), respectively, with the remaining 37\% belonging to intermediate cluster (3) (Table 5.4). In addition, 96\% of the individuals in cluster 2 were classified as a silvery level 2 or 3 , while cluster 1 and 3 contained $37 \%$ and $53 \%$ of individuals classified as a level 0 or 1, respectively (Figure 5.4). The highest trophic level, 4.9, was detected in cluster 2, whereas cluster 1 exhibited the lowest at 3.1 (Table 5.5). Therefore, the different isotopic signatures likely reveal different life history strategies.

Significant variation was observed in length, $\delta^{13} \mathrm{C}$ and $\delta^{15} \mathrm{~N}$ between all clusters (length: $\chi^{2}=$ 75.62, $\left.p=<0.001 ; \delta^{13} \mathrm{C}: \chi^{2}=135.34, p=<0.001 ; \delta^{15} \mathrm{~N}: \chi^{2}=95.90, p=<0.001\right)$. Pairwise comparisons revealed significant variation between all cluster for length (clusters 1 and $2 p=$ $<0.001$; clusters 1 and $3 p=0.041$; clusters 2 and $3 p=<0.001$, Figure 5.2c). In addition, significant variation was observed between clusters 1 and 2 and clusters 2 and 3 when comparing $\delta^{13} \mathrm{C}$ and $\delta^{15} \mathrm{~N}$ (pairwise Wilcox test all $<0.001$, Figure 5.2d/e), whereas cluster 1 and 3 only varied significantly for carbon and not nitrogen $(<0.001$ and 0.14 , respectively, Figure 5.2).

Table 5.4. Life history strategies of Falkland Islands brown trout predicted through K-means cluster analysis based on $\delta^{13} \mathrm{C}$ and $\delta^{15} \mathrm{~N}$ values from adipose fin tissue from 14 sampling sites.

\begin{tabular}{lllll}
\hline Site & $\mathbf{N}$ & $\begin{array}{l}\text { Cluster 1 (resident) } \\
\mathbf{\%}\end{array}$ & $\begin{array}{l}\text { Cluster 2 } \\
\text { (anadromous) } \%\end{array}$ & $\begin{array}{l}\text { Cluster 3 } \\
\text { (intermediate) \% }\end{array}$ \\
\hline Camilla Creek & 12 & 0 & 17 & 83 \\
Cobbs Pass & 11 & 0 & 27 & 73 \\
Colorado Pond & 25 & 68 & 0 & 32 \\
Doctors Creek & 17 & 82 & 6 & 12 \\
Fitzroy & 2 & 0 & 100 & 0 \\
Fox Pass & 2 & 0 & 0 & 100 \\
Green Hill & 7 & 57 & 0 & 43 \\
Head of the Bay & 17 & 6 & 65 & 29 \\
Herbert & 6 & 17 & 17 & 67 \\
Malo Arroyo & 6 & 0 & 0 & 100 \\
Moody Brook & 6 & 50 & 0 & 50 \\
Pedro & 4 & 0 & 0 & 100 \\
San Carlos & 20 & 0 & 100 & 0 \\
Swan Inlet & 20 & 0 & 90 & 10 \\
Overall & 155 & 26 & 37 & 37 \\
\hline
\end{tabular}


Stable isotope analysis reveals multiple life history strategies and the extent of migratory brown trout in the Falkland Islands

Table 5.5. Summary of brown trout stable isotope signatures for cluster 1,2 and 3. Sample size (N), mean Trophic level (TL)

\begin{tabular}{|c|c|c|c|c|c|c|}
\hline Cluster & Isotope & Mean $\delta \%$ & Min, $\max (\delta \%)$ & $\mathbf{N}$ & TL (SD) & Mean length (range) \\
\hline $\begin{array}{l}\text { Cluster 1 } \\
\text { (freshwater) }\end{array}$ & $\begin{array}{l}\delta^{13} \mathrm{C} \\
\delta^{15} \mathrm{~N}\end{array}$ & $\begin{array}{l}-27.46 \\
9.75\end{array}$ & $\begin{array}{l}-32.11,-25.14 \\
7.41,12.90\end{array}$ & 40 & $3.07(0.50)$ & $211.8(142-325)$ \\
\hline $\begin{array}{l}\text { Cluster } 2 \\
\text { (anadromous) }\end{array}$ & $\begin{array}{l}\delta^{13} \mathrm{C} \\
\delta^{15} \mathrm{~N}\end{array}$ & $\begin{array}{l}-15.34 \\
16.32\end{array}$ & $\begin{array}{l}-18.37,-10.66 \\
9.00,20.08\end{array}$ & 58 & $4.95(0.53)$ & $374.8(199-770)$ \\
\hline $\begin{array}{l}\text { Cluster } 3 \\
\text { (intermediate) }\end{array}$ & $\begin{array}{l}\delta^{13} \mathrm{C} \\
\delta^{15} \mathrm{~N}\end{array}$ & $\begin{array}{l}-23.01 \\
10.47\end{array}$ & $\begin{array}{l}-25.81,-18.75 \\
7.61,15.01\end{array}$ & 57 & $3.23(0.49)$ & $233.5(146-355)$ \\
\hline
\end{tabular}

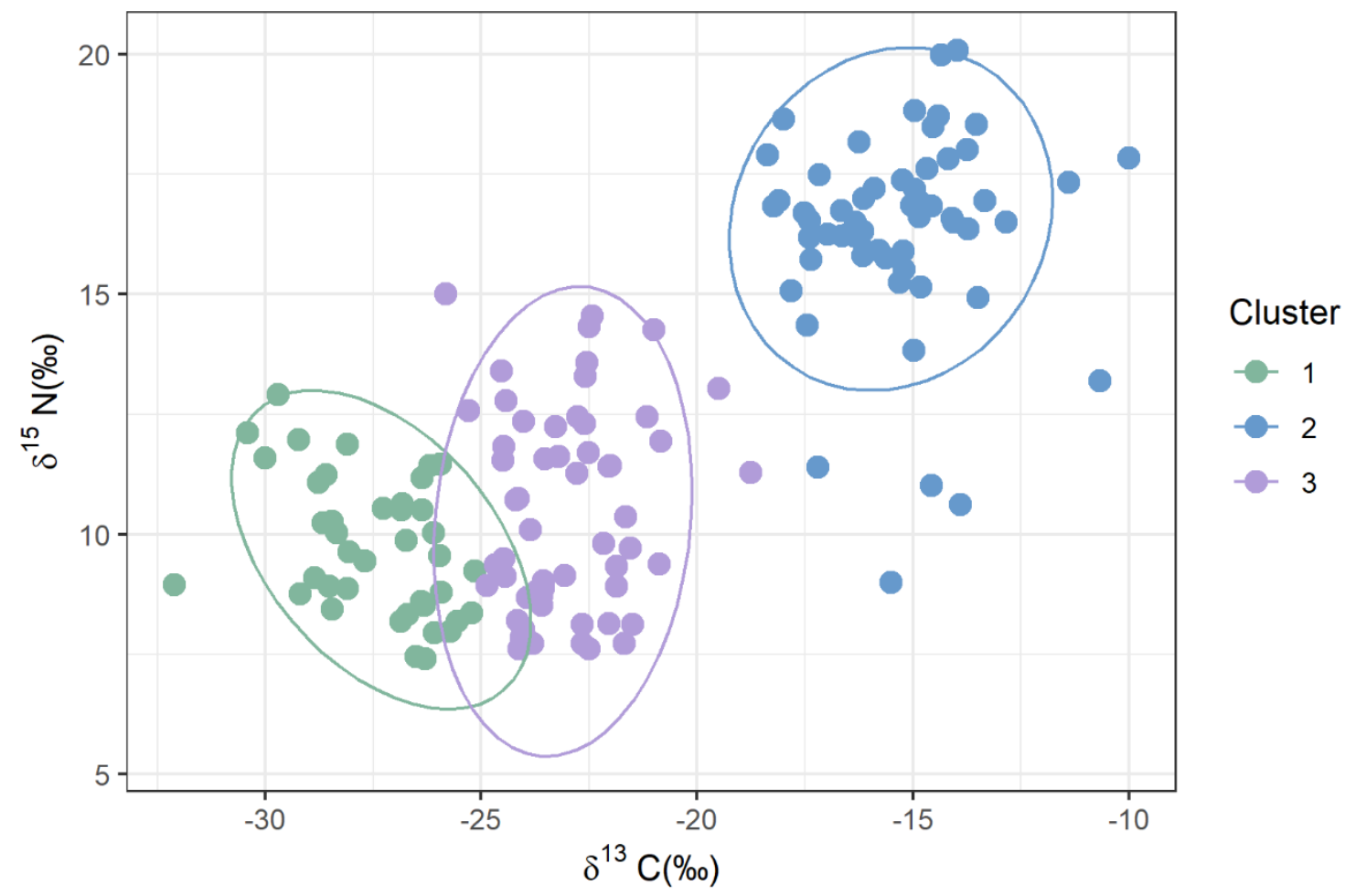

Figure 5.3. Scatter plot of results of $\mathrm{K}$-means cluster analysis using $\delta^{13} \mathrm{C}$ and $\delta^{15} \mathrm{~N}$ stable isotopes found in adipose fin clips of brown trout in the Falkland Islands. 
Stable isotope analysis reveals multiple life history strategies and the extent of migratory brown trout in the Falkland Islands



Figure 5.4. Examples of brown trout from cluster 1 (A), cluster 3 (B), and cluster 2 (C). Brown trout from Head of the Bay, Camilla Creek, and San Carlos, respectively. 
Stable isotope analysis reveals multiple life history strategies and the extent of migratory brown trout in the Falkland Islands

\subsection{Discussion}

The analysis of stable isotopes revealed the presence of three distinct clusters of brown trout in the Falkland Islands, based on $\delta^{13} \mathrm{C}$ and $\delta^{15} \mathrm{~N}$ values from adipose fin clips, likely reflecting their different ecotypes/life history strategies: resident (freshwater), intermediate (estuarine/slob trout), and anadromous (marine). Strong relationships were observed with $\delta^{13} \mathrm{C}$ and $\delta^{15} \mathrm{~N}$ values and length likely reflecting the faster growth of brown trout in the marine environment compared to the relatively poor freshwater environments typical of the Falkland Islands (McDowall et al., 2001; Flower, 2005; Ferguson et al., 2019). Furthermore, migratory (estuarine and marine) brown trout were detected in all sample sites, indicating the potential for brown trout to spread beyond their current distribution in the Falklands, which could possibly cause additional impacts to the already restricted and threatened native galaxiid populations of Aplochiton zebra and A. taeniatus.

A wide range of both carbon and nitrogen stable isotope values were observed, similar to those observed in other studies for both freshwater resident and sea migrating anadromous fish in both native and invasive brown trout populations (McCarthy and Waldron, 2000; Ciancio et al., 2008a; Ciancio et al., 2008b). In addition, an intermediate cluster (cluster 3) was identified, which exhibited enriched $\delta^{13} \mathrm{C}$, mean increase of $4 \%$, yet similar $\delta^{15} \mathrm{~N}$ values compared to freshwater fish, and depleted $\delta^{13} \mathrm{C}$ and $\delta^{15} \mathrm{~N}$ values compared to marine fish, approximately $4 \%$ and 6\%o lower, respectively. Thus, these intermediate isotopic values in fish identified as cluster 3 could be due to estuarine feeding at a similar tropic level to freshwater fish. Estuarine/slob trout have previously been observed in native (McCarthy and Waldron, 2000) and invasive (Ciancio et al., 2008a) populations of brown trout and are thought to arise due to competition for resources. Previous work examining freshwater ecosystems in the Falklands has indicated low biological productivity due to low invertebrate abundance and diversity (McDowall et al., 2001; Flower, 2005), consequently, individuals may adopt an estuarine feeding strategy due to inter- and intraspecific competition for food. All intermediate (cluster 3 ) fish except one were classified as a silvery level 0 or 1 , resident trout have been known to adapt to brackish conditions without undergoing smoltification (McCarthy and Waldron, 2000).

Carbon and nitrogen stable isotope values allow ecotype/life history strategies to be assumed, through information on the source of carbon in the food web $(\delta 13 \mathrm{C})$ and the trophic level at which individuals feed $(\delta 15 \mathrm{~N})$ (McCarthy and Waldron, 2000; Charles et al., 2004). 
Stable isotope analysis reveals multiple life history strategies and the extent of migratory brown trout in the Falkland Islands

However, other more conclusive methods could have been used to determine migratory status with more certainty. For example, examining strontium stable isotope ratios in otoliths, scales or eggs has previously been shown to be able to distinguish between freshwater-resident and marine migrating individuals (Eek and Bohlin, 1997; Zimmerman, 2005; Gibson-Reinemer et al., 2009; Kristensen et al., 2011). It was not possible to examine strontium in these samples due to limited tissue availability.

Strong relationships between length and $\delta^{13} \mathrm{C}$ and $\delta^{15} \mathrm{~N}$ reflect the use and importance of feeding habitats and strategies. Smaller individuals are more likely to feed in freshwaters and at lower trophic levels while fish that migrated to the marine environment obtained larger sizes. While migration to the marine environment can incur costs from increased risk of predation and physiological changes, it can also provide access to better and more abundant food sources (Klemetsen et al., 2003; Ferguson et al., 2019). The relationship between $\delta^{15} \mathrm{~N}$ enrichment and increasing size was also reflected in the trophic level calculated for each cluster. In a biologically poor freshwater system, dispersal to the marine environment increases the abundance and sources of possible prey (Klemetsen et al., 2003), which would otherwise be limited in freshwaters such as the Falkland Islands due to their limited invertebrate community and presence of few native fish species (McDowall et al., 2001; Flower, 2005). Thus, migrating to the marine environment enables individuals to grow to larger sizes and exhibit increased fecundity (Jensen et al., 2019). Anadromy was first observed in Falklands brown trout 20-years after initial introductions and five years before any stock from anadromous parents was introduced (Arrowsmith and Pentelow, 1965; Stewart, 1973; Minett et al., 2021a). This switch to a migratory ecotype is likely due to changes in freshwater prey, as observed in Patagonia, where brown trout considerably reduced the abundance of native galaxiids and depleted invertebrate biomass through direct predation, consequently, driving fish to migrate to sea in order to obtain sufficient food resources (O’Neal and Stanford, 2011). Similar reductions in both abundance and distribution of native galaxiids (two Aplochiton species) have also been observed in the Falklands following the introduction brown trout. Thus, the migratory life history strategy in the Falklands likely developed as a result of a limited food supply, perhaps due to a reduction in the abundance of native fish, which brown trout have been known to predate on (Arismendi et al., 2009; Ross, 2009), and competition for already limited invertebrate food resources (Flecker and Townsend, 1994; McDowall et al., 2001; Townsend, 2003; Flower, 2005). 
Stable isotope analysis reveals multiple life history strategies and the extent of migratory brown trout in the Falkland Islands

Migratory ecotypes, either estuarine or marine migrants, were detected in all sample sites, with $74 \%$ of fish sampled belonging to a migratory life history strategy. This is consistent with previous work estimating the level of migration and gene flow between the same sites, calculated using single nucleotide polymorphisms (SNPs). Previous SNP analysis (Chapter 4) identified high levels of migration between all sites, indicating the potential of widespread migration of brown trout across the Falklands via anadromous dispersal (Minett et al., 2021b). Migratory brown trout are not restricted to certain rivers or introduction sites, therefore, suggesting that all rivers containing brown trout can act a source for future spread, thus increasing the potential for brown trout to invade new areas. Further spread could lead to the invasion of the last known refuges for threatened Aplochiton species, possibly resulting in the extinction of these native fishes in the Falklands (McDowall et al., 2001).

In summary, the presence of three distinct clusters, which correspond to three life history strategies/ecotypes were detected through the analysis of $\delta^{13} \mathrm{C}$ and $\delta^{15} \mathrm{~N}$ stable isotopes from adipose fin clips in brown trout. Although anadromy likely occurred in the Falklands due to limited freshwater productivity, it is now widespread across the Falklands, thus enabling further migration and spread (Launey et al., 2010; Westley and Fleming, 2011). Previous work on invasive brown trout populations in Chile and New Zealand has revealed impacts on invertebrate communities (Townsend, 2003; O’Neal and Stanford, 2011), further work is required in the Falklands to determine the diet of resident, estuarine and anadromous brown trout in the Falklands, and how their presence impacts native fauna. 


\section{Chapter 6 General discussion}

Freshwater ecosystems are home to $\sim 50 \%$ of global fish diversity (Lundberg et al., 2000; Lehner and Do, 2004; Balian et al., 2008; Vega and Wiens, 2012), yet they are experiencing declines in biodiversity at a far greater rate than any terrestrial ecosystem (Collen et al., 2009; World Wildlife Foundation, 2016) and are classified as the most endangered ecosystem in the world (Sala et al., 2000; Dudgeon et al., 2006). Such declines are attributed to many reasons including the introduction of invasive species (Dudgeon et al., 2006; Reid et al., 2019). Despite the impacts brown trout have had on native communities they have been introduced around the world and are now classified as one of the 100 world's worst invasive species (Lowe et al., 2000). Islands, such as the Falklands, provide ideal scenarios to study invasive species, particularly when the introduction history is well known and there are few native species (Ewel and Högberg, 1995). Thus, the Falklands provide an ideal setting to study the invasion ecology of brown trout, with data collected here not only contributing to the conservation of native species in the Falklands but being also relevant to invasive brown trout populations elsewhere.

This thesis aimed to explore the invasion ecology of brown trout in the Falkland Islands in order to assess their current distribution and dispersal to inform management and facilitate the conservation of native galaxiids. First, I developed eDNA assays to detect the presence of brown trout and native Aplochiton species (A. zebra and A. taeniatus), enabling the distribution of invasive brown trout and native Aplochiton spp. populations to be monitored without physical capture, which can be difficult when species are rare or present in low densities (Jerde et al., 2011). Subsequently, I developed a species distribution model to predict the invasion risk of brown trout across the Falklands, demonstrating the importance of human-mediated translocations, and determined the possible effects that varying levels of containment would have on their spread, revealing that brown trout are likely to continue spreading and invade all sites within $\sim 70$ years unless strong containment and strict measures are implemented. Thirdly, I assessed the population structure of brown trout populations in the Falklands and the results indicated high levels of gene flow suggesting widespread migration of brown trout, likely due to anadromous dispersal, as supported by data from acoustically tagged fish. Finally, this thesis examined the life history strategies of brown trout, thus allowing the incidence of anadromy to be uncovered, exposing the extensive 
presence of migratory ecotypes, which likely enable the migration and spread of invasive brown trout in the Falkland Islands.

Work presented in this thesis shows two possible methods that have been employed to enable brown trout to spread from their site of introduction and across East and West Falklands. Species distribution modelling (Chapter 3) revealed the importance of Euclidean distance to the nearest invaded site, representing human-mediated translocations, over distance around the coast, representing natural dispersal through the marine environment. In addition, population genetics (Chapter 4) and stable isotope analysis (Chapter 5) uncovered the importance of anadromy in the Falklands as demonstrated by estimates of gene flow between all sites, the correlation between genetic and geographic distance (distance around the coast), and the prevalence of migratory ecotypes in all sample sites. Intentional releases of brown trout into uninvaded and landlocked sites have previously been reported in the Falkland Islands (McDowall et al., 2001). However, their occurrence is believed to have decreased following the conservation of wildlife and nature ordinance in 1999, making it an offence to transport any protected animal, including brown trout (Falkland Islands Government, 1999). Therefore, it is likely that the most recent spread is due to natural dispersal, as indicated by SNPs and stable isotope analysis.

Without the implementation of sufficient management actions, brown trout will continue to spread and invade all possible sites. Native species have already been severely impacted by the introduction of brown trout, whereas Aplochiton spp. were previously found all over the islands, they now are mainly located in refuges in the South of the Islands (McDowall et al., 2001; Ross, 2009). The continued spread of brown trout is likely to cause additional impacts and further limit the distribution of native species, possibly leading to their extinction on the islands, as was similarly observed with the native grayling Prototroctes oxyrhynchus in New Zealand (McDowall, 2006). Although zebra trout are protected from being deliberately captured and killed, little is known about their current distribution or abundance. Only one species (Aplochiton zebra) is referred to under the current legislation. Distinguishing between A. zebra and A. taeniatus is challenging due to their similar ecology and morphology (McDowall, 2006). A. taeniatus was only identified to be found in the Falklands in 2012, further complicating their conservation as A. taeniatus was found to be more widespread, and therefore A. zebra populations were more at risk than previously believed (Vanhaecke et al., $2012 \mathrm{~b}$ ). In addition, the introduction of brown trout seems to be increasing the occurrence of 
sympatry between both Aplochiton spp., potentially leading to hybridisation, which could cause further declines and their extirpation in the Falklands (Huxel, 1999; Vanhaecke et al., 2012b). Therefore, to conserve native freshwater fauna in the Falklands, it is essential to limit the spread of brown trout and protect native habitats and refugia, which could be achieved through strong and stringent management; see Chapter 2 conclusions and recommendations for possible ways brown trout distribution and spread could be limited.

Furthermore, freshwater ecosystems in the Falklands need to be monitored for future invasions from salmonids from Chile and Patagonia. Chinook (Oncorhynchus tshawytscha, (Fowler, 2013)) and coho salmon (Oncorhynchus kisutch) have already been captured in/around the islands, demonstrating that the Falklands are not completely isolated and have the potential to be invaded by other species.

Without substantial and urgent management, brown trout will continue to spread throughout the Falkland Islands, impacting native freshwater fauna. Despite the recreational and economic opportunities, the introduction of brown trout has brought to the Falklands (Ross, 2009), they have also had major impacts on the native freshwater fish (McDowall et al., 2001), as has also been observed around the world, particularly in the Southern Hemisphere (McDowall, 2003; McDowall, 2006; Young et al., 2010; Elgueta et al., 2013). Although existing legislation makes it illegal to propagate and transport brown trout (Falkland Islands Government, 1964; Falkland Islands Government, 1999), more needs to be done to limit the spread and conserve habitats and refugia for native Aplochiton spp., without which their survival in the Falklands is at risk.

- Brown trout are continuing to spread throughout the Falklands and will likely be distributed throughout the Falklands if management is not put in place. Similar invasion risk models could be conducted in other areas/countries with invasive brown trout populations using similar anthropogenic and bio-climatic variables, enabling information regarding the area's most at risk of invasion and those areas that would likely benefit from management to be determined.

- Using a combination of markers (both SNPs and stable isotopes) it was possible to reveal the importance of anadromy in the Falklands, uncovering that all occupied sites could act as a potential source for future invasions. Such methods could enable brown trout in newly invaded sites to be traced back to source populations, thus, allowing 
management measures, such as the use of selective barriers, to be implemented to limit their dispersal.

- The use of environmental DNA assays, such as those developed here, allows for the detection of invasive and rare species without the need for visual confirmation which can be difficult when species are at low densities. These markers could be used to determine the distribution of brown trout and native zebra trout both in the Falklands and in Chile. Such information is essential for monitoring these threatened and protected native species and could be used and built upon to evaluate the extinction risk of zebra trout.

\section{Suggested management actions}

- Increase public awareness of the impacts from salmonid invasions and the importance of conserving native galaxiid populations.

- Implement more stringent legislation to prevent the deliberate movement and release of brown trout around the islands, and to prevent further importation of brown trout.

- Deploy exclusion barriers around Aplochiton spp. refugia to prevent and reduce the risk of brown trout invading these sites. However, the impacts of installing such barriers need to be carefully monitored to ensure that they do not negatively impact native galaxiids.

- Angling regulations: remove/increase bag limit and fishing season in areas around Aplochiton spp. refugia/invasion front to slow down the spread of brown trout. Intensive fishing could help eradicate brown trout from these regions and establish a buffer zone between brown trout and Aplochiton spp. populations.

- Set up an eDNA monitoring program to establish the locations of Aplochiton spp. refugia, act as an early warning system for brown trout invasions and invasions of any other salmonid species (e.g., chinook/coho salmon), and to determine whether containment measures are successful.

- Develop a species action plan to aid in the conservation of native Aplochiton spp. and consider designating sites containing Aplochiton spp. as Nature Reserves to protect populations. 


\section{References}

Aarestrup, K., Birnie-Gauvin, K., and Larsen, M.H. (2018) Another paradigm lost? Autumn downstream migration of juvenile brown trout: Evidence for a presmolt migration. Ecol Freshw Fish 27: $513-516$.

Abbott, R.J. (1992) Plant invasions, interspecific hybridization and the evolution of new plant taxa. Trends Ecol Evol 7: 401-405.

Alanärä, A., Burns, M.D., and Metcalfe, N.B. (2001) Intraspecific resource partitioning in brown trout: The temporal distribution of foraging is determined by social rank. J Anim Ecol 70: 980-986.

Allan, J.D., Abell, R., Hogan, Z., Revenga, C., Taylor, B.W., Welcomme, R.L., and Winemiller, K.O. (2005) Overfishing of inland waters. Bioscience 55: 1041-1051.

Alò, D., Correa, C., Arias, C., and Cárdenas, L. (2013) Diversity of Aplochiton fishes (Galaxiidea) and the taxonomic resurrection of A. marinus. PLoS One 8: 1-11.

Amberg, J.J., Mccalla, S.G., Monroe, E., Lance, R., Baerwaldt, K., and Gaikowski, M.P. (2015) Improving efficiency and reliability of environmental DNA analysis for silver carp. J Great Lakes Res 41: $367-373$.

Andersson, E., Nilsson, C., and Johansson, M.E. (2000) Effects of river fragmentation on plant dispersal and riparian flora. River Res Appl 16: 83-89.

Arismendi, I., Penaluna, B.E., Dunham, J.B., García de Leaniz, C., Soto, D., Fleming, I.A., et al. (2014) Differential invasion success of salmonids in southern Chile: Patterns and hypotheses. Rev Fish Biol Fish 24: 919-941.

Arismendi, I., Sanzana, J., and Soto, D. (2011) Seasonal age distributions and maturity stage in a naturalized rainbow trout (Oncorhynchus mykiss Walbaum) population in southern Chile reveal an adfluvial life history. Ann Limnol 47: 133-140.

Arismendi, I., Soto, D., Penaluna, B., Jara, C., Leal, C., and León-Muñoz, J. (2009) Aquaculture, nonnative salmonid invasions and associated declines of native fishes in Northern Patagonian lakes. Freshw Biol 54: 1135-1147.

Arrowsmith, E., and Pentelow, F.T.K. (1965) The introduction of trout and salmon to the Falkland Islands. Salmon Trout Mag 119-129.

Asche, F., Roll, K.H., Sandvold, H.N., Sørvig, A., and Zhang, D. (2013) Salmon aquaculture: larger companies and increased production. Aquac Econ Manag 17: 322-339. 
References

Austin, M. (2007) Species distribution models and ecological theory: A critical assessment and some possible new approaches. Ecol Modell 200: 1-19.

Baigún, C., and Quirós, R. (1985) Introducción de peces exóticos en la República Argentina. Inf Técnicos del Dep Aguas Cont 93.

Balian, E. V., Segers, H., Lévèque, C., and Martens, K. (2008) The freshwater animal diversity assessment: an overview of the results. Hydrobiologia 595: 627-637.

Banha, F., Diniz, A., and Anastácio, P.M. (2019) Patterns and drivers of aquarium pet discharge in the wild. Ecol Indic 106: 105513.

Barnett, A., Redd, K.S., Frusher, S.D., Stevens, J.D., and Semmens, J.M. (2010) Non-lethal method to obtain stomach samples from a large marine predator and the use of DNA analysis to improve dietary information. J Exp Mar Bio Ecol 393: 188-192 http://dx.doi.org/10.1016/j.jembe.2010.07.022.

Bassar, R.D., Letcher, B.H., Nislow, K.H., and Whiteley, A.R. (2016) Changes in seasonal climate outpace compensatory density-dependence in eastern brook trout. Glob Chang Biol 22: 577-593.

Basulto, S. (2003) El largo viaje de los salmones: Una crónica olvidada: propagación y cultivo de especies acuáticas en Chile. Maval Limitada, Santiago, Chile.

Bates, D., Mächler, M., Bolker, B.M., and Walker, S.C. (2015) Fitting linear mixed-effects models using lme4. J Stat Softw 67.

Bayley, P.B., and Peterson, J.T. (2001) An approach to estimate probability of presence and richness of fish species. Trans Am Fish Soc 130: 620-633.

Behrens-Chapuis, S., Malewski, T., Suchecka, E., Geiger, M.F., Herder, F., and Bogdanowicz, W. (2018) Discriminating European cyprinid specimens by barcode high-resolution melting analysis (Bar-HRM) — A cost efficient and faster way for specimen assignment? Fish Res 204: 61-73.

Beja-Pereira, A., Oliveira, R., Alves, P.C., Schwartz, M.K., and Luikart, G. (2009) Advancing ecological understandings through technological transformations in noninvasive genetics. Mol Ecol Resour 9: 1279-1301.

Belletti, B., Garcia de Leaniz, C., Jones, J., Bizzi, S., Börger, L., Segura, G., et al. (2020) More than one million barriers fragment Europe's rivers. Nature 588: 436-441.

Bendall, L.B., Moore A N, A., and Quayle, D. V (2005) The post-spawning movements of migratory brown trout Salmo trutta L. J Fish Biol 67: 809-822.

Benjamini, Y., and Hochberg, Y. (2007) Controlling the false discovery rate: A practical and powerful 
References

approach to multiple testing. $J$ R Stat Soc Ser B 57: 289-300.

Bertelsmeier, C., Ollier, S., Liebhold, A.M., Brockerhoff, E.G., Ward, D., and Keller, L. (2018) Recurrent bridgehead effects accelerate global alien ant spread. Proc Natl Acad Sci U S A 115: 54865491.

Berg, O.K., and Berg, M. (1987) The seasonal pattern of growth of the sea trout (Salmo trutta L.) from the Vardnes river in northern Norway. Aquaculture 62: 143-152.

Best, D.J., and Roberts, D.E. (1975) Algorithm AS 89: The upper tail probabilities of Spearman's Rho. J R Stat Soc 24: 377-379.

Bickford, D., Lohman, D.J., Sodhi, N.S., Ng, P.K.L., Meier, R., Winker, K., et al. (2006) Cryptic species as a window on diversity and conservation. Trends Ecol Evol 22: 148-155.

Biggs, B.J.F., Francoeur, S.N., Huryn, A.D., Young, R., Arbuckle, C.J., and Townsend, C.R. (2000) Trophic cascades in streams: effects of nutrient enrichment on autotrophic and consumer benthic communities under two different fish predation regimes. Can J Fish Aquat Sci 57: 1380-1394.

Biggs, J., Ewald, N., Valentini, A., Gaboriaud, C., Dejean, T., Griffiths, R.A., et al. (2015) Using eDNA to develop a national citizen science-based monitoring programme for the great crested newt (Triturus cristatus). Biol Conserv 183: 19-28.

Bio-Rad (2013) CFX96 Touch $^{\mathrm{TM}}$, CFX96 Touch Deep Well ${ }^{\mathrm{TM}}$, CFX Connect ${ }^{\mathrm{TM}}$, and CFX384 Touch $^{\text {TM }}$ Real-Time PCR Detection Systems - Instruction Manual. Bio-Rad Lab Inc 1-178 http://www.bio-rad.com/webroot/web/pdf/lsr/literature/10021337.pdf.

Birnie-Gauvin, K., and Aarestrup, K. (2019) A call for a paradigm shift: Assumed-to-be premature migrants actually yield good returns. Ecol Freshw Fish 28: 62-68.

Birnie-Gauvin, K., Bordeleau, X., Cooke, S.J., Davidsen, J.G., Eldøy, S.H., Eliason, E.J., et al. (2021) Life-history strategies in salmonids: the role of physiology and its consequences. Biol Rev 96: 23042320 .

Birnie-Gauvin, K., Thorstad, E.B., and Aarestrup, K. (2019) Overlooked aspects of the Salmo salar and Salmo trutta lifecycles. Rev Fish Biol Fish 29: 749-766.

Bivand, R., Keitt, T., and Rowlingson, B. (2019) rgdal: Bindings for the "geospatial" data abstraction library. https://cran.r-project.org/package=rgdal.

Bivand, R., Pebesma, E., and Gomez-Rubio, V. (2013) Applied spatial data analysis with R, second edition. Springer, NY, . https://asdar-book.org/. 
References

Blackman, R.C., Constable, D., Hahn, C., Sheard, A.M., Durkota, J., Hänfling, B., and Handley, L.L. (2017) Detection of a new non-native freshwater species by DNA metabarcoding of environmental samples - first record of Gammarus fossarum in the UK. 12: 177-189.

Bohl, R.J., Henry, T.B., Strange, R.J., and Rakes, P.L. (2009) Effects of electroshock on cyprinid embryos: implications for threatened and endangered fishes. Trans Am Fish Soc 138: 768-776.

Boivin-Delisle, D., Laporte, M., Burton, F., Dion, R., Normandeau, E., and Bernatchez, L. (2021) Using environmental DNA for biomonitoring of freshwater fish communities: Comparison with established gillnet surveys in a boreal hydroelectric impoundment. Environ DNA 3: 105-120.

Bosch, J., Bielby, J., Martin-Beyer, B., Rincón, P., Correa-Araneda, F., and Boyero, L. (2019) Eradication of introduced fish allows successful recovery of a stream-dwelling amphibian. PLoS One 14: $1-9$.

Brandon-Mong, G.J., Gan, H.M., Sing, K.W., Lee, P.S., Lim, P.E., and Wilson, J.J. (2015) DNA metabarcoding of insects and allies: an evaluation of primers and pipelines. Bull Entomol Res 105: $717-727$.

Breiner, F.T., Guisan, A., Bergamini, A., and Nobis, M.P. (2015) Overcoming limitations of modelling rare species by using ensembles of small models. Methods Ecol Evol 6: 1210-1218.

Bridson, P. (2018) Salmon Farming in the Falkland Islands : A review of environmental and social challenges and opportunities. .

Broughton, D.A., and McAdam, J.H. (2005) A checklist of the native vascular flora of the Falkland Islands (Islas Malvinas): New information on the species present, their ecology, status and distribution. J Torrey Bot Soc 132: 115-148.

Brown, G.E., Rive, A.C., Ferrari, M.C.O., and Chivers, D.P. (2006) The dynamic nature of antipredator behavior: Prey fish integrate threat-sensitive antipredator responses within background levels of predation risk. Behav Ecol Sociobiol 61: 9-16.

Brumfield, R.T., Beerli, P., Nickerson, D.A., and Edwards, S. V. (2003) The utility of single nucleotide polymorphisms in inferences of population history. Trends Ecol Evol 18: 249-256.

Budy, P., and Gaeta, J.W. (2018) Brown trout as an invader: A synthesis of problems and perspectives in North America. John Wiley \& Sons Ltd, .

Buisson, L., Thuiller, W., Lek, S., Lim, P., and Grenouillet, G. (2008) Climate change hastens the turnover of stream fish assemblages. Glob Chang Biol 14: 2232-2248. 
References

Burlakova, L.E., Karatayev, A.Y., Karatayev, V.A., May, M.E., Bennett, D.L., and Cook, M.J. (2011) Endemic species: Contribution to community uniqueness, effect of habitat alteration, and conservation priorities. Biol Conserv 144: 155-165.

Buxton, A.S., Groombridge, J.J., Zakaria, N.B., and Griffiths, R.A. (2017) Seasonal variation in environmental DNA in relation to population size and environmental factors. Sci Rep 7: 1-9.

Bylemans, J., Furlan, E.M., Pearce, L., Daly, T., and Gleeson, D.M. (2016) Improving the containment of a freshwater invader using environmental DNA (eDNA) based monitoring. Biol Invasions 18: 3081-3089.

Bylemans, J., Hardy, C.M., Gleeson, D.M., Duncan, R.P., and Furlan, E.M. (2019) A performance evaluation of targeted eDNA and eDNA metabarcoding analyses for freshwater fishes. Environ DNA 2: $402-414$.

Cambray, J.A. (2003) Impact on indigenous species biodiversity caused by the globalisation of alien recreational freshwater fisheries. Aquat Biodivers 217-230.

Campana, S.E., and Neilson, J.D. (1985) Microstructure of fish otoliths. Can J Fish Aquat Sci 42: $1014-1032$.

Capo, E., Spong, G., Königsson, H., and Byström, P. (2019) Effects of filtration methods and water volume on the quantification of brown trout (Salmo trutta) and Arctic char (Salvelinus alpinus) eDNA concentrations via droplet digital PCR. Environ DNA 2: 152-160.

Carlsson, J.E.L., Egan, D., Collins, P.C., Farrell, E.D., Igoe, F., and Carlsson, J. (2017) A qPCR MGB probe based eDNA assay for European freshwater pearl mussel (Margaritifera margaritifera L.). Aquat Conserv Mar Freshw Ecosyst 27: 1341-1344.

Catford, J.A., Jansson, R., and Nilsson, C. (2009) Reducing redundancy in invasion ecology by integrating hypotheses into a single theoretical framework. Divers Distrib 15: 22-40.

Chadderton, W.L. (2001) Management of invasive freshwater fish: striking the right balance! Manag invasive Freshw fish New Zeal Proc a Work hosted by Dep Conserv 71-83.

Charles, K., Roussel, J., and Cunjak, R.A. (2004) Estimating the contribution of sympatric anadromous and freshwater resident brown trout to juvenile production. Mar Freshw Res 55: 185191.

Chu, C., Mandrak, N.E., and Minns, C.K. (2005) Potential impacts of climate change on the distributions of several common and rare freshwater fishes in Canada. Divers Distrib 11: 299-310. 
References

Ciancio, J.E., Pascual, M.A., Botto, F., Amaya-Santi, M., O’Neal, S., Riva Rossi, C., and Iribarne, O. (2008a) Stable isotope profiles of partially migratory salmonid populations in Atlantic rivers of Patagonia. J Fish Biol 72: 1708-1719.

Ciancio, J.E., Pascual, M.A., Botto, F., Frere, E., and Iribarne, O. (2008b) Trophic relationships of exotic anadromous salmonids in the southern Patagonian Shelf as inferred from stable isotopes. Limnol Oceanogr 53: 788-798.

Ciancio, J.E., Pascual, M.A., Lancelotti, J., Rossi, C.M.R., and Botto, F. (2005) Natural colonization and establishment of a chinook salmon, Oncorhynchus tshawytscha, population in the Santa Cruz River, an Atlantic basin of Patagonia. Environ Biol Fishes 74: 219-227.

Coates, B.S., Sumerford, D. V., Miller, N.J., Kim, K.S., Sappington, T.W., Siegfried, B.D., and Lewis, L.C. (2009) Comparative performance of single nucleotide polymorphism and microsatellite markers for population genetic analysis. $J$ Hered 100: 556-564.

Colautti, R.I., and MacIsaac, H.I. (2004) A neutral terminology to define "invasive" species. Divers Distrib 10: 135-141.

Collen, B.E.N., Loh, J., Whitmee, S., Rae, L.M.C., Amin, R., and Baillie, J.E.M. (2009) Monitoring change in vertebrate abundance: the Living Planet Index. Conserv Biol 23: 317-327.

Consuegra, S., Phillips, N., Gajardo, G., and Garcia de Leaniz, C. (2011) Winning the invasion roulette: escapes from fish farms increase admixture and facilitate establishment of non-native rainbow trout. Evol Appl 4: 660-671.

Coplen, T.B. (1995) Discontinuance of SMOW and PDB. Nature 375: 285.

Coplen, T.B. (2011) Guidelines and recommended terms for expression of stable-isotope-ratio and gas-ratio measurement results. Rapid Commun Mass Spectrom 25: 2538-2560.

Correa, C., and Gross, M.R. (2008) Chinook salmon invade southern South America. Biol Invasions 10: 615-639.

Couto, T.B.A., and Olden, J.D. (2018) Global proliferation of small hydropower plants - science and policy. Front Ecol Environ 16: 91-100.

Cowan, C.A., and Peckarsky, B.L. (1994) Diel feeding and positioning periodicity of a grazing mayfly in a trout stream and a fishless stream. Can J Fish Aquat Sci 51: 450-459.

Crawford, S.S., and Muir, A.M. (2008) Global introductions of salmon and trout in the genus Oncorhynchus: 1870-2007. Rev Fish Biol Fish 18: 313-344. 
Crowl, T.A., Townsend, C.R., and McIntosh, A.R. (1992) The impact of introduced brown and rainbow trout on native fish: the case of Australasia. Rev Fish Biol Fish 2: 217-241.

Cunjak, R.A., Roussel, J.M., Gray, M.A., Dietrich, J.P., Cartwright, D.F., Munkittrick, K.R., and Jardine, T.D. (2005) Using stable isotope analysis with telemetry or mark-recapture data to identify fish movement and foraging. Oecologia 144: 636-646.

Dannewitz, J., and Petersson, E. (2001) Association between growth, body condition and antipredator behaviour in maturing and immature brown trout parr. J Fish Biol 59: 1081-1091.

Darling, J.A., and Blum, M.J. (2007) DNA-based methods for monitoring invasive species: a review and prospectus. Biol Invasions 9: 751-765.

David, P., Thébault, E., Anneville, O., Duyck, P.F., Chapuis, E., and Loeuille, N. (2017) Impacts of invasive species on Food Webs: A review of empirical data. Adv Ecol Res 56: 1-60.

Davidsen, J.G., Bordeleau, X., Eldøy, S.H., Whoriskey, F., Power, M., Crossin, G.T., et al. (2021) Marine habitat use and feeding ecology of introduced anadromous brown trout at the colonization front of the sub-Antarctic Kerguelen archipelago. Sci Rep 11: 1-13.

Deiner, K., Bik, H.M., Elvira, M., Seymour, M., Lacoursière-Roussel, A., Altermatt, F., et al. (2017) Environmental DNA metabarcoding: Transforming how we survey animal and plant communities. Mol Ecol 26: 5872-5895.

Deiner, K., Walser, J.C., Mächler, E., and Altermatt, F. (2015) Choice of capture and extraction methods affect detection of freshwater biodiversity from environmental DNA. Biol Conserv 183: 5363.

Deines, A.M., Bbole, I., Katongo, C., Feder, J.L., and Lodge, D.M. (2014) Hybridisation between native Oreochromis species and introduced Nile tilapia $O$. niloticus in the Kafue River, Zambia. African J Aquat Sci 39: 23-34.

Degerman, E., Leonardsson, K., and Lundqvist, H. (2012) Coastal migrations, temporary use of neighbouring rivers, and growth of sea trout (Salmo trutta) from nine northern Baltic Sea rivers. ICES J Mar Sci 69: 971-980.

Deniro, M.J., and Epstein, S. (1981) Influence of diet on the distribution of nitrogen isotopes in animals. Geochim Cosmochim Acta 45: 341-351.

Díaz-Ferguson, E., Herod, J., Galvez, J., and Moyer, G. (2014) Development of molecular markers for eDNA detection of the invasive African jewelfish (Hemichromis letourneuxi): a new tool for monitoring aquatic invasive species in National Wildlife Refuges. Manag Biol Invasions 5: 121-131. 
Do, C., Waples, R.S., Peel, D., Macbeth, G.M., Tillett, B.J., and Ovenden, J.R. (2014a) NeEstimator v2: re-implementation of software for the estimation of contemporary effective population size $(\mathrm{Ne})$ from genetic data. Mol Ecol Resour 14: 209-214.

Do, K.-T., Lee, J.-H., Lee, H.-K., Kim, J., and Park, K.-D. (2014b) Estimation of effective population size using single-nucleotide polymorphism (SNP) data in Jeju horse. J Anim Sci Technol 56: 28.

Doherty, T.S., Glen, A.S., Nimmo, D.G., Ritchie, E.G., and Dickman, C.R. (2016) Invasive predators and global biodiversity loss. Proc Natl Acad Sci U S A 113: 11261-11265.

Doi, H., Inui, R., Akamatsu, Y., Kanno, K., Yamanaka, H., Takahara, T., and Minamoto, T. (2017) Environmental DNA analysis for estimating the abundance and biomass of stream fish. Freshw Biol 62: $30-39$.

Doi, H., Uchii, K., Takahara, T., Matsuhashi, S., Yamanaka, H., and Minamoto, T. (2015) Use of droplet digital PCR for estimation of fish abundance and biomass in environmental DNA surveys. PLoS One 10: 1-11.

Douda, K., Lopes-Lima, M., Hinzmann, M., Machado, J., Varandas, S., Teixeira, A., and Sousa, R. (2013) Biotic homogenization as a threat to native affiliate species: Fish introductions dilute freshwater mussel's host resources. Divers Distrib 19: 933-942.

Du, Z., Wu, Y., Chen, Z., Cao, L., Ishikawa, T., Kamitani, S., et al. (2021) Global phylogeography and invasion history of the spotted lanternfly revealed by mitochondrial phylogenomics. Evol Appl 14: 915-930.

Dudgeon, D., Arthington, A.H., Gessner, M.O., Kawabata, Z.I., Knowler, D.J., Lévêque, C., et al. (2006) Freshwater biodiversity: importance, threats, status and conservation challenges. Biol Rev Camb Philos Soc 81: 163-182.

Dufresnes, C., Pellet, J., Bettinelli-Riccardi, S., Thiébaud, J., Perrin, N., and Fumagalli, L. (2016) Massive genetic introgression in threatened northern crested newts (Triturus cristatus) by an invasive congener (T. carnifex) in Western Switzerland. Conserv Genet 17: 839-846.

Durbec, M., Cavalli, L., Grey, J., Chappaz, R., and Nguyen The, B. (2010) The use of stable isotopes to trace small-scale movements by small fish species. Hydrobiologia 641: 23-31.

Duyke, A.L. Von, Kruger, E., Wijkmark, N., Näslund, J., Hellström, P., and Hellström, M. (2019) Evaluation of environmental DNA (eDNA) collected from tracks in the snow as a means to monitor individual polar bears (Ursus maritimus) in the Chukchi and Beaufort Seas. Research Reports, North Slope Borough Department of Wildlife Management, NSB. DWM. PRR, 1 . 
References

Echelle, A.A., and Echelle, A.F. (1997) Genetic introgression of endemic taxa by non-natives: a case study with Leon Springs pupfish and sheepshead minnow. Conserv Biol 11: 153-161.

Edge, K.A., Townsend, C.R., and Crowl, T.A. (1993) Investigating anti-predator behaviour in three genetically differentiated populations of non-migratory galaxiid fishes in a New Zealand river. New Zeal J Mar Freshw Res 27: 357-363.

Eek, D., and Bohlin, T. (1997) Strontium in scales verifies that sympatric sea-run and stream-resident brown trout can be distinguished by coloration. J Fish Biol 51: 659-661.

Egeter, B., Peixoto, S., Brito, J.C., Jarman, S., Puppo, P., and Velo-Antón, G. (2018) Challenges for assessing vertebrate diversity in turbid Saharan water-bodies using environmental DNA. Genome 61: $807-814$.

Elbrecht, V., Vamos, E.E., Meissner, K., Aroviita, J., and Leese, F. (2017) Assessing strengths and weaknesses of DNA metabarcoding-based macroinvertebrate identification for routine stream monitoring. Methods Ecol Evol 8: 1265-1275.

Elgueta, A., González, J., Ruzzante, D.E., Walde, S.J., and Habit, E. (2013) Trophic interference by Salmo trutta on Aplochiton zebra and Aplochiton taeniatus in southern Patagonian lakes. J Fish Biol 82: $430-443$.

Ellender, B.R., and Weyl, O.L.F. (2014) A review of current knowledge, risk and ecological impacts associated with non-native freshwater fish introductions in South Africa. Aquat Invasions 9: 117-132.

Emenyeonu, L.C., Croxford, A.E., and Wilkinson, M.J. (2018) The potential of aerosol eDNA sampling for the characterisation of commercial seed lots. PLoS One 13: 1-18.

Emery-Butcher, H.E., Beatty, S.J., and Robson, B.J. (2020) The impacts of invasive ecosystem engineers in freshwaters: A review. Freshw Biol 65: 999-1015.

Esa, Y.B., Waters, J.M., and Wallis, G.P. (2000) Introgressive hybridization between Galaxias depressiceps and Galaxias sp D (Teleostei: Galaxiidae) in Otago, New Zealand: Secondary contact mediated by water races. Conserv Genet 1: 329-339.

Etten, J. van (2017) R package gdistance: distances and routes on geographical grids. J Stat Softw 76: $1-21$.

Euzenat, G., Fournel, F., and Richard, A. (1999) Sea trout (Salmo trutta L.) in Normandy and Picardy. In Biology and ecology of the brown and sea trout. Springer, pp. 175-203.

Evans, N.T., Olds, B.P., Renshaw, M.A., Turner, C.R., Li, Y., Jerde, C.L., et al. (2016) Quantification 
References

of mesocosm fish and amphibian species diversity via environmental DNA metabarcoding. Mol Ecol Resour 16: 29-41.

Evans, N.T., Shirey, P.D., Wieringa, J.G., Mahon, A.R., and Lamberti, G.A. (2017) Comparative Cost and Effort of Fish Distribution Detection via Environmental DNA Analysis and Electrofishing. Fisheries 42: 90-99.

Ewel, J.., and Högberg, P. (1995) Experimental studies on islands. Springer Berlin Heidelberg, .

Falkland Islands Government (1964) Trout and Salmon Fishing Regulations 1964. 1-4.

Falkland Islands Government (1999) Conservation of wildlife and nature ordinance 1999. Falkl Islands Gaz Suppl 10: 2-18.

Falkland Islands Government (2015) Trout fishing in the Falkland Islands. .

Faundez, V., Blanco, G., Vázquez, E., and Sánchez, J.A. (1997) Allozyme variability in brown trout Salmo trutta in Chile. Freshw Biol 37: 507-514.

Ferguson, A., Reed, T., McGinnity, P., and Prodöhl, P. (2016) Anadromy in brown trout (Salmo trutta): A review of the relative roles of genes and environmental factors and the implications for management and conservation. In Sea Trout: from Science to Management (Proceedings of the 2nd International Sea Trout Symposium, Dundalk, Ireland, October 2015). Troubador Publishing Ltd.

Ferguson, A., Reed, T.E., Cross, T.F., McGinnity, P., and Prodöhl, P.A. (2019) Anadromy, potamodromy and residency in brown trout Salmo trutta: the role of genes and the environment. $J$ Fish Biol 95: 692-718.

Ficetola, G.F., Miaud, C., Pompanon, F., and Taberlet, P. (2008) Species detection using environmental DNA from water samples. Biol Lett 4: 423-425.

Fielding, A.H., and Bell, J.F. (1997) A review of methods for the assessment of prediction errors in conservation presence/absence models. Environ Conserv 24: 38-49.

Fincel, M.J., Vandehey, J.A., and Chipps, S.R. (2012) Non-lethal sampling of walleye for stable isotope analysis: A comparison of three tissues. Fish Manag Ecol 19: 283-292.

Firmat, C., Alibert, P., Losseau, M., Baroiller, J.F., and Schliewen, U.K. (2013) Successive invasionmediated interspecific hybridizations and population structure in the endangered cichlid Oreochromis mossambicus. PLoS One 8: 1-12.

Fish Loch Leven (2019) History of Loch Leven. http://www.fishlochleven.co.uk/history-of-fishingon-loch-leven/. Accessed April 29, 2019. 
References

Flecker, A.S. (1992) Fish predation and the evolution of invertebrate drift periodicity: evidence from neotropical streams. Ecology 73: 438-448.

Flecker, A.S., and Townsend, C.R. (1994) Community-wide consequences of trout introduction in New Zealand streams. Ecol Appl 4: 798-807.

Flower, R. (2001) Aquatic invertebrates collected from inland waters of the Falkland Islands 2001. https://www.geog.ucl.ac.uk/people/emeritus/roger-flower/research/fi-bril/aquatic-invertebratescollected-from-inland-waters-of-the-falkland-islands- 2001.

Flower, R.J. (2005) A taxonomic and ecological study of diatoms from freshwater habitats in the Falkland Islands, South Atlantic. Diatom Res 20: 23-96.

Fowler, D.M. (2013) Brown trout in the Falklands: origin, life history, and public attitudes to an invasive species.

Fowler, D.M. and Garcia de Leaniz, C. (2012) Assessing the impact of culverts on population connectivity of endangered galaxiid fishes in the Falkland Islands. From Sea to Source. International Guidnace for the Resoration of Fish Migration Highways (ed. by Gough, P., Philipsen, P., Schollema, P.P., and Wanningen, H.) Regional Water Authority Hunze en Aa's Postbus 195, 9640 AD Veendam, The Netherlands, pp. 58-59).

France, R.L., and Peters, R.H. (1997) Ecosystem differences in the trophic enrichment ${ }^{13} \mathrm{C}$ in aquatic food webs. Can J Fish Aquat Sci 54: 1255-1258.

Fry, B. (2006) Stable isotope ecology. Springer, New York.

Fry, B., Baltz, D.M., Benfield, M.C., Fleeger, J.W., Gace, A., Haas, H.L., and Quiñones-Rivera, Z.J. (2003) Stable isotope indicators of movement and residency for brown shrimp (Farfantepenaeus aztecus) in coastal Louisiana marshscapes. Estuaries 26: 82-97.

Furlan, E.M., Gleeson, D., Hardy, C.M., and Duncan, R.P. (2016) A framework for estimating the sensitivity of eDNA surveys. Mol Ecol Resour 16: 641-654.

Gallardo, B., Clavero, M., Sánchez, M.I., and Vilà, M. (2016) Global ecological impacts of invasive species in aquatic ecosystems. Glob Chang Biol 22: 151-163.

García-Díaz, P., Ross, J. V., Ayres, C., and Cassey, P. (2015) Understanding the biological invasion risk posed by the global wildlife trade: Propagule pressure drives the introduction and establishment of Nearctic turtles. Glob Chang Biol 21: 1078-1091.

Garcia de Leaniz, C., Gajardo, G., and Consuegra, S. (2010) From best to pest: changing perspectives 
References

on the impact of exotic salmonids in the southern hemisphere. Syst Biodivers 8: 447-459.

Gertzen, E., Familiar, O., and Leung, B. (2014) Quantifying invasion pathways: Fish introductions from the aquarium trade. Can J Fish Aquat Sci 65: 1265-1273.

Gibson-Reinemer, D.K., Johnson, B.M., Martinez, P.J., Winkelman, D.L., Koenig, A.E., and Woodhead, J.D. (2009) Elemental signatures in otoliths of hatchery rainbow trout (Oncorhynchus mykiss): distinctiveness and utility for detecting origins and movement. Can J Fish Aquat Sci 66: $513-524$

Glova, G.J. (2003) A test for interaction between brown trout (Salmo trutta) and inanga (Galaxias maculatus) in an artificial stream. Ecol Freshw Fish 12: 247-253.

Glova, G.J., and Sagar, P.M. (1993) A further assessment of trophic and spatial inter-relations of galaxiids and salmonids in New Zealand. Ecol Freshw Fish 2: 132-140.

Glova, G.J., Sagar, P.M., and Näslund, I. (1992) Interaction for food and space between populations of Galaxias vulgaris Stokell and juvenile Salmo trutta L. in a New Zealand stream. J Fish Biol 41: 909-925.

Goldberg, C.S., Pilliod, D.S., Arkle, R.S., and Waits, L.P. (2011) Molecular detection of vertebrates in stream water: A demonstration using rocky mountain tailed frogs and Idaho giant salamanders. PLoS One 6: 1-5.

Goldberg, C.S., Turner, C.R., Deiner, K., Klymus, K.E., Thomsen, P.F., Murphy, M.A., et al. (2016) Critical considerations for the application of environmental DNA methods to detect aquatic species. Methods Ecol Evol 7: 1299-1307.

Goudet, J. (2005) HIERFSTAT, a package for R to compute and test hierarchical F-statistics. Mol Ecol Notes 5: 184-186.

Goudet, J., and Jombart, T. (2020) hierfstat: estimation and tests of hierarchical F-statistics. https://github.com/jgx65/hierfstat.

Gozlan, R.E. (2008) Introduction of non-native freshwater fish: Is it all bad? Fish Fish 9: 106-115.

Gozlan, R.E., Britton, J.R., Cowx, I., and Copp, G.H. (2010) Current knowledge on non-native freshwater fish introductions. $J$ Fish Biol 76: 751-786.

Graham, C.T., Harrison, S.S.C., and Harrod, C. (2013) Development of non-lethal sampling of carbon and nitrogen stable isotope ratios in salmonids: effects of lipid and inorganic components of fins. Isotopes Environ Health Stud 49: 555-566. 
References

Greenberg, L.A., Steinwall, T., and Persson, H. (2001) Effect of depth and substrate on use of stream pools by brown trout. Trans Am Fish Soc 130: 699-705.

Grey, J. (2001) Ontogeny and dietary specialization in brown trout (Salmo trutta L.) from Loch Ness, Scotland, examined using stable isotopes of carbon and nitrogen. Ecol Freshw Fish 10: 168-176.

Grill, G., Lehner, B., Thieme, M., Geenen, B., Tickner, D., Antonelli, F., et al. (2019) Mapping the world's free-flowing rivers. Nature 569: 215-221.

Gu, D.E., Ma, G.M., Zhu, Y.J., Xu, M., Luo, D., Li, Y.Y., et al. (2015) The impacts of invasive Nile tilapia (Oreochromis niloticus) on the fisheries in the main rivers of Guangdong Province, China. Biochem Syst Ecol 59: 1-7.

Gu, W., and Swihart, R.K. (2004) Absent or undetected? Effects of non-detection of species occurrence on wildlife - habitat models. Biol Conserv 116: 195-203.

Guillette, L.J., Gross, T.S., Masson, G.R., Matter, J.M., Percival, H.F., and Woodwardff, A.R. (1994) Developmental abnormalities of the gonad and abnormal sex hormone concentrations in juvenile alligators from contaminated and control lakes in Florida. Environ Health Perspect 1980: 680-688.

Guiry, E., Royle, T.C.A., Matson, R.G., Ward, H., Weir, T., Waber, N., et al. (2020) Differentiating salmonid migratory ecotypes through stable isotope analysis of collagen: Archaeological and ecological applications. PLoS One 15: 1-25.

Guo, S.W., and Thompson, E.A. (1992) Performing the exact test of Hardy-Weinberg proportion for multiple alleles. Biometrics 48: 361-372.

Gutiérrez-Pesquara, L.M., Tejedo, M., Olalla-Tárraga, M., Duarte, H., Nicieza, A., and Solé, M. (2016) Testing the climate variability hypothesis in thermal tolerance limits of tropical and temperate tadpoles. J Biogeogr 43: 1166-1178.

Haas, H.L., Freeman, C.J., Logan, J.M., Deegan, L., and Gaines, E.F. (2009) Examining mummichog growth and movement: Are some individuals making intra-season migrations to optimize growth? $J$ Exp Mar Bio Ecol 369: 8-16.

Habit, E., Gonzalez, J., Ruzzante, D.E., and Walde, S.J. (2012) Native and introduced fish species richness in Chilean Patagonian lakes: inferences on invasion mechanisms using salmonid-free lakes. Divers Distrib 18: 1153-1165.

Habit, E., Piedra, P., Ruzzante, D.E., Walde, S.J., Belk, M.C., Cussac, V.E., et al. (2010) Changes in the distribution of native fishes in response to introduced species and other anthropogenic effects. Glob Ecol Biogeogr 19: 697-710. 
Haile, J., Froese, D.G., Macphee, R.D.E., Roberts, R.G., Arnold, L.J., Reyes, A. V, et al. (2009) Ancient DNA reveals late survival of mammoth and horse in interior Alaska. Proc Natl Acad Sci U S A 106: 22352-22357.

Halekoh, U., and Højsgaard, S. (2014) A kenward-Roger approximation and parametric bootstrap methods for tests in linear mixed models-the R package pbkrtest. J Stat Softw 59: 1-32.

Hall, T. (1999) BioEdit: a user-friendly biological sequence alignment editor and analysis program for Windows 95/98/NT. Nucleic Acids Symp Ser 41: 95-98.

Hanisch, J.R., Tonn, W.M., Paszkowski, C.A., and Scrimgeour, G.J. (2010) $\delta^{13} \mathrm{C}$ and $\delta^{15} \mathrm{~N}$ signatures in muscle and fin tissues: nonlethal sampling methods for stable isotope analysis of salmonids. North Am J Fish Manag 30: 1-11.

Hanley, N., and Roberts, M. (2019) The economic benefits of invasive species management. People Nat 1: 124-137.

Hardie, S.A., Jackson, J.E., Barmuta, L.A., and White, R.W.G. (2006) Status of galaxiid fishes in Tasmania, Australia: conservation listings, threats and management issues. Aquat Conserv Mar Freshw Ecosyst 16: 235-250.

Hargrove, J.S., Weyl, O.L.F., Zhao, H., Peatman, E., and Austin, J.D. (2019) Using species-diagnostic SNPs to detail the distribution and dynamics of hybridized black bass populations in southern Africa. Biol Invasions 21: 1499-1509.

Harper, K.J., Goodwin, K.D., Harper, L.R., LaCasella, E.L., Frey, A., and Dutton, P.H. (2020) Finding Crush: Environmental DNA Analysis as a Tool for Tracking the Green Sea Turtle Chelonia mydas in a Marine Estuary. Front Mar Sci 6: 1-13.

Harper, L.R., Lawson Handley, L., Hahn, C., Boonham, N., Rees, H.C., Lewis, E., et al. (2019) Generating and testing ecological hypotheses at the pondscape with environmental DNA metabarcoding: A case study on a threatened amphibian. Environ DNA 00: 1-6.

Harris, C.A., Hamilton, P.B., Runnalls, T.J., Vinciotti, V., Henshaw, A., Hodgson, D., et al. (2011) The consequences of feminization in breeding groups of wild fish. Environ Health Perspect 119: 306311.

He, F., Zar, C., Bremerich, V., Henshaw, A., Darwall, W., Tockner, K., and Jähnig, S.C. (2017) Disappearing giants: a review of threats to freshwater megafauna. WIREs Water 4: 1-14.

Heady, W.N., and Moore, J.W. (2013) Tissue turnover and stable isotope clocks to quantify resource shifts in anadromous rainbow trout. Oecologia 172: 21-34. 
References

Healy, B.D., Schelly, R.C., Yackulic, C.B., Smith, E.C.O., and Budy, P. (2020) Remarkable response of native fishes to invasive trout suppression varies with trout density, temperature, and annual hydrology. Can J Fish Aquat Sci 77: 1477-1486.

Heggenes, J. (2002) Flexible summer habitat selection by wild, allopatric brown trout in lotic environments. Trans Am Fish Soc 131: 287-298.

Heggnes, J., Saltveit, S.J., Bird, D., and Grew, R. (2002) Static habitat partitioning and dynamic selection by sympatric young Atlantic salmon and brown trout in south-west England streams. J Fish Biol 60: 72-86.

Heisler, J., Burkholder, J., Anderson, D., Cochlan, W., Dennison, W., Gobler, C., et al. (2008) Eutropication and harmful algal blooms: A scientific consensus. Harmful Algae 8: 3-13.

Helfman, G.S. (2007) Fish conservation: a guide to understanding and restoring global aquatic biodiversity and fishery resources. Island Press,.

Hellström, M., Wijkmark, N., Edbom-Blomstrand, C., Hellström, P., and Näslund, J. (2019) Footsteps in the snow - Pilot study for future monitoring of individual lynx (Lynx lynx) from eDNA in snow tracks. AquaBiota Rep 10.

Hijmans, R.J. (2020) raster: geographic data analysis and modeling. https://cran.rproject.org/package $=$ raster.

Hill, W.G. (1981) Estimation of effective population size from data on linkage disequilibrium. Genet Res 38: 209-216.

Hinlo, R., Gleeson, D., Lintermans, M., and Furlan, E. (2017) Methods to maximise recovery of environmental DNA from water samples. PLoS One 12: 1-22.

Hobbs, J.P.A., Jones, G.P., and Munday, P.L. (2011) Extinction risk in endemic marine fishes. Conserv Biol 25: 1053-1055.

Hobson, K.A. (2008) Isotopic Tracking of Migrant Wildlife. Stable Isot Ecol Environ Sci Second Ed $155-175$

Hobson, K.A., Wassenaar, L.I., and Taylor, O.R. (1999) Stable isotopes ( $\delta \mathrm{D}$ and $\left.\delta^{13} C\right)$ are geographic indicators of natal origins of monarch butterflies in eastern North America. Oecologia 120: 397-404.

Holman, L.E., Bruyn, M. De, Creer, S., Carvalho, G., Robidart, J., and Rius, M. (2019) Detection of introduced and resident marine species using environmental DNA metabarcoding of sediment and water. Sci Rep 9: 1-10. 
References

Hooten, M.B., and Hobbs, N.T. (2015) A guide to Bayesian model selection for ecologists. Concepts Synth 85: 3-28.

Hopkins, G.W., and Freckleton, R.P. (2002) Declines in the numbers of amateur and professional taxonomists: Implications for conservation. Anim Conserv 5: 245-249.

Huber, V., and Geist, J. (2019) Host fish status of native and invasive species for the freshwater mussel Anodonta anatina (Linnaeus, 1758). Biol Conserv 230: 48-57.

Hulme, P.E. (2009) Trade, transport and trouble: Managing invasive species pathways in an era of globalization. $J$ Appl Ecol 46: 10-18.

Hulme, P.E. (2015) Invasion pathways at a crossroad: Policy and research challenges for managing alien species introductions. $J$ Appl Ecol 52: 1418-1424.

Humair, F., Humair, L., Kuhn, F., and Kueffer, C. (2015) E-commerce trade in invasive plants. Conserv Biol 29: 1658-1665.

Huryn, A.D. (1996) An appraisal of the Allen paradox in a New Zealand trout stream. Limnol Oceanogr 41: 243-252.

Huxel, G.R. (1999) Rapid displacement of native species by invasive species: effects of hybridization. Biol Conserv 89: 143-152.

Iriarte, J.A., Lobos, G.A., and Jaksic, F.M. (2005) Invasive vertebrate species in Chile and their control and monitoring by governmental agencies. Rev Chil Hist Nat 78: 143-154.

Iversen, A., Asche, F., Hermansen, Ø., and Nystøyl, R. (2020) Production cost and competitiveness in major salmon farming countries 2003-2018. Aquaculture 522: 735089.

Jackson, D.A. (2002) Ecological effects of Micropterus introductions: The dark side of black bass. Am Fish Soc Symp 2002: 221-232.

Jardine, T.D., Hunt, R.J., Pusey, B.J., and Bunn, S.E. (2011) A non-lethal sampling method for stable carbon and nitrogen isotope studies of tropical fishes. Mar Freshw Res 62: 83-90.

Jensen, A.J., Finstad, B., and Fiske, P. (2019) The cost of anadromy: Marine and freshwater mortality rates in anadromous Arctic char and brown trout in the Arctic region of Norway. Can J Fish Aquat Sci 76: $2408-2417$.

Jerde, C.L., Mahon, A.R., Chadderton, W.L., and Lodge, D.M. (2011) "Sight-unseen" detection of rare aquatic species using environmental DNA. Conserv Lett 4: 150-157. 
References

Jobling, S., Beresford, N., Nolan, M., Rodgers-Gray, T., Brighty, G.C., Sumpter, J.P., and Tyler, C.R. (2002) Altered sexual maturation and gamete production in wild roach (Rutilus rutilus) living in rivers that receive treated sewage effluents. Biol Reprod 66: 272-281.

Jombart, T. (2008) Adegenet: a R package for the multivariate analysis of genetic markers. Bioinformatics 24: 1403-1405.

Jombart, T., and Ahmed, I. (2011) adegenet 1.3-1: new tools for the analysis of genome-wide SNP data. Bioinformatics 27: 3070-3071.

Jombart, T., Devillard, S., and Balloux, F. (2010) Discriminant analysis of principle components: a new method for the analysis of genetically structured populations. BMC Genomics 11: 1-15.

Jones, J., Börger, L., Tummers, J., Jones, P.E., Lucas, M., Kerr, J., et al. (2019) A comprehensive assessment of stream fragmentation in Great Britain. Sci Total Environ 673: 756-762.

Jones, P.E., Champneys, T., Vevers, J., Börger, L., Svendsen, J.C., Consuegra, S., et al. (2021a) Selective effects of small barriers on river-resident fish. J Appl Ecol 1-12.

Jones, P.E., and Closs, G.P. (2018) The introduction of brown trout to New Zealand and their impact on native fish communities. In Brown Trout: Biology, Ecology and Management. Lobón-cerviá, J., and Sanz, N. (eds). John Wiley and Sons Ltd, Hoboken, New Jersey, USA. pp. 545-567.

Jones, P.E., Tummers, J.S., Galib, S.M., Woodford, D.J., Hume, J.B., Silva, L.G.M., et al. (2021b) The Use of Barriers to Limit the Spread of Aquatic Invasive Animal Species: A Global Review. Front Ecol Evol 9: 1-19.

Jonsson, B. (1985) Life history patterns of freshwater resident and sea run brown trout in Norway. Trans Am Fish Soc 114: 182-194.

Jonsson, N., and Jonsson, B. (2002) Migration of anadromous brown trout Salmo trutta in a Norwegian river. Freshw Biol 47: 1391-1401.

Jørgensen, T., Haile, J., Möller, P., Andreev, A., Boessenkool, S., Rasmussen, M., et al. (2012) A comparative study of ancient sedimentary DNA, pollen and macrofossils from permafrost sediments of northern Siberia reveals long-term vegetational stability. Mol Ecol 21: 1989-2003.

Kadye, W.T., Chakona, A., Marufu, L.T., and Samukange, T. (2013) The impact of non-native rainbow trout within Afro-montane streams in eastern Zimbabwe. Hydrobiologia 720: 75-88.

Kassambara, A., and Mindt, F. (2020) factoextra: extract and visualize the results of mulitvariate data analysis. https://cran.r-project.org/package=factoextra. 
Kats, L.B., and Ferrer, R.P. (2003) Alien predators and amphibian declines: Review of two decades of science and the transition to conservation. Divers Distrib 9: 99-110.

Kaufman, S.D., Snucins, E., Gunn, J.M., and Selinger, W. (2009) Impacts of road access on lake trout (Salvelinus namaycush) populations: Regional scale effects of overexploitation and the introduction of smallmouth bass (Micropterus dolomieu). Can J Fish Aquat Sci 66: 212-223.

Kay, S.H., and Hoyle, S.T. (2001) Mail order, the internet, and invasive aquatic weeds. J Aquat Plant Manag 39: 88-91.

Keenan, K., Mcginnity, P., Cross, T.F., Crozier, W.W., and Prodöhl, P.A. (2013) diveRsity: An R package for the estimation and exploration of population genetics parameters and their associated errors. Methods Ecol Evol 4: 782-788.

Keller, R.P., and Lodge, D.M. (2007) Species invasions from commerce in live aquatic organisms: Problems and possible solutions. Bioscience 57: 428-436.

Kelly, M.H., Hagar, W.G., Jardine, T.D., and Cunjak, R.A. (2006) Nonlethal Sampling of Sunfish and Slimy Sculpin for Stable Isotope Analysis: How Scale and Fin Tissue Compare with Muscle Tissue. North Am J Fish Manag 26: 921-925.

Kelly, R.P., Port, J.A., Yamahara, K.M., and Crowder, L.B. (2014) Using Environmental DNA to census marine fishes in a large mesocosm. PLoS One $\mathbf{9}$.

Kilian, J. V., Klauda, R.J., Widman, S., Kashiwagi, M., Bourquin, R., Weglein, S., and Schuster, J. (2012) An assessment of a bait industry and angler behavior as a vector of invasive species. Biol Invasions 14: 1469-1481.

King, R.S., Baker, M.E., Kazyak, P.F., and Weller, D.E. (2011) How novel is too novel? Stream community thresholds at exceptionally low levels of catchment urbanization. Ecol Appl 21: 16591678 .

Kitano, S. (2004) Ecological impacts of rainbow, brown and brook trout in Japanese inland waters. Glob Environ Res 8: 41-50.

Kizuka, T., Akasaka, M., Kadoya, T., and Takamura, N. (2014) Visibility from roads predict the distribution of invasive fishes in agricultural ponds. PLoS One 9: 1:10.

Klemetsen, A., Amundsen, P.A., Dempson, J.B., Jonnson, B., Jonnson, N., O’Connell, M.F., and Mortensen, E. (2003) Atlantic salmon, Salmo salar L., brown trout Salmo trutta L., and Arctic charr Salvelinus alpinus (L.): a review of aspects of their life histories. Ecol Freshw Fish 12: 1-59. 
Kock, N., and Lynn, G.S. (2012) Lateral collinearity and misleading results in variance-based SEM: an illustration and recommendations. J Assoc Inf Syst 14: 225-241.

Korsu, K., Huusko, A., and Muotka, T. (2007) Niche characteristics explain the reciprocal invasion success of stream salmonids in different continents. Proc Natl Acad Sci U S A 104: 9725-9729.

Krabbenhoft, T.J., Platania, S.P., and Turner, T.F. (2014) Interannual variation in reproductive phenology in a riverine fish assemblage: implications for predicting the effects of climate change and altered flow regimes Reproductive readiness. Freshw Biol 59: 1744-1754.

Kristensen, E.A., Closs, G.P., Olley, R., Kim, J., Reid, M., and Stirling, C. (2011) Determining the spatial distribution of spawning by anadromous and resident brown trout Salmo trutta L using strontium content of eggs collected from redds. Ecol Freshw Fish 20: 377-383.

Krysko, K.L., Burgess, J.P., Rochford, M.R., Gillette, C.R., Cueva, D., Enge, K.M., et al. (2011) Verified non-indigenous amphibians and reptiles in Florida from 1863 through 2010: Outlining the invasion process and identifying invasion pathways and stages. Zootaxa 3028: 1-64.

Kutyavin, I. V, Afonina, I.A., Mills, A., Gorn, V. V, Lukhtanov, E.A., Belousov, E.S., et al. (2000) 3'Minor groove binder-DNA probes increase sequence specificity at PCR extension temperatures. Nucleic Acids Res 28: 655-661.

Labonne, J., Vignon, M., Prévost, E., Lecomte, F., Dodson, J.J., Kaeuffer, R., et al. (2013) Invasion Dynamics of a Fish-Free Landscape by Brown Trout (Salmo trutta). PLoS One 8: 1-7.

Lacoursière-Roussel, A., Côté, G., Leclerc, V., and Bernatchez, L. (2016a) Quantifying relative fish abundance with eDNA: a promising tool for fisheries management. $J$ Appl Ecol 53: 1148-1157.

Lacoursière-Roussel, A., Howland, K., Normandeau, E., Grey, E.K., Archambault, P., Deiner, K., et al. (2018) eDNA metabarcoding as a new surveillance approach for coastal Arctic biodiversity. Ecol Evol 8: 7763-7777.

Lacoursière-Roussel, A., Rosabal, M., and Bernatchez, L. (2016b) Estimating fish abundance and biomass from eDNA concentrations: variability among capture methods and environmental conditions. Mol Ecol Resour 16: 1401-1414.

Lacroix, G.L., Knox, D., and Stokesbury, M.J.W. (2005) Survival and behaviour of post-smolt Atlantic salmon in coastal habitat with extreme tides. J Fish Biol 66: 485-498.

Lahti, K., Laurila, A., Enberg, K., and Piironen, J. (2001) Variation in aggressive behaviour and growth rate between populations and migratory forms in the brown trout, Salmo trutta. Anim Behav 62: 935-944. 
References

Laramie, M.B., Pilliod, D.S., and Goldberg, C.S. (2015) Characterizing the distribution of an endangered salmonid using environmental DNA analysis. Biol Conserv 183: 29-37.

Launey, S., Brunet, G., Guyomard, R., and Davaine, P. (2010) Role of introduction history and landscape in the range expansion of brown trout (Salmo trutta L.) in the Kerguelen Islands. $J$ Hered 101: $270-283$.

Leaché, A.D., and Oaks, J.R. (2017) The Utility of Single Nucleotide Polymorphism (SNP) Data in Phylogenetics. Annu Rev Ecol Evol Syst 48: 69-84.

Lecomte, F., Beall, E., Chat, J., Davaine, P., and Gaudin, P. (2013) The complete history of salmonid introductions in the Kerguelen Islands, Southern Ocean. Polar Biol 36: 457-475.

Lehner, B., and Do, P. (2004) Development and validation of a global database of lakes, reservoirs and wetlands. J. Hydrol 296: 1-22.

Levine, J.M., Adler, P.B., and Yelenik, S.G. (2004) A meta-analysis of biotic resistance to exotic plant invasions. Ecol Lett 7: 975-989.

Lewis, R., and Gardens, R.B. (2014) Invasive Plants in the Falkland Islands Final Report.

Limburg, K.E., Landergren, P., Westin, L., Elfman, M., and Kristiansson, P. (2001) Flexible modes of anadromy in Baltic sea trout: Making the most of marginal spawning streams. J Fish Biol 59: 682695.

Lindahl, T. (1993) Instability and decay of the primary structure of DNA. Nature 362: 709-715.

Litvak, M.K., and Mandrak, N.E. (1993) Ecology of Freshwater Baitfish Use in Canada and the United States. Fisheries 18: 6-13.

Lockwood, J.L., Cassey, P., and Blackburn, T. (2005) The role of propagule pressure in explaining species invasions. Trends Ecol Evol 20: 223-228.

Lockwood, J.L., Welbourne, D.J., Romagosa, C.M., Cassey, P., Mandrak, N.E., Strecker, A., et al. (2019) When pets become pests: the role of the exotic pet trade in producing invasive vertebrate animals. Front Ecol Environ 17: 323-330.

Lodge, D.M., Turner, C.R., Jerde, C.L., Barnes, M.A., Chadderton, L., Egan, S.P., et al. (2012) Conservation in a cup of water: estimating biodiversity and population abundance from environmental DNA. Mol Ecol 21: 2555-2558.

Lohr, C.A., and Lepczyk, C.A. (2014) Desires and management preferences of stakeholders regarding feral cats in the hawaiian Islands. Conserv Biol 28: 392-403. 
References

Lowe, S., Browne, M., Boudjelas, S., and Poorter, M. De (2000) 100 of the worlds worst invasive alien species: a selection from the global invasive species database. Vol 12., Invasive Species Specialist Group, Auckland.

Lugendo, B.R., Nagelkerken, I., Velde, G. Van Der, and Mgaya, Y.D. (2006) The importance of mangroves, mud and sand flats, and seagrass beds as feeding areas for juvenile fishes in Chwaka Bay, Zanzibar: Gut content and stable isotope analyses. J Fish Biol 69: 1639-1661.

Lundberg, J.G., Kottelat, M., Smith, G.R., Stiassny, M.L.J., and Gill, A.C. (2000) So many fishes, so little time: An overview of recent ichthyological discovery in continental waters. Ann Missouri Bot Gard 87: 26-62.

Macchi, P.J., Pascual, M.A., and Vigliano, P.H. (2007) Differential piscivory of the native Percichthys trucha and exotic salmonids upon the native forage fish Galaxias maculatus in Patagonian Andean lakes. Limnologica 37: 76-87.

MacCrimmon, H.R. (2011) World Distribution of Rainbow Trout (Salmo gairdneri): Further Observations . J Fish Res Board Canada 29: 1788-1791.

MacCrimmon, H.R., and Marshall, T.L. (1968) World distribution of brown trout Salmo trutta. J Fish Res Board Canada 25: 2527-2548.

Mächler, E., Deiner, K., Spahn, F., and Altermatt, F. (2016) Fishing in the water: effect of sampled water volume on environmental DNA-based detection of macroinvertebrates. Environ Sci Technol 50: $305-312$.

Magnuson, J.J., Benson, B.J., and McLain, A.S. (1994) Insights on Species Richness and Turnover from Long-Term Ecological Research : Fishes in North Temperate Lakes '. Am Zool 34: 437-451.

Mahon, A.R., Nathan, L.R., and Jerde, C.L. (2014) Meta-genomic surveillance of invasive species in the bait trade. Conserv Genet Resour 6: 563-567.

Malmqvist, B., and Rundle, S. (2002) Threats to the running water ecosystems of the world. Environ Conserv 29: 134-153.

Mamoozadeh, N.R., Graves, J.E., and McDowell, J.R. (2020) Genome-wide SNPs resolve spatiotemporal patterns of connectivity within striped marlin (Kajikia audax), a broadly distributed and highly migratory pelagic species. Evol Appl 13: 677-698.

Mantel, N. (1967) The detection of disease clustering and a generalized regression approach. Cancer Res 27: 209-220. 
References

Marco-Rius, F., Caballero, P., Morán, P., and Garcia de Leaniz, C. (2013) Can migrants escape from density dependence? Ecol Evol 3: 2524-2534.

Mariotti, A. (1983) Atmospheric nitrogen is a reliable standard for natural ${ }^{15} \mathrm{~N}$ abundance measurements. Nature 303: 685-687.

Martín-Torrijos, L., Kokko, H., Makkonen, J., Jussila, J., and Diéguez-Uribeondo, J. (2019) Mapping 15 years of crayfish plague in the Iberian Peninsula: The impact of two invasive species on the endangered native crayfish. PLoS One 14: 1-14.

Martin, C.W., Valentine, M.M., and Valentine, J.F. (2010) Competitive interactions between invasive nile tilapia and native fish: The potential for altered trophic exchange and modification of food webs. PLoS One 5: 57-59.

Martinuzzi, S., Januchowski-Hartley, S.R., Pracheil, B.M., Mcintyre, P.B., Plantinga, A.J., Lewis, D.J., and Radeloff, V.C. (2014) Threats and opportunities for freshwater conservation under future land use change scenarios in the United States. Glob Chang Biol 20: 113-124.

Matsuzaki, S.I.S., Usio, N., Takamura, N., and Washitani, I. (2009) Contrasting impacts of invasive engineers on freshwater ecosystems: An experiment and meta-analysis. Oecologia 158: 673-686.

May, B., and Marsden, J.E. (1992) Genetic identification and implications of another invasive species of dreissenid mussel in the Great Lakes. Can J Fish Aquat Sci 49: 1501-1506.

McCarroll, D., and Loader, N.J. (2004) Stable isotopes in tree rings. Quat Sci Rev 23: 771-801.

McCarthy, I.D., and Waldron, S. (2000) Identifying migratory Salmo trutta using carbon and nitrogen stable isotope ratios. Rapid Commun Mass Spectrom 14: 1325-1331.

Mcdonald, L. (2004) Sampling Rare Populations. In Sampling rare or elusive species. W.L. Thompson (ed.). Island Press, New York. pp. 11-42.

Mcdowall, A.R.M., and Nakaya, K. (1988) Morphological divergence in the two species of Aplochiton Jenyns (Salmoniformes: Aplochitonidae): a generalist and a specialist. Am Soc Ichthyol Herpetol 1988: 233-236.

McDowall, R.M. (1971) The galaxiid fishes of South America. Zool J Linn Soc 50: 33-73.

McDowall, R.M. (2003) Impacts of introduced salmonids on native galaxiids in New Zealand upland streams: a new look at an old problem. Trans Am Fish Soc 132: 229-238.

McDowall, R.M. (2005) Falkland Islands biogeography: converging trajectories in the South Atlantic Ocean. J Biogeogr 32: 49-62. 
References

McDowall, R.M. (2006) Crying wolf, crying foul, or crying shame: alien salmonids and a biodiversity crisis in the southern cool-temperate galaxioid fishes? Rev Fish Biol Fish 16: 233-422.

McDowall, R.M., Allibone, R.M., and Chadderton, W.L. (2001) Issues for the conservation and management of Falkland Islands fresh water fishes. Aquat Conserv Mar Freshw Ecosyst 11: 473-486.

McGeoch, M.A., Genovesi, P., Bellingham, P.J., Costello, M.J., McGrannachan, C., and Sheppard, A. (2016) Prioritizing species, pathways, and sites to achieve conservation targets for biological invasion. Biol Invasions 18: 299-314.

McHugh, P., and Budy, P. (2006) Experimental effects of nonnative brown trout on the individualand population-level performance of native Bonneville cutthroat trout. Trans Am Fish Soc 135: 14411455.

McIntosh, A.R. (2000) Habitat- and size-related variations in exotic trout impacts on native galaxiid fishes in New Zealand streams. Can J Fish Aquat Sci 57: 2140-2151.

McIntosh, A.R., Crowl, T.A., and Townsend, C.R. (1994) Size-related impacts of introduced brown trout on the distribution of native common river galaxias. New Zeal J Mar Freshw Res 28: 135-144.

McIntosh, A.R., McHugh, P.A., Dunn, N.R., Goodman, J.M., Howard, S.W., Jellyman, P.G., et al. (2010) The impact of trout on galaxiid fishes in New Zealand. N Z J Ecol 34: 195-206.

McIntosh, A.R., and Townsend, C.R. (1995) Impacts of an introduced predatory fish on mayfly grazing in New Zealand streams. Limnol Oceanogr 40: 1508-1512.

McIntosh, A.R., and Townsend, C.R. (1996) Interactions between fish, grazing invertebrates and algae in a New Zealand stream: A trophic cascade mediated by fish-induced changes to grazer behaviour? Oecologia 108: 174-181.

McIntosh, A.R., and Townsend, C.R. (1998) Do different predators affect distance, direction, and destination of movements by a stream mayfly? Can J Fish Aquat Sci 55: 1954-1960.

McIntosh, A.R., Townsend, C.R., and Crowl, T.A. (1992) Competition for space between introduced brown trout (Salmo trutta L.) and native galaxiid (Galaxias vulgaris Stokell) in a New Zeland stream. J Fish Biol 41:63-81.

McIntyre, P.B., Liermann, C.R., Childress, E., Hamann, E.J., Hogan, J.D., Januchowski-Hartley, S.R., et al. (2015) Conservation of freshwater fishes. 342-360.

Mckinney, M.L., and Lockwood, J.L. (1999) Biotic homogenization: a few winners replacing many losers in the next mass extinction. Trends Ecol Evol 14: 450-453. 
Mehta, S. V, Haight, R.G., Homans, F.R., Polasky, S., and Venette, R.C. (2006) Optimal detection and control strategies for invasive species management. Ecol Econ 61: 237-245.

Meisner, J.D. (1990) Potential Loss of Thermal Habitat for Brook Trout, Due to Climatic Warming, in Two Southern Ontario Streams. Trans Am Fish Soc 199:2, 282-291.

Meyer, K.A., Lamansky, J.A., and Schill, D.J. (2006) Evaluation of an Unsuccessful Brook Trout Electrofishing Removal Project in a Small Rocky Mountain Stream. North Am J Fish Manag 26: 849860.

Miaud, C., Dejean, T., Savard, K., Millery-Vigues, A., Valentini, A., Curt Grand Gaudin, N., and Garner, T.W.J. (2016) Invasive North American bullfrogs transmit lethal fungus Batrachochytrium dendrobatidis infections to native amphibian host species. Biol Invasions 18: 2299-2308.

Mills, E.L., Casselman, J.M., Dermott, R., Fitzsimons, J.D., Gal, G., Holeck, K.T., et al. (2003) Lake Ontario: food web dynamics in a changing ecosystem (1970-2000). Can J Fish Aquat Sci 60: 471490.

Minagawa, M., and Wada, E. (1984) Stepwise enrichment of ${ }^{15} \mathrm{~N}$ along food chains: Further evidence and the relation between $\delta^{15} \mathrm{~N}$ and animal age. Geochim Cosmochim Acta 48: 1135-1140.

Minett, J.F., Fowler, D.M., Jones, J.A.H., Brickle, P., Crossin, G.T., Consuegra, S., and Garcia de Leaniz, C. (2021a) Conservation of endangered galaxiid fishes in the Falkland Islands requires urgent action on invasive brown trout. bioRxiv 1-25.

Minett, J.F., Garcia de Leaniz, C., Brickle, P., and Consuegra, S. (2020) A new high-resolution melt curve eDNA assay to monitor the simultaneous presence of invasive brown trout (Salmo trutta) and endangered galaxiids. Environ DNA 3: 1-12.

Minett, J.F., Garcia de Leaniz, C., Sobolewska, H., Brickle, P., Crossin, G.T., and Consuegra, S. (2021b) SNP analyses and acoustic tagging reveal multiple origins and widespread dispersal of invasive brown trout in the Falkland Islands. Evol Appl 1-11.

Miranda, L.E., and Kidwell, R.H. (2010) Unintended effects of electrofishing on nongame fishes. Trans Am Fish Soc 139: 1315-1321.

Mitchell, C.E., Agrawal, A.A., Bever, J.D., Gilbert, G.S., Hufbauer, R.A., Klironomos, J.N., et al. (2006) Biotic interactions and plant invasions. Ecol Lett 9: 726-740.

Mollot, G., Pantel, J.H., and Romanuk, T.N. (2017) The effects of invasive species on the decline in species richness: a global meta-analysis. Advances in ecological research, 56, 61-83. 
References

Monzón-Argüello, C., Consuegra, S., Gajardo, G., Marco-Rius, F., Fowler, D.M., DeFaveri, J., and Garcia de Leaniz, C. (2014a) Contrasting patterns of genetic and phenotypic differentiation in two invasive salmonids in the southern hemisphere. Evol Appl 7: 921-936.

Monzón-Argüello, C., Garcia de Leaniz, C., Gajardo, G., and Consuegra, S. (2013) Less can be more: loss of MHC functional diversity can reflect adaptation to novel conditions during fish invasions. Ecol Evol 3: 3359-3368.

Monzón-Argüello, C., Garcia de Leaniz, C., Gajardo, G., and Consuegra, S. (2014b) Eco-immunology of fish invasions: the role of MHC variation. Immunogenetics 66: 393-402.

Morgan, D.L., Gill, H.S., Maddern, M.G., and Beatty, S.J. (2004) Distribution and impacts of introduced freshwater fishes in Western Australia. New Zeal J Mar Freshw Res 38: 511-523.

Morin, P.A., Luikart, G., and Wayne, R.K. (2004) SNPs in ecology, evolution and conservation. Trends Ecol Evol 19: 208-216.

Morita, K. (2018) Assessing the long-term causal effect of trout invasion on a native charr. Ecol Indic 87: 189-192.

Moser, D., Lenzner, B., Weigelt, P., Dawson, W., Kreft, H., Pergl, J., et al. (2018) Remoteness promotes biological invasions on islands worldwide. Proc Natl Acad Sci U S A 115: 9270-9275.

Moss, B. (2008) Water pollution by agriculture. Philos Trans R Soc B 363: 659-666.

Mueller, M., Pander, J., and Geist, J. (2011) The effects of weirs on structural stream habitat and biological communities. J Appl Ecol 48: 1450-1461.

Muha, T.P., Robinson, C.V., Garcia de Leaniz, C., and Consuegra, S. (2019) An optimised eDNA protocol for detecting fish in lentic and lotic freshwaters using a small water volume. PLoS One 14: $1-20$.

Nathan, L.R., Jerde, C.L., Budny, M.L., and Mahon, A.R. (2014) The use of environmental DNA in invasive species surveillance of the Great Lakes commercial bait trade. Conserv Biol 29: 430-439.

Nei, M. (1987) Molecular evolutionary genetics. Columbia Univ Press.

Nevoux, M., Finstad, B., Davidsen, J.G., Finlay, R., Josset, Q., Poole, R., et al. (2019) Environmental influences on life history strategies in partially anadromous brown trout (Salmo trutta, Salmonidae). Fish Fish 20: 1051-1082.

Newton, M., Barry, J., Dodd, J.A., Lucas, M.C., Boylan, P., and Adams, C.E. (2016) Does size matter? A test of size-specific mortality in Atlantic salmon Salmo salar smolts tagged with acoustic 
References

transmitters. J Fish Biol 89: 1641-1650.

Nielsen, K.M., Johnsen, P.J., Bensasson, D., and Daffonchio, D. (2007) Thematic Issue on Horizontal Gene Transfer Release and persistence of extracellular DNA. Environ Biosafety Res 6: 37-53.

Noble, D.W.A., Qi, Y., and Fu, J. (2010) Species delineation using Bayesian model-based assignment tests: A case study using Chinese toad-headed agamas (genus Phrynocephalus). BMC Evol Biol 10: 115.

Nyström, P., and McIntosh, A.R. (2003) Are impacts of an exotic predator on a stream food web influenced by disturbance history? Oecologia 136: 279-288.

O’Neal, S.L., and Stanford, J.A. (2011) Partial migration in a robust brown trout population of a Patagonian river. Trans Am Fish Soc 140: 623-635.

Oele, D.L., Gaeta, J.W., Rypel, A.L., and McIntyre, P.B. (2019) Growth and recruitment dynamics of young-of-year northern pike: Implications for habitat conservation and management. Ecol Freshw Fish 28: 285-301.

Ong, X., Wang, Y., Sithithaworn, P., Grundy-warr, C., Ong, X., Wang, Y., et al. (2016) Dam Influences on Liver Fluke Transmission : Fish Infection and Human Fish Consumption Behavior. Ann Am Assoc Geogr 106: 4, 755-772.

Otley, H., Clausen, A., and Ingham, B. (2008) Falkand Islands state if the environment report 2008. Stanley.

Padgham, M., and Sumner, M.D. (2020) geodist: Fast, dependency-free geodesic distance calculations. https://github.com/hypertidy/geodist.

Padilla, D.K., and Williams, S.L. (2004) Beyond ballast water: Aquarium and ornamental trades as sources of invasive species in aquatic ecosystems. Front Ecol Environ 2: 131-138.

Panek, F.M., and Densmore, C.L. (2011) Electrofishing and the effects of depletion sampling on fish health: a review and recommendations for additional study. Khaled bin Sultan Living Ocean Found Landover, $M D$.

Pascual, M.A., Cussac, V., Dyer, B., Soto, D., Vigliano, P., Ortubay, S., and Macchi, P. (2007) Freshwater fishes of Patagonia in the 21st Century after a hundred years of human settlement, species introductions, and environmental change. Aquat Ecosyst Heal Manag 10: 212-227.

Pebesma (2018) Simple features for R: standardized support for spatial vector data. $R J$ 10: 439-446.

Pebesma, E., and Bivand, R. (2005) Classes and methods for spatial data in R. R News 5: 9-13. 
References

Penaluna, B.E., Arismendi, I., and Soto, D. (2009) Evidence of interactive segregation between introduced trout and native fishes in northern Patagonian rivers, Chile. Trans Am Fish Soc 138: 839845.

Pépino, M., Rodríguez, M.A., and Magnan, P. (2012) Impacts of highway crossings on density of brook charr in streams. $J$ Appl Ecol 49: 395-403.

Perga, M.E., and Gerdeaux, D. (2005) “Are fish what they eat" all year round? Oecologia 144: 598606.

Perry, W.L., Lodge, D.M., and Feder, J.L. (2002) Importance of hybridization between indigenous and nonindigenous freshwater species: An overlooked threat to North American biodiversity. Syst Biol 51: 255-275.

Peterson, B.J., and Fry, B. (1987) Stable Isotopes in Ecosystem. Annu Rev Ecol Syst 18: 293-320.

Piferrer, F. (2008) Temperature-Dependent Sex Determination in Fish Revisited : Prevalence, a Single Sex Ratio Response Pattern, and Possible Effects of Climate Change. PLoS One 3: 2-4.

Pikitch, E.K., Doukakis, P., Lauck, L., Chakrabarty, P., and Erickson, D.L. (2005) Status, trends and management of sturgeon and paddlefish fisheries. Fish Fish 6: 233-265.

Pilliod, D.S., Goldberg, C.S., Arkle, R.S., and Waits, L.P. (2013) Estimating occupancy and abundance of stream amphibians using environmental DNA from filtered water samples. Can J Fish Aquat Sci 70: 1123-1130.

Pilliod, D.S., Goldberg, C.S., Arkle, R.S., and Waits, L.P. (2014) Factors influencing detection of eDNA from a stream-dwelling amphibian. Mol Ecol Resour 14: 109-116.

Poff, N.L.R., Allan, J.D., Bain, M.B., Karr, J.R., Prestegaard, K.L., Richter, B.D., et al. (1997) The natural flow regime. Bioscience 47: 769-784.

Poncet, S., Poncet, L., Poncet, D., Christie, D., Dockrill, C., and Brown, D. (2011) Introduced mammal eradications in the Falkland Islands and South Georgia. Isl Invasives Erad Manag 332-336.

Post, D.M. (2002) Using stable isotopes to estimate trophic position: models, methods, and assumptions. Ecology 83: 703-718.

Post, D.M., Layman, C.A., Arrington, D.A., Takimoto, G., Quattrochi, J., and Montaña, C.G. (2007) Getting to the fat of the matter: Models, methods and assumptions for dealing with lipids in stable isotope analyses. Oecologia 152: 179-189.

Pratten, D.J., and Shearer, W.M. (1983) Sea trout of the North Esk. Aquac Res 14: 49-65. 
References

Prinzio, C.Y. Di, and Pascual, M.A. (2009) The establishment of exotic Chinook salmon (Oncorhynchus tshawytscha) in Pacific rivers of Chubut, Patagonia, Argentina. Ann Limnol - Int J Limnol 44: 25-32.

Pyšek, P., and Richardson, D.M. (2006) The biogeography of naturalization in alien plants. $J$ Biogeogr 33: 2040-2050.

QGIS Development Team (2020) QGIS Geographic Information System. Open Source Geospatial Foundation Project. https://qgis.org/en/site/.

Quezada-Romegialli, C., Jackson, A.L., Hayden, B., Kahilainen, K.K., Lopes, C., and Harrod, C. (2018) tRophicPosition, an r package for the Bayesian estimation of trophic position from consumer stable isotope ratios. Methods Ecol Evol 9: 1592-1599.

R Core Team (2019) R: A language and environment for statistical computing. https://www.rproject.org/.

Raby, G.D., Colotelo, A.H., Blouin-demers, G., and Cooke, S.J. (2011) Freshwater Commercial bycatch: An understated conservation problem. Bioscience 61: 271-280.

Rahel, F.J. (2000) Homogenization of fish faunas across the United States. Science 288: 854-856.

Rahel, F.J. (2002) Using current biogeographical limits to predict fish distribution following climate change. Am Fish Soc Symp 33: 99-110.

Rahel, F.J. (2007) Biogeographic barriers, connectivity and homogenization of freshwater faunas: It's a small world after all. Freshw Biol 52: 696-710.

Rahel, F.J., and Olden, J.D. (2008) Assessing the effects of climate change on aquatic invasive species. Conserv Biol 22: 521-533.

Ramón-Laca, A., Gleeson, D., Yockney, I., Perry, M., Nugent, G., and Forsyth, D.M. (2014) Reliable discrimination of 10 ungulate species using high resolution melting analysis of faecal DNA. PLoS One 9: 1-8.

Ramsay, A.L., Milner, N.J., Hughes, R.N., and McCarthy, I.D. (2011) Comparison of the performance of scale and otolith microchemistry as fisheries research tools in a small upland catchment. Can J Fish Aquat Sci 68: 823-833.

Rasmussen, J.B., Trudeau, V., and Morinville, G. (2009) Estimating the scale of fish feeding movements in rivers using $\delta^{13} \mathrm{C}$ signature gradients. $J$ Anim Ecol 78: 674-685.

Rees, H.C., Maddison, B.C., Middleditch, D.J., Patmore, J.R.M., and Gough, K.C. (2014) The 
References

detection of aquatic animal species using environmental DNA - a review of eDNA as a survey tool in ecology. J Appl Ecol 51: 1450-1459.

Reid, A.J., Carlson, A.K., Creed, I.F., Eliason, E.J., Gell, P.A., Johnson, P.T.J., et al. (2019) Emerging threats and persistent conservation challenges for freshwater biodiversity. Biol Rev 94: 849-873.

Rendell, N. (2011) UK Overseas Territories and Crown Dependencies: 2011 Biodiversity snapshot.

Rennie, M.D., Collins, N.C., Purchase, C.F., and Tremblay, A. (2005) Predictive models of benthic invertebrate methylmercury in Ontario and Quebec lakes. Can J Fish Aquat Sci 62: 2770-2783.

Renshaw, M.A., Olds, B.P., Jerde, C.L., Mcveigh, M.M., and Lodge, D.M. (2015) The room temperature preservation of filtered environmental DNA samples and assimilation into a phenol chloroform - isoamyl alcohol DNA extraction. Mol Ecol Resour 15: 168-176.

Resh, C.A., Galaska, M.P., Benesh, K.C., Gardner, J.P.A., Wei, K., Yan, R., and Mahon, A.R. (2021) Using Genomics to Link Populations of an Invasive Species to Its Potential Sources. Front Ecol Evol 9: $1-11$.

Resh, C.A., Galaska, M.P., and Mahon, A.R. (2018) Genomic analyses of Northern snakehead (Channa argus) populations in North America. PeerJ 6: e4581.

Reynolds, L., Herlihy, A.T., Kaufmann, P.R., Gregory, S. V., and Hughes, R.M. (2003) Electrofishing effort requirements for assessing species richness and biotic integrity in western Oregon streams. North Am J Fish Manag 23: 450-461.

Richardson, D.M., Pyšek, P., Rejmánek, M., Barbour, M.G., Dane Panetta, F., and West, C.J. (2000) Naturalization and invasion of alien plants: Concepts and definitions. Divers Distrib 6: 93-107.

Richter-Boix, A., Garriga, N., Montori, A., Franch, M., San Sebastián, O., Villero, D., and Llorente, G.A. (2013) Effects of the non-native amphibian species Discoglossus pictus on the recipient amphibian community: Niche overlap, competition and community organization. Biol Invasions 15: 799-815.

Roberts, M., Cresswell, W., and Hanley, N. (2018) Prioritising Invasive Species Control Actions: Evaluating Effectiveness, Costs, Willingness to Pay and Social Acceptance. Ecol Econ 152: 1-8.

Robinson, C.V., Garcia de Leaniz, C., and Consuegra, S. (2019a) Effect of artificial barriers on the distribution of the invasive signal crayfish and Chinese mitten crab. Sci Rep 9: 1-11.

Robinson, C.V., Garcia de Leaniz, C., Rolla, M., and Consuegra, S. (2019b) Monitoring the eradication of the highly invasive topmouth gudgeon (Pseudorasbora parva) using a novel eDNA 
References

assay. Environ DNA 1: 74-85.

Robinson, C.V., Uren Webster, T.M., Cable, J., James, J., and Consuegra, S. (2018) Simultaneous detection of invasive signal crayfish, endangered white-clawed crayfish and the crayfish plague pathogen using environmental DNA. Biol Conserv 222: 241-252.

Rockström, J., and Karlberg, L. (2010) The quadruple squeeze: Defining the safe operating space for freshwater use to achieve a triply green revolution in the anthropocene. Ambio 39: 257-265.

Rodríguez-Rey, M., Consuegra, S., Börger, L., and Leaniz, C.G. de (2019) Improving Species Distribution Modelling of freshwater invasive species for management applications. PLoS One 14.

Ross, K. (2009) Freshwater fish in the Falklands: Conservation of native zebra trout.

Rounick, J.S., and Winterbourn, M.J. (1986) Stable Carbon Isotopes and Carbon Flow in Ecosystems. Bioscience 36: 171-177.

Roussel, J.M., and Bardonnet, A. (1999) Ontogeny of diel pattern of stream-margin habitat use by emerging brown trout, Salmo trutta, in experimental channels: Influence of food and predator presence. Environ Biol Fishes 56: 253-262.

Roux, J. Le, and Wieczorek, A.M. (2009) Molecular systematics and population genetics of biological invasions: Towards a better understanding of invasive species management. Ann Appl Biol 154: 1-17.

Rowe, D.K. (2001) Rotenone-based approaches to pest fish control in New Zealand. Munro, R. ed. Department of Conservation, Hamilton, New Zealand.

Roy, A.H., Rosemond, A.D., Paul, M.J., Leigh, D.S., and Wallace, J.B. (2003) Stream macroinvertebrate response to catchment urbanisation (Georgia, U.S.A.). Freshw Biol 48: 329-346.

Rubenstein, D.R., and Hobson, K.A. (2004) From birds to butterflies: Animal movement patterns and stable isotopes. Trends Ecol Evol 19: 256-263.

Saint-Pé, K., Blanchet, S., Tissot, L., Poulet, N., Plasseraud, O., Loot, G., et al. (2018) Genetic admixture between captive-bred and wild individuals affects patterns of dispersal in a brown trout (Salmo trutta) population. Conserv Genet 19: 1269-1279.

Sakai, A.K., Allendorf, F.W., Holt, J.S., Lodge, D.M., Molofsky, J., With, K.A., et al. (2001) The Population Biology of Invasive Species. Annu Rev Ecol Evol Syst 32: 305-332.

Sala, O.E., Chapin, F.S., Armesto, J.J., Berlow, E., Bloomfield, J., Dirzo, R., et al. (2000) Global biodiversity scenarios for the year 2100. Science 287: 1770-1774. 
References

Salmon and Trout Association (2012) Falklands in the Family. William Powell Ctry https://www.williampowell.com/blog/fishing/falklands-in-the-family/. Accessed May 2, 2019.

Sanderson, B.L., Tran, C.D., Coe, H.J., Pelekis, V., Steel, E.A., and Reichert, W.L. (2009) Nonlethal sampling of fish caudal fins yields valuable stable isotope data for threatened and endangered fishes. Trans Am Fish Soc 138: 1166-1177.

Saunders, W.C., Budy, P., and Thiede, G.P. (2015) Demographic changes following mechanical removal of exotic brown trout in an Intermountain West (USA), high-elevation stream. Ecol Freshw Fish 24: 252-263.

Savini, D., Occhipinti-Ambrogi, A., Marchini, A., Tricarico, E., Gherardi, F., Olenin, S., and Gollasch, S. (2010) The top 27 animal alien species introduced into Europe for aquaculture and related activities. $J$ Appl Ichthyol 26: 1-7.

Sax, D.F., and Brown, J.H. (2000) The paradox of invasion. Glob Ecol Biogeogr 9: 363-371.

Scanlon, B.R., Jolly, I., Sophocleous, M., and Zhang, L. (2007) Global impacts of conversions from natural to agricultural ecosystems on water resources: Quantity versus quality. Water Resour Res $\mathbf{4 3}$

Schabacker, J.C., Amish, S.J., Ellis, B.K., Gardner, B., Miller, D.L., Rutledge, E.A., et al. (2020) Increased eDNA detection sensitivity using a novel high-volume water sampling method. Environ DNA 2: 244-251.

Schaller, J.L., Royer, T. V., David, M.B., and Tank, J.L. (2004) Denitrification associated with plants and sediments in an agricultural stream. $J$ North Am Benthol Soc 23: 667-676.

Schlosser, I.J. (1995) Critical landscape attributes that influence fish population dynamics in headwater streams. Hydrobiologia 303: 71-81.

Schultz, M.T., and Lance, R.F. (2015) Modeling the sensitivity of field surveys for detection of environmental DNA (eDNA). PLoS One 10: 1-16.

Schwindt, A.R., Winkelman, D.L., Keteles, K., Murphy, M., and Vajda, A.M. (2014) An environmental oestrogen disrupts fish population dynamics through direct and transgenerational effects on survival and fecundity. J Appl Ecol 51: 582-591.

Seeb, J.E., Carvalho, G., Hauser, L., Naish, K., Roberts, S., and Seeb, L.W. (2011) Single-nucleotide polymorphism (SNP) discovery and applications of SNP genotyping in nonmodel organisms. $\mathrm{Mol}$ Ecol Resour 11: 1-8.

Sepulveda, A.J., Schabacker, J., Smith, S., Al-Chokhachy, R., Luikart, G., and Amish, S.J. (2019) 
References

Improved detection of rare, endangered and invasive trout in using a new large-volume sampling method for eDNA capture. Environ DNA 1: 227-237.

Seymour, M., Edwards, F.K., Cosby, B.J., Bista, I., Scarlett, P.M., Brailsford, F.L., et al. (2021) Environmental DNA provides higher resolution assessment of riverine biodiversity and ecosystem turnover partitioning. Commun Biol 4: 1-12.

Seymour, M., Edwards, F.K., Cosby, B.J., Kelly, M.G., Bruyn, M. de, Carvalho, G.R., and Creer, S. (2020) Executing multi-taxa eDNA ecological assessment via traditional metrics and interactive networks. Sci Total Environ 729: 138801.

Sheremet, O., Healey, J.R., Quine, C.P., and Hanley, N. (2017) Public Preferences and Willingness to Pay for Forest Disease Control in the UK. J Agric Econ 68: 781-800.

Sigsgaard, E.E., Carl, H., Møller, P.R., and Thomsen, P.F. (2015) Monitoring the near-extinct European weather loach in Denmark based on environmental DNA from water samples. Biol Conserv 183: 46-52.

Simon, K.S., and Townsend, C.R. (2003) Impacts of freshwater invaders at different levels of ecological organisation, with emphasis on salmonids and ecosystem consequences. Freshw Biol 48: 982-994.

Simon, K.S., Townsend, C.R., Biggs, B.J.F., Bowden, W.B., and Frew, R.D. (2004) Habitat-specific nitrogen dynamics in New Zealand streams containing native or invasive fish. Ecosystems 7: 777792.

Sloat, M.R., Fraser, D.J., Dunham, J.B., Falke, J.A., Jordan, C.E., McMillan, J.R., and Ohms, H.A. (2014) Ecological and evolutionary patterns of freshwater maturation in Pacific and Atlantic salmonines. Rev Fish Biol Fish 24: 689-707.

Soto, D., Arismendi, I., González, J., Sanzana, J., Jara, F., Jara, C., et al. (2006) Southern Chile, trout and salmon country: invasion patterns and threats for native species. Rev Chil Hist Nat 79: 97-117.

Spens, J., Evans, A.R., Halfmaerten, D., Knudsen, S.W., Sengupta, M.E., Mak, S.S.T., et al. (2017) Comparison of capture and storage methods for aqueous macrobial eDNA using an optimized extraction protocol: advantage of enclosed filter. Methods Ecol Evol 8: 635-645.

Stanley, E.H., and Doyle, M.W. (2002) A geomorphic perspective on nutrient retention following dam removal. Bioscience 52: 693-701.

Steenweg, R.J., Crossin, G.T., Kyser, T.K., Merkel, F.R., Gilchrist, H.G., Hennin, H.L., et al. (2017) Stable isotopes can be used to infer the overwintering locations of prebreeding marine birds in the 
References

Canadian Arctic. Ecol Evol 7: 8742-8752.

Steinmann, P., Keiser, J., Bos, R., Tanner, M., and Utzinger, J. (2006) Schistosomiasis and water resources development: systematic review, meta-analysis, and estimates of people at risk. Lancet Infect dieseases 6: 411-425.

Stepien, C., and Tumeo, M. (2006) Invasion genetics of Ponto-Caspian gobies in the Great Lakes: a "cryptic" species, absent of founder effects, and predicting the impacts of an introduced species. Biol Invasions 8: 61-78.

Stewart, L. (1973) Fisheries of the Falkland Islands. Overseas Dev Adm.

Stewart, L. (1980) A history of migratory salmon acclimatization experiments in parts of the southern hemisphere and the possible effects of oceanic currents and gyres upon their outcome. Adv Mar Biol 17: $397-466$.

Sundqvist, L., Keenan, K., Zackrisson, M., Prodöhl, P., and Kleinhans, D. (2016) Directional genetic differentiation and relative migration. Ecol Evol 6: 3461-3475.

Sušnik Bajec, S., Pustovrh, G., Jesenšek, D., and Snoj, A. (2015) Population genetic SNP analysis of marble and brown trout in a hybridization zone of the Adriatic watershed in Slovenia. Biol Conserv 184: 239-250.

Suzuki, K.W., Kasai, A., Nakayama, K., and Tanaka, M. (2005) Differential isotopic enrichment and half-life among tissues in Japanese temperate bass (Lateolabrax japonicus) juveniles: implications for analyzing migration. Can J Fish Aquat Sci 62: 671-678.

Szekeres, P., Brownscombe, J.W., Cull, F., Danylchuk, A.J., Shultz, A.D., Suski, C.D., et al. (2014) Physiological and behavioural consequences of cold shock on bone fish (Albula vulpes) in The Bahamas. J Exp Mar Bio Ecol 459: 1-7.

Szekeres, P., Eliason, E.J., Lapointe, D., Donaldson, M.R., Brownscombe, J.W., and Cooke, S.J. (2016) On the neglected cold side of climate change and what it means to fish. Clim Res 69: 239-245.

Taal, I., Kesler, M., Saks, L., Rohtla, M., Verliin, A., Svirgsden, R., et al. (2014) Evidence for an autumn downstream migration of Atlantic salmon Salmo salar (Linnaeus) and brown trout Salmo trutta (Linnaeus) parr to the Baltic Sea. Helgol Mar Res 68: 373-377.

Tabak, M.A., Piaggio, A.J., Miller, R.S., Sweitzer, R.A., and Ernest, H.B. (2017) Anthropogenic factors predict movement of an invasive species. Ecosphere $\mathbf{8}$.

Taberlet, P., Coissac, E., Hajibabaei, M., and Rieseberg, L.H. (2012a) Environmental DNA. Mol Ecol 
21: $1789-1793$.

Taberlet, P., Coissac, E., Pompanon, F., Brochmann, C., and Willerslev, E. (2012b) Towards nextgeneration biodiversity assessment using DNA metabarcoding. Mol Ecol 21: 2045-2050.

Taberlet, P., Waits, L.P., and Luikart, G. (1999) Noninvasive genetic sampling: look before you leap. Trends Ecol Evol 14: 323-327.

Takahara, T., Minamoto, T., and Doi, H. (2013) Using Environmental DNA to Estimate the Distribution of an Invasive Fish Species in Ponds. PLoS One 8: 1-5.

Takahara, T., Minamoto, T., Yamanaka, H., Doi, H., and Kawabata, Z. (2012) Estimation of fish biomass using environmental DNA. PLoS One 7: 3-10.

Taylor, E.B. (2004) An analysis of homogenization and differentiation of Canadian freshwater fish faunas with an emphasis on British Columbia. Can J Fish Aquat Sci 61: 68-79.

Thioulouse, J., Dray, S., Dufour, A., Siberchicot, A., Jombart, T., and Pavoine, S. (2018) Multivariate analysis of ecological data with ade4. Springer, New York.

Thompson, R.M. (2016) Consequences of altered temperature regimes for emerging freshwater invertebrates. Aquat Sci 79: 265-276.

Thomsen, P.F., Kielgast, J., Iversen, L.L., Wiuf, C., Rasmussen, M., Gilbert, M.T.P., et al. (2012) Monitoring endangered freshwater biodiversity using environmental DNA. Mol Ecol 21: 2565-2573.

Thomson, M., and Lyndon, A.R. (2018) Comparing anadromous brown trout Salmo trutta in small, neighbouring catchments across contrasting landscapes: What is the role of environment in determining life-history characteristics? J Fish Biol 92: 593-606.

Tieszen, L.L., Boutton, T.W., Tesdahl, K.G., and Slade, N.A. (1983) Fractionation and turnover of stable carbon isotopes in animal tissues: Implications for $\delta^{13} \mathrm{C}$ analysis of diet. Oecologia 57: 32-37.

Toussaint, A., Beauchard, O., Oberdorff, T., Brosse, S., and Villéger, S. (2016) Worldwide freshwater fish homogenization is driven by a few widespread non-native species. Biol Invasions 18: 1295-1304.

Townsend, C.R. (1996) Invasion biology and ecological impacts of brown trout Salmo trutta in New Zealand. Biol Conserv 78: 13-22.

Townsend, C.R. (2003) Individual, Population, Community, and Ecosystem Consequences of a Fish Invader in New Zealand StreamsConsecuencias de un Pez Invasor sobre Individuos, Poblaciones, Comunidades y Ecosistema en Arroyos de Nueva Zelanda. Conserv Biol 17: 38-47. 
References

Townsend, C.R., and Crowl, T.A. (1991) Fragmented Population Structure in a Native New Zealand Fish: An Effect of Introduced Brown Trout? Oikos 61: 347.

Turner, C.R., Barnes, M.A., Xu, C.C.Y., Jones, S.E., Jerde, C.L., and Lodge, D.M. (2014) Particle size distribution and optimal capture of aqueous macrobial eDNA. Methods Ecol Evol 5: 676-684.

Turner, C.R., Uy, K.L., and Everhart, R.C. (2015) Fish environmental DNA is more concentrated in aquatic sediments than surface water. Biol Conserv 183: 93-102.

Turvey, S.T., Pitman, R.L., Taylor, B.L., Barlow, J., Akamatsu, T., Barrett, L.A., et al. (2007) First human-caused extinction of a cetacean species? Biol Lett 3: 537-540.

Tzadik, O.E., Curtis, J.S., Granneman, J.E., Kurth, B.N., Pusack, T.J., Wallace, A.A., et al. (2017) Chemical archives in fishes beyond otoliths: A review on the use of other body parts as chronological recorders of microchemical constituents for expanding interpretations of environmental, ecological, and life-history changes. Limnol Oceanogr Methods 15: 238-263.

Valentini, A., Taberlet, P., Miaud, C., Civade, R., Herder, J., Thomsen, P.F., et al. (2016) Nextgeneration monitoring of aquatic biodiversity using environmental DNA metabarcoding. Mol Ecol $\mathbf{2 5}$ : 929-942.

Valiente, A.G., Ayllon, F., Nuñez, P., Juanes, F., and Garcia-Vazquez, E. (2010a) Not all lineages are equally invasive: genetic origin and life-history in Atlantic salmon and brown trout acclimated to the Southern Hemisphere. Biol Invasions 12: 3485-3495.

Valiente, A.G., Juanes, F., Nuñez, P., and Garcia-Vazquez, E. (2010b) Brown trout (Salmo trutta) invasiveness: Plasticity in life-history is more important than genetic variability. Biol Invasions 12: $451-462$.

Vanhaecke, D., Garcia de Leaniz, C., Gajardo, G., Dunham, J., Giannico, G., and Consuegra, S. (2015) Genetic signatures of historical dispersal of fish threatened by biological invasions: the case of galaxiids in South America. J Biogeogr 42: 1942-1952.

Vanhaecke, D., Garcia de Leaniz, C., Gajardo, G., Thomas, C.J., and Consuegra, S. (2012a) Metapopulation dynamics of a diadromous galaxiid fish and potential effects of salmonid aquaculture. Freshw Biol 57: 1241-1252.

Vanhaecke, D., Garcia de Leaniz, C., Gajardo, G., Young, K., Sanzana, J., Orellana, G., et al. (2012b) DNA barcoding and microsatellites help species delimitation and hybrid identification in endangered galaxiid fishes. PLoS One 7: 1-10.

Vega, G.C., and Wiens, J.J. (2012) Why are there so few fish in the sea? Proc R Soc B 279: 2323- 
References

2329.

Vose, D. (2008) Risk analysis: a quantitative guide. Wiley, Germany.

Weir, B.S., and Cockerham, C.C. (1984) Estimating F-statistics for the analysis of population structure. Evolution (NY) 38: 1358-1370.

Welcomme, R.L., Cowx, I.G., Coates, D., Bènè, C., Funge-Smith, S., Halls, A., and Lorenzen, K. (2010) Inland capture fisheries. Philos Trans R Soc B 365: 2881-2896.

Westley, P.A.H., and Fleming, I.A. (2011) Landscape factors that shape a slow and persistent aquatic invasion: brown trout in Newfoundland 1883-2010. Divers Distrib 17: 566-579.

Wilcox, T.M., McKelvey, K.S., Young, M.K., Jane, S.F., Lowe, W.H., Whiteley, A.R., and Schwartz, M.K. (2013) Robust detection of rare species using environmental DNA: the importance of primer specificity. PLoS One 8: 1-9.

Wild Trout Trust (2021) Trout lifecycle. https://www.wildtrout.org/content/trout-lifecycle.

Willerslev, E., Cappellini, E., Boomsma, W., Nielsen, R., Hebsgaard, M.B., Brand, T.B., et al. (2007) Ancient Biomolecules from Deep Ice Cores Reveal a Forested. Science 317: 111-115.

Williamson, M. (1993) Invaders, weeds and the risk from genetically manipulated organisms. Experientia 49: 219-224.

Williamson, M., and Fitter, A. (1996) The Varying Success of Invaders. Ecology 77: 1661-1666.

Wilson, C., and Wright, E. (2016) Using environmental DNA (eDNA) as a tool in Risk-Based Decision-Making.

Winter, E.R., Nyqvist, M., and Britton, J.R. (2019) Non-lethal sampling for stable isotope analysis of pike Esox lucius: how mucus, scale and fin tissue compare to muscle. J Fish Biol 95: 956-958.

Winter, E.R., Tummers, J.S., Aarestrup, K., Baktoft, H., and Lucas, M.C. (2016) Investigating the phenology of seaward migration of juvenile brown trout (Salmo trutta) in two European populations. Hydrobiologia 775: 139-151.

Wittwer, C.T. (2009) High-resolution DNA melting analysis: advancements and limitations. Hum Mutat 30: 857-859.

Wolf, D.E., Takebayashi, N., and Rieseberg, L.H. (2001) Predicting the risk of extinction through hybridization. Conserv Biol 15: 1039-1053.

Wollebaek, J., Heggenes, J., and Roed, K.H. (2018) Life histories and ecotype conservation in an 
References

adaptive vertebrate: Genetic constitution of piscivorous brown trout covaries with habitat stability. Ecol Evol 8: 2729-2745.

Woodford, D.J., and Impson, N.D. (2004) A preliminary assessment of the impact of alien rainbow trout (Oncorhynchus mykiss) on indigenous fishes of the upper Berg River, Western Cape Province, South Africa. African J Aquat Sci 29: 107-111.

World Conservation Monitoring Centre (1996) IUCN Red List of Threatened Species. https://dx.doi.org/10.2305/IUCN.UK.1996.RLTS.T1866A8504998.en.

World Wildlife Foundation (2016) Living Planet Report 2016.

Xenopoulos, M.A., Lodge, D.M., Alcamo, J., Märker, M., Schulze, K., and Vuuren, D.P. Van (2005) Scenarios of freshwater fish extinctions from climate change and water withdrawal. Glob Chang Biol 11: $1557-1564$.

Xie, Y., Zhang, X., Yang, J., Kim, S., Hong, S., Giesy, J.P., et al. (2018) eDNA-based bioassessment of coastal sediments impacted by an oil spill. Environ Pollut 238: 739-748.

Ye, J., Coulouris, G., Zaretskaya, I., Cutcutache, I., Rozen, S., and Madden, T.L. (2012) PrimerBLAST: a tool to design target-specific primers for polymerase chain reaction. BMC Bioinformatics 13: 134 .

Ye, J., McGinnis, S., and Madden, T.L. (2006) BLAST: Improvements for better sequence analysis. Nucleic Acids Res 34: 6-9.

Young, K.A., Dunham, J.B., Stephenson, J.F., Terreau, A., Thailly, A.F., Gajardo, G., and Garcia de Leaniz, C. (2010) A trial of two trouts: comparing the impacts of rainbow and brown trout on a native galaxiid. Anim Conserv 13: 399-410.

Young, K.A., Stephenson, J., Terreau, A., Thailly, A.F., Gajardo, G., and Leaniz, C.G. de (2009) The diversity of juvenile salmonids does not affect their competitive impact on a native galaxiid. Biol Invasions 11: 1955-1961.

Youngson, A.F., Mitchell, A.I., Noack, P.T., and Laird, L.M. (1997) Carotenoid pigment profiles distinguish anadromous and nonanadromous brown trout (Salmo trutta). Can J Fish Aquat Sci 54: 1064-1066.

Zhang, F., Li, Y., Guo, Z., and Murray, B.R. (2009) Climate warming and reproduction in Chinese alligators. Anim Conserv 12: 128-137.

Zimmerman, C.E. (2005) Relationship of otolith strontium-to-calcium ratios and salinity: 
References

experimental validation for juvenile salmonids. Can J Fish Aquat Sci 62: 88-97

Zuur, A.F., Ieno, E.N., Walker, N.J., Saveliev, A.A., and Smith, G.M. (2009) Mixed effects models and extensions in ecology with R. Springer Science \& Business Media. 


\section{Appendix 1: Supplementary Table and Figures}

Table S1. Model output and AIC for all possible models used to determine species distribution model. For information on predictor variables used see Table 3.1.

\begin{tabular}{|c|c|c|c|c|c|c|c|c|c|c|}
\hline Model & Eucl_dist_inv & Road_cross_No & Ap & $\begin{array}{l}\text { Coast_dist } \\
\text { intro }\end{array}$ & Coast_dist_inv & $\begin{array}{l}\text { Min_winter } \\
\text { _temp }\end{array}$ & Slope & Settle_dist & Road_dist & LC \\
\hline \multirow[t]{4}{*}{ Starting model } & $E=-0.169$ & $E=0.093$ & $E=-2.092$ & $E=0.029$ & $E=-0.038$ & $E=0.242$ & $E=-0.343$ & $E=0.121$ & $E=-0.173$ & $E=0.121$ \\
\hline & $S E=0.100$ & $\mathrm{SE}=0.087$ & $\mathrm{SE}=1.088$ & $\mathrm{SE}=0.024$ & $\mathrm{SE}=0.022$ & $\mathrm{SE}=0.178$ & $\mathrm{SE}=0.244$ & $\mathrm{SE}=0.102$ & $\mathrm{SE}=0.133$ & $\mathrm{SE}=0.120$ \\
\hline & $t=-1.695$ & $t=1.075$ & $t=-1.922$ & $t=1.223$ & $t=-1.740$ & $t=1.362$ & $t=-1.406$ & $t=1.178$ & $t=-1.302$ & $t=1.001$ \\
\hline & $p=0.090$ & $p=0.282$ & $p=0.055$ & $p=0.221$ & $p=0.082$ & $p=0.173$ & $p=0.160$ & $p=0.239$ & $p=0.193$ & $p=0.317$ \\
\hline Intermediate & $E=-0.168$ & $E=0.094$ & $E=-2.095$ & $E=0.029$ & $E=-0.038$ & $E=0.242$ & $E=-0.334$ & $\mathrm{E}=0.121$ & $E=-0.172$ & $\mathrm{E}=0.121$ \\
\hline \multirow[t]{3}{*}{ model 1} & $\mathrm{SE}=0.097$ & $\mathrm{SE}=0.086$ & $\mathrm{SE}=1.088$ & $\mathrm{SE}=0.024$ & $\mathrm{SE}=0.022$ & $\mathrm{SE}=0.177$ & $\mathrm{SE}=0.205$ & $\mathrm{SE}=0.102$ & $\mathrm{SE}=0.132$ & $\mathrm{SE}=0.120$ \\
\hline & $t=-1.731$ & $t=1.097$ & $t=-1.925$ & $t=1.229$ & $t=-1.746$ & $t=1.362$ & $t=-1.633$ & $t=1.195$ & $t=-1.303$ & $t=1.005$ \\
\hline & $p=0.083$ & $p=0.272$ & $p=0.054$ & $p=0.219$ & $p=0.081$ & $p=0.173$ & $p=0.103$ & $p=0.232$ & $p=0.193$ & $p=0.315$ \\
\hline Intermediate & $E=-0.171$ & $E=0.095$ & $E=-2.113$ & $E=0.029$ & $E=-0.038$ & $E=0.244$ & $E=-0.335$ & $E=0.120$ & $E=-0.173$ & $\mathrm{E}=0.120$ \\
\hline \multirow[t]{3}{*}{ model 2} & $S E=0.089$ & $\mathrm{SE}=0.085$ & $\mathrm{SE}=1.063$ & $\mathrm{SE}=0.022$ & $\mathrm{SE}=0.022$ & $\mathrm{SE}=0.174$ & $\mathrm{SE}=0.204$ & $\mathrm{SE}=0.099$ & $\mathrm{SE}=0.131$ & $\mathrm{SE}=0.120$ \\
\hline & $t=-1.922$ & $t=1.114$ & $t=-1.988$ & $t=1.294$ & $t=-1.743$ & $t=1.399$ & $t=-1.643$ & $t=1.209$ & $t=-1.319$ & $t=1.004$ \\
\hline & $p=0.055$ & $p=0.266$ & $p=0.047$ & $p=0.196$ & $p=0.081$ & $p=0.162$ & $p=0.100$ & $p=0.227$ & $p=0.187$ & $p=0.316$ \\
\hline Intermediate & $E=-0.172$ & $E=0.096$ & $E=-2.094$ & $E=0.028$ & $E=-0.037$ & $\mathrm{E}=0.241$ & $E=-0.341$ & $\mathrm{E}=0.116$ & $E=-0.173$ & $\mathrm{E}=0.118$ \\
\hline \multirow[t]{3}{*}{ model 3} & $S E=0.089$ & $S E=0.084$ & $\mathrm{SE}=1.057$ & $\mathrm{SE}=0.022$ & $\mathrm{SE}=0.021$ & $\mathrm{SE}=0.174$ & $S E=0.202$ & $S E=0.097$ & $\mathrm{SE}=0.131$ & $\mathrm{SE}=0.118$ \\
\hline & $t=-1.924$ & $t=1.144$ & $t=-1.981$ & $t=1.291$ & $t=-1.744$ & $t=1.386$ & $t=-1.692$ & $t=1.192$ & $t=-1.321$ & $t=0.995$ \\
\hline & $p=0.054$ & $p=0.253$ & $p=0.048$ & $p=0.197$ & $p=0.081$ & $p=0.166$ & $p=0.091$ & $p=0.233$ & $p=0.186$ & $p=0.320$ \\
\hline Intermediate & $E=-0.176$ & $E=0.094$ & $E=-2.099$ & $E=0.029$ & $E=-0.037$ & $\mathrm{E}=0.255$ & $E=-0.340$ & $E=0.125$ & $E=-0.176$ & $\mathrm{E}=0.120$ \\
\hline \multirow[t]{3}{*}{ model 4} & $\mathrm{SE}=0.087$ & $\mathrm{SE}=0.084$ & $\mathrm{SE}=1.058$ & $\mathrm{SE}=0.021$ & $\mathrm{SE}=0.021$ & $S E=0.165$ & $S E=0.201$ & $\mathrm{SE}=0.092$ & $\mathrm{SE}=0.130$ & $S E=0.118$ \\
\hline & $t=-2.008$ & $t=1.114$ & $t=-1.983$ & $t=1.361$ & $t=-1.732$ & $t=1.364$ & $t=-1.695$ & $t=1.1347$ & $t=-1.348$ & $t=1.019$ \\
\hline & $p=0.045$ & $p=0.265$ & $p=0.047$ & $p=0.174$ & $p=0.083$ & $p=0.173$ & $p=0.090$ & $p=0.178$ & $p=0.178$ & $p=0.308$ \\
\hline Intermediate & $\mathrm{E}=-0.171$ & $\mathrm{E}=0.095$ & $E=-2.161$ & $E=0.030$ & $E=-0.038$ & $\mathrm{E}=0.239$ & $\mathrm{E}=-0.320$ & $\mathrm{E}=0.103$ & $E=-0.081$ & $\mathrm{E}=0.113$ \\
\hline \multirow[t]{3}{*}{ model 5} & $\mathrm{SE}=0.086$ & $\mathrm{SE}=0.085$ & $\mathrm{SE}=1.044$ & $\mathrm{SE}=0.021$ & $\mathrm{SE}=0.021$ & $S E=0.163$ & $\mathrm{SE}=0.196$ & $\mathrm{SE}=0.083$ & $\mathrm{SE}=0.129$ & $\mathrm{SE}=0.118$ \\
\hline & $t=-1.988$ & $t=1.125$ & $t=-2.070$ & $t=1.438$ & $t=-1.833$ & $t=1.468$ & $t=-1.631$ & $t=1.240$ & $t=-1.405$ & $t=0.960$ \\
\hline & $p=0.047$ & $p=0.261$ & $p=0.039$ & $p=0.151$ & $p=0.067$ & $p=0.142$ & $p=0.130$ & $p=0.215$ & $p=0.160$ & $p=0.337$ \\
\hline Intermediate & $E=-0.175$ & $E=0.132$ & $E=-2.361$ & $E=0.031$ & $\mathrm{E}=-0.037$ & $E=0.217$ & $\mathrm{E}=-0.318$ & $E=0.112$ & $E=-0.205$ & $\mathrm{E}=0.117$ \\
\hline \multirow[t]{3}{*}{ model 6} & $\mathrm{SE}=0.085$ & $\mathrm{SE}=0.078$ & $\mathrm{SE}=1.030$ & $\mathrm{SE}=0.021$ & $\mathrm{SE}=0.021$ & $\mathrm{SE}=0.157$ & $\mathrm{SE}=0.195$ & $\mathrm{SE}=0.084$ & $\mathrm{SE}=0.127$ & $\mathrm{SE}=0.118$ \\
\hline & $t=-2.061$ & $t=1.706$ & $t=-2.292$ & $t=1.456$ & $t=-1.779$ & $t=1.382$ & $t=-1.635$ & $t=1.333$ & $t=-1.611$ & $t=0.992$ \\
\hline & $p=0.039$ & $p=0.088$ & $p=0.022$ & $p=0.145$ & $p=0.075$ & $p=0.167$ & $p=0.102$ & $p=0.182$ & $p=0.107$ & $p=0.321$ \\
\hline Intermediate & $E=-0.185$ & $\mathrm{E}=0.125$ & $E=-2.287$ & $E=0.026$ & $\mathrm{E}=-0.035$ & $\mathrm{E}=0.167$ & $E=-0.287$ & $\mathrm{E}=0.117$ & $E=-0.193$ & $E=0.126$ \\
\hline \multirow[t]{3}{*}{ model 7} & $\mathrm{SE}=0.083$ & $\mathrm{SE}=0.075$ & $\mathrm{SE}=1.014$ & $\mathrm{SE}=0.020$ & $\mathrm{SE}=0.020$ & $\mathrm{SE}=0.133$ & $\mathrm{SE}=0.188$ & $\mathrm{SE}=0.083$ & $\mathrm{SE}=0.122$ & $\mathrm{SE}=0.117$ \\
\hline & $t=-2.243$ & $t=1.663$ & $t=-2.255$ & $t=1.332$ & $t=-1.729$ & $t=1.254$ & $t=-1.523$ & $t=1.404$ & $t=-1.582$ & $t=1.074$ \\
\hline & $p=0.025$ & $p=0.096$ & $p=0.024$ & $p=0.183$ & $p=0.084$ & $p=0.210$ & $p=0.128$ & $p=0.160$ & $p=0.144$ & $p=0.283$ \\
\hline Intermediate & $E=-2.05$ & $E=0.149$ & $E=-2.326$ & $E=0.028$ & $E=-0.035$ & $E=0.179$ & $E=-0.263$ & $\mathrm{E}=0.120$ & $E=-0.152$ & $E=0.128$ \\
\hline \multirow[t]{3}{*}{ model 8} & $\mathrm{SE}=0.081$ & $\mathrm{SE}=0.078$ & $\mathrm{SE}=1.008$ & $\mathrm{SE}=0.019$ & $\mathrm{SE}=0.020$ & $\mathrm{SE}=0.128$ & $\mathrm{SE}=0.182$ & $S E=0.083$ & $\mathrm{SE}=0.109$ & $\mathrm{SE}=0.114$ \\
\hline & $t=-2.528$ & $t=1.918$ & $t=-2.308$ & $t=1.461$ & $t=-1.729$ & $t=1.401$ & $t=-1.443$ & $t=1.457$ & $t=-1.392$ & $t=1.131$ \\
\hline & $p=0.012$ & $p=0.055$ & $p=0.021$ & $p=0.144$ & $p=0.123$ & $p=0.161$ & $p=0.149$ & $p=0.145$ & $p=0.164$ & $p=0.258$ \\
\hline
\end{tabular}


Appendix 1: Supplementary Table and Figures

\begin{tabular}{|c|c|c|c|c|c|c|c|c|c|}
\hline Model & BFL_share & EW & BFL & Rain & Intro_site & Flow_accum & $\begin{array}{l}\text { Eucl_dist } \\
\text { _intro }\end{array}$ & Alt & AIC \\
\hline \multirow[t]{4}{*}{ Starting model } & $E=2 \times 10^{-5}$ & $E=-0.869$ & $E=-0.965$ & $E=0.002$ & $E=-0.291$ & $E=-0.219$ & $E=-0.005$ & $E=0.002$ & 112.76 \\
\hline & $S E=2 \times 10^{-5}$ & $\mathrm{SE}=0.926$ & $\mathrm{SE}=1.137$ & $\mathrm{SE}=0.004$ & $S E=0.866$ & $\mathrm{SE}=1.401$ & $\mathrm{SE}=0.079$ & $\mathrm{SE}=0.025$ & \\
\hline & $t=1.215$ & $t=-0.939$ & $t=-0.849$ & $t=0.462$ & $t=-0.336$ & $t=-0.156$ & $t=-0.067$ & $t=0.063$ & \\
\hline & $p=0.224$ & $p=0.348$ & $p=0.396$ & $p=0.644$ & $p=0.737$ & $p=0.876$ & $p=0.947$ & $p=0.950$ & \\
\hline Intermediate & $E=2 \times 10^{-5}$ & $E=-0.872$ & $E=-0.957$ & $E=0.002$ & $E=-0.285$ & $E=-0.228$ & $E=-0.006$ & & 110.77 \\
\hline \multirow[t]{3}{*}{ model 1} & $S E=2 \times 10^{-5}$ & $\mathrm{SE}=0.925$ & $\mathrm{SE}=1.128$ & $S E=0.004$ & $\mathrm{SE}=0.861$ & $\mathrm{SE}=1.392$ & $\mathrm{SE}=0.078$ & & \\
\hline & $t=1.221$ & $t=-0.943$ & $t=-0.848$ & $t=0.535$ & $t=-0.331$ & $t=-0.164$ & $t=-0.075$ & & \\
\hline & $p=0.222$ & $p=0.346$ & $p=0.396$ & $p=0.593$ & $p=0.740$ & $p=0.870$ & $p=0.940$ & & \\
\hline Intermediate & $E=2 \times 10^{-5}$ & $E=09.885$ & $E=-0.936$ & $E=0.002$ & $E=-0.279$ & $E=-0.264$ & & & 108.77 \\
\hline \multirow[t]{3}{*}{ model 2} & $\mathrm{SE}=2 \times 10^{-5}$ & $\mathrm{SE}=0.908$ & $\mathrm{SE}=1.092$ & $\mathrm{SE}=0.004$ & $\mathrm{SE}=0.857$ & $\mathrm{SE}=1.307$ & & & \\
\hline & $t=1.227$ & $t=-0.975$ & $t=-0.857$ & $t=0.535$ & $t=-0.325$ & $t=-0.202$ & & & \\
\hline & $p=0.220$ & $p=0.330$ & $p=0.392$ & $p=0.592$ & $p=0.745$ & $p=0.840$ & & & \\
\hline Intermediate & $E=2 \times 10^{-5}$ & $E=-0.895$ & $E=-0.956$ & $E=0.002$ & $E=-0.274$ & & & & 106.82 \\
\hline \multirow[t]{3}{*}{ model 3} & $S E=2 \times 10^{-5}$ & $\mathrm{SE}=0.907$ & $\mathrm{SE}=1.092$ & $S E=0.004$ & $S E=0.856$ & & & & \\
\hline & $t=1.241$ & $t=-0.986$ & $t=-0.876$ & $t=0.499$ & $t=-0.321$ & & & & \\
\hline & $p=0.125$ & $p=0.324$ & $p=0.381$ & $p=0.618$ & $p=0.749$ & & & & \\
\hline Intermediate & $E=2 \times 10^{-5}$ & $E=-0.814$ & $E=-0.905$ & $E=0.002$ & & & & & 104.92 \\
\hline \multirow[t]{3}{*}{ model 4} & $\mathrm{SE}=2 \times 10^{-5}$ & $\mathrm{SE}=0.864$ & $\mathrm{SE}=1.018$ & $\mathrm{SE}=0.004$ & & & & & \\
\hline & $t=1.212$ & $t=-0.942$ & $t=-0.837$ & $t=0.556$ & & & & & \\
\hline & $p=0.226$ & $p=0.346$ & $p=0.403$ & $p=0.579$ & & & & & \\
\hline Intermediate & $E=2 \times 10^{-5}$ & $E=-0.717$ & $E=-0.871$ & & & & & & 103.23 \\
\hline \multirow[t]{3}{*}{ model 5} & $S E=2 \times 10^{-5}$ & $S E=0.855$ & $\mathrm{SE}=1.084$ & & & & & & \\
\hline & $t=1.260$ & $t=-0.838$ & $t=-0.804$ & & & & & & \\
\hline & $p=0.208$ & $p=0.402$ & $p=0.422$ & & & & & & \\
\hline Intermediate & $E=2 \times 10^{-5}$ & $E=-0.524$ & & & & & & & 101.89 \\
\hline \multirow[t]{3}{*}{ model 6} & $S E=1 \times 10^{-5}$ & $S E=0.817$ & & & & & & & \\
\hline & $t=1.072$ & $t=-0.641$ & & & & & & & \\
\hline & $p=0.284$ & $p=0.521$ & & & & & & & \\
\hline Intermediate & $E=1 \times 10^{-5}$ & & & & & & & & 100.29 \\
\hline \multirow[t]{3}{*}{ model 7} & $S E=1 \times 10^{-5}$ & & & & & & & & \\
\hline & $t=0.985$ & & & & & & & & \\
\hline & $p=0.325$ & & & & & & & & \\
\hline $\begin{array}{l}\text { Intermediate } \\
\text { model } 8\end{array}$ & & & & & & & & & 99.489 \\
\hline
\end{tabular}


Appendix 1: Supplementary Table and Figures

\begin{tabular}{|c|c|c|c|c|c|c|c|c|c|c|}
\hline Model & Eucl_dist_inv & Road_cross_No & Ap & $\begin{array}{l}\text { Coast_dist } \\
\text { intro }\end{array}$ & Coast_dist_inv & $\begin{array}{l}\text { Min_winter } \\
\text { _temp }\end{array}$ & Slope & Settle_dist & Road_dist & AIC \\
\hline $\begin{array}{l}\text { Intermediate } \\
\text { model } 9\end{array}$ & $\begin{array}{l}\mathrm{E}=-0.195 \\
\mathrm{SE}=0.079 \\
t=-2.475 \\
p=0.013\end{array}$ & $\begin{array}{l}\mathrm{E}=0.141 \\
\mathrm{SE}=0.076 \\
t=1.864 \\
p=0.062\end{array}$ & $\begin{array}{l}\mathrm{E}=-2.480 \\
\mathrm{SE}=1.003 \\
t=-2.471 \\
p=0.014\end{array}$ & $\begin{array}{l}\mathrm{E}=0.031 \\
\mathrm{SE}=0.018 \\
t=1.705 \\
p=0.088\end{array}$ & $\begin{array}{l}\mathrm{E}=-0.028 \\
\mathrm{SE}=0.018 \\
t=-1.577 \\
p=0.115\end{array}$ & $\begin{array}{l}\mathrm{E}=0.192 \\
\mathrm{SE}=0.126 \\
t=1.526 \\
p=0.127\end{array}$ & $\begin{array}{l}\mathrm{E}=-0.254 \\
\mathrm{SE}=0.176 \\
t=-1.441 \\
p=0.150\end{array}$ & $\begin{array}{l}\mathrm{E}=0.120 \\
\mathrm{SE}=0.083 \\
t=1.452 \\
p=0.147\end{array}$ & $\begin{array}{l}\mathrm{E}=-0.154 \\
\mathrm{SE}=0.110 \\
t=-1.401 \\
p=0.161\end{array}$ & 98.84 \\
\hline $\begin{array}{l}\text { Intermediate } \\
\text { model } 10\end{array}$ & $\begin{array}{l}\mathrm{E}=-0.204 \\
\mathrm{SE}=0.077 \\
t=-2.661 \\
p=0.008\end{array}$ & $\begin{array}{l}\mathrm{E}=0.167 \\
\mathrm{SE}=0.077 \\
t=2.176 \\
p=0.030\end{array}$ & $\begin{array}{l}\mathrm{E}=-2.074 \\
\mathrm{SE}=0.920 \\
t=-2.254 \\
p=0.024\end{array}$ & $\begin{array}{l}\mathrm{E}=0.020 \\
\mathrm{SE}=0.016 \\
t=1.237 \\
p=0.216\end{array}$ & $\begin{array}{l}\mathrm{E}=-0.026 \\
\mathrm{SE}=0.017 \\
t=-1.466 \\
p=0.143\end{array}$ & $\begin{array}{l}\mathrm{E}=0.110 \\
\mathrm{SE}=0.099 \\
t=1.108 \\
p=0.028\end{array}$ & $\begin{array}{l}\mathrm{E}=-0.187 \\
\mathrm{SE}=0.167 \\
t=-1.123 \\
p=0.262\end{array}$ & $\begin{array}{l}\mathrm{E}=0.064 \\
\mathrm{SE}=0.073 \\
t=0.879 \\
p=0.379\end{array}$ & & 99.14 \\
\hline $\begin{array}{l}\text { Intermediate } \\
\text { model } 11\end{array}$ & $\begin{array}{l}\mathrm{E}=-0.199 \\
\mathrm{SE}=0.074 \\
t=-2.690 \\
p=0.007\end{array}$ & $\begin{array}{l}\mathrm{E}=0.168 \\
\mathrm{SE}=0.078 \\
t=2.143 \\
p=0.032\end{array}$ & $\begin{array}{l}\mathrm{E}=-1.996 \\
\mathrm{SE}=0.929 \\
t=-2.148 \\
p=0.032\end{array}$ & $\begin{array}{l}\mathrm{E}=0.022 \\
\mathrm{SE}=0.016 \\
t=1.403 \\
p=0.161\end{array}$ & $\begin{array}{l}\mathrm{E}=-0.026 \\
\mathrm{SE}=0.018 \\
t=-1.495 \\
p=0.135\end{array}$ & $\begin{array}{l}\mathrm{E}=1.112 \\
\mathrm{SE}=0.098 \\
t=1.147 \\
p=0.251\end{array}$ & $\begin{array}{l}\mathrm{E}=-0.146 \\
\mathrm{SE}=0.160 \\
t=-0.913 \\
p=0.361\end{array}$ & & & 97.94 \\
\hline $\begin{array}{l}\text { Intermediate } \\
\text { model } 12\end{array}$ & $\begin{array}{l}\mathrm{E}=-0.215 \\
\mathrm{SE}=0.073 \\
t=-2.928 \\
p=0.003\end{array}$ & $\begin{array}{l}\mathrm{E}=0.151 \\
\mathrm{SE}=0.073 \\
t=2.065 \\
p=0.039\end{array}$ & $\begin{array}{l}\mathrm{E}=-2.059 \\
\mathrm{SE}=0.918 \\
t=-2.242 \\
p=0.025\end{array}$ & $\begin{array}{l}\mathrm{E}=0.022 \\
\mathrm{SE}=0.016 \\
t=1.382 \\
p=0.167\end{array}$ & $\begin{array}{l}\mathrm{E}=-0.022 \\
\mathrm{SE}=0.017 \\
t=-1.319 \\
p=0.187\end{array}$ & $\begin{array}{l}\mathrm{E}=0.093 \\
\mathrm{SE}=0.096 \\
t=0.965 \\
p=0.335\end{array}$ & & & & 96.78 \\
\hline $\begin{array}{l}\text { Intermediate } \\
\text { model } 13\end{array}$ & $\begin{array}{l}\mathrm{E}=-0.210 \\
\mathrm{SE}=0.071 \\
t=-2.976 \\
p=0.003\end{array}$ & $\begin{array}{l}\mathrm{E}=0.149 \\
\mathrm{SE}=0.074 \\
t=2.007 \\
p=0.045\end{array}$ & $\begin{array}{l}\mathrm{E}=-2.110 \\
\mathrm{SE}=0.902 \\
t=-2.338 \\
p=0.019\end{array}$ & $\begin{array}{l}\mathrm{E}=0.022 \\
\mathrm{SE}=0.016 \\
t=1.404 \\
p=0.160\end{array}$ & $\begin{array}{l}\mathrm{E}=-0.022 \\
\mathrm{SE}=0.016 \\
t=-1.357 \\
p=0.175\end{array}$ & & & & & 95.72 \\
\hline $\begin{array}{l}\text { Intermediate } \\
\text { model } 14\end{array}$ & $\begin{array}{l}\mathrm{E}=-0.246 \\
\mathrm{SE}=0.069 \\
t=-3.573 \\
p=<0.001\end{array}$ & $\begin{array}{l}\mathrm{E}=0.153 \\
\mathrm{SE}=0.071 \\
t=2.155 \\
p=0.031\end{array}$ & $\begin{array}{l}\mathrm{E}=-1.883 \\
\mathrm{SE}=0.868 \\
t=-2.171 \\
p=0.030\end{array}$ & $\begin{array}{l}\mathrm{E}=0.010 \\
\mathrm{SE}=0.012 \\
t=0.808 \\
p=0.419\end{array}$ & & & & & & 95.77 \\
\hline Final model & $\begin{array}{l}\mathrm{E}=-0.238 \\
\mathrm{SE}=0.067 \\
t=-3.559 \\
p=<0.001\end{array}$ & $\begin{array}{l}\mathrm{E}=0.156 \\
\mathrm{SE}=0.006 \\
t=2.370 \\
p=0.018\end{array}$ & $\begin{array}{l}\mathrm{E}=-1.572 \\
\mathrm{SE}=0.769 \\
t=-2.044 \\
p=0.041\end{array}$ & & & & & & & 94.46 \\
\hline
\end{tabular}




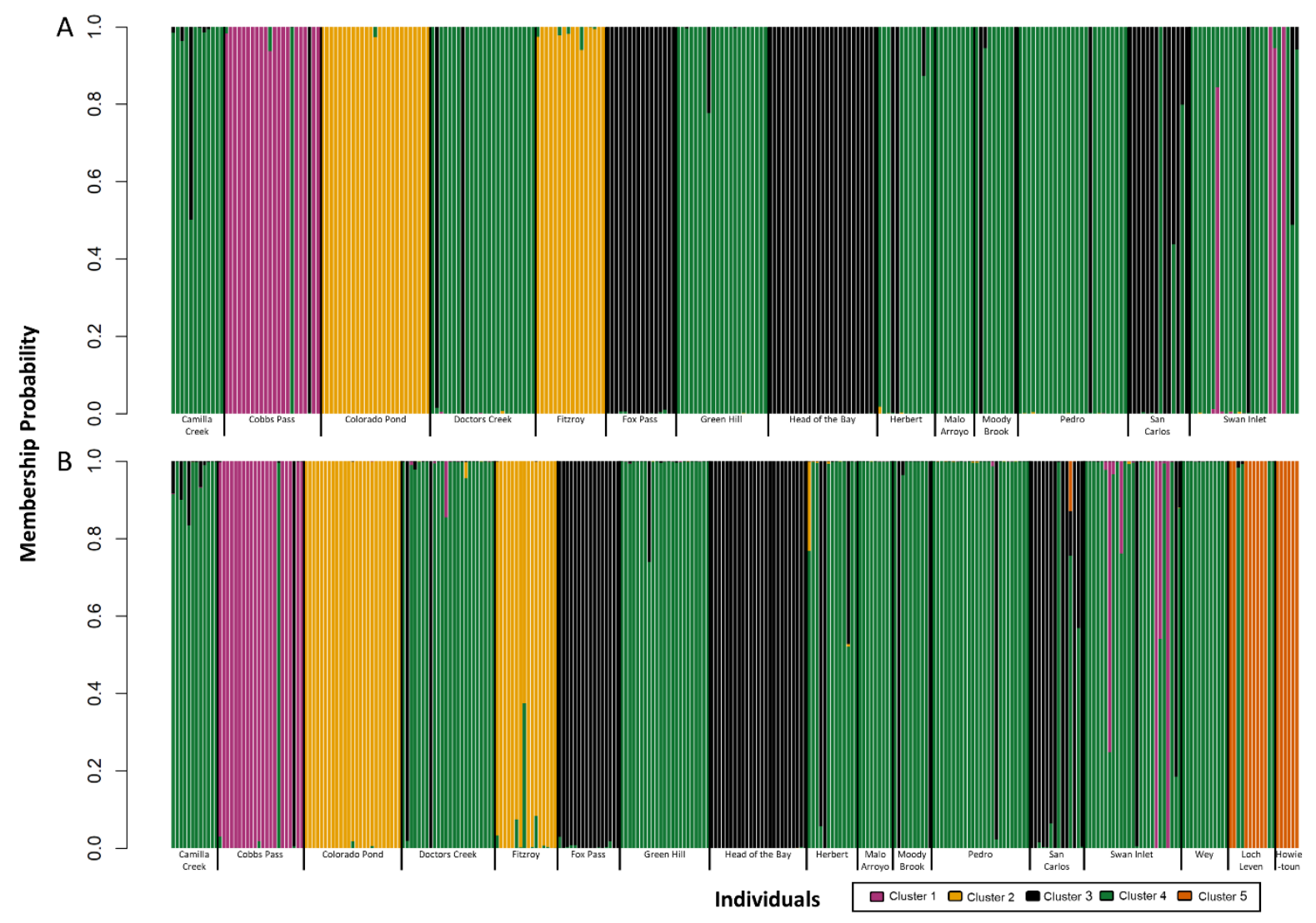

Figure S1. Population structure for Falkland Islands (A) and Falkland Islands GB comparison (B) when SNPs that significantly deviate from Hardy-Weinberg equilibrium are removed. A total of eight and nine SNPs were removed from Falkland Islands only and Falklands-GB comparisons, respectively. 
Appendix 1: Supplementary Table and Figures

Table S2. Breakdown of fish acoustically tagged in the San Carlos River, Falkland Islands, including latitude and longitude, acoustic tag number, Length $(\mathrm{mm})$, and date tagged.

\begin{tabular}{|c|c|c|c|c|c|}
\hline Fish ID & Acoustic tag & Length (mm) & Latitude & Longitude & Date \\
\hline R13.1 & 4451 & 536 & -51.5311 & -58.7603 & $30 / 09 / 2018$ \\
\hline R13.6 & 4449 & 345 & -51.5311 & -58.7603 & $30 / 09 / 2018$ \\
\hline $\mathrm{R} 13.10$ & 4452 & 447 & -51.5311 & -58.7603 & $30 / 09 / 2018$ \\
\hline R13.11 & 4450 & 397 & -51.5311 & -58.7603 & $30 / 09 / 2018$ \\
\hline R13.14 & 4446 & 334 & -51.5311 & -58.7603 & $30 / 09 / 2018$ \\
\hline R13.16 & 4448 & 347 & -51.5311 & -58.7603 & $30 / 09 / 2018$ \\
\hline $\mathrm{R} 13.23$ & 4441 & 309 & -51.5311 & -58.7603 & $30 / 09 / 2018$ \\
\hline $\mathrm{R} 13.26$ & 4443 & 412 & -51.5311 & -58.7603 & $30 / 09 / 2018$ \\
\hline $\mathrm{R} 13.27$ & 4445 & 501 & -51.5311 & -58.7603 & $30 / 09 / 2018$ \\
\hline $\mathrm{R} 13.28$ & 4439 & 331 & -51.5311 & -58.7603 & $30 / 09 / 2018$ \\
\hline R13.30 & 4444 & 328 & -51.5311 & -58.7603 & $30 / 09 / 2018$ \\
\hline R19.1 & 4453 & 423 & -51.5311 & -58.7606 & $14 / 10 / 2018$ \\
\hline R19.3 & 4455 & 341 & -51.5311 & -58.7606 & $14 / 10 / 2018$ \\
\hline R19.4 & 4464 & 325 & -51.5311 & -58.7606 & $14 / 10 / 2018$ \\
\hline R19.5 & 4454 & 545 & -51.5311 & -58.7606 & $14 / 10 / 2018$ \\
\hline R19.8 & 4466 & 403 & -51.5311 & -58.7606 & $14 / 10 / 2018$ \\
\hline R19.9 & 4458 & 320 & -51.5311 & -58.7606 & $14 / 10 / 2018$ \\
\hline R19.12 & 4459 & 305 & -51.5311 & -58.7606 & $14 / 10 / 2018$ \\
\hline R19.14 & 4462 & 277 & -51.5231 & -58.7056 & $14 / 10 / 2018$ \\
\hline R19.18 & 4465 & 188 & -51.5231 & -58.7056 & $14 / 10 / 2018$ \\
\hline R19.21 & 4461 & 495 & -51.5231 & -58.7056 & $14 / 10 / 2018$ \\
\hline R19.22 & 4463 & 198 & -51.5231 & -58.7056 & $14 / 10 / 2018$ \\
\hline R19.24 & 4460 & 329 & -51.5231 & -58.7056 & $14 / 10 / 2018$ \\
\hline R19.25 & 4457 & 175 & -51.5231 & -58.7056 & $14 / 10 / 2018$ \\
\hline R19.27 & 4456 & 544 & -51.5081 & -58.7769 & $14 / 10 / 2018$ \\
\hline
\end{tabular}


Appendix 1: Supplementary Table and Figures

Table S3. Breakdown of invertebrate's present (1) and absent (0) at each sampling site, number of samples for sample isotope analysis (N) and mean and standard error for Carbon and Nitrogen stable isotopes.

\begin{tabular}{|c|c|c|c|c|c|c|c|c|c|c|c|c|c|c|}
\hline \multirow{2}{*}{ Site } & \multirow{2}{*}{ Amphipoda } & \multirow{2}{*}{ Oligochaeta } & \multirow{2}{*}{ Hirudinea } & \multirow{2}{*}{ Diptera } & \multirow{2}{*}{ Coleoptera } & \multirow{2}{*}{ Gastropoda } & \multirow{2}{*}{ Plecoptera } & \multirow{2}{*}{ Tricoptera } & \multirow{2}{*}{ Unknown } & \multirow[t]{2}{*}{$\mathbf{N}$} & \multicolumn{2}{|c|}{$\delta^{13} \mathrm{C}$} & \multicolumn{2}{|c|}{$\delta^{15} \mathrm{~N}$} \\
\hline & & & & & & & & & & & Mean & SE & Mean & SE \\
\hline $\begin{array}{l}\text { Camilla } \\
\text { Creek }\end{array}$ & 1 & 0 & 0 & 1 & 0 & 0 & 0 & 1 & 0 & 2 & -27.3 & 0.3 & 68.3 & 3.1 \\
\hline $\begin{array}{l}\text { Colorado } \\
\text { Pond }\end{array}$ & 1 & 1 & 1 & 1 & 1 & 1 & 0 & 1 & 0 & 3 & -29.3 & 0.2 & 37.5 & 3.2 \\
\hline $\begin{array}{l}\text { Doctors } \\
\text { Creek }\end{array}$ & 1 & 1 & 0 & 1 & 0 & 1 & 0 & 1 & 1 & 3 & -28.6 & 1.3 & 8.1 & 2.6 \\
\hline Fitzroy & 1 & 1 & 0 & 1 & 0 & 0 & 1 & 1 & 1 & 1 & -26.7 & NA & 24.0 & NA \\
\hline $\begin{array}{l}\text { Green } \\
\text { Hill }\end{array}$ & 1 & 1 & 0 & 1 & 1 & 1 & 1 & 1 & 1 & 3 & -30.4 & 0.5 & 4.0 & 2.5 \\
\hline $\begin{array}{l}\text { Head of } \\
\text { the Bay }\end{array}$ & 1 & 0 & 0 & 1 & 0 & 0 & 0 & 1 & 1 & 0 & NA & NA & NA & NA \\
\hline Herbert & 1 & 1 & 1 & 1 & 0 & 1 & 1 & 1 & 1 & 3 & -28.7 & 1.5 & 7.1 & 2.5 \\
\hline $\begin{array}{l}\text { Malo } \\
\text { Arroyo }\end{array}$ & 1 & 1 & 1 & 1 & 0 & 1 & 0 & 1 & 0 & 2 & -26.7 & 2.1 & 11.5 & 12.6 \\
\hline $\begin{array}{l}\text { Mary } \\
\text { Hill } \\
\text { Quarry }\end{array}$ & 1 & 1 & 1 & 0 & 1 & 1 & 0 & 0 & 1 & 3 & -21.4 & 0.1 & 57.3 & 3.9 \\
\hline $\begin{array}{l}\text { Moody } \\
\text { Brook }\end{array}$ & 1 & 1 & 0 & 1 & 0 & 0 & 1 & 1 & 0 & 3 & -30.4 & 0.3 & 1.6 & 1.3 \\
\hline $\begin{array}{l}\text { San } \\
\text { Carlos }\end{array}$ & 1 & 1 & 1 & 1 & 0 & 1 & 1 & 1 & 1 & 3 & -28.6 & 0.3 & 0.1 & 0.1 \\
\hline
\end{tabular}


Appendix 1: Supplementary Table and Figures

Table S4. Stable isotope and sample data for fish from each sample site assigned to each cluster.

\begin{tabular}{|c|c|c|c|c|c|}
\hline Cluster & Site & $\delta^{13} \mathrm{C}$ & $\delta^{15} \mathbf{N}$ & Length & Silvery \\
\hline \multirow[t]{40}{*}{ Freshwater (1) } & Colorado Pond & -27.3 & 10.5 & 238 & 1 \\
\hline & Colorado Pond & -25.1 & 9.2 & 286 & 0 \\
\hline & Colorado Pond & -26.3 & 7.4 & 207 & 0 \\
\hline & Colorado Pond & -26.7 & 9.9 & 229 & 1 \\
\hline & Colorado Pond & -25.7 & 8.0 & 203 & 0 \\
\hline & Colorado Pond & -26.0 & 11.5 & 248 & 0 \\
\hline & Colorado Pond & -26.4 & 10.5 & 197 & 2 \\
\hline & Colorado Pond & -26.2 & 11.4 & 190 & 0 \\
\hline & Colorado Pond & -25.2 & 8.4 & 193 & 1 \\
\hline & Colorado Pond & -26.1 & 7.9 & 157 & 0 \\
\hline & Colorado Pond & -26.5 & 7.5 & 163 & 0 \\
\hline & Colorado Pond & -26.4 & 8.6 & 236 & 0 \\
\hline & Colorado Pond & -26.9 & 8.2 & 215 & 0 \\
\hline & Colorado Pond & -27.7 & 9.4 & 231 & 0 \\
\hline & Colorado Pond & -26.8 & 10.5 & 256 & 0 \\
\hline & Colorado Pond & -28.8 & 11.1 & 216 & 1 \\
\hline & Colorado Pond & -26.1 & 10.0 & 211 & 0 \\
\hline & Doctors Creek & -30.4 & 12.1 & 325 & 0 \\
\hline & Doctors Creek & -28.4 & 10.3 & 230 & 0 \\
\hline & Doctors Creek & -28.9 & 9.1 & 216 & 0 \\
\hline & Doctors Creek & -32.1 & 8.9 & 203 & 0 \\
\hline & Doctors Creek & -29.7 & 12.9 & 256 & 0 \\
\hline & Doctors Creek & -29.2 & 12.0 & 185 & 0 \\
\hline & Doctors Creek & -28.3 & 10.0 & 278 & 0 \\
\hline & Doctors Creek & -26.7 & 8.3 & 241 & 0 \\
\hline & Doctors Creek & -28.1 & 8.9 & 188 & 0 \\
\hline & Doctors Creek & -28.7 & 10.2 & 163 & 0 \\
\hline & Doctors Creek & -29.2 & 8.8 & 159 & 0 \\
\hline & Doctors Creek & -26.0 & 9.6 & 224 & 0 \\
\hline & Doctors Creek & -28.6 & 11.2 & 227 & 0 \\
\hline & Doctors Creek & -28.5 & 8.9 & 192 & 0 \\
\hline & Green Hill & -28.5 & 8.4 & 144 & 0 \\
\hline & Green Hill & -28.1 & 9.6 & 166 & 0 \\
\hline & Green Hill & -26.3 & 8.5 & 144 & 0 \\
\hline & Green Hill & -30.0 & 11.6 & 142 & 0 \\
\hline & Head of the Bay & -25.6 & 8.2 & 237 & 0 \\
\hline & Herbert & -28.1 & 11.9 & 244 & 0 \\
\hline & Moody Brook & -26.8 & 10.6 & 234 & 0 \\
\hline & Moody Brook & -25.9 & 8.8 & 188 & 0 \\
\hline & Moody Brook & -26.4 & 11.2 & 208 & 0 \\
\hline \multirow[t]{16}{*}{ Marine (2) } & Camilla Creek & -13.5 & 18.5 & 648 & 2 \\
\hline & Camilla Creek & -18.1 & 17.0 & 770 & 3 \\
\hline & Cobbs Pass & -15.8 & 15.9 & 199 & 1 \\
\hline & Cobbs Pass & -12.8 & 16.5 & 323 & 2 \\
\hline & Cobbs Pass & -10.7 & 13.2 & 254 & 0 \\
\hline & Doctors Creek & -14.0 & 16.5 & 276 & 3 \\
\hline & Fitzroy & -14.0 & 20.1 & 433 & 0 \\
\hline & Fitzroy & -15.5 & 9.0 & 210 & 0 \\
\hline & Head of the Bay & -11.4 & 17.3 & 444 & 2 \\
\hline & Head of the Bay & -13.5 & 14.9 & 267 & 3 \\
\hline & Head of the Bay & -13.3 & 17.0 & 216 & 3 \\
\hline & Head of the Bay & -14.3 & 20.0 & 515 & 2 \\
\hline & Head of the Bay & -10.0 & 17.8 & 350 & 2 \\
\hline & Head of the Bay & -13.7 & 16.4 & 416 & 2 \\
\hline & Head of the Bay & -14.9 & 16.6 & 410 & 3 \\
\hline & Head of the Bay & -14.1 & 16.6 & 245 & 3 \\
\hline
\end{tabular}




\begin{tabular}{|c|c|c|c|c|c|}
\hline & Head of the Bay & -15.0 & 16.9 & 399 & 2 \\
\hline & Head of the Bay & -18.4 & 17.9 & 231 & 3 \\
\hline & Head of the Bay & -16.2 & 18.2 & 272 & 2 \\
\hline & Herbert & -14.4 & 18.7 & 243 & 3 \\
\hline & San Carlos & -16.5 & 16.3 & 536 & 3 \\
\hline & San Carlos & -17.4 & 15.7 & 447 & 3 \\
\hline & San Carlos & -14.5 & 18.5 & 623 & 0 \\
\hline & San Carlos & -17.8 & 15.1 & 334 & 3 \\
\hline & San Carlos & -16.2 & 15.8 & 347 & 3 \\
\hline & San Carlos & -18.2 & 16.8 & 309 & 3 \\
\hline & San Carlos & -16.1 & 17.0 & 412 & 3 \\
\hline & San Carlos & -15.2 & 15.5 & 501 & 3 \\
\hline & San Carlos & -15.0 & 13.8 & 331 & 3 \\
\hline & San Carlos & -16.4 & 16.2 & 328 & 3 \\
\hline & San Carlos & -16.7 & 16.7 & 345 & 3 \\
\hline & San Carlos & -17.0 & 16.3 & 423 & 3 \\
\hline & San Carlos & -18.0 & 18.7 & 305 & 3 \\
\hline & San Carlos & -17.4 & 14.4 & 277 & 2 \\
\hline & San Carlos & -13.7 & 18.0 & 495 & 2 \\
\hline & San Carlos & -17.4 & 16.5 & 341 & 3 \\
\hline & San Carlos & -17.2 & 17.5 & 325 & 2 \\
\hline & San Carlos & -14.8 & 16.9 & 545 & 3 \\
\hline & San Carlos & -16.6 & 16.2 & 403 & 2 \\
\hline & San Carlos & -17.4 & 16.2 & 320 & 3 \\
\hline & Swan Inlet & -14.8 & 15.2 & 395 & 3 \\
\hline & Swan Inlet & -15.6 & 15.8 & 416 & 3 \\
\hline & Swan Inlet & -15.9 & 17.2 & 337 & 3 \\
\hline & Swan Inlet & -14.2 & 17.8 & 424 & 1 \\
\hline & Swan Inlet & -15.2 & 17.4 & 377 & 1 \\
\hline & Swan Inlet & -14.6 & 11.0 & 270 & 1 \\
\hline & Swan Inlet & -14.9 & 18,8 & 470 & 2 \\
\hline & Swan Inlet & -15.2 & 15.9 & 384 & 2 \\
\hline & Swan Inlet & -16.3 & 16.5 & 327 & 2 \\
\hline & Swan Inlet & -15.0 & 17.2 & 482 & 3 \\
\hline & Swan Inlet & -13.9 & 10.6 & 265 & 2 \\
\hline & Swan Inlet & -15.3 & 15.2 & 288 & 2 \\
\hline & Swan Inlet & -17.2 & 11.4 & 233 & 1 \\
\hline & Swan Inlet & -17.5 & 16.7 & 370 & 2 \\
\hline & Swan Inlet & -14.7 & 17.6 & 501 & 1 \\
\hline & Swan Inlet & -16.2 & 16.3 & 354 & 2 \\
\hline & Swan Inlet & -16.1 & 15.9 & 344 & 3 \\
\hline & Swan Inlet & -14.5 & 16.8 & 440 & 3 \\
\hline Intermediate (3) & Camilla Creek & -24.5 & 11.5 & 278 & 0 \\
\hline & Camilla Creek & -22.6 & 12.3 & 252 & 0 \\
\hline & Camilla Creek & -21.0 & 14.3 & 364 & 0 \\
\hline & Camilla Creek & -22.0 & 8.1 & 205 & 0 \\
\hline & Camilla Creek & -22.7 & 7.7 & 165 & 0 \\
\hline & Camilla Creek & -23.9 & 10.1 & 243 & 0 \\
\hline & Camilla Creek & -21.9 & 8.9 & 214 & 0 \\
\hline & Camilla Creek & -23.1 & 9.1 & 183 & 0 \\
\hline & Camilla Creek & -22.5 & 7.6 & 179 & 0 \\
\hline & Camilla Creek & -24.2 & 10.7 & 207 & 0 \\
\hline & Cobbs Pass & -23.8 & 7.7 & 164 & 0 \\
\hline & Cobbs Pass & -22.0 & 11.4 & 217 & 1 \\
\hline & Cobbs Pass & -23.2 & 11.6 & 178 & 0 \\
\hline & Cobbs Pass & -23.3 & 12.2 & 225 & 1 \\
\hline & Cobbs Pass & -22.5 & 14.3 & 251 & 0 \\
\hline & Cobbs Pass & -23.5 & 11.6 & 285 & 0 \\
\hline & Cobbs Pass & -23.6 & 8.9 & 272 & 0 \\
\hline & Cobbs Pass & -24.0 & 7.8 & 251 & 1 \\
\hline
\end{tabular}


Appendix 1: Supplementary Table and Figures

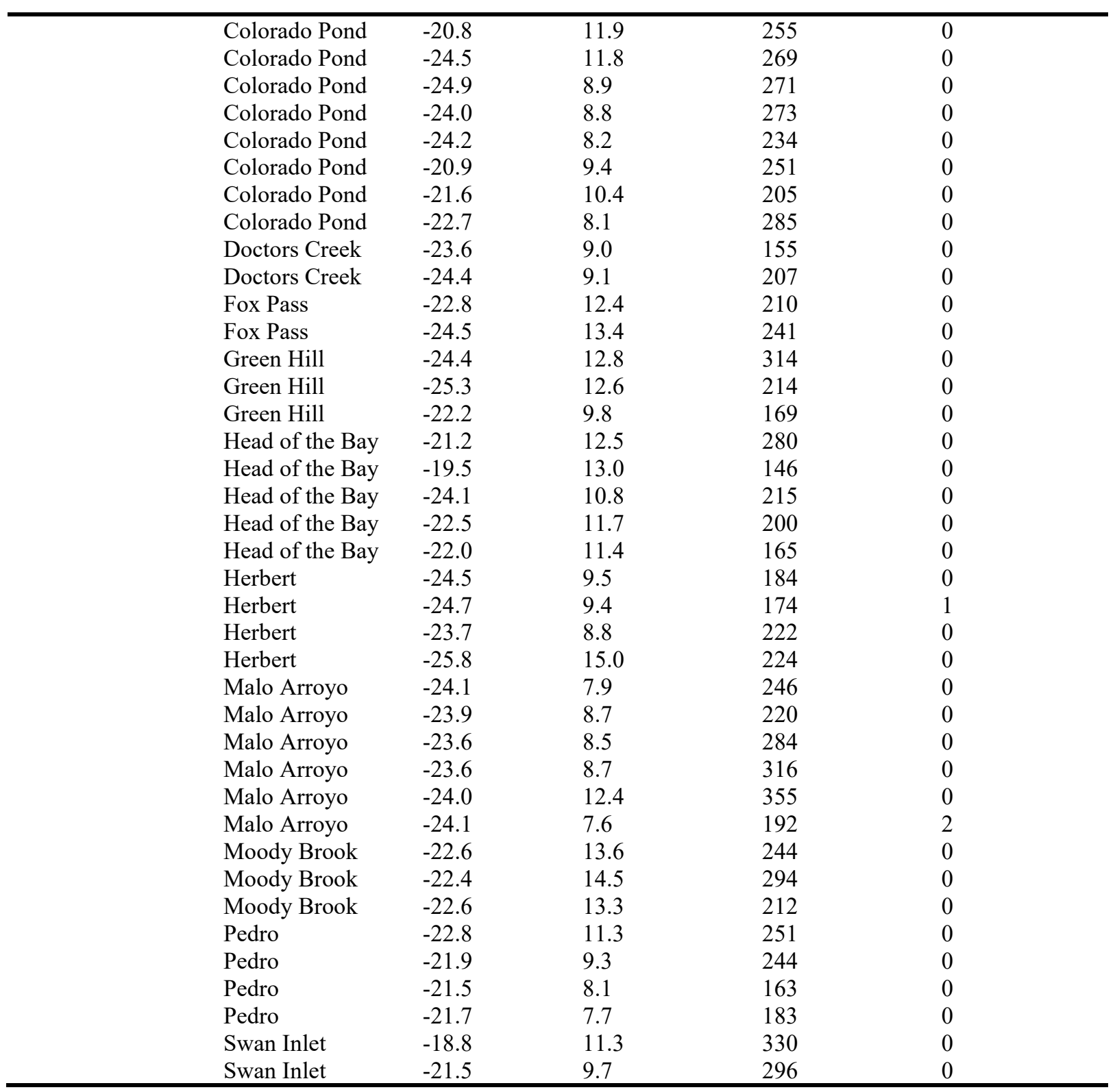




\title{
Appendix 2: Script Chapter 2
}

\author{
Invasion model

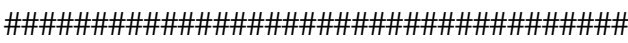 \\ \#\#\#\# Brown Trout Invasion Model \#\#\# \\ \#\#\#\# Jess Minett and Josh Jones \#\#\#\#

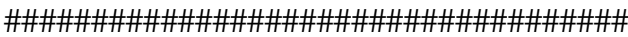 \\ \#\#\#\#Load Libraries \#\#\#\# \\ library(tidyverse) \\ library(caret) \\ library(moments) \\ library(mgcv) \\ library(dismo) \\ library(ggplot2) \\ library(readr) \\ library(lme4) \\ library(broom) \\ library(gridExtra) \\ \# library(pbkrtest) \\ library(effects) \\ library(lmerTest) \\ library(scales) \\ library(MuMIn) \\ library(dismo) \\ library(pbkrtest) \\ \#library(tidyverse); theme_set(theme_classic()) \\ \#\#\#\# Load Data \#\#\#\# \\ FIsampled<-read.csv("data/New.FI.Model.SmallDF.csv", header=TRUE) \\ \#DF contains - gridRef, lon, lat, st, eastWest, intro, zebra, basinInv, basinIntro, d2set, d2r, d2culvert, d2introW, \\ d2introL \\ \#d2invW, d2invL, slope, height, nCulverts, density, fraglen, bfl, FA_scales, winterTmin, annualRain, landType \\ \#changing some of the variables to factors \\ FIsampled\$gridRef<-as.factor(FIsampled\$gridRef) \\ invad<-FIsampled[which(FIsampled\$st==1),] \\ absent $<$-FIsampled[which(FIsampled $\$$ st==0), ] \\ \#randomly sampling invaded data = so same number of points as absent data \\ invad<-invad[sample(nrow(invad), 62), ] \\ \#spliting data into testing and training \\ \#arbitarily assign group 1 as the testing data group \\ testing.group $<-1$ \\ \#creat a vector of group memberships \\ group.presence $<-\operatorname{kfold}(\mathrm{x}=$ invad, $\mathrm{k}=5)$ \\ head(group.presence) \\ table(group.presence) \# should see even representation in each group \\ \#output table shows how many points have been assigned to each of the 5 groups \\ \#separate observations into training and testing groups \\ presence.train <- invad[group.presence !=testing.group,] \\ presence.test $<-$ invad[group.presence $==$ testing.group,] \\ \#repeat process for pseudo-asence points \\ group.background $<-$ kfold $(\mathrm{x}=$ absent, $\mathrm{k}=5$ ) \\ background.train<-absent[group.background != testing.group,] \\ background.test $<-$ absent[group.background $==$ testing.group,] \\ \#combine presence and absence traing and testing data \\ dframe $1<$-rbind(presence.train, background.train) \\ dframe.test<-rbind(presence.test, background.test) \\ \#\#\# Checking Coliniarity of Covariates \#\#\# \\ \#Corvif Function https://github.com/biometry/muledeer/blob/master/HighstatLibV6_correlation_functions.R
}


\#\# put correlations on the panels, \#\# with size proportional to the correlations.

panel.cor <- function $(x, y$, digits $=1$, prefix $="$ ", cex.cor $)$

\{ usr <- par("usr"); on.exit(par(usr))

$\operatorname{par}(\mathrm{usr}=\mathrm{c}(0,1,0,1))$

$\mathrm{r} 1=\operatorname{cor}(\mathrm{x}, \mathrm{y}, \mathrm{use}=$ "pairwise.complete.obs")

$\mathrm{r}<-\operatorname{abs}(\operatorname{cor}(\mathrm{x}, \mathrm{y}, \mathrm{use}=$ "pairwise.complete.obs"))

txt $<$ - format (c(r1, 0.123456789), digits=digits)[1]

txt $<-$ paste(prefix, txt, sep="")

if(missing(cex.cor)) cex <- 0.9/strwidth(txt)

text $(0.5,0.5$, txt, cex $=\operatorname{cex} * \mathrm{r})$

\}

panel.smooth2=function (x, y, col = par("col"), bg = NA, pch = par("pch"), cex $=1$, col.smooth $=$ "red", $\operatorname{span}=2 / 3$, iter $=3, \ldots$ )

\{

points $(x, y, p c h=p c h, c o l=c o l, b g=b g, c e x=c e x)$

ok <- is.finite $(x) \&$ is.finite $(y)$

if (any $(\mathrm{ok}))$

lines(stats::lowess(x[ok], $\mathrm{y}[\mathrm{ok}], \mathrm{f}=$ span, iter $=$ iter $)$, $\operatorname{col}=1, \ldots)$

\}

panel.lines2=function $(\mathrm{x}, \mathrm{y}, \mathrm{col}=\operatorname{par}(" \mathrm{col} "), \mathrm{bg}=\mathrm{NA}, \mathrm{pch}=\operatorname{par}($ "pch"),

\{ cex $=1, \ldots)$

points $(\mathrm{x}, \mathrm{y}, \mathrm{pch}=\mathrm{pch}, \mathrm{col}=\mathrm{col}, \mathrm{bg}=\mathrm{bg}, \mathrm{cex}=\mathrm{cex})$

ok $<$ - is.finite $(x) \&$ is.finite $(y)$

if $(\operatorname{any}(\mathrm{ok}))\{$

tmp $=\operatorname{lm}(y[\mathrm{ok}] \sim \mathrm{x}[\mathrm{ok}])$

abline(tmp) $\}$

\}

panel.hist $<$ - function $(\mathrm{x}, \ldots)$

\{

usr <- par("usr"); on.exit(par(usr))

$\operatorname{par}(\mathrm{usr}=\mathrm{c}(\mathrm{usr}[1: 2], 0,1.5))$

$\mathrm{h}<-$ hist $(\mathrm{x}$, plot $=$ FALSE $)$

breaks <- h\$breaks; nB <- length(breaks)

$\mathrm{y}<-\mathrm{h} \$$ counts; $\mathrm{y}<-\mathrm{y} / \max (\mathrm{y})$

rect(breaks[-nB], 0, breaks[-1], y, col="white", ...)

\}

\#VIF

myvif $<$ - function(mod) \{

$\mathrm{v}<-\mathrm{v} \operatorname{cov}(\bmod )$

assign $<-$ attributes(model.matrix(mod))\$assign

if $($ names $($ coefficients $(\bmod )[1])==$ "(Intercept $) ")\{$

$\mathrm{v}<-\mathrm{v}[-1,-1]$

assign $<-\operatorname{assign}[-1]$

\} else warning("No intercept: vifs may not be sensible.")

terms <- labels(terms(mod))

n.terms $<-$ length(terms)

if (n.terms < 2) stop("The model contains fewer than 2 terms")

if (length(assign) $>\operatorname{dim}(\mathrm{v})[1])\{$

diag(tmp_cor $)<-0$

if (any(tmp_cor==1.0)) \{

return("Sample size is too small, $100 \%$ collinearity is present")

\} else \{

return("Sample size is too small")

(

\}

$\mathrm{R}<-\operatorname{cov} 2 \operatorname{cor}(\mathrm{v})$ 


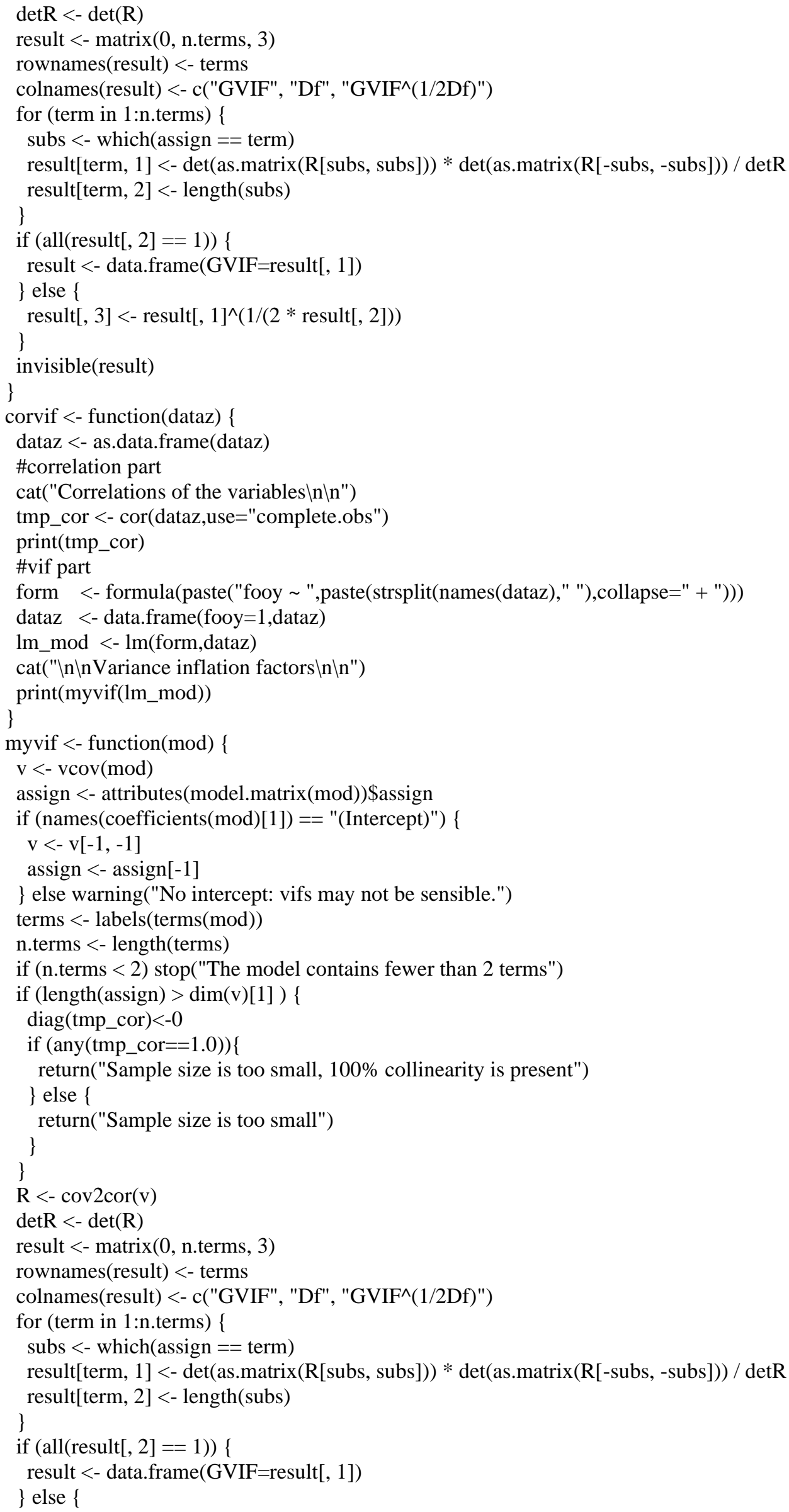




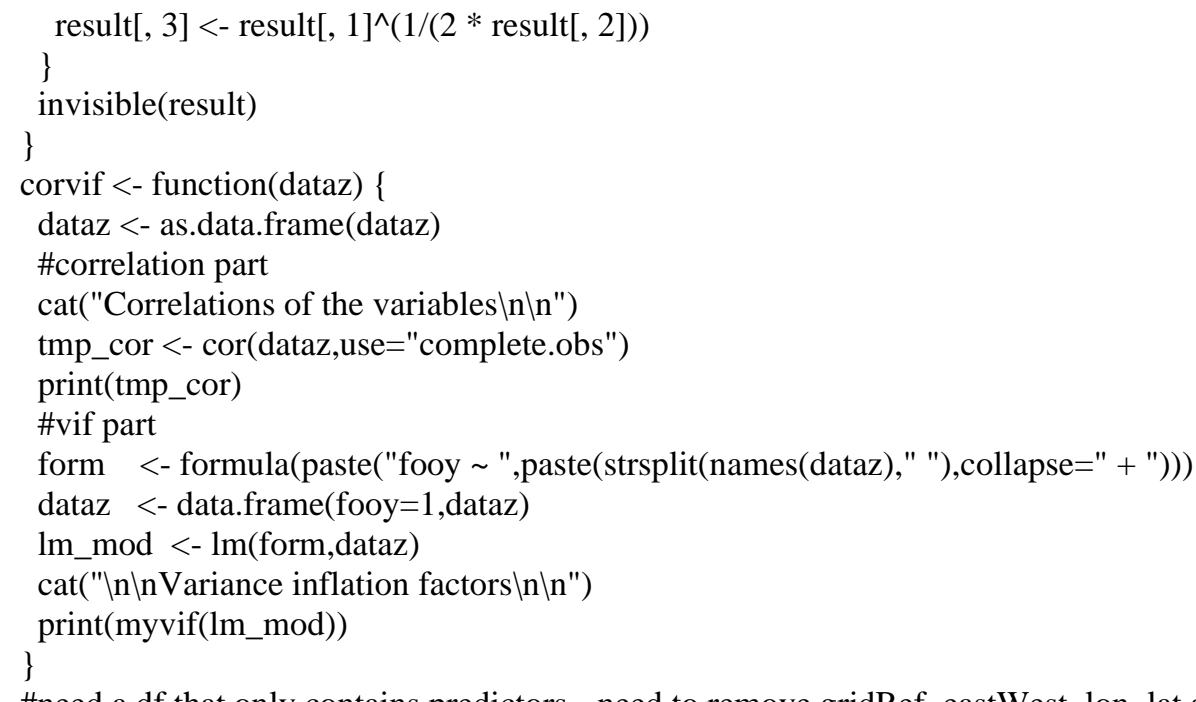

\#need a df that only contains predictors - need to remove gridRef, eastWest, lon, lat and st

\#checking coliniarity - removing d2uninvaded also as dont think should be included in model- as it is distance to nearest known

\#(sampled) uninvaded site not true uninvaded site- dont know what means in practice

vifdf <- FIsampled[, c(6:16, 18:27)]

summary(vifdf)

str(vifdf)

\# VIF $<3$ is good

\#https://www.researchgate.net/post/Multicollinearity_issues_is_a_value_less_than_10_acceptable_for_VIF

\#https://www.researchgate.net/post/How_high_of_VIF_value_in_regression_can_be_accepted

corvif(vifdf)

\#remove d2culvert $=86.2$

vifdf <- FIsampled[, c(6:11, 13:16, 18:27)]

corvif(vifdf)

\#density $=5.0$

vifdf <- FIsampled[, c(6:11, 13:16, 18:20, 22:27)]

corvif(vifdf)

\#basinIntro $=3.5$

vifdf <- FIsampled[, c(6:8,10,11, 13:16, 18:20, 22:27)]

corvif(vifdf)

\#all below 3

\#\#\#\# Building Models \#\#\#\#

\#need to change 2 variable numbers as have the wrong way around

\#dframe1[55,7]=1

\#dframe1[71,7]=0

\#now fixed in csv file loaded in $r$

\#try and build a model with everything in it.

\#only basinInv not included as model freaks out

model4 <- glm(st d2invL.km. + d2r.km. + zebra + d2invW..km. + d2introW.km. + d2introL.km. + intro + eastWest +

height,

slope + nCulverts + fraglen + FA_scaled + landType + bfl + winterTmin + annualRain + d2set.km. +

family = binomial(link $=$ "logit"), maxit $=100$,

data $=$ dframe1) \#only basinInv not included

drop1 (model4, test $=$ "Chi")

\#remove height

model4 <- glm(st d2invL.km. + d2r.km. + zebra + d2invW..km. + d2introW.km. + d2introL.km. + intro + eastWest +

slope + nCulverts + fraglen + FA_scaled + landType + bfl + winterTmin + annualRain + d2set.km., family $=$ binomial $($ link $=$ "logit"), $\operatorname{maxit}=100$, data $=$ dframe 1$)$

drop1 $($ model4, test $=$ "Chi") 
\# remove d2introL.km.

model4 <- glm(st d2invL.km. + d2r.km. + zebra + d2invW..km. + d2introW.km. + intro + eastWest + slope + nCulverts + fraglen + FA_scaled + landType + bfl + winterTmin + annualRain + d2set.km., family $=$ binomial $($ link $=$ "logit"), maxit $=100$, data $=$ dframe 1$)$

drop1 (model4, test $=$ "Chi")

\#remove FA_scaled

model4 <- glm $($ st $\sim$ d2invL.km. + d2r.km. + zebra + d2invW..km. + d2introW.km. + intro + eastWest + slope + nCulverts + fraglen + landType + bfl + winterTmin + annualRain $+\mathrm{d} 2$ set.km., family $=$ binomial(link $=$ "logit"), maxit $=100$, data $=$ dframe 1$)$

drop1 $($ model 4 , test $=$ "Chi")

\# remove intro

model4 <- glm(st $\sim$ d2invL.km. + d2r.km. + zebra + d2invW..km. + d2introW.km. + eastWest + slope + nCulverts + fraglen + landType + bfl + winterTmin + annualRain $+\mathrm{d} 2$ set.km., family $=$ binomial $($ link $=$ "logit"), maxit $=100$, data $=$ dframe 1$)$

drop1 (model4, test $=$ "Chi")

\#remove annualRain

model4 <- glm(st d2invL.km. + d2r.km. + zebra + d2invW..km. + d2introW.km. + eastWest + slope + nCulverts + fraglen + landType + bfl + winterTmin $+\mathrm{d} 2$ set.km., family $=$ binomial(link $=$ "logit"), maxit $=100$, data $=$ dframe 1$)$

drop1 $($ model 4 , test $=$ "Chi")

\#remove bfl

model4 <- glm(st d2invL.km. + d2r.km. + zebra + d2invW..km. + d2introW.km. + eastWest + slope + nCulverts + fraglen + landType + winterTmin $+\mathrm{d} 2$ set.km., family $=$ binomial(link $=$ "logit"), maxit $=100$, data $=$ dframe 1$)$

drop1 (model4, test $=$ "Chi")

\#remove eastWest

model4 <- glm(st d2invL.km. + d2r.km. + zebra + d2invW..km. + d2introW.km. + slope + nCulverts + fraglen + landType + winterTmin $+\mathrm{d} 2$ set.km., family $=$ binomial $($ link $=$ "logit"), maxit $=100$, data $=$ dframe 1$)$

drop1 $($ model 4 , test $=$ "Chi")

\#remove fraglen

model4 <- glm(st $\sim$ d2invL.km. + d2r.km. + zebra + d2invW..km. + d2introW.km. + slope + nCulverts + landType + winterTmin $+\mathrm{d} 2$ set.km., family $=$ binomial(link $=$ "logit"), maxit $=100$, data $=$ dframe 1$)$

drop1 $($ model 4, test $=$ "Chi")

\#remove landType

model4 <- glm(st $\sim$ d2invL.km. + d2r.km. + zebra + d2invW..km. + d2introW.km. + slope + nCulverts + winterTmin $+\mathrm{d} 2$ set.km., family $=$ binomial(link $=$ "logit"), maxit $=100$, data $=$ dframe 1$)$

drop1 $($ model 4 , test $=$ "Chi")

\#remove d2r.km.

model4 <- glm(st $\sim$ d2invL.km. + zebra + d2invW..km. + d2introW.km. + slope + nCulverts + winterTmin $+\mathrm{d} 2$ set.km., family $=$ binomial(link $=$ "logit"), maxit $=100$, data $=$ dframe 1$)$

drop1 $($ model 4, test $=$ "Chi")

\#remove d2set.km.

model4 <- glm(st $\sim$ d2invL.km. + zebra + d2invW..km. + d2introW.km. + slope + nCulverts + winterTmin, family $=$ binomial $(\operatorname{link}=$ "logit"), $\operatorname{maxit}=100$, data $=$ dframe 1$)$

drop1 $($ model4, test $=$ "Chi") 


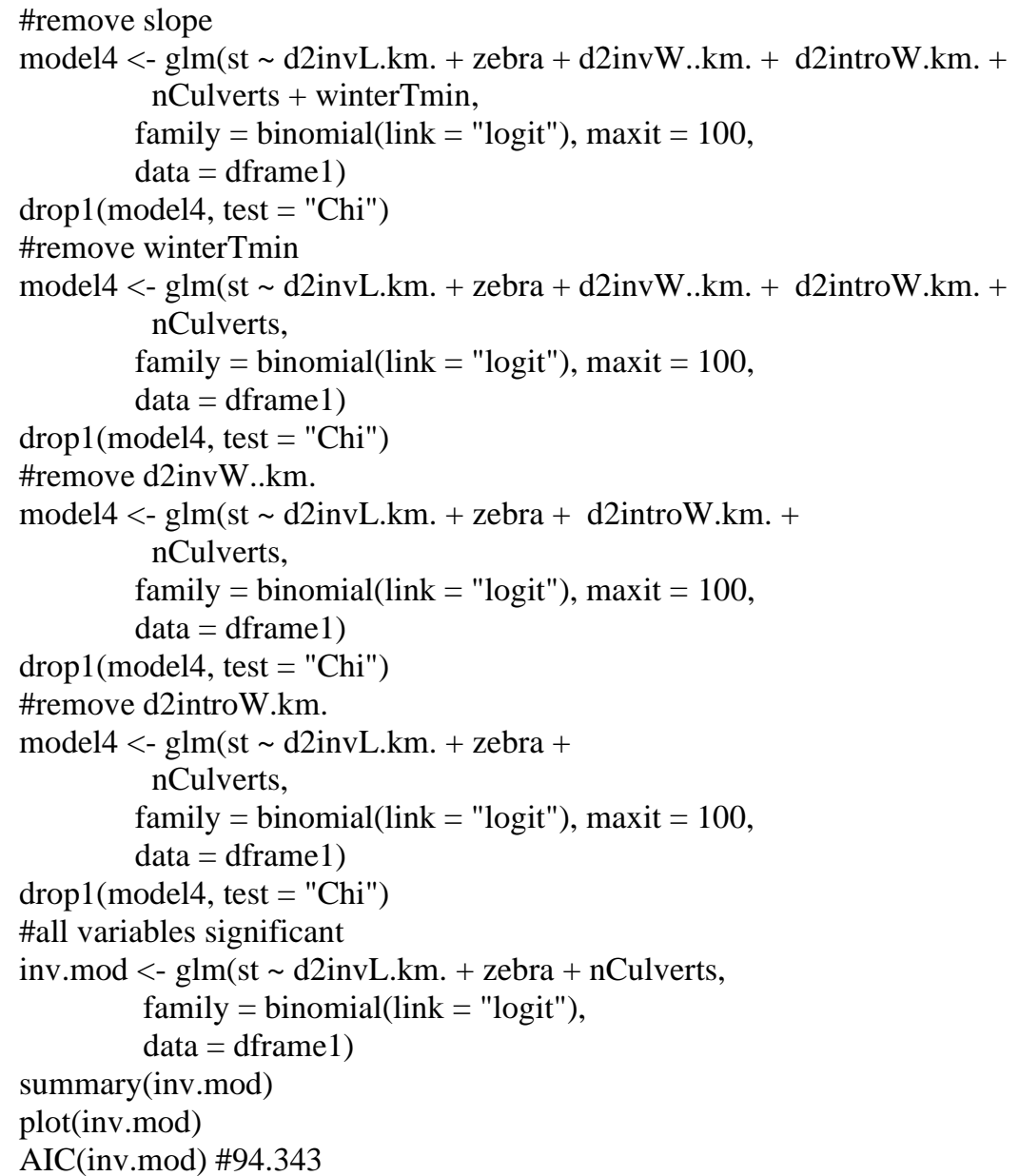

\#\#\#\# Comparing models for Null Model \#\#\#\#

nullMod $<-\operatorname{glm}($ st $\sim 1$, family = binomial $($ link = "logit"), data $=$ dframe 1$)$

\#compare models with anova

\#comparing models to Null anova(nullMod, inv.mod, test $=$ "LRT") $\#$ chi -value $=2.602 \times 10-11$

\#seem to be significantly different from Null

\#LRT = likihood ratio test statistic - assuming LRT has a chi-squared distribution

\#PBtest $=$ fraction of simulated LRT values that are greater or equal to the observed LRT value PBmodcomp(inv.mod, nullMod, $\mathrm{nsim}=1000)$ \#LRT $=2.602 \times 10-11 \quad$ PBtest $=0.01961$

\#get the same results when you compare with anova or PBmodcomp

\#think this means that model is significantly different from random (null model)

\#will now try predicting some values using model and seeing how they compare to actual results \#can also do some SDM evaluation - as done with SDM with $\mathrm{R}$

\#\#\#\# SDM - Chapter 7 Model Evaluation \#\#\#\#

\#there are a number of different measure that can help access how good a model fits the data \#AUC is a measure of rank correlation -

\#high AUC indicates sites with high predicted suitability values are areas of known presence \#locations with model prediction tend to be areas where species are known to be absent \#AUC score of $0.5=$ model is as good as ransom guesses \#need to have the presence and absence data split into testing and training datasets bc.inv <- glm(st $\sim$ d2invL.km. + zebra + nCulverts, family = binomial(link $=$ "logit"), data $=$ dframe 1$)$

e.inv <- evaluate (dframe.test[dframe.test $\$$ st $==1$,$] , dframe.test[dframe.test \$$ st $==0$,$] , bc.inv )$ e.inv 
\#get 12 presences and 12 absences which is correct

$\#$ AUC $=0.847$

$\#$ cor $=0.600$

plot(e.inv, 'ROC')

\#now we will try with k-fold instead of a single random sample

\#already have df of presence and df of absence $=$

pres <- invad

back <- absent \#background data will only be used for model testing and doesnt need to be partioned

\#now need to split data into 5 groups $(\mathrm{k}=5)$

$\mathrm{k}<-5$

group $<-$ kfold(pres, $\mathrm{k})$

group [1:10]

unique(group)

\#now we can fit and test the model 5 times

e <- list ()

for (i in $1: k)\{$

train <- pres[group !=i,]

test $<$ - pres[group $==\mathrm{i}$, ]

bc $<-$ glm(st $\sim$ d2invL.km. + zebra + nCulverts,

family = binomial(link = "logit"),

data $=$ dframe 1$)$

\}

\#we can extract ment things from onjects in e - just looking at AUC, max sum of sensitivity (true positive rate), and

\#specificity (true negative rate) - sometimes used as threshold for setting presence/absence

auc <- sapply(e, function $\left.(x)\left\{\operatorname{slot}\left(x,{ }^{\prime a u c '}\right)\right\}\right)$

auc

\#0.864 0.8550 .8950 .9160 .828

mean (auc) \#0.872

sapply(e, function(x)\{x@t[which.max(x@TPR+x@TNR)]\})

\#-0.463 -0.4638 -0.589 $0.232-1.122$

\#\#\#\# LOOCV - Prediciting Results \#\#\#\#

\#going to try and predict results for model

\#combining dframe 1 and dframe.test so $i$ have a larger $\mathrm{df} n=124$ containing the same number of presnce and absence records

dframe.all <- rbind(dframe1, dframe.test)

\#write.csv(file = "output/EqualPresAbsData.csv", dframe.all)

\#Try prediciting for inv.mod

\#first have to define training control

train.control <- trainControl $(\operatorname{method}=$ "LOOCV")

model.inv <- train(st $\sim$ d2invL.km. + zebra + nCulverts, data $=$ dframe 1, method $=$ "glm", family = binomial(link = "logit"),

\#summarise results trControl $=$ train.control)

print(model.2)

\#RMSE $=0.383 \quad \mathrm{R} 2=0.415 \quad \mathrm{MAE}=0.286$

predict.inv <- predict(model.inv, dframe.all)

summary(predict.inv) \# ranges from 0.000 to 0.995

inv.predicitions <- cbind(predict.inv, dframe.all)

write.csv(file = "output/model_inv_Predictions.csv", inv.predicitions)

\# Now have predicted results for dframe.all for inv.mod - now need to compare predictions

\#\#\#\# Predicting Invasion for All Points \#\#\#\#

invasionData_All <- read.csv("data/InvasionModel_DataNeeded.csv", header = TRUE)

\#this is a df containing data for all $\sim 8800$ points for gridRef, lon, lat, st, zebra, d2invL, nculverts (what needed for model) 
\#zebra $=1$ or 0 ( $\mathrm{o}=$ sites know dont inhabit or sites we dont know if present or not (sites that havent been sampled))

summary(invasionData_All)

\#Invasion Model

\#First define training control

train.control <- trainControl(method = "LOOCV")

\#Training Model

invasion.model <- train (st d2invL.km. + zebra + nCulverts,

data $=$ dframe 1 , method $=$ "glm",

family = binomial (link = "logit"),

\#Summarise Results

trControl $=$ train.control)

print(invasion.model)

invasion.predict <- predict(invasion.model, invasionData_All)

summary(invasion.predict)

\#ranges from 0.000 to 0.998

InvasionPredictions <- cbind(invasion.predict, invasionData_All)

write.csv(file = "output/InvasionPredictions.csv", InvasionPredictions)

Invasion scenarios

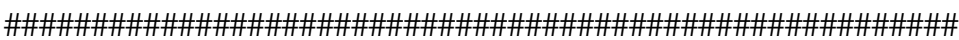

\#\#\#\# Invasion Scenario Predictions with Standard Error \#\#\#\#

\#\#\#\# Jess Minett and Josh Jones \#\#\#

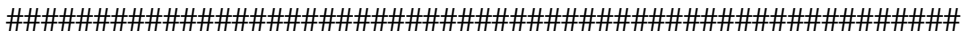

\#\#\#\# Packages \#\#\#\#

library(tidyverse)

library(sf)

library(caret)

\#install.packages("geodist")

library(geodist)

set.seed(321)

\#\#\#\# Data \#\#\#\#

testdata <- read.csv("data/Scenario1_SEdata.csv", header = TRUE) \#scenario 1 with upper and lower SE \#testdata <- read.csv("data/Scenario2_SEdata.csv", header = TRUE) \#scenario 2 (-0.1) data with upper and lower SE

\#testdata <- read.csv("data/Scenario3_SEdata.csv", header = TRUE) \#scenario 3 (-0.3) data with upper and lower SE

testdata $<-$ testdata $\%>\%$

mutate(st $=$ if_else(is.na(st), 0 , as.numeric(st))) $\%>\%$

rename $($ invaded $=\mathrm{st}$ )

dframe1 <- read.csv("data/dframe1 data for loocv.csv", header = TRUE) \#data for training model

\#rename st to invaded and distance to invaded to nn_dist

names (dframe1)[names (dframe1)=="st"] <- "invaded"

names(dframe1)[names(dframe1)=="d2invL.km."] <- "nn_dist"

\#\#\#\# Quick distance calculations \#\#\#\#

\# special projection for quick distance calculation

(wkt <- 'GEOGCRS["spherical",

DATUM["MySphere",

ELLIPSOID["WGS 84Sphere", 6378137, 0,

LENGTHUNIT["metre",1]]],

PRIMEM["Greenwich",0,

ANGLEUNIT["degree",0.0174532925199433]],

CS[ellipsoidal,2],

AXIS["geodetic latitude (Lat)",north,

ORDER[1],

ANGLEUNIT["degree",0.0174532925199433]],

AXIS["geodetic longitude (Lon)",east, 


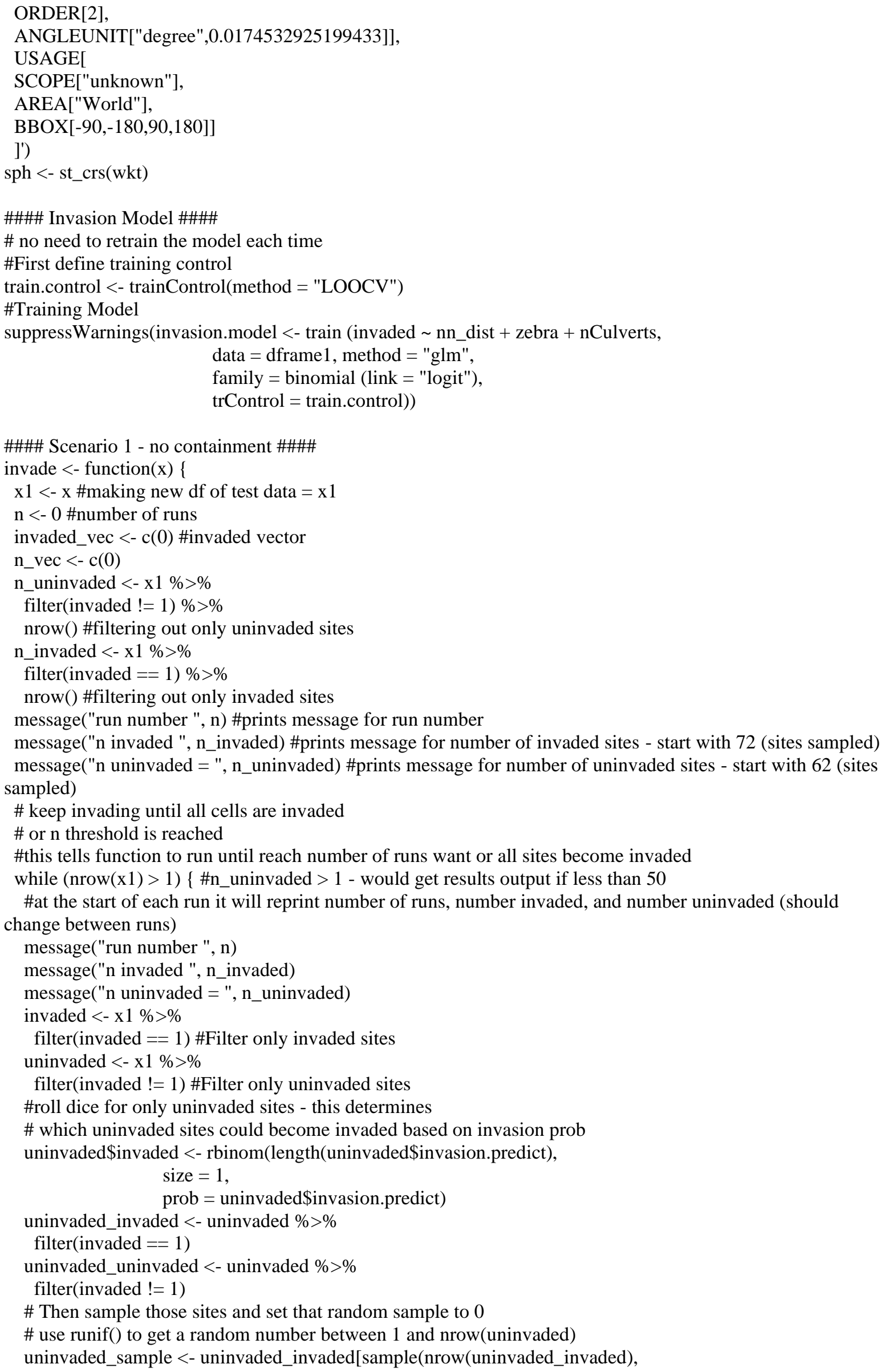


\# set the sample to be uninvaded

runif $(1,1$, nrow(uninvaded_invaded))), ]

uninvaded_sample\$invaded $<-0$

\# get a list of gridRefs that have had the invasion revered

not_invaded <- unique(uninvaded_sample\$gridRef)

\# get the rest of the uninvaded_invaded that weren't reversed

uninvaded_invaded $<-$ uninvaded_invaded $\%>\%$

filter(!gridRef \%in\% not_invaded)

\# remove those gridRefs from uninvaded_invaded

\# and add the other uninvaded sites

\# this is now all uninvaded sites

uninvaded_with_reversed <- uninvaded_uninvaded $\%>\%$

add_row(uninvaded_sample)

\# rejoin all the data

$\mathrm{x} 1<$ - invaded $\%>\%$

add_row(uninvaded_with_reversed) $\%>\%$

add_row(uninvaded_invaded)

$\mathrm{x} 1 \$ \mathrm{n}<-\mathrm{n} \#$ number of run

sum_invaded <- sum(x1\$invaded) \#number become invaded

sum_prob <- sum(x1\$invasion.predict) \#sum of probabilities from all invaded sites

\#sum_invaded and sum_prob should increase with each run (as long as a site has become invaded)

\# update the prob ability if a site becomes invaded

\#where a site has become invaded we update the invasion probability to 1

$\mathrm{x} 1<-\mathrm{x} 1 \%>\%$

mutate(invasion.predict $=$ if_else $($ invaded $==1,1$, invasion.predict $)$ )

message(sum_invaded, " cells invaded in total.") \#prints sum of invaded sites (how many sites invaded)

message(sum_prob, " = sum of prob. Should increase.") \#prints of of invasion probability (sum of prob for all

sites invaded)

\#now need to re speaparate uninvaded and invaded sites as site have become invaded through rolling dice on

probability

\# get uninvaded sites

\# e.g. uninvaded $<-\mathrm{x} 1 \%>\%$ filter(invaded != 1)

uninvaded $<-\mathrm{x} 1 \%>\%$ filter(invaded != 1) \#filtering to look at only uninvaded sites

message("nrow(uninvaded ", nrow(uninvaded)) \#prints number of uninvaded sites

\# get invaded sites

\# e.g. invaded $<-\mathrm{x} 1 \%>\%$ filter(invaded $==1$ )

invaded $\langle-\mathrm{x} 1 \%>\%$ filter(invaded $==1$ ) \#filtering to get only invaded sites

message("nrow(invaded ", nrow(invaded)) \# prints number of invaded sites

\#Need to get sf object of all uninvaded and invaded sites to recalcualte distatnce to nearest invaded site

\# all invaded sites with lat lon in sf object

\# MAKE it an sf object

invaded_sf $<$ - st_as_sf $(x=$ invaded,

coords = c("lon", "lat"),

$\mathrm{crs}=\mathrm{sph}) \%>\%$

rename $(\mathrm{id}=$ gridRef $)$ \#renaming gridref as id as called id in distance function above

\# all uninvaded sites with lat lon in sf object

\# MAKE it an sf object

uninvaded_sf $<-$ st_as_sf $(\mathrm{x}=$ uninvaded, coords = c("lon", "lat"), $\mathrm{crs}=\mathrm{sph}) \%>\%$

rename $(\mathrm{id}=$ gridRef $)$ \#renaming gridref as id as called id in distance function above

\#make matrix of invaded and uninvaded sites - need this for the nn_geo function

\# recalculate distance to nearest invaded site

a1 <-st_coordinates(uninvaded_sf)

message(nrow(a1)) \#prints number of invaded sites

b1 <- st_coordinates(invaded_sf)

\# nearest neighbor function

\# Ignore the $>100 \mathrm{~km}$ warning

\# as these will have a low prop of

\# being invaded anyway 


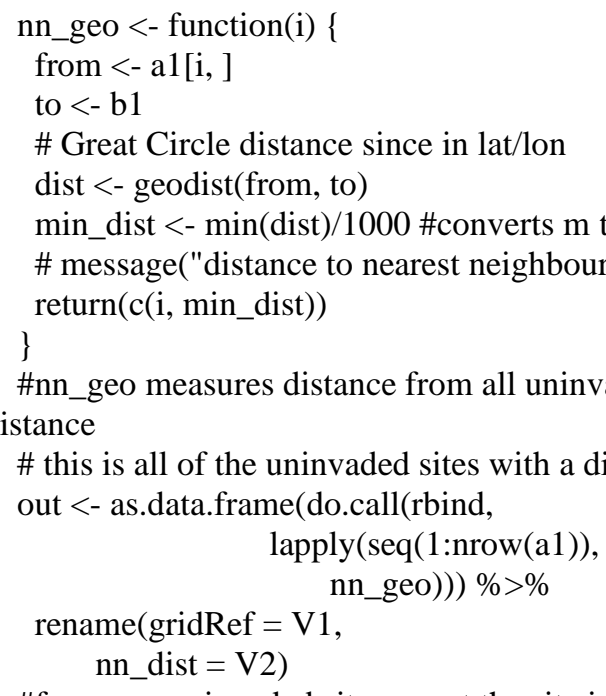

\#for every uninvaded site we get the site id and the distance to the nearest invaded site in $\mathrm{km}$

\#we then need to recover gridref id which we can get from uninvaded df

\# recover id

out\$gridRef <- uninvaded_sf\$id

\# add the other variables back to this df

\# e.g.

\# outModel <- out $\%>\%$

\# left_join(siteVariables, by = "gridRef")

outModel <- out \%>\%

full_join(uninvaded, by = "gridRef") \#added all varaibles and new distances back together

\# message("colnames(outModel) ", colnames(outModel))

\# re run glm to get new probabilities using new distances

\#Summarise Results

invasion.predict <- predict(invasion.model, outModel)

\#adding new probailities to uninvaded

uninvaded\$invasion.predict <- invasion.predict

\#uninvaded doesnt have new distances nn_dist but dont think this matters as is recalculated in outmodel each time

\#and outmodel is used to calculate the new invasion.predict

\#now need to reduce any probabilities $<0.8$ by 0.1 for scenario 2 and 0.3 for scenario 3 and set min

probability to

n_uninvaded $<-\mathrm{x} 1 \%>\%$

filter(invaded != 1) $\%>\%$

nrow() \#get new number of uninvaded sites

\#\#\#\#

\#\# add new probabilities

\#uninvaded\$invasion.predict <- invasion.predict

message("uninvaded nrow ", n_uninvaded) \#prints number of uninvaded sites

\# $\mathrm{x} 1$ needs to be all sites, invaded and uninvaded

\# this is take back to the top of the while statement

\# and processed again

$\mathrm{x} 1<$ - invaded \%>\% add_row(uninvaded) \#add uninvaded sites back into $\mathrm{x} 1$ with new invasion probabilities for uninvaded sites

message("all sites (x1) nrow ", nrow(x1)) \#prints number of sites in x1 - should be 8813

$\mathrm{n}<-\mathrm{n}+1$ \# addes a 1 to the number of runs - will increase each time and stop running when reach number of cycles wanted

message $(" n$ cycles $=$ ", $n$ )

\# outputs

n_vec <- append(n_vec, n) \#vector of number of runns

n_invaded <- $\operatorname{nrow}(\mathrm{x})$ - n_uninvaded \# number of invaded sites

invaded_vec <- append(invaded_vec, n_invaded) \#number of uninvaded sites

\#this will then cycle back upto the while function until we reach a specified number of runs (50)

\#or all sites become invaded 


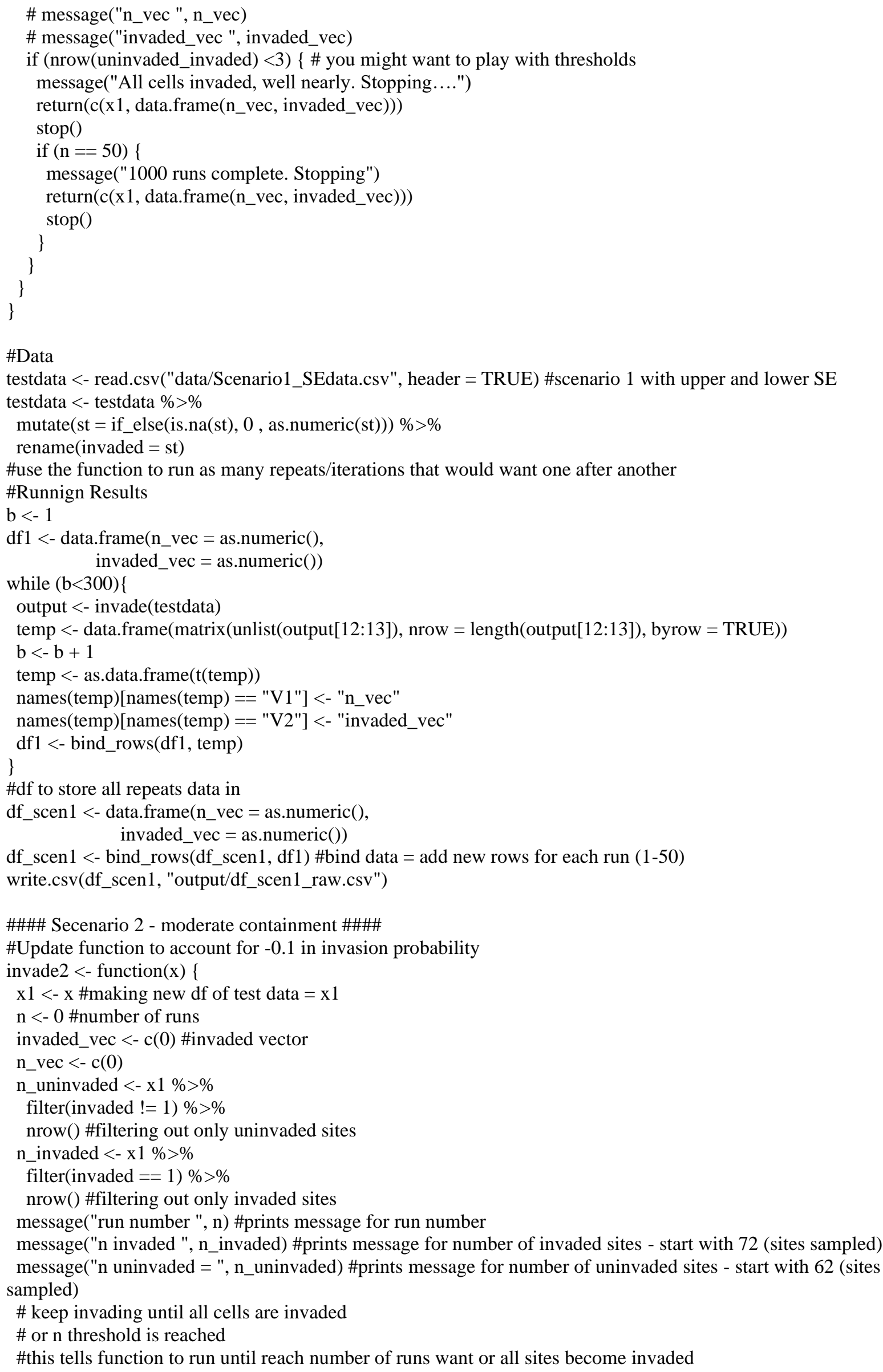


while (nrow $(x 1)>1)\{\#$ _n uninvaded > 1 - would get results output if less than 50

\#at the start of each run it will reprint number of runs, number invaded, and number uninvaded (should

change between runs)

message("run number ", n)

message("n invaded ", n_invaded)

message("n uninvaded = ", n_uninvaded)

invaded <- $\mathrm{x} 1 \%>\%$

filter(invaded $==1$ ) \#Filter only invaded sites

uninvaded $<-\mathrm{x} 1 \%>\%$

filter(invaded !=1) \#Filter only uninvaded sites

\#roll dice for only uninvaded sites - this determines

\# which uninvaded sites could become invaded based on invasion prob

uninvaded\$invaded <- rbinom(length(uninvaded\$invasion.predict),

size $=1$

prob $=$ uninvaded $\$$ invasion.predict $)$

uninvaded_invaded $<-$ uninvaded $\%>\%$

filter(invaded $==1$ )

uninvaded_uninvaded $<-$ uninvaded $\%>\%$

filter(invaded !=1)

\# Then sample those sites and set that random sample to 0

\# use runif() to get a random number between 1 and nrow(uninvaded)

uninvaded_sample <- uninvaded_invaded[sample(nrow(uninvaded_invaded),

\# set the sample to be uninvaded

runif $(1,1, \operatorname{nrow}($ uninvaded_invaded $)))$,

uninvaded_sample\$invaded $<-0$

\# get a list of gridRefs that have had the invasion revered

not_invaded <- unique(uninvaded_sample\$gridRef)

\# get the rest of the uninvaded_invaded that weren't reversed

uninvaded_invaded <- uninvaded_invaded \% $\% \%$

filter(!gridRef \%in\% not_invaded)

\# remove those gridRefs from uninvaded_invaded

\# and add the other uninvaded sites

\# this is now all uninvaded sites

uninvaded_with_reversed <- uninvaded_uninvaded \%>\%

add_row(uninvaded_sample)

\# rejoin all the data

$\mathrm{x} 1<$ - invaded $\%>\%$

add_row(uninvaded_with_reversed) $\%>\%$

add_row(uninvaded_invaded)

$\mathrm{x} 1 \$ \mathrm{n}<-\mathrm{n}$ \#number of run

sum_invaded <- sum(x1\$invaded) \#number become invaded

sum_prob <- sum(x1 \$invasion.predict) \#sum of probabilities from all invaded sites

\#sum_invaded and sum_prob should increase with each run (as long as a site has become invaded)

\# update the prob ability if a site becomes invaded

\#where a site has become invaded we update the invasion probability to 1

$\mathrm{x} 1<-\mathrm{x} 1 \%>\%$

mutate(invasion.predict $=$ if_else(invaded $==1,1$, invasion.predict $)$ )

message(sum_invaded, " cells invaded in total.") \#prints sum of invaded sites (how many sites invaded)

message(sum_prob, " = sum of prob. Should increase.") \#prints of of invasion probability (sum of prob for all

sites invaded)

\#now need to re speaparate uninvaded and invaded sites as site have become invaded through rolling dice on probability

\# get uninvaded sites

\# e.g. uninvaded $<-\mathrm{x} 1 \%>\%$ filter(invaded != 1)

uninvaded <- x1 \%>\% filter(invaded != 1) \#filtering to look at only uninvaded sites

message("nrow(uninvaded ", nrow(uninvaded)) \#prints number of uninvaded sites

\# get invaded sites

\# e.g. invaded $\langle-\mathrm{x} 1 \%\rangle \%$ filter(invaded $==1$ )

invaded $<-\mathrm{x} 1 \%>\%$ filter(invaded == 1) \#filtering to get only invaded sites

message("nrow(invaded ", nrow(invaded)) \# prints number of invaded sites 
\#Need to get sf object of all uninvaded and invaded sites to recalcualte distatnce to nearest invaded site \# all invaded sites with lat lon in sf object

\# MAKE it an sf object

invaded_sf <-st_as_sf $(x=$ invaded, coords = c("lon", "lat"), $\mathrm{crs}=\mathrm{sph}) \%>\%$

rename $(\mathrm{id}=$ gridRef $)$ \#renaming gridref as id as called id in distance function above

\# all uninvaded sites with lat lon in sf object

\# MAKE it an sf object

uninvaded_sf <-st_as_sf $(x=$ uninvaded, coords = c("lon", "lat"), $\mathrm{crs}=\mathrm{sph}) \%>\%$

rename $(\mathrm{id}=$ gridRef $)$ \#renaming gridref as id as called id in distance function above \#make matrix of invaded and uninvaded sites - need this for the nn_geo function \# recalculate distance to nearest invaded site

a1 <- st_coordinates(uninvaded_sf)

message(nrow(a1)) \#prints number of invaded sites

b1 <- st_coordinates(invaded_sf)

\# nearest neighbor function

\# Ignore the $>100 \mathrm{~km}$ warning

\# as these will have a low prop of

\# being invaded anyway

nn_geo $<$ - function(i) \{

from $<-\mathrm{a} 1[\mathrm{i}$,

to $<-\mathrm{b} 1$

\# Great Circle distance since in lat/lon

dist $<$ - geodist(from, to)

min_dist <- $\min ($ dist $) / 1000$ \#converts $\mathrm{m}$ to $\mathrm{km}$

\# message("distance to nearest neighbour, excluding self and repeat pairs = ", min_dist)

return(c(i, min_dist))

\}

\#nn_geo measures distance from all uninvaded sites in circles to all invaded sites - then select for the smallest distance

\# this is all of the uninvaded sites with a distance to nearest invaded site column

out <- as.data.frame(do.call(rbind,

rename $($ gridRef $=\mathrm{V} 1$,

lapply(seq(1:nrow(a1)),

nn_geo)) $\%>\%$

nn_dist $=$ V2)

\#for every uninvaded site we get the site id and the distance to the nearest invaded site in $\mathrm{km}$

\#we then need to recover gridref id which we can get from uninvaded df

\# recover id

out\$gridRef <- uninvaded_sf\$id

\# add the other variables back to this df

\# e.g.

\# outModel <- out $\%>\%$

\# left_join(siteVariables, by = "gridRef")

outModel <- out \%>\%

full_join(uninvaded, by = "gridRef") \#added all varaibles and new distances back together

\# message("colnames(outModel) ", colnames(outModel))

\# re run glm to get new probabilities using new distances

\#Summarise Results

invasion.predict <- predict(invasion.model, outModel)

\#adding new probailities to uninvaded

uninvaded\$invasion.predict <- invasion.predict

\#uninvaded doesnt have new distances nn_dist but dont think this matters as is recalculated in outmodel each time

\#and outmodel is used to calculate the new invasion.predict

\#now need to reduce any probabilities $<0.8$ by 0.1 for scenario 2 and 0.3 for scenario 3 and set min probability to 
uninvaded <- uninvaded $\%>\%$

mutate(invasion.predict $=$ if_else(invasion.predict $\langle 0.8$, invasion.predict-0.1, invasion.predict)) $\%>\%$

mutate(invasion.predict $=$ if_else(invasion.predict $<0,0$, invasion.predict $)$ )

n_uninvaded $<-\mathrm{x} 1 \%>\%$

filter(invaded !=1) $\%>\%$

nrow() \#get new number of uninvaded sites

\#\#\#\#

\#\# add new probabilities

\#uninvaded\$invasion.predict <- invasion.predict

message("uninvaded nrow ", n_uninvaded) \#prints number of uninvaded sites

\# $\mathrm{x} 1$ needs to be all sites, invaded and uninvaded

\# this is take back to the top of the while statement

\# and processed again

$\mathrm{x} 1<$ - invaded \%>\% add_row(uninvaded) \#add uninvaded sites back into x1 with new invasion probabilities

for uninvaded sites

message("all sites (x1) nrow ", nrow(x1)) \#prints number of sites in x1 - should be 8813

$\mathrm{n}<-\mathrm{n}+1 \#$ addes a 1 to the number of runs - will increase each time and stop running when reach number of cycles wanted

message $(" n$ cycles $=$ ", n)

\# outputs

n_vec <- append(n_vec, $n)$ \#vector of number of runns

$\mathrm{n} \_$invaded $<-\operatorname{nrow}(\mathrm{x})$ - $\mathrm{n}$-uninvaded \# number of invaded sites

invaded_vec <- append(invaded_vec, $n$ _invaded) \#number of uninvaded sites

\#this will then cycle back upto the while function until we reach a specified number of runs (50)

\#or all sites become invaded

\# message("n_vec ", n_vec)

\# message("invaded_vec", invaded_vec)

if (nrow(uninvaded_invaded) <3) \{ \# you might want to play with thresholds

message("All cells invaded, well nearly. Stopping....")

return(c(x1, data.frame(n_vec, invaded_vec)))

$\operatorname{stop}()$

if $(\mathrm{n}==50)$ \{

message("1000 runs complete. Stopping")

return(c(x1, data.frame(n_vec, invaded_vec)))

$\operatorname{stop}()$

\}

\}

\}

\#Running 300 times $=300$ repeats to build CI

\# Data \#\#

testdata <-read.csv("data/Scenario2_SEdata.csv", header = TRUE) \#scenario 1 with upper and lower SE

testdata $<$ - testdata $\%>\%$

mutate(st $=$ if_else(is.na(st), 0 , as.numeric(st)) $\%>\%$

rename $($ invaded $=$ st)

\#repeating 300 times

$\mathrm{b}<-0$

df2 <- data.frame(n_vec $=$ as.numeric () ,

while $(b<300)\{$

invaded_vec $=$ as.numeric ()$)$ \#clear anything previously stored in df1

output $<$ - invade2(testdata)

temp <- data.frame(matrix(unlist(output[12:13]), nrow = length(output[12:13]), byrow = TRUE))

$\mathrm{b}<-\mathrm{b}+1$

temp $<-$ as.data.frame $(\mathrm{t}(\mathrm{temp}))$

names(temp)[names(temp) == "V1"] <- "n_vec"

names(temp)[names(temp) == "V2"] <- "invaded_vec"

df $2<$ - bind_rows(df2, temp)

\} 
\#df to store all repeats data in

df_scen $2<$ - data.frame $($ n_vec $=$ as.numeric () , invaded_vec $=$ as.numeric ()$)$

df_scen $2<-$ bind_rows(df_scen2, df2) \#bind data = add new rows for each run (1-50)

write.csv(df_scen2, "output/df_scen2_raw.csv")

\#\#\#\# Scenario 3 - strong containment \#\#\#\#

invade $3<-$ function $(\mathrm{x})\{$

$\mathrm{x} 1<-\mathrm{x}$ \#making new df of test data $=\mathrm{x} 1$

$\mathrm{n}<-0$ \#number of runs

invaded_vec $<-\mathrm{c}(0)$ \#invaded vector

n_vec $<-\mathrm{c}(0)$

n_uninvaded $<-\mathrm{x} 1 \%>\%$

filter(invaded != 1) $\%>\%$

nrow() \#filtering out only uninvaded sites

n_invaded $<-\mathrm{x} 1 \%>\%$

filter(invaded $==1) \%>\%$

nrow() \#filtering out only invaded sites

message("run number ", n) \#prints message for run number

message("n invaded ", n_invaded) \#prints message for number of invaded sites - start with 72 (sites sampled)

message("n uninvaded = ", n_uninvaded) \#prints message for number of uninvaded sites - start with 62 (sites sampled)

\# keep invading until all cells are invaded

\# or $\mathrm{n}$ threshold is reached

\#this tells function to run until reach number of runs want or all sites become invaded

while (nrow $(x 1)>1)\{\#$ _ uninvaded $>1$ - would get results output if less than 50

\#at the start of each run it will reprint number of runs, number invaded, and number uninvaded (should

change between runs)

message("run number ", n)

message("n invaded ", n_invaded)

message("n uninvaded = ", n_uninvaded)

invaded $<-\mathrm{x} 1 \%>\%$

filter(invaded $==1$ ) \#Filter only invaded sites

uninvaded $<-\mathrm{x} 1 \%>\%$

filter(invaded != 1) \#Filter only uninvaded sites

\#roll dice for only uninvaded sites - this determines

\# which uninvaded sites could become invaded based on invasion prob

uninvaded\$invaded <- rbinom(length(uninvaded\$invasion.predict),

size $=1$,

prob $=$ uninvaded $\$$ invasion.predict)

uninvaded_invaded $<$ - uninvaded \%>\%

filter(invaded $==1$ )

uninvaded_uninvaded <- uninvaded $\%>\%$

filter(invaded != 1)

\# Then sample those sites and set that random sample to 0

\# use runif() to get a random number between 1 and nrow(uninvaded)

uninvaded_sample <- uninvaded_invaded[sample(nrow(uninvaded_invaded),

\# set the sample to be uninvaded runif $(1,1$, nrow(uninvaded_invaded) $))$, ]

uninvaded_sample\$invaded <- 0

\# get a list of gridRefs that have had the invasion revered

not_invaded <- unique(uninvaded_sample\$gridRef)

\# get the rest of the uninvaded_invaded that weren't reversed

uninvaded_invaded <- uninvaded_invaded \%>\%

filter(!gridRef \%in\% not_invaded)

\# remove those gridRefs from uninvaded_invaded

\# and add the other uninvaded sites

\# this is now all uninvaded sites

uninvaded_with_reversed <- uninvaded_uninvaded \%>\%

add_row(uninvaded_sample) 
\# rejoin all the data

$\mathrm{x} 1<$ - invaded $\%>\%$

add_row(uninvaded_with_reversed) $\%>\%$

add_row(uninvaded_invaded)

$\mathrm{x} 1 \$ \mathrm{n}<-\mathrm{n} \#$ number of run

sum_invaded <- sum(x1\$invaded) \#number become invaded

sum_prob <-sum(x1\$invasion.predict) \#sum of probabilities from all invaded sites

\#sum_invaded and sum_prob should increase with each run (as long as a site has become invaded)

\# update the prob ability if a site becomes invaded

\#where a site has become invaded we update the invasion probability to 1

$\mathrm{x} 1<-\mathrm{x} 1 \%>\%$

mutate(invasion.predict $=$ if_else(invaded $==1,1$, invasion.predict)

message(sum_invaded, " cells invaded in total.") \#prints sum of invaded sites (how many sites invaded)

message(sum_prob, " = sum of prob. Should increase.") \#prints of of invasion probability (sum of prob for all sites invaded)

\#now need to re speaparate uninvaded and invaded sites as site have become invaded through rolling dice on probability

\# get uninvaded sites

\# e.g. uninvaded $<-\mathrm{x} 1 \%>\%$ filter(invaded != 1)

uninvaded $<-\mathrm{x} 1 \%>\%$ filter(invaded != 1) \#filtering to look at only uninvaded sites

message("nrow(uninvaded ", nrow(uninvaded)) \#prints number of uninvaded sites

\# get invaded sites

\# e.g. invaded $<-\mathrm{x} 1 \%>\%$ filter(invaded $==1$ )

invaded $<-\mathrm{x} 1 \%>\%$ filter(invaded == 1) \#filtering to get only invaded sites

message("nrow(invaded ", nrow(invaded)) \# prints number of invaded sites

\#Need to get sf object of all uninvaded and invaded sites to recalcualte distatnce to nearest invaded site

\# all invaded sites with lat lon in sf object

\# MAKE it an sf object

invaded_sf <-st_as_sf $(x=$ invaded,

coords = c("lon", "lat"), $\mathrm{crs}=\mathrm{sph}) \%>\%$

rename $(\mathrm{id}=$ gridRef $)$ \#renaming gridref as id as called id in distance function above

\# all uninvaded sites with lat lon in sf object

\# MAKE it an sf object

uninvaded_sf <- st_as_sf $(x=$ uninvaded, coords = c("lon", "lat"), $\mathrm{crs}=\mathrm{sph}) \%>\%$

rename $(\mathrm{id}=$ gridRef $)$ \#renaming gridref as id as called id in distance function above

\#make matrix of invaded and uninvaded sites - need this for the nn_geo function

\# recalculate distance to nearest invaded site

a1 <- st_coordinates(uninvaded_sf)

message(nrow(a1)) \#prints number of invaded sites

b1 <- st_coordinates(invaded_sf)

\# nearest neighbor function

\# Ignore the $>100 \mathrm{~km}$ warning

\# as these will have a low prop of

\# being invaded anyway

nn_geo $<$ - function(i) \{

from $<-$ a $1[i$,

to $<-\mathrm{b} 1$

\# Great Circle distance since in lat/lon

dist $<$ - geodist(from, to)

min_dist <- $\min ($ dist $) / 1000$ \#converts $\mathrm{m}$ to $\mathrm{km}$

\# message("distance to nearest neighbour, excluding self and repeat pairs = ", min_dist)

return(c(i, min_dist))

\}

\#nn_geo measures distance from all uninvaded sites in circles to all invaded sites - then select for the smallest distance

\# this is all of the uninvaded sites with a distance to nearest invaded site column

out <- as.data.frame(do.call(rbind, 


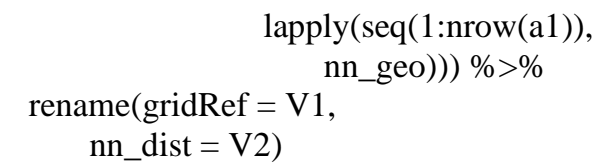

\#for every uninvaded site we get the site id and the distance to the nearest invaded site in $\mathrm{km}$ \#we then need to recover gridref id which we can get from uninvaded df

\# recover id

out\$gridRef <- uninvaded_sf\$id

\# add the other variables back to this df

\# e.g.

\# outModel <- out $\%>\%$

\# left_join(siteVariables, by = "gridRef")

outModel <- out \%>\%

full_join(uninvaded, by = "gridRef") \#added all varaibles and new distances back together

\# message("colnames(outModel) ", colnames(outModel))

\# re run glm to get new probabilities using new distances

\#Summarise Results

invasion.predict <- predict(invasion.model, outModel)

\#adding new probailities to uninvaded

uninvaded \$invasion.predict <- invasion.predict

\#uninvaded doesnt have new distances nn_dist but dont think this matters as is recalculated in outmodel each time

\#and outmodel is used to calculate the new invasion.predict

\#now need to reduce any probabilities $<0.8$ by 0.1 for scenario 2 and 0.3 for scenario 3 and set min

probability to

uninvaded <- uninvaded \%>\%

mutate(invasion.predict $=$ if_else $($ invasion.predict $<0.8$, invasion.predict- 0.3 , invasion.predict) $) \%>\%$

mutate(invasion.predict $=$ if_else(invasion.predict $<0,0$, invasion.predict) $)$

n_uninvaded $<-\mathrm{x} 1 \%>\%$

filter(invaded $!=1) \%>\%$

nrow() \#get new number of uninvaded sites

\#\#\#\#

\#\# add new probabilities

\#uninvaded\$invasion.predict <- invasion.predict

message("uninvaded nrow ", n_uninvaded) \#prints number of uninvaded sites

\# $\mathrm{x} 1$ needs to be all sites, invaded and uninvaded

\# this is take back to the top of the while statement

$\#$ and processed again

$\mathrm{x} 1<$ - invaded $\%>\%$ add_row(uninvaded) \#add uninvaded sites back into $\mathrm{x} 1$ with new invasion probabilities for uninvaded sites

message("all sites (x1) nrow ", nrow(x1)) \#prints number of sites in x1 - should be 8813

$\mathrm{n}<-\mathrm{n}+1$ \# addes a 1 to the number of runs - will increase each time and stop running when reach number of cycles wanted

message $(" n$ cycles $=$ ", $\mathrm{n})$

\# outputs

n_vec <- append(n_vec, $\mathrm{n})$ \#vector of number of runns

$\mathrm{n} \_$invaded $<-\operatorname{nrow}(\mathrm{x})$ - $\mathrm{n} \_$uninvaded \# number of invaded sites

invaded_vec <- append(invaded_vec, $n$ _invaded) \#number of uninvaded sites

\#this will then cycle back upto the while function until we reach a specified number of runs (50)

\#or all sites become invaded

\# message("n_vec ", n_vec)

\# message("invaded_vec ", invaded_vec)

if (nrow(uninvaded_invaded) <3) \{ \# you might want to play with thresholds

message("All cells invaded, well nearly. Stopping....")

return(c(x1, data.frame(n_vec, invaded_vec)))

stop()

if $(\mathrm{n}==50)\{$

message("1000 runs complete. Stopping")

return(c(x1, data.frame(n_vec, invaded_vec)))

stop() 
Appendix 2: Script Chapter 2

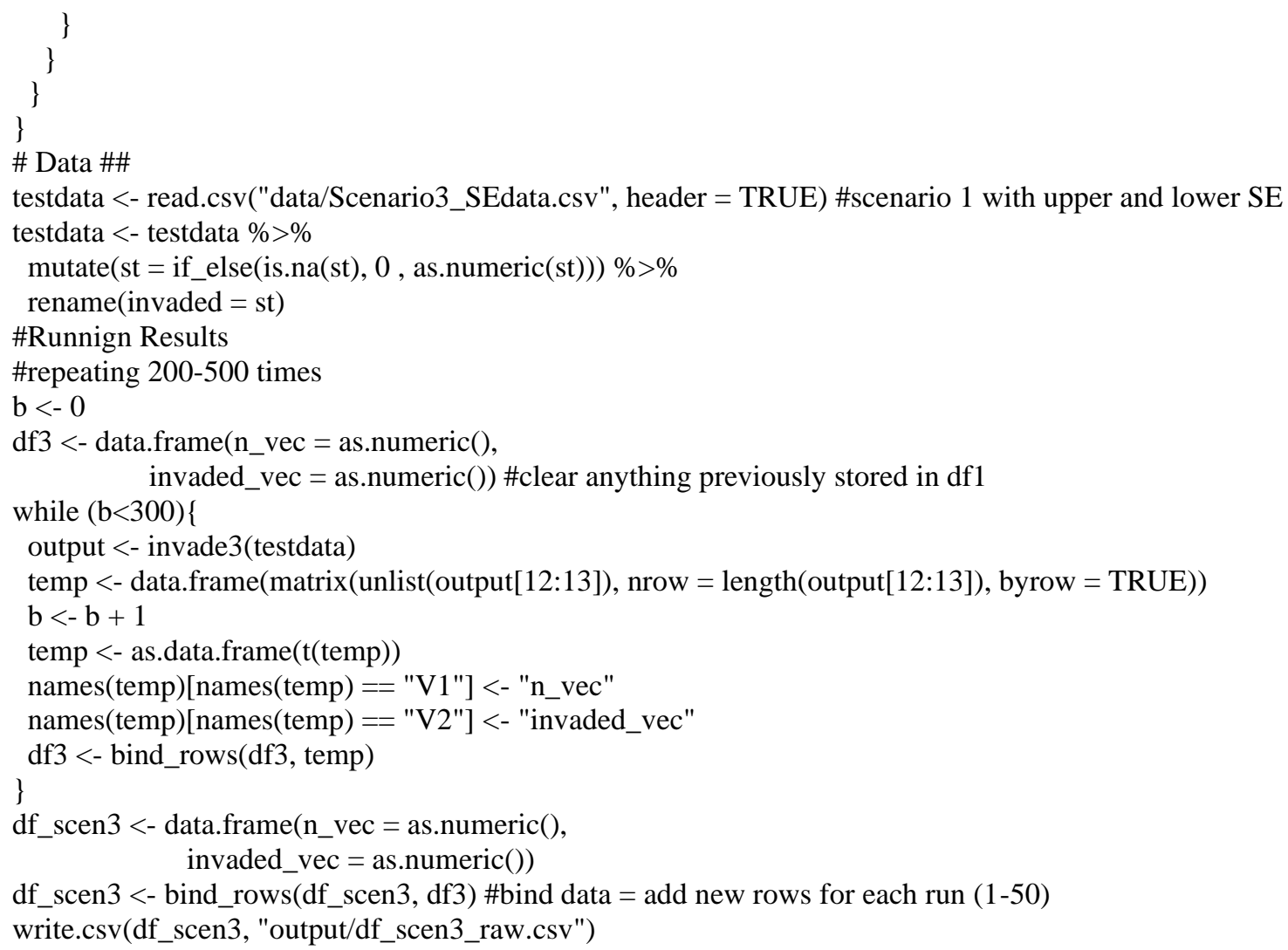




\title{
Appendix 3: Ethics and health and safety
}

\author{
Approval No: SU-Ethics-Student-160118/307
}

Reference No: STU_BIOL_82474_261017111138_2

\section{Approval No: SU-Ethics-Student-090118/299}

1. Title of research project/teaching activity:

Brown trout in the Falklands: Invasive ecology, population structure and genetic diversity

2. College:

Science

3. Staff contact:

Carlos Garcia De Leaniz

4. Summary of project/activity:

Acoustic/ combined acoustic-radio tagging: Up to 80 brown trout $(>17.5 \mathrm{~cm})$ caught from electrofishing will be anesthetized ( 2 phenoxy-ethanol) one at a time, fish will then be placed into a V-trough board covered with wetted absorbent towel, ventral side up. Acoustic or combined radio-acoustic tags (VEMCO model V13 $13 \mathrm{~mm}$ x $36 \mathrm{~mm}$, weight in water $6 \mathrm{~g}$ ) will be sterilized for a minimum of 15 minutes in a iodine solution before use and all hands and work surfaces will be washed with the same solution. A small mid-ventral incision will be made starting $1 \mathrm{~cm}$ anterior to the pelvic girdle. The disinfected tag will then be rinsed in sterile saline and positioned to lie directly under the incision in the pectoral cavity. The incision will be closed with three simple interrupted stitches tied with surgeon's knots. The closed incision will then be cleaned with iodine and a small abound of liquid tissue adhesive. After surgery, fish will be placed in a recovery tank and allowed to recover from anesthesia before being released. The operation will be carried under veterinary supervision or by trained member of the team signed off by the local veterinary. Please note this is NOT a regulated procedure in the Falkland Islands and does not require a project licence there. 
The number of fish to be tagged (60-80 over 2 years) has been calculated based on the advice of the local sponsor, the need to sample 6 watersheds (10-12 fish per watershed) and the results from other studies (Crossin et al al,.2016; Cons Physiology 4: 2-12) The local sponsors (SAERI Falkland Islands, Falklands Conservation, Env Dept) are handling the local ethical application and will also issue the necessary sampling permits.

Environmental DNA will allow us to detect the presence of brown trout and native galaxiids and predict the number of individuals present in an area. However, to gain information on the health and reproductive status of the population we will need to catch (via electrofishing) and examine individuals. Electrofishing will also give us the opportunity to tag individuals, allowing us to track their movement, and take samples for genotyping and isotope analysis which will allow us to determine population structure and how brown trout and native species compete and interact.

Brown trout and native galaxiids caught during electrofishing we will measured for length and body mass, and fin clips will be taken to do genotype and isotope analysis. Samples of possible brown trout and native galaxiid prey will also be obtained for isotope analysis. Water samples will also be taken from different catchments for environmental DNA.

I will also obtain fin clips from brown trout and native galaxiids, a minimum of 15 native galaxiids and 15 brown trout will be sampled per catchment (preferably 30 fish per catchment) in order to preform genotype analysis to determine their population structure, and isotope analysis to determine what fish are feeding from and how invasive brown trout and native species are interacting and competing for resources.

5. Location(s) at which the proposed project/activity is to be undertaken:

Falklands Islands

6. External approvals required for the proposed project/activity:

Yes, these are being processed by the Local sponsor (SAERI, Falklands)

7. Does the proposed project/activity involve schedule 1 method (as defined by ASPA 1986) being carried out by members of this University's staff or by its student? If yes, please list the individuals involved:

Yes, for stomach content and elemental composition analysis.

Jessica Minett - I have been trained in Schedule I 


\section{The AWERB committee cannot approve this application but welcomes a re-submission once the following comments have been addressed $(30 / 11 / 2017)$}

R1 - My only comments are regarding the use of 2-phenoxy for this. Would MS222 be more appropriate for released fish if there is a possibility of the fish ending up in the human food chain? Also, can the student comment on how welfare of the fish during recovery will be monitored and what will happen if a fish is showing adverse effects from the procedure? Can the student also obtain the relevant ethical permissions from colleagues in the Falklands for this work and provide them to AWERB?

R2 - No ethical concerns regarding the implant of tags within the fish peritoneal cavity as is happening here.

R1 \& 3's point about anaesthetic choice would also fall into this category (MS-222 still has a 70degree-day meat withdrawal after use, there is also a synthetic clove oil product called Aqui-S licenced in nearby Chile that has a 0-day meat withdrawal but it is not licenced in UK, and I presume Falklands) - if their veterinary governing body has approved the use of phenoxyethanol for this work then I don't have ethical concerns.

R3 - I was wondering which fin(s) the samples will be taken from? The applicant mentioned using fin clips for genotype and isotope analysis. To obtain enough material for both types of analysis could there be a risk of removing too much material, that could then affect the performance of the subject when released back into the natural environment? I had a brief look online and found a few articles that describe the pros and cons of fin clipping. For captive fish this is not such a problem but for fish released back into their natural habitat it might not only affect their ability to swim against strong currents but might also affect their breeding performance.

Could an alternative method be considered for obtaining samples for genotype analysis, such as body swabs? This could reduce the amount of fin material required.

\section{Applicants comments to the issues/concerns raised for the previous submission}

Following the advice of the AWERB committee we have considered alternatives to the use of 2phenoxy-ethanol as an anaesthetic. Of these, clove oil (isoeugenol, marketed as AQUI-S) is licenced for use in the Falklands, does not enter the food chain and has also antiseptic properties, so we propose to use this at a concentration of 40-60 p.p.m, as this was found to induce rapid anaesthesia and a relatively short recovery time in juvenile trout (Keene et al. 1998). Fish will be assessed over three stages of recovery to monitor individual welfare. During stage one individuals remain immobilised and start to regain opercula movements, stage two individuals begin to regain body 
movements, and stage three individuals regain equilibrium and their pre-anaesthetic appearance. Any fish that show adverse effects to the anaesthetic will be monitored and if they do not recover fully they will be killed using schedule 1 procedures. A small clip of the adipose fin (c. $2 \mathrm{~mm}$ ) and a sample of 2-3 scales will be taken for genetic identification and isotope analysis. These are standard procedures in salmonid field studies and do not compromise the welfare of the fish, provided these are larger than c. $50 \mathrm{~mm}$ (Vander Haegen et al. 2005; Petersson et al. 2014; Andrews et al. 2014). A project proposal is being submitted for ethical review in the Falklands and this will be submitted to AWERB when approval is granted.

Andrews, M., Stormoen, M., Schmidt-Posthaus, H., Wahli, T. and Midtlyng, P. J. (2015), Rapid temperature-dependent wound closure following adipose fin clipping of Atlantic salmon Salmo salar L. J Fish Dis, 38: 523-531. doi:10.1111/jfd.12261

Keene, J. L., Noakes, D. L. G., Moccia, R. D. and Soto, C. G. (1998), The efficacy of clove oil as an anaesthetic for rainbow trout, Oncorhynchus mykiss (Walbaum). Aquaculture Research, 29: 89-101. doi:10.1046/j.1365-2109.1998.00927.x

Petersson, E., Rask, J., Ragnarsson, B., Karlsson, L. and Persson, J., 2014. Effects of fin-clipping regarding adult return rates in hatchery-reared brown trout. Aquaculture, 422, pp.249-252.

Vander Haegen, G.E., Blankenship, H.L., Hoffmann, A. and Thompson, D.A., 2005. The effects of adipose fin clipping and coded wire tagging on the survival and growth of spring Chinook salmon. North American Journal of Fisheries Management, 25(3), pp.1161-1170.

\section{College Ethics Committee/AWERB Group DECISION on Ethical Review}

Having examined the information included in the above application with Reference No. STU_BIOL_82474_241017115552_1, this Committee has decided to:

\section{УApprove this application}

With the following reputation risk to the university

口Low risk $\quad \square$ Moderate Risk $\quad \square$ High Risk 


\section{Approval No: SU-Ethics-Student-081217/307}

1. Title of Research Project

Brown trout in the Falklands: Invasive ecology, population structure and genetic diversity

2. Staff/students undertaking research:

Jessica Minett

3. Primary staff contact detail (Name, E-mail, Phone):

Carlos Garcia de Leaniz -

4. Location where the study will take place:

Falkland Islands

5. If the proposal involves working with a partner body or organisation, please provide the following information

a. Full official title of the partner(s);

b. Details of the work to be carried out (a) at the partner(s) and (b) at the university;

c. Details of the relevant ethical approval processes at the partner(s).

South Atlantic Environmental Research Institute (SAERI), assistance with all aspects of the project

Fishermen in the Falklands, help with tagging and collecting fin clips for genotyping and isotope analysis

Dr Glenn Crossin, Assistance with tagging brown trout in the Falklands

6. Please state or tick, as appropriate, the following questions relating to your project: (tick any that apply during the progression of an experiment)

a. Species and taxon:

Brown trout (Salmo trutta)

b. Approximate number:

Tag 60-80 individuals with acoustic tags/ combined acoustic-radio tags. Fin clips from a minimum of 15 brown trout and 15 native galaxiids per catchment for genotype and isotope analysis (preferably 30 per catchment) 
Appendix 3: Ethics and health and safety

c. Life stages:

Juvenile/Adults $\square$

Mammal, bird or reptile embryo beyond halfway through incubation/gestation period

Amphibian, cephalopod or fish larvae capable of independent feeding

Strictly only gametes/very early developmental stages of embryos

7. Provide a brief scientific background for the work, and describe any pilot work undertaken:

Brown trout (Salmo trutta) were introduced to the Falkland Islands several times in the 1940's and 1950's, mostly to support recreational fishing opportunities. Since introduction, there has been a marked decline in the native fish fauna, which consists of only two species of galaxiid fishes (zebra trout Aplochiton zebra and the Falklands minnow Galaxias maculatus). Given the threats to the long-term sustainability of the native galaxiids, fundamental knowledge about the movement ecology of brown trout, and their overlap and interactions with galaxiids, is critically needed. However, at present virtually nothing is known about the extent and seasonality of brown trout movements throughout the Falkland Islands and their impacts on native galaxiids, and no studies have documented the distribution and abundance of native galaxiids prior to brown trout introductions.

8. Please provide a clear methodology for the work to be undertaken:

Acoustic/ combined acoustic-radio tagging: Up to 80 brown trout $(>17.5 \mathrm{~cm})$ caught from electrofishing will be anesthetized ( 2 phenoxy-ethanol) one at a time, fish will then be placed into a V-trough board covered with wetted absorbent towel, ventral side up. Acoustic or combined radio-acoustic tags (VEMCO model V13 $13 \mathrm{~mm}$ x $36 \mathrm{~mm}$, weight in water $6 \mathrm{~g}$ ) will be sterilized for a minimum of 15 minutes in a iodine solution before use and all hands and work surfaces will be washed with the same solution. A small mid-ventral incision will be made starting $1 \mathrm{~cm}$ anterior to the pelvic girdle. The disinfected tag will then be rinsed in sterile saline and positioned to lie directly under the incision in the pectoral cavity. The incision will be closed with three simple interrupted stitches tied with surgeon's knots. The closed incision will then be cleaned with iodine and a small abound of liquid tissue adhesive. After surgery, fish will be placed in a recovery tank and allowed to recover from anaesthesia before being released. The operation will be carried under veterinary supervision or by trained member of the team signed off by the local veterinary. 
Brown trout and native galaxiids caught during electrofishing we will measured for length and body mass, and fin clips will be taken to do genotype and isotope analysis. Samples of possible brown trout and native galaxiid prey will also be obtained for isotope analysis. Water samples will also be taken from different catchments for environmental DNA.

9. Provide a brief statement of how science will advance or people or animals will benefit from this project:

This project will provide information on how invasive brown trout are effecting native species in the falklands, we will be able to determine the abundance of brown trout and native galaxiids in different catchments, how they are interacting and what effect brown trout have on native species. We will also be able to determine if there are any refugia for native species and provide information on possible ways to prevent the spread on invasive brown trout.

10. Why do animals have to be used in this study? Explain your choice of species, and justify the number of subjects to be used with a power analysis where appropriate.

The number of fish to be tagged (60-80 over 2 yers) has been calculated based on the advice of the local sponsor, the need to sample 6 watersheds (10-12 fish per watershed) and the results from other studies (Crossin et al al,.2016; Cons Physiology 4: 2-12) The local sponsors (SAERI Falkland Islands, Falklands Conservation, Env Dept) are handling the local ethical application and will also issue the necessary sampling permits.

Environmental DNA will allow us to detect the presence of brown trout and native galaxiids and predict the number of individuals present in an area. However, to gain information on the health and reproductive status of the population we will need to catch (via electrofishing) and examine individuals. Electrofishing will also give us the opportunity to tag individuals, allowing us to track their movement, and take samples for genotyping and isotope analysis which will allow us to determine population structure and how brown trout and native species compete and interact.

11. What effects will your research have on the study organisms, and how will suffering be kept to a minimum?

Fish will be anesthetized during tagging and all other samples required (a c $2 \mathrm{~mm}$ clip of the adipose fin) is minimally invasive, nonlethal, and routinely carried out on salmonids. 
12. How will you dispose of carcasses/animals (tick any that apply):

Landfill

Sampled/analysis/other destruction of biomass $\square$

Released $\square$

Sent live to external organisation

\section{DECLARATION}

I certify that the answers to the questions given above are true and accurate to the best of my knowledge and belief and I take full responsibility for it. I also conform that I have read the University's Policy Framework on Research Ethics \& Governance and will abide by its ethical guidelines, as well as the ethical principles underlying good practice appropriate to my discipline $\square$

\section{College Ethics Committee/AWERB Group DECISION on Ethical Review}

Having examined the information included in the above application with Reference No. STU_BIOL_82472_2610171111382, this Committee has decided to:

\section{УApprove this application}

With the following reputation risk to the university

चLow risk $\quad \square$ Moderate Risk $\quad \square$ High Risk

\section{Comments:}

The CoS Ethics Committee approves this application but recommends that the following points are considered

R1 - given that the invasive procedures will be carried out by non-Swansea researchers, under nonUK licences, I understand we will not require an AWERB submission. Conditional on this being correct, the procedures appear to me to be fairly standard and acceptable and the supervisor involved certainly has the necessary knowledge and experience to train the student. Overall the question addressed is important, especially from a conservation/management point, hence the data that will be collected justify the procedures involved. Green light from my part. 
Appendix 3: Ethics and health and safety

R2 - I agree with R1 that this is important work and the supervisor is clearly experienced. My understanding is that we still need institutional oversight, however, and that this still needs to be reviewed through AWERB 
CONSERVATION OF WILDLIFE AND NATURE ORDINANCE 1999

\section{SECTION 9}

\section{LICENCE TO CARRY OUT SCIENTIFIC RESEARCH}

1. Licensee:

\begin{tabular}{|l|l|}
\hline $\begin{array}{l}\text { Name of the person leading } \\
\text { the research }\end{array}$ & Jessica Minett \\
\hline Affiliation & Swansea University \\
\hline Position & PhD Student \\
\hline Postal Address & 8PP, Wales, UK \\
\hline Phone number & \\
\hline Email & \\
\hline
\end{tabular}

\section{Nature of licence:}

This licence is issued to Jessica Minett under Section 9 of the Conservation of Wildlife and Nature Ordinance 1999. It is granted to Jessica Minett to permit her staff and bona fide field assistants or researchers employed on their behalf or under their overall jurisdiction. It is granted only for the following activities using methods specified in the research licence application on research on Brown trout in the Falklands: invasion ecology, population structure and genetic diversity submitted to the Environmental Committee on $12^{\text {th }}$ April 2018 and amendment submitted to the Environmental Officer on the 12 April 2021:

Electrofishing - to assess health and reproductive status of the population and examine individuals as well as to tag individuals and take samples for genotyping and isotope analysis. The length and body mass of brown trout and native galaxiids caught during electrofishing will be measured, and any additional samples required can be obtained. In locations where electrofishing is not possible seine and fyke nets will be used.

Genotype and isotope analysis -to determine the population structure and what brown trout and native species are feeding on and how they are interacting and competing. Individuals will be anesthetized (clove oil at a proposed concentration of $40-80$ p.p.m) one at a time and a $2 \mathrm{~mm}$ fin clip and a sample of 2-3 scales will be obtained from brown trout and native galaxiids. Samples of possible brown trout and native galaxiid 
prey will be obtained along with stomach contents and muscle samples from dead individuals for isotope analysis. A minimum of 15 native galaxiids and 30 brown trout will be sampled per catchment (preferably 30 fish pre catchment).

Tagging fish - to tag a maximum of 80 individuals from six different watersheds with acoustic tags/ combined acoustic radio tags to gain an understanding into how brown trout move in and between watersheds. Place pairs of acoustic receivers (VR2Ws) at the mouth of six watersheds ( $\mathrm{N}=12$ receivers), which will allow us to detect the movement of individuals in and out of the rivers/estuaries. We will also place additional receivers $(\mathrm{N}=8)$ up into a single watershed that is populated by brown trout to track finer-scale movements. Up to 80 brown trout $(>20 \mathrm{~cm})$ caught from electrofishing or rod and line will be anesthetized (clove oil at a proposed concentration of $40-80$ p.p.m) one at a time, fish will then be placed into a V-trough board covered with wetted absorbent towel, ventral side up. Acoustic or combined radio-acoustic tags (Thelma Biotel model ID-2LP9 $9 \mathrm{~mm} \times 28 \mathrm{~mm}$, weight in water $2.4 \mathrm{~g}$ ) will be sterilized for a minimum of 15 minutes in ethanol or an iodine solution before use and all hands and work surfaces will be washed with the same solution. A small mid-ventral incision will be made starting $1 \mathrm{~cm}$ anterior to the pelvic girdle. The disinfected tag will then be rinsed in sterile saline and positioned to lie directly under the incision in the pectoral cavity. The incision will be closed with three simple interrupted stitches tied with surgeon's knots. The small amount of liquid tissue adhesive will then be placed on the closed incision. The operation will be carried under veterinary supervision or by trained member of the team signed off by the local veterinary.

Catch and release of brown trout - Will provide us with information on their abundance around the Falklands, as well as providing insights into their movements between rivers and estuaries. A few experienced anglers will be trained by the local vet and me to PIT tag, they will be provided with PIT tags $(12 \times 2 \mathrm{~mm})$ so that any brown trout $(>20 \mathrm{~cm})$ the capture can be tagged and recorded when recaptured. All fish to be PIT tagged will be anaesthetised with clove oil (40-80 ppm).

2.2 This licence shall not be construed as authorising the licensee to enter upon the land of another without the owner's permission or consent.

2.3 Anaesthesia and tagging of fish will be undertaken in the presence of a FIG vet.

2.4 This licence does not constitute a permit to remove biological items from protected species from the Falkland Islands. An export licence should be sought from the Customs and Immigration Department to allow for the removal of any biological material or protected species from the Falkland Islands.

\section{Period of licence}

3.1 This licence is valid for the period commencing on $17^{\text {th }}$ April 2018 and terminating on the $31^{\text {st }}$ October 2021.

3.2 This licence may be revoked at any time by the Governor, but otherwise shall be valid for the period stated in paragraph 3.1. 
Appendix 3: Ethics and health and safety

\section{Conditions of licence}

4.1 This licence is issued on condition that the licensee shall:

a) Submit to the Environmental Officer, Policy Unit, Secretariat, Stanley, Falkland Islands, not later than $1^{\text {st }}$ June 2021, a report detailing the research work carried out and the methods used in that research; and

b) Deposit with the Environmental Officer copies of all subsequent reports on the research work carried out.

c) Deposit with the Environmental Officer copies of any data collected as part of this study. Data will be stored and will not be published or circulated without researcher approval for a period of 2 years.

\section{Purpose of Research}

The purpose of the research work carried out by the licensee is set out in the research proposal submitted to the Environmental Committee on $12^{\text {th }}$ April 2018 and amendment submitted to the Environmental Officer on the 12 April 2021.

Signed:

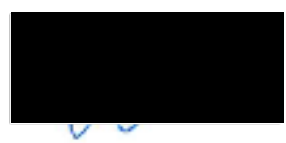

\section{Denise Blake}

Environmental Officer

Dated: 13 April 2021 


\section{Bioscience and Geography Protocol Risk Assessment Form}

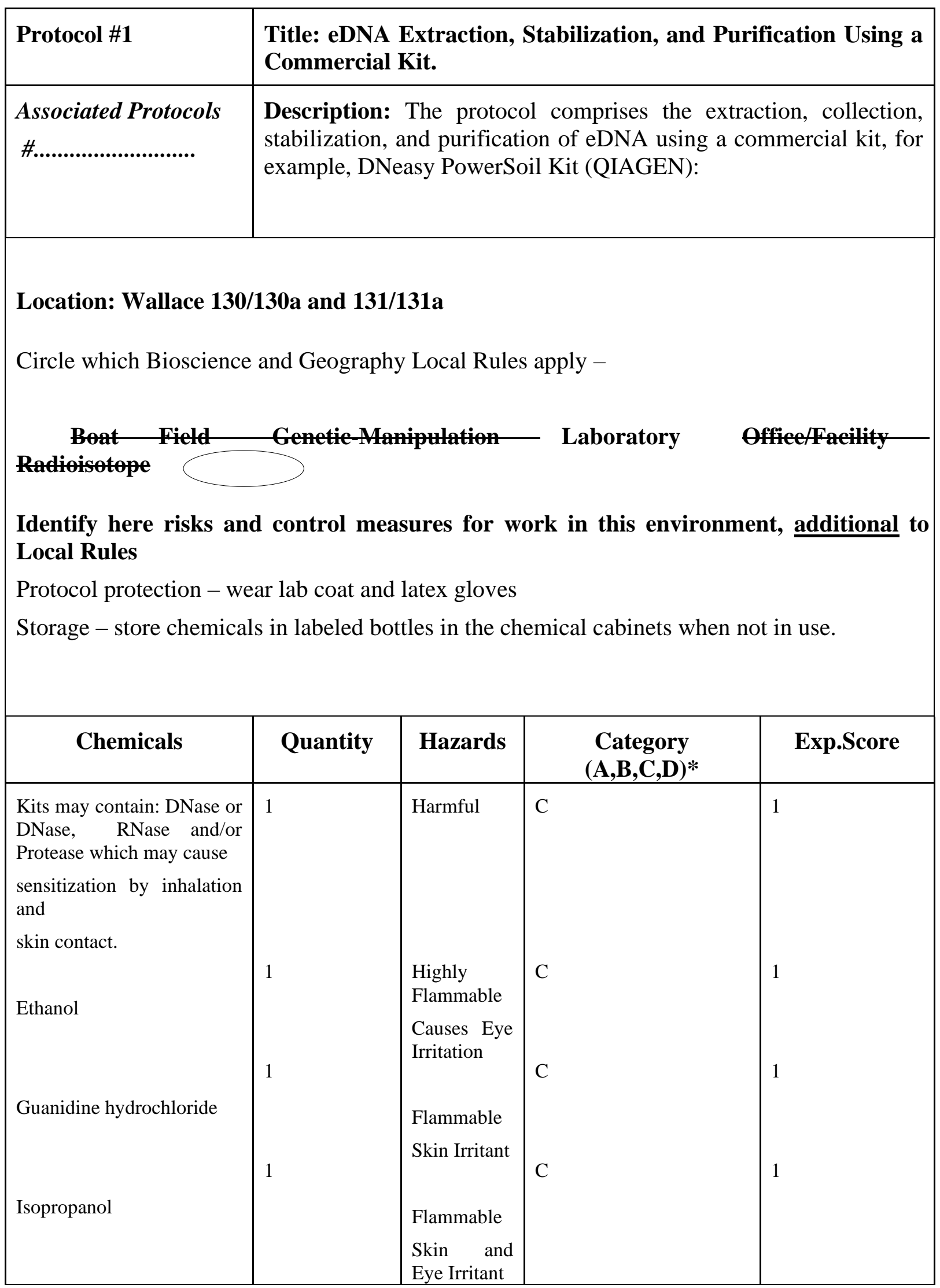




\begin{tabular}{|c|c|}
\hline 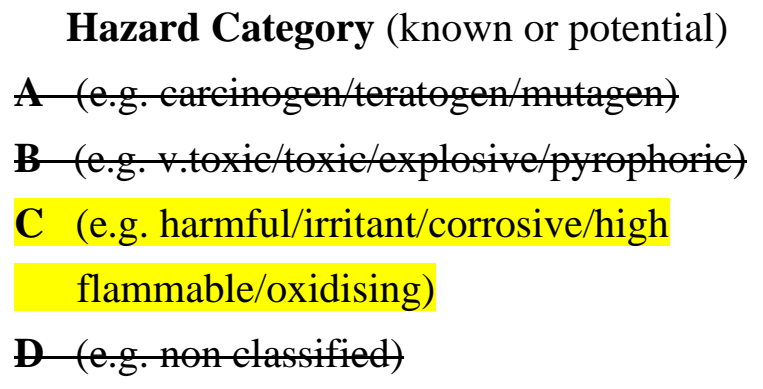 & $\begin{array}{l}\text { Exposure Potential Circle the highest } \\
\text { Exposure Score above. Use this to calculate } \\
\text { the exposure potential for the entire protocol } \\
\text { (see handbook). Indicate this value below. }\end{array}$ \\
\hline \multicolumn{2}{|c|}{$\begin{array}{l}\text { Storage conditions and maximum duration :- All components should be stored dry and at } \\
\text { room temperature. }\end{array}$} \\
\hline \multicolumn{2}{|c|}{$\begin{array}{l}\text { When stored under the recommended conditions and handled correctly, full efficacy of } \\
\text { reagents is retained until the expiry date indicated on the outer box label. Each bottle will be } \\
\text { labelled with date opened and initials. }\end{array}$} \\
\hline \multicolumn{2}{|c|}{ Secondary containment (of protocol) Fume-hood and open bench } \\
\hline \multicolumn{2}{|c|}{$\begin{array}{l}\text { Disposal Autoclaving of biohazardous material and sent to Swansea University chemical } \\
\text { disposal }\end{array}$} \\
\hline \multicolumn{2}{|c|}{ Identify other control measures Latex/Nitrile gloves and Laboratory Coat } \\
\hline \multicolumn{2}{|c|}{ Justification and controls for any work outside normal hours N/A } \\
\hline \multicolumn{2}{|c|}{ Emergency procedures Wipe up any spillages } \\
\hline \multicolumn{2}{|l|}{ After Inhalation } \\
\hline \multicolumn{2}{|c|}{$\begin{array}{l}\text { If unconscious place in recovery position and seek medical advice. } \\
\text { After Swallowing }\end{array}$} \\
\hline \multicolumn{2}{|c|}{$\begin{array}{l}\text { If accidentally swallowed obtain immediate medical attention. Rinse mouth with } \\
\text { water. Never give anything by mouth to an unconscious person. }\end{array}$} \\
\hline \multicolumn{2}{|l|}{ After Contact with Eyes } \\
\hline \multirow{2}{*}{\multicolumn{2}{|c|}{$\begin{array}{l}\text { Immediately flush eye(s) with plenty of water. Remove any contact lenses. Protect unharmed } \\
\text { eye. Rinse thoroughly with plenty of water for at least } 15 \text { minutes and consult a physician. } \\
\text { After Contact with Skin } \\
\text { Wash off immediately with soap and plenty of water while removing all contaminated clothes } \\
\text { and shoes }\end{array}$}} \\
\hline & \\
\hline \multirow{2}{*}{\multicolumn{2}{|c|}{$\begin{array}{l}\text { Supervision/training for worker } \\
\text { Already trained }\end{array}$}} \\
\hline & \\
\hline \multicolumn{2}{|c|}{$\begin{array}{l}\text { Declaration I declare that I have assessed the hazards and risks associated with my work } \\
\text { and will take appropriate measures to decrease these risks, as far as possible eliminating } \\
\text { them, and will monitor the effectiveness of these risk control measures. }\end{array}$} \\
\hline
\end{tabular}


Appendix 3: Ethics and health and safety

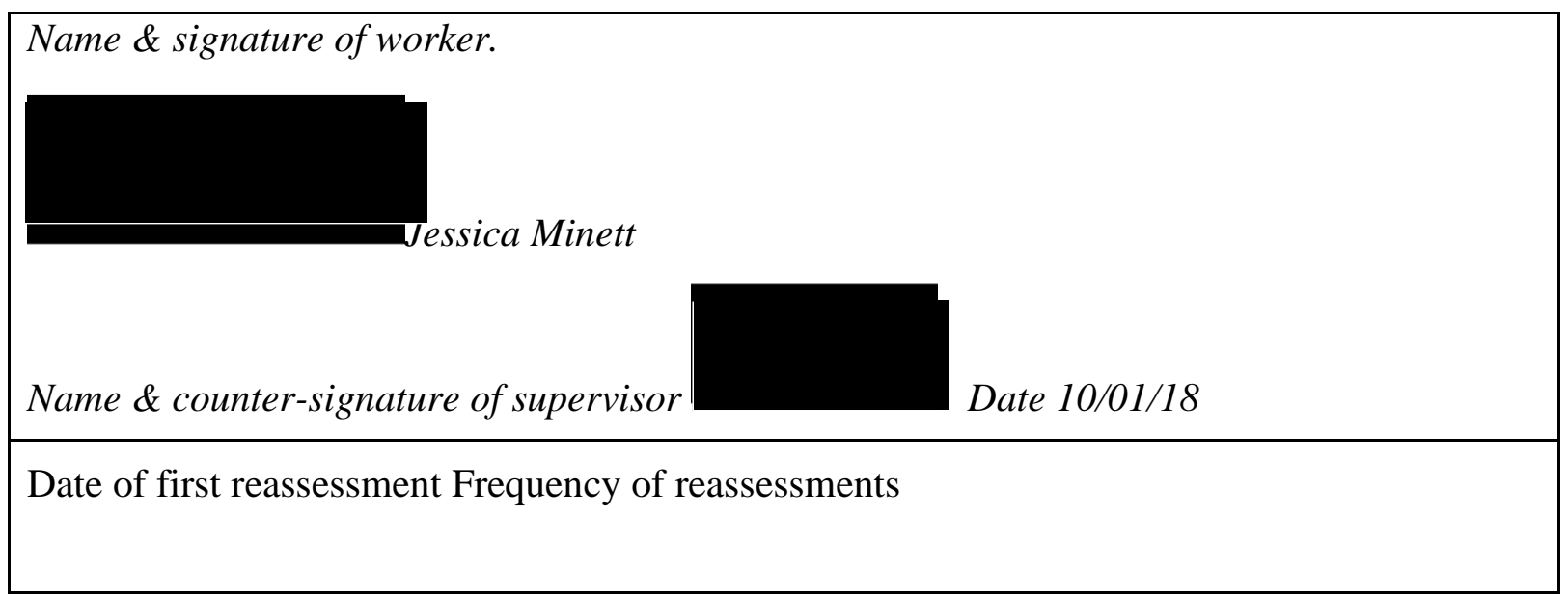


Bioscience and Geography Protocol Risk Assessment Form (Expand or contract fields, or append additional sheets as required; insert NA if not applicable)

\begin{tabular}{|l|l|}
\hline Protocol \#3 & Title: Nucleic acid Quantification \\
\hline $\begin{array}{l}\text { Associated Protocols } \\
\text { \#............................ }\end{array}$ & $\begin{array}{l}\text { Description: Nucleic acid Quantification using Nanodrop or Qubit. } \\
\text { Buantification imply sample preparation using fluorometer and } \\
\text { sensitive specific Qubit }\end{array}$ \\
\hline
\end{tabular}

\section{Location: N 130-Lab Qubit // N131-Nanodrop}

circle which Bioscience and Geography Local Rules apply -

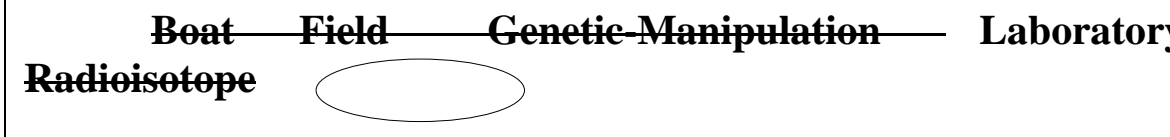

\section{Office/Facility}

Identify here risks and control measures for work in this environment, additional to Local Rules

Protocol protection - wear lab coat and latex gloves

Storage - store chemicals in labeled bottles in the chemical cabinets when not in use.

\begin{tabular}{|c|c|c|c|c|}
\hline Chemicals & Quantity & Hazards & $\begin{array}{c}\text { Category } \\
(\mathbf{A , B}, \mathbf{C}, \mathbf{D}) \\
*\end{array}$ & $\begin{array}{c}\text { Exp.Scor } \\
\text { e }\end{array}$ \\
\hline Qubit ${ }^{\circledR} \quad$ dsDNA $\quad$ BR & 1 & No Hazards & $\mathrm{D}$ & 1 \\
\hline $\begin{array}{l}\text { Reagent } * 200 \mathrm{X} \\
\text { concentrate in DMSO* }\end{array}$ & 1 & No Hazards & $\mathrm{D}$ & 1 \\
\hline Qubit ${ }^{\circledR} \quad$ dsDNA $\quad$ BR & 1 & No Hazards & $\mathrm{D}$ & 1 \\
\hline Buffer & 2 & No Hazards & $\mathrm{D}$ & 1 \\
\hline Qubit ${ }^{\circledR} \quad$ dsDNA $\quad$ BR & 1 & No Hazards & $\mathrm{D}$ & 1 \\
\hline Standards & 1 & No Hazards & $\mathrm{D}$ & 1 \\
\hline Qubit ${ }^{\circledR} \quad$ dsDNA $\quad$ HS & 1 & No Hazards & $\mathrm{D}$ & 1 \\
\hline $\begin{array}{l}\text { Reagent } \\
\text { concentrate in DMSO* }\end{array}$ & 2 & No Hazards & $\mathrm{D}$ & 1 \\
\hline Qubit ${ }^{\circledR}$ dsDNA HS Buffer & 1 & No Hazards & $\mathrm{D}$ & 1 \\
\hline Qubit ${ }^{\circledR} \quad$ dsDNA $\quad$ HS & 1 & No Hazards & $\mathrm{D}$ & 1 \\
\hline Standards & 1 & No Hazards & $\mathrm{D}$ & 1 \\
\hline Qubit ${ }^{\circledR} \quad$ dsRNA BR & 2 & No Hazards & $\mathrm{D}$ & 1 \\
\hline $\begin{array}{l}\text { Reagent } \\
\text { concentrate in DMSO* }\end{array}$ & 1 & No Hazards & $\mathrm{D}$ & 1 \\
\hline Qubit ${ }^{\text {dsRNA BR Buffer }}$ & 1 & No Hazards & $\mathrm{D}$ & 1 \\
\hline Qubit ${ }^{\circledR} \quad$ dsRNA $\quad$ BR & 1 & No Hazards & $\mathrm{D}$ & 1 \\
\hline Standards & 2 & No Hazards & $\mathrm{D}$ & 1 \\
\hline Qubit ${ }^{\circledR} \quad$ dsRNA $\quad$ HS & & & & \\
\hline
\end{tabular}


Appendix 3: Ethics and health and safety

\begin{tabular}{|c|c|c|c|}
\hline $\begin{array}{l}\text { Reagent }{ }^{* 200 X} \\
\text { concentrate in DMSO* } \\
\text { Qubit@ dsRNA HSBuffer } \\
\text { Qubit }{ }^{\circledR} \text { dsRNA BR } \\
\text { Standards }\end{array}$ & & & \\
\hline 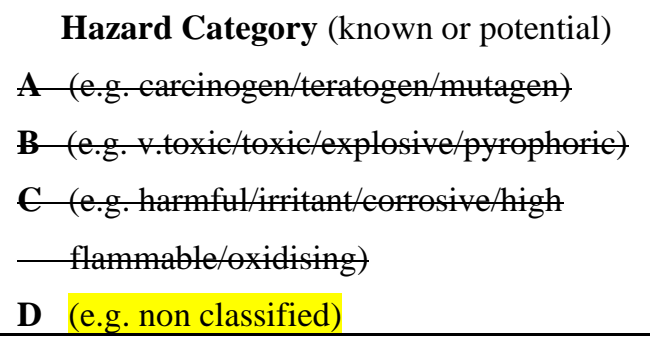 & \multicolumn{3}{|c|}{$\begin{array}{l}\text { Exposure Potential Circle the highest Exposure Score } \\
\text { above. Use this to calculate the exposure potential for the } \\
\text { entire protocol (see handbook). Indicate this value below. }\end{array}$} \\
\hline \multicolumn{4}{|c|}{$\begin{array}{l}\text { Primary containment (of product) sealed flask/bottle/glass/plastic/other (state) :- sealed bottle } \\
\text { Storage conditions and maximum duration :- Room temperature }\end{array}$} \\
\hline \multicolumn{4}{|c|}{ Secondary containment (of protocol) open bench/fume hood/special (state) :- OB } \\
\hline \multicolumn{4}{|c|}{ Disposal e.g. autoclaving of biohazard, SU chemical disposal: UWS chemical disposal } \\
\hline \multicolumn{4}{|c|}{$\begin{array}{l}\text { Identify other control measures (circle or delete) - latex/nitrile/heavy gloves; sereens; full face mask; } \\
\text { dust mask; protective shoes; spillage tray; ear-defenders; other (state) }\end{array}$} \\
\hline \multicolumn{4}{|c|}{ Justification and controls for any work outside normal hours N/A } \\
\hline
\end{tabular}




\section{SECTION 4: First aid measures}

Description of first aid measures

Skin contact

Eye contact

INGESTION

Inhalation

Notes to Physician
Rinse with plenty of water. Immediate medical attention is not required.

Rinse cautiously with water for several minutes. Remove contact lenses, if present and easy to do.

Not expected to present a significant ingestion hazard under anticipated conditions of normal use. If you feel unwell, seek medical advice.

Not expected to be an inhalation hazard under anticipated conditions of normal use of this material. Consult a physician if necessary.

Treat symptomatically.

Most important symptoms and effects, both acute and delayed

Not applicable.

Indication of any immediate medical attention and special treatment needed

None.

\section{SECTION 5: Firefighting measures}

Extinguishing media

Suitable Extinguishing Media

Unsuitable Extinguishing Media
Water spray. Carbon dioxide (CO2). Foam. Dry chemical. No information available.

Special hazards arising from the substance or mixture Not Known.

Advice for fire-fighters

Standard procedure for chemical fires.

\section{SECTION 6: Accidental release measures}

Personal precautions, protective equipment and emergency procedures

ELIMINATE all ignition sources (no smoking, flares, sparks or flames in immediate area). Use personal protection equipment. See Section 8 for more detail.

\section{Environmental precautions}

No special environmental precautions required. Avoid discharge into drains and waterways whenever possible.

Methods and material for containment and cleaning up

Soak up with inert absorbent material.

Reference to other sections

See section 8 for more information.

\section{Supervision/training for worker (circle)}

None required Already trained Training required Supervised always

Declaration I declare that I have assessed the hazards and risks associated with my work and will take appropriate measures to decrease these risks, as far as possible eliminating them, and will monitor the effectiveness of these risk control measures.

Name \& signature of worker

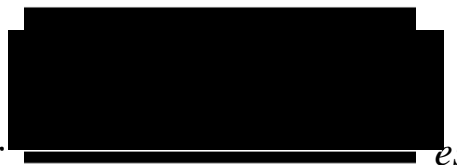

essica Minett

Name \& counter-signature of supervisor

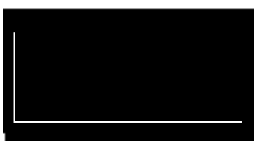

Date $10 / 01 / 18$ 


\section{Bioscience and Geography Protocol Risk Assessment Form}

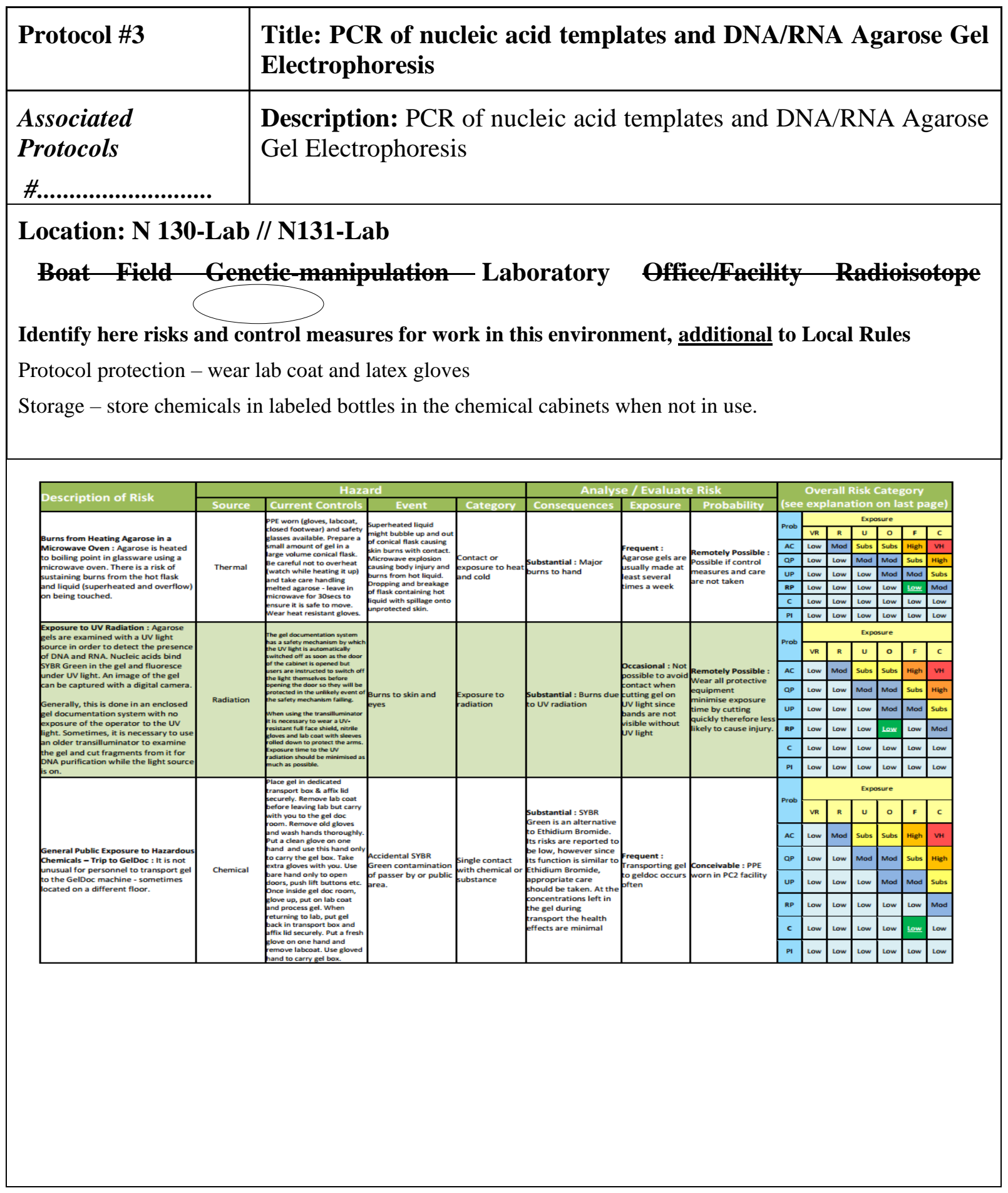


Appendix 3: Ethics and health and safety

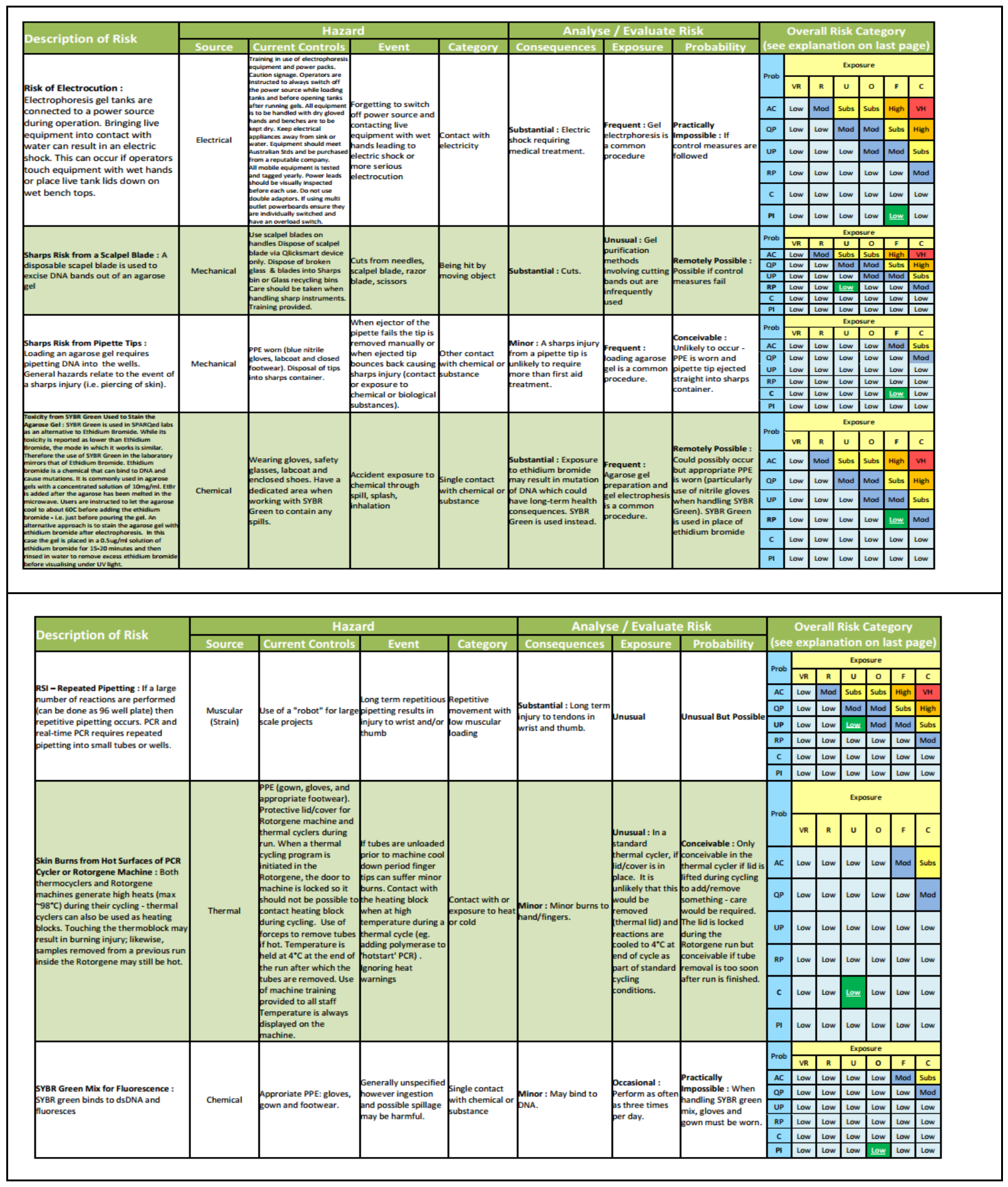




\section{Explanation of Overall Risk Categories \\ Explanation of Overall Risk Categories}

\begin{tabular}{|l|l|l|l|l|l|}
\hline Exposure & $\begin{array}{l}\text { Rare (R) - hardly every } \\
\text { occurs (but has been } \\
\text { known to occur) }\end{array}$ & $\begin{array}{l}\text { Unusual (U) - does not } \\
\text { occur often (from once } \\
\text { per month to once per } \\
\text { year) }\end{array}$ & $\begin{array}{l}\text { Occasional (O) - } \\
\text { sometimes occurs (from } \\
\text { once per week to once } \\
\text { per month) }\end{array}$ & $\begin{array}{l}\text { Frequent (F)- occurs } \\
\text { often (approximately } \\
\text { once daily) }\end{array}$ & $\begin{array}{l}\text { Continuous (C) - occurs } \\
\text { repeatedly (or many } \\
\text { times daily) }\end{array}$ \\
\hline
\end{tabular}

$\mid$\begin{tabular}{|l|l|l|l|l|l|}
\hline Probability (Prob) \\
\hline $\begin{array}{l}\text { Almost Certain (AC) - is } \\
\text { the most likely and } \\
\text { expected result if the } \\
\text { hazard event takes place }\end{array}$ & $\begin{array}{l}\text { Quite Possible (QP) - is } \\
\text { quite possible, not } \\
\text { unusual, has an even } \\
50 / 50 \text { chance }\end{array}$ & $\begin{array}{l}\text { Unlikely but Possible } \\
\text { (UP)-Would be an } \\
\text { unusual sequence or } \\
\text { coincidence }\end{array}$ & $\begin{array}{l}\text { Remotely Possible (RP) - } \\
\text { would be a remotely } \\
\text { possible coincidence }\end{array}$ & $\begin{array}{l}\text { Conceivable (C)- has } \\
\text { never happened after } \\
\text { many years of exposure, } \\
\text { but is conceivably } \\
\text { possible }\end{array}$ & $\begin{array}{l}\text { Practically Impossible } \\
\text { (P) - has never } \\
\text { happened after many } \\
\text { years of exposure and is } \\
\text { virtually impossible }\end{array}$ \\
\hline
\end{tabular}

\begin{tabular}{|l|l|l|l|l|}
\hline Overall Risk Category \\
\hline $\begin{array}{l}\text { Low - risk is normally } \\
\text { acceptable }\end{array}$ & $\begin{array}{l}\text { Moderate (Mod) - } \\
\text { should be dealt with as } \\
\text { soon as possible but } \\
\text { situation is not an } \\
\text { emergency }\end{array}$ & $\begin{array}{l}\text { Substantial (Subs) - } \\
\text { should receive attention } \\
\text { as soon as possible }\end{array}$ & $\begin{array}{l}\text { High - immediate } \\
\text { correction required }\end{array}$ & $\begin{array}{l}\text { Very High (VH) - } \\
\text { immediate correction } \\
\text { required }\end{array}$ \\
\hline
\end{tabular}

The Overall Risk Category for each element is highlighted in green.

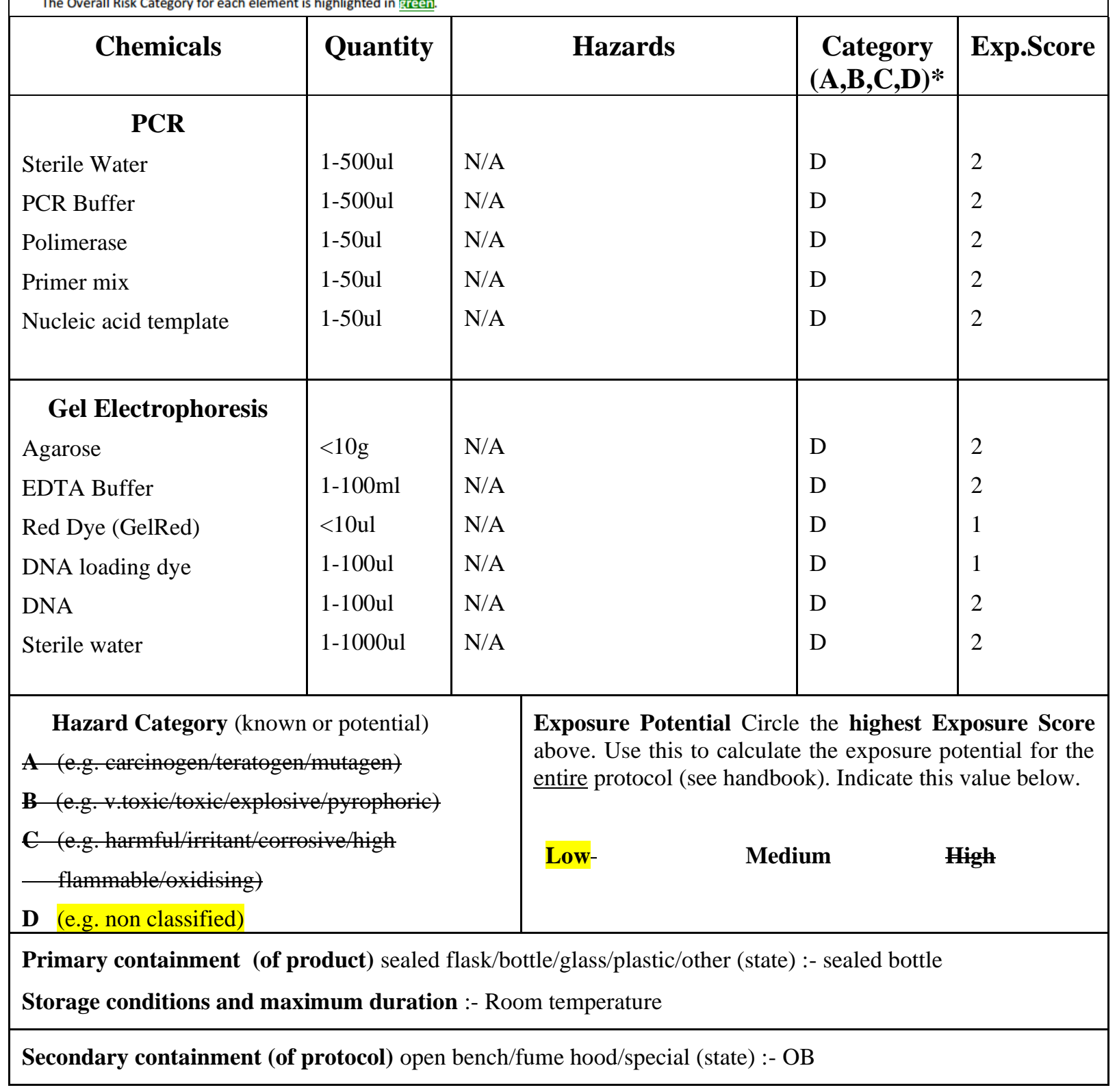


Disposal e.g. autoclaving of biohazard, SU chemical disposal: UWS chemical disposal

Identify other control measures (circle or delete) - latex/nitrile/heavy gloves; sereens; full face mask; dust mask; protective shoes; spillage tray; ear-defenders; other (state)

Justification and controls for any work outside normal hours N/A

Emergency procedures (e.g. spillage clearance; communication methods): Absorb spillage with liquid binding material

\section{Supervision/training for worker (circle)}

None required Already trained Training required Supervised always

Declaration I declare that I have assessed the hazards and risks associated with my work and will take appropriate measures to decrease these risks, as far as possible eliminating them, and will monitor the effectiveness of these risk control measures.

Name \& signature of worker.

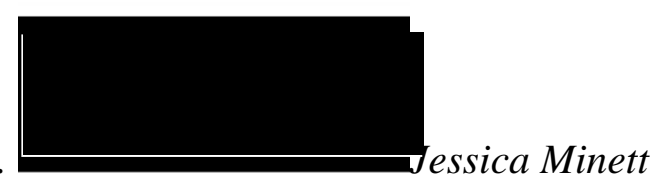

Name \& counter-signature of supervisor

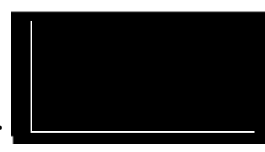

Date 10/01/18

Date of first reassessment 


\section{Bioscience and Geography Protocol Risk Assessment Form}

(Expand or contract fields, or append additional sheets as required; insert NA if not applicable)

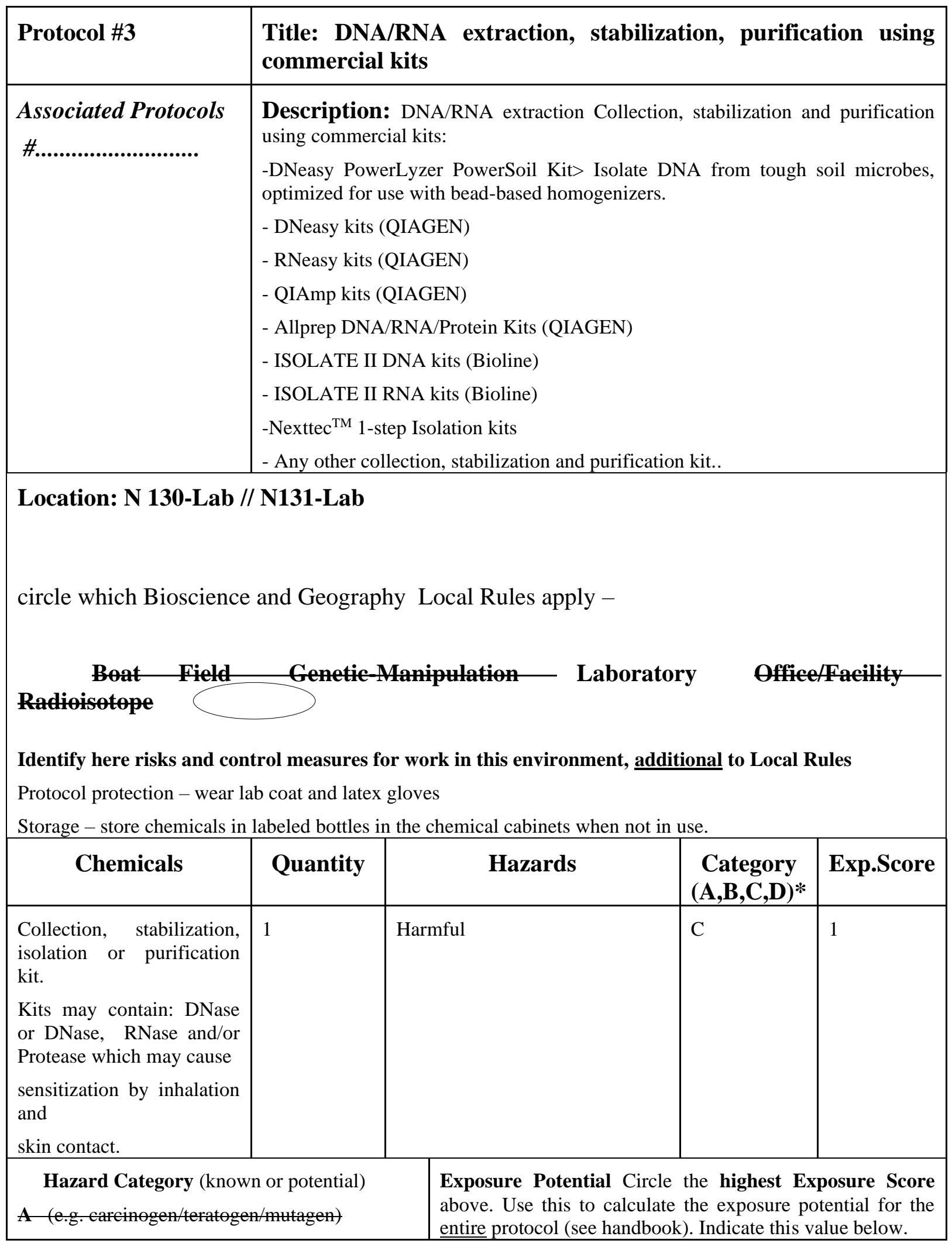




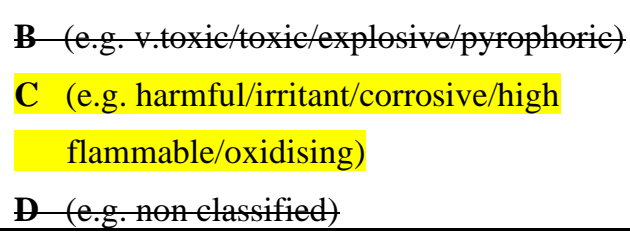

Primary containment (of product) sealed flask/bottle/glass/plastic/other (state) :- sealed bottle Storage conditions and maximum duration :- All components should be stored dry and at room temperature. When stored under the recommended conditions and handled correctly, full activity of reagents is retained until the expiry date indicated on the outer box label.

Secondary containment (of protocol) open bench/fume hood/special (state) :- OB

Disposal e.g. autoclaving of biohazard, SU chemical disposal: UWS chemical disposal

Identify other control measures (circle or delete) - latex/nitrile/heavy gloves; screens; full face mask; dust mask; protective shoes; spillage tray; ear defenders; other (state)

\section{Justification and controls for any work outside normal hours N/A}

Emergency procedures (e.g. spillage clearance; communication methods): Absorb spillage with liquid binding material

\section{After Inhalation}

Remove to fresh air. Keep airways free.

After Swallowing

Drink lots of water after ingestion.

\section{After Contact with Eyes}

Rinse eyes with running water with eyelids open. Tilt the head to prevent chemical transferring to uncontaminated eye.

\section{After Contact with Skin}

Remove contaminated clothing. Rinse the affected skin or mucous membrane thoroughly under running water. Use soap if possible.

\section{Note to Physician}

No additional recommendations

\section{Supervision/training for worker (circle)}

None required Already trained Training required Supervised always

Declaration I declare that I have assessed the hazards and risks associated with my work and will take appropriate measures to decrease these risks, as far as possible eliminating them, and will monitor the effectiveness of these risk control measures.

Name \& signature of worker.

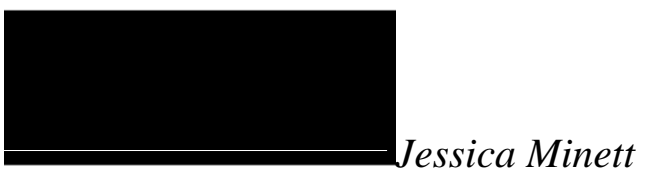

Name \& counter-signature of supervisor

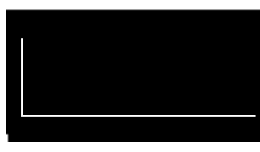

Date 10/01/18 
Appendix 3: Ethics and health and safety

Date of first reassessment

Frequency

of reassessments 
Bioscience and Geography Protocol Risk Assessment Form (Expand or contract fields, or append additional sheets as required; insert NA if not applicable)

\begin{tabular}{|l|l|}
\hline Protocol \#3 & Title: Real time quantitative PCR \\
\hline $\begin{array}{l}\text { Associated Protocols } \\
\text { \#............................... }\end{array}$ & $\begin{array}{l}\text { Description: reverse transcription RNA. Quantitative PCR and high resolution } \\
\text { melt curve analysis of cDNA/DNA with SYBR Green }\end{array}$ \\
\hline
\end{tabular}

\section{Location: N 130-Lab // N131-Lab}

circle which Bioscience and Geography Local Rules apply -

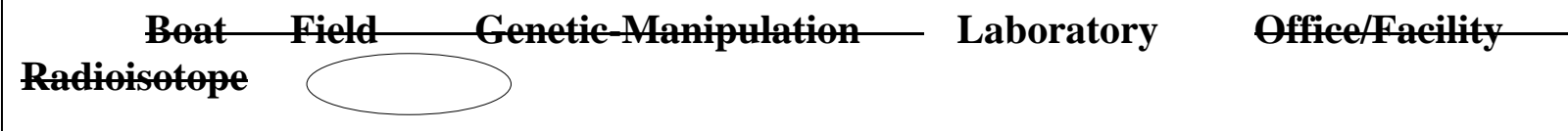

Identify here risks and control measures for work in this environment, additional to Local Rules

Protocol protection - wear lab coat and latex gloves

Storage - store chemicals in labeled bottles in the chemical cabinets when not in use.

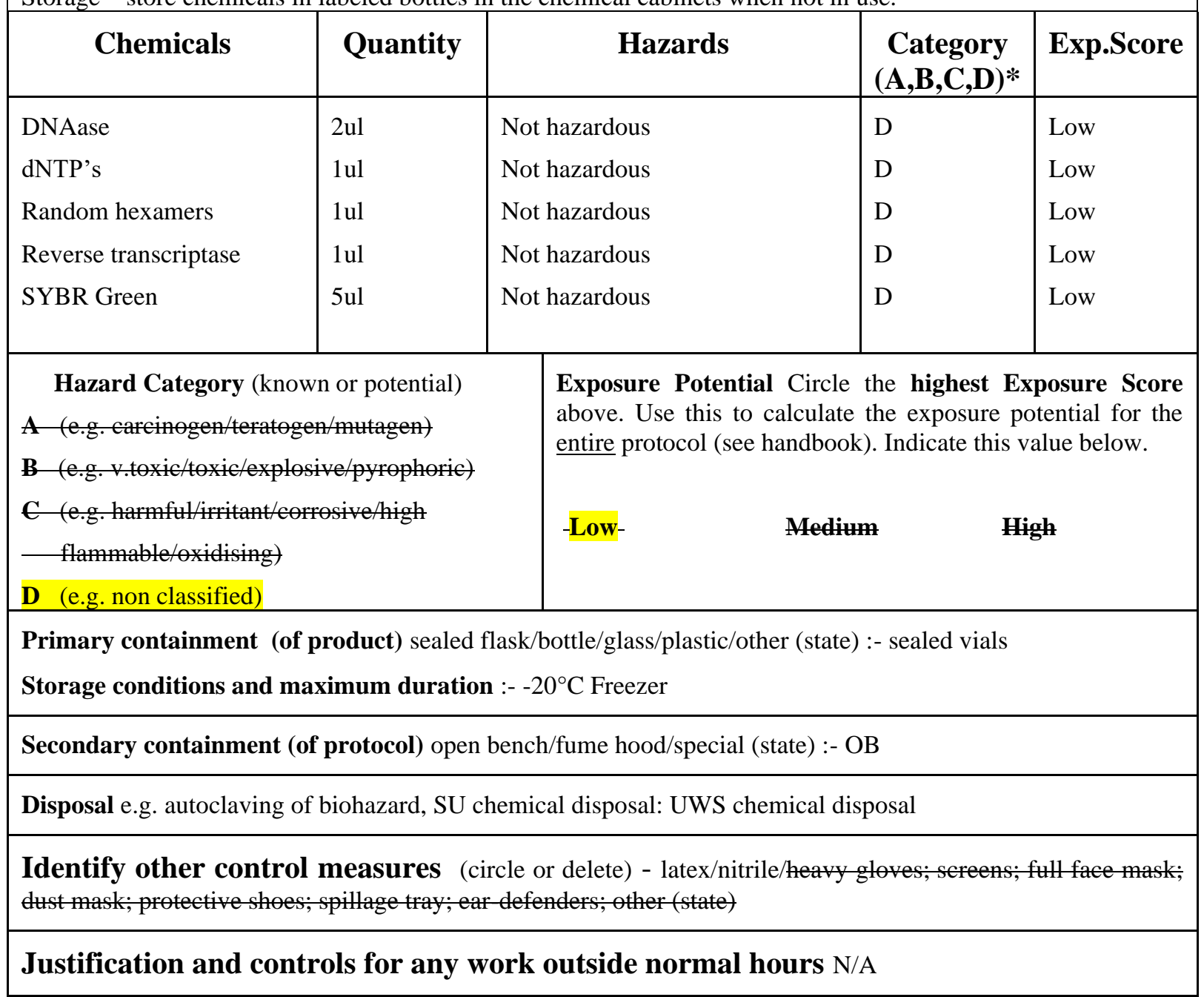


Emergency procedures (e.g. spillage clearance; communication methods): Absorb spillage with liquid binding material and dispose of safely

\section{After Swallowing}

Drink lots of water after ingestion.

\section{After Contact with Eyes}

Rinse eyes with running water with eyelids open. Tilt the head to prevent chemical transferring to uncontaminated eye.

\section{After Contact with Skin}

Remove contaminated clothing. Rinse the affected skin or mucous membrane thoroughly under running water. Use soap if possible.

\section{Supervision/training for worker (circle)}

None required Already trained Training required Supervised always

Declaration I declare that I have assessed the hazards and risks associated with my work and will take appropriate measures to decrease these risks, as far as possible eliminating them, and will monitor the effectiveness of these risk control measures.

Name \& signature of worker.

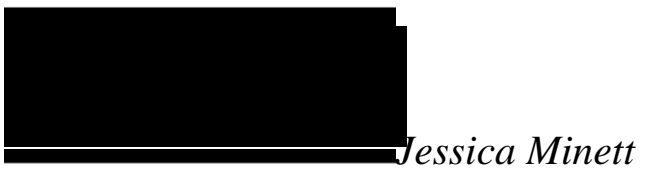

Name \& counter-signature of supervisor

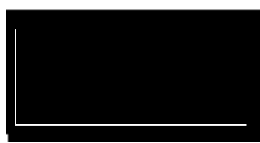

Date $10 / 01 / 18$ 


\section{Bioscience and Geography Protocol Risk Assessment Form}
(Expand or contract fields, or append additional sheets as required; insert NA if not applicable)

\begin{tabular}{|l|l|}
\hline Protocol \#3 & Title: DNA extraction from animal tissue \\
\hline $\begin{array}{l}\text { Associated } \\
\text { Protocols } \\
\text { \#........................... }\end{array}$ & Description: working in the laboratory extracting DNA from animal tissue \\
\hline
\end{tabular}

Location: N 130-Lab // N131-Lab

circle which Bioscience and Geography Local Rules apply -

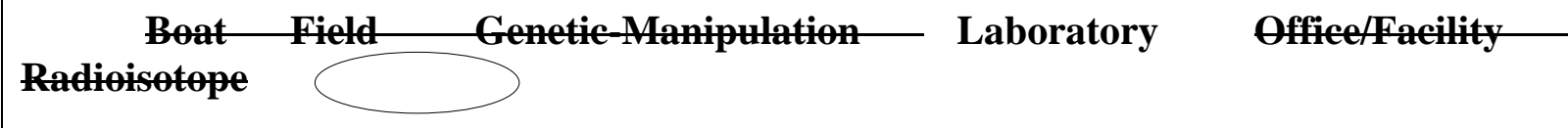

Identify here risks and control measures for work in this environment, additional to Local Rules

Protocol protection - wear lab coat and latex gloves

Storage - store chemicals in labeled bottles in the chemical cabinets when not in use.

\begin{tabular}{|l|l|l|l|l|}
\hline \multicolumn{1}{|c|}{ Chemicals } & Quantity & Hazards & Category (A,B,C,D)* & Exp.Score \\
\hline $\begin{array}{l}\text { Nexttec TM 1-step DNA } \\
\text { Isolation Kit }\end{array}$ & 1 & Harmful & C & 1 \\
\hline
\end{tabular}

Hazard Category (known or potential)

A (e.g. carcinogen/teratogen/mutagen)

B- (e.g. v.toxic/toxic/explosive/pyrophoric)

C (e.g. harmful/irritant/corrosive/high

flammable/oxidising)

D (e.g. non classified)
Exposure Potential Circle the highest Exposure Score above. Use this to calculate the exposure potential for the entire protocol (see handbook). Indicate this value below.

Low

Medium

High

Primary containment (of product) sealed flask/bottle/glass/plastic/other (state) :- sealed bottle

Storage conditions and maximum duration :- -room temperature

Secondary containment (of protocol) open bench/fume hood/special (state) :- OB

Disposal e.g. autoclaving of biohazard, SU chemical disposal: UWS chemical disposal

Identify other control measures (circle or delete) - latex/nitrile/heavy gloves; sereens; full face mask; dust mask; protective shoes; spillage tray; ear-defenders; other (state)

Justification and controls for any work outside normal hours N/A

Emergency procedures (e.g. spillage clearance; communication methods): Absorb spillage with liquid binding material and dispose of safely

Supervision/training for worker (circle) 
Appendix 3: Ethics and health and safety

\begin{tabular}{|l|l|}
\hline None required Already trained Praining required Supervised always \\
\hline $\begin{array}{l}\text { Declaration I declare that I have assessed the hazards and risks associated with my work and will take appropriate } \\
\text { measures to decrease these risks, as far as possible eliminating them, and will monitor the effectiveness of these risk control } \\
\text { measures. }\end{array}$ \\
$\begin{array}{l}\text { Name \& signature of worker. } \\
\text { Name \& counter-signature of supervison }\end{array}$ \\
\hline $\begin{array}{l}\text { Date of first reassessment } \\
\text { reassessments }\end{array}$ \\
\hline
\end{tabular}




\section{Bioscience and Geography Protocol Risk Assessment Form}

(Expand or contract fields, or append additional sheets as required; insert NA if not applicable)

\begin{tabular}{|l|l|}
\hline Protocol \#3 & Title: PCR of DNA templates \\
\hline $\begin{array}{l}\text { Associated Protocols } \\
\text { \#............................ }\end{array}$ & Description: PCR of DNA templates \\
\hline
\end{tabular}

Location: N 130-Lab // N131-Lab

circle which Bioscience and Geography Local Rules apply -

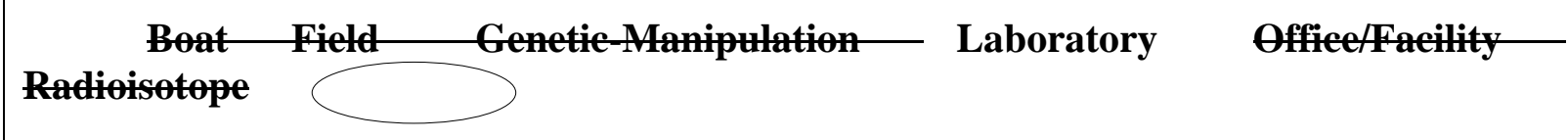

Identify here risks and control measures for work in this environment, additional to Local Rules

Protocol protection - wear lab coat and latex gloves

Storage - store chemicals in labeled bottles in the chemical cabinets when not in use.

\begin{tabular}{|c|c|c|c|c|}
\hline Chemicals & Quantity & Hazards & $\begin{array}{c}\text { Category } \\
(\mathbf{A}, \mathbf{B}, \mathbf{C}, \mathbf{D}) *\end{array}$ & Exp.Score \\
\hline Sterile water & 1-500ul & N/A & $\mathrm{D}$ & 2 \\
\hline PCR buffer & 1-500ul & N/A & $\mathrm{D}$ & 2 \\
\hline Primer mix & $1-50 \mathrm{ul}$ & N/A & $\mathrm{D}$ & 2 \\
\hline DNA & $1-50 \mathrm{ul}$ & N/A & $\mathrm{D}$ & 2 \\
\hline \multirow{2}{*}{\multicolumn{2}{|c|}{$\begin{array}{l}\text { Hazard Category (known or potential) } \\
\text { A } \text { (e.g. carcinogen/teratogen/mutagen) } \\
\text { B } \text { (e.g. v.toxic/toxic/explosive/pyrophoric) } \\
\text { C } \text { (e.g. harmful/irritant/corrosive/high } \\
\quad \text { flammable/oxidising) } \\
\text { D } \\
\text { (e.g. non classified) }\end{array}$}} & \multicolumn{3}{|c|}{$\begin{array}{l}\text { Exposure Potential Circle the highest Exposure Score } \\
\text { above. Use this to calculate the exposure potential for the } \\
\text { entire protocol (see handbook). Indicate this value below. }\end{array}$} \\
\hline & & -Low- & $\mathbf{H i}_{\xi}$ & \\
\hline \multicolumn{5}{|c|}{$\begin{array}{l}\text { Primary containment (of product) sealed flask/bottle/glass/plastic/other (state) :- sealed bottle } \\
\text { Storage conditions and maximum duration :- room temperature }\end{array}$} \\
\hline \multicolumn{5}{|c|}{ Secondary containment (of protocol) open bench/fume hood/special (state) :- OB } \\
\hline \multicolumn{5}{|c|}{ Disposal e.g. autoclaving of biohazard, SU chemical disposal: UWS chemical disposal } \\
\hline
\end{tabular}




\section{Justification and controls for any work outside normal hours N/A}

Emergency procedures (e.g. spillage clearance; communication methods): Absorb spillage with liquid binding material and dispose of safely

\section{Supervision/training for worker (circle)}

None required Already trained Training required Supervised always

Declaration I declare that I have assessed the hazards and risks associated with my work and will take appropriate measures to decrease these risks, as far as possible eliminating them, and will monitor the effectiveness of these risk control measures.

Name \& signature of worker.

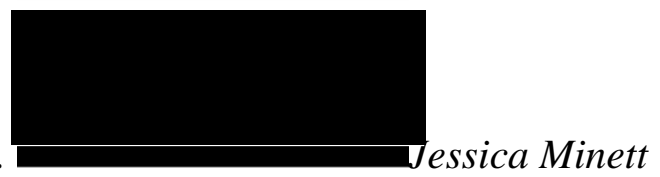

Name \& counter-signature of supervisor

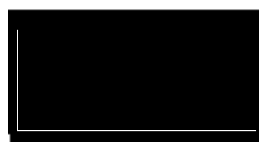

Date $10 / 01 / 18$

Date of first reassessment 


\section{Bioscience and Geography Protocol Risk Assessment Form}

(Expand or contract fields, or append additional sheets as required; insert NA if not applicable)

\begin{tabular}{|l|l|}
\hline Protocol \#3 & Title: Working out of hours \\
\hline Associated Protocols & Description: Working out of hours in the office/lab environment of N037, \\
\#.............................. & N130 and N131Wallace Building \\
\hline
\end{tabular}

Location: N 130-Lab // N131-Lab // N037-Office

circle which Bioscience and Geography Local Rules apply -



Identify here risks and control measures for work in this environment, additional to Local Rules

Fire safety - sign in and out of hours book in the foyer

Local security - do not let others into the building

Working prolonged periods - see VDU Safety

Laboratory work must not take place without supervision and prior assent from supervisor due to risks involved

\begin{tabular}{|l|l|l|l|l|}
\hline \multicolumn{1}{|c|}{ Chemicals } & \multicolumn{1}{|c|}{ Quantity } & \multicolumn{1}{c|}{ Hazards } & $\begin{array}{c}\text { Category } \\
\text { (A,B,C,D)* }\end{array}$ & Exp.Score \\
\hline N/A & & & \\
\hline \multicolumn{1}{|c|}{ Hazard Category (known or potential) } \\
A (e.g. carcinogen/teratogen/mutagen) \\
B-(e.g. v.toxic/toxic/explosive/pyrophoric) \\
C (e.g. harmful/irritant/corrosive/high \\
$\begin{array}{l}\text { flammable/oxidising) } \\
\text { D (e.g. non classified) }\end{array}$ & $\begin{array}{l}\text { Exposure Potential Circle the highest Exposure Score } \\
\text { above. Use this to calculate the exposure potential for the } \\
\text { entire protocol (see handbook). Indicate this value below. }\end{array}$ \\
\hline $\begin{array}{l}\text { Primary containment (of product) sealed flask/bottle/glass/plastic/other (state) :- N/A } \\
\text { Storage conditions and maximum duration :- N/A }\end{array}$ \\
\hline Secondary containment (of protocol) open bench/fume hood/special (state) :- N/A \\
\hline Disposal e.g. autoclaving of biohazard, SU chemical disposal: N/A \\
\hline Identify other control measures (circle or delete) - none \\
\hline $\begin{array}{l}\text { Justification and controls for any work outside normal hours - access to building to access } \\
\text { samples for analysis. Requirement to check welfare of livestock }\end{array}$ \\
\hline
\end{tabular}


Appendix 3: Ethics and health and safety

Emergency procedures (e.g. spillage clearance; communication methods) - telephone communications

\section{Supervision/training for worker (circle)}

None required Already trained Training required Supervised always

Declaration I declare that I have assessed the hazards and risks associated with my work and will take appropriate measures to decrease these risks, as far as possible eliminating them, and will monitor the effectiveness of these risk control measures.

Name \& signature of worker.

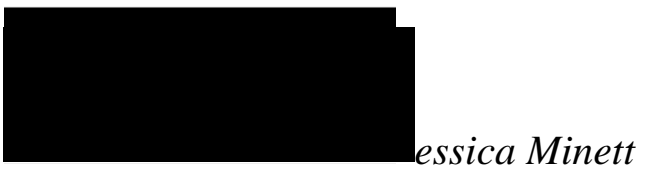

Name \& counter-signature of supervisor

Date 10/01/18

Date of first reassessment 


\section{Bioscience and Geography Protocol Risk Assessment Form}

(Expand or contract fields, or append additional sheets as required; insert NA if not applicable)

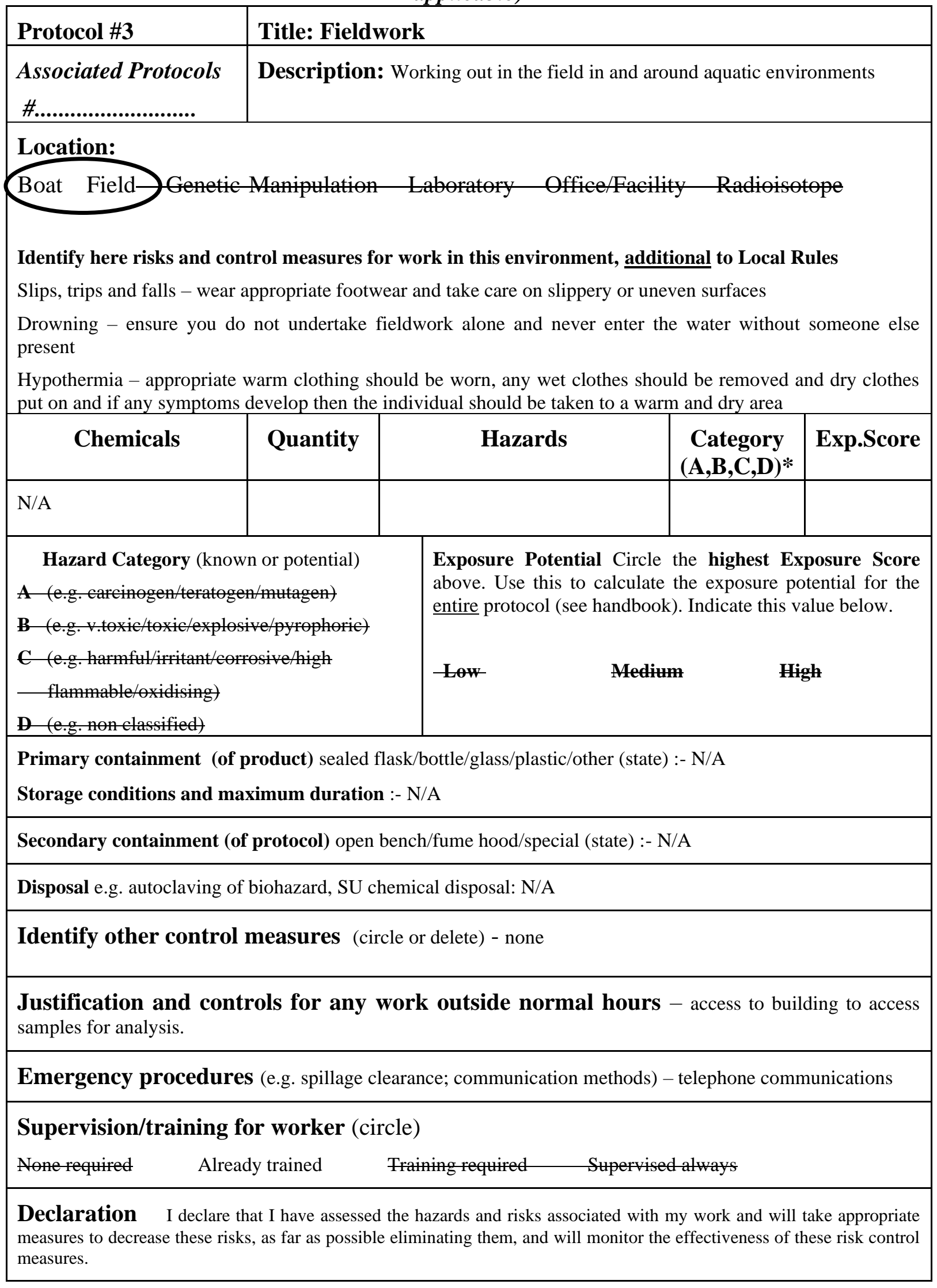


Appendix 3: Ethics and health and safety

\begin{tabular}{|l|l|}
\hline Name \& signature of worker & Date 10/01/18 \\
Name \& counter-signature of supervison & Frequency \\
\hline $\begin{array}{l}\text { Date of first reassessment } \\
\text { reassessments }\end{array}$ & \\
\hline
\end{tabular}




\section{Bioscience and Geography Protocol Risk Assessment Form}

(Expand or contract fields, or append additional sheets as required; insert NA if not applicable)




Appendix 3: Ethics and health and safety

\begin{tabular}{|l|l|}
\hline Name \& signature of worker. & \\
Name \& counter-signature of supervisor & Date 10/01/18 \\
\hline $\begin{array}{l}\text { Date of first reassessment } \\
\text { reassessments }\end{array}$ & Frequency \\
\hline
\end{tabular}


PROJECT PROPOSAL AND RISK ASSESSMENT FOR THE CONTAINED USE OF GENETICALLY MODIFIED ORGANISMS

Section 1: General information

\subsection{PROJECT SUPERVISOR}

\begin{tabular}{ll}
\hline Surname: & Consuegra \\
\hline Forename: & Sonia \\
\hline Email address: & \\
\hline College/Department/Other: & College of Science/Department of Biosciences \\
\hline
\end{tabular}

\subsection{Title of Project}

Brown trout in the Falkland Islands: invasion ecology, population structure and genetic diversity

\subsection{GM PROJECT NUMBER (SCBHGM TO ALLOCATE)}

\subsection{IS THIS PROPOSAL IS AN EXTENSION OF A PREVIOUSLY-APPROVED PROJECT? \\ If so please tick box and enter previous reference number.

\begin{tabular}{|l|l|}
\hline Previously-approved project & $\square$ Yes $\otimes$ No \\
\hline Previous reference number & \\
\hline
\end{tabular}

Please complete the form, emphasising the connection between the original project and this application.

\subsection{PROJECT LAY SUMMARY}

Please describe the project, detailing aims and objectives, significance and outcomes, indicating how the GMMs will help to achieve the objectives of the project. This description should contain enough detail to help a non-specialist to understand the project.

The project aims to determine the distribution of fish in the Falkland Islands using environmental 
DNA. Water samples were collected from a number of streams across the Islands. From these samples an $89 \mathrm{bp}$ and $139 \mathrm{bp}$ fragment of the cytochrome $\mathrm{b}$ region of the mitochondrial genome were amplified. The DNA fragments amplified cannot be expressed. Several products were amplified; therefore, cloning and subsequent sequencing is necessary to validate the intended targets.

\subsection{IS THIS GM ACTIVITY GOING TO FORM PART OF AN UNDERGRADUATE PRACTICAL CLASS?}

If yes please provide details:

No

\section{Section 2: Details of genetic modification}

Please complete:

- Part A for Genetically modified microorganisms and/or

- Part B for Genetically modified higher organisms.

Part A: Projects involving the contained use of genetically modified microorganisms (GMMs).

2A.1 THE IDENTITY, SOURCE ORGANISM AND FUNCTION OF EACH SEQUENCE OF GENETIC MATERIAL TO BE INSERTED/MODIFIED.

Mitochondrial DNA from the fish...

$2 \mathrm{~A} .2$ Is the donor organism pathogenic?

IF SO WHAT HARM DOES IT CAUSE.

No

2A.3 If the donor organisms has pathological or harmful characteristics, are the donated sequences implicated in them.

IF YES PLEASE GIVE DETAILS.

N/A

2A.4 Will the sequences cause harm if expressed in humans after accidental transfer? 
IF YES, WHAT HARM WOULD OCCUR AND HOW SEVERE WOULD IT BE?

No

2A.5 Will the sequences cause harm if transferred to species in the environment

IF YES, WHAT HARM WOULD OCCUR AND HOW SEVERE WOULD IT BE?

No

2A.6 Identity of the vector(s), and nature of any potential harmful properties(to humans and/or the environment).

INCLUDE IN YOUR DESCRIPTION THEIR ABILITY TO MOBILISE AND THE PRESENCE OF ACTIVE PROMOTERS OF EXPRESSION.

NOTE: DISABLES VIRUSES USED AS A VECTOR SHOULD BE TREATED AS RECIPIENT ORGANISMS.

Linearized plasmid for T-A cloning such as $\mathrm{PGEM}^{\circledR} \mathrm{T}$ (Promega) or $\mathrm{PCR}^{\mathrm{TM}}$ 2.1. vector (Invitrogen). These vectors are not harmful to humans or the environment. These vectors are mobilization defective or non-mobilizable (i.e., the genomic information contained in the plasmid cannot be transferred from a bacterial cell to another).

2A.6 If using a disabled viral vector, state its origin and the mechanisms of attenuation.

\section{N/A}

2A.7 State identity [Species, strain(s)] and ACDP/SAPO hazard category of all recipient microorganisms.

E. coli (e.g., strain JM109, DH5-alpha) - lab adapted strains with a long history of safe use equivalent to ACDP 1

2A.8 Are the intended recipient organisms pathogenic to humans?

IF YES WHAT HARM WILL THEY DO AND HOW SEVERE IS THE HARM?

No

2A.9 Are the intended recipient organisms capable of independent survival in the environment, or will infect or transfer to other hosts? 


\section{IF YES PLEASE GIVE DETAILS}

No. E. coli JM109 or DH5-alpha contains several disabling mutations, and is therefore considerably attenuated, and unlikely to be competitive in the environment.

2A.10 Natural host (if any) of recipient organism(s) and routes of transmission/infection (if known).

N/A

2A.11 Characteristics of the genetically modified microorganisms. What effect will the modification have on the intended recipient organisms?

Include in your description any changes to pathogenicity or toxicity to humans

None. E. coli is only used for cloning and plasmid replication and storage.

2A.12 Will the modification alter the recipient organisms ability to survive in the environment, compete with other organisms or transfer to them the inserted sequences?

IF YES PLEASE GIVE DETAILS.

No. E. coli JM109 or DH5 -alpha contains several disabling mutations, and is therefore considerably attenuated, and unlikely to be competitive in the environment.

Part B: Projects involving the contained use of larger genetically modified organisms.

\section{B.1 LIST THE IDENTIFY OF ALL RECIPIENT ORGANISM(S)}

Give common and scientific names and where relevant strain, cultivar or subspecies designations

2B.2 Identity of the host/vector system or the method used for genetic modification

2B.3 Nature and identity of any toxic, allergenic or other potentially harmful effects attributed to the recipient organism, or its metabolic products 
2B.4 Origin and intended function of inserted genetic material. Identify any harmful effects attributable to the inserted sequences

2B.5 Do these LGMO pose greater risk to humans than the unmodified parental organism

$\begin{array}{lll}\text { Yes } & \square\end{array}$

Please summarise the justification for this statement

\section{Section 3: Risk Assessment}

Please complete:

- Part A for Genetically modified microorganisms and/or

- Part B for Genetically modified higher organisms.

\subsection{Part A: Risk Assessment for Working with Genetically modified microorganisms}

3A.1 SUMMARISE ALL POTENTIALLY HAZARDOUS PROPERTIES OF EACH GMM IN RELATION TO HUMAN SAFETY.

Do not forget hazardous properties of the parental organism.

Consider ALL properties of the host, vector, insert, and of the final GMM

E. coli JM109 or DH5-alpha is classified as not hazardous to humans

E. coli $\mathrm{DH} 5$ alpha is classified as not hazardous to humans.

\Laboratory workers, co-workers and other staff and students accessing laboratories

$\square$ other ...

3A.2 Do any of these GMM pose a potential hazard to the environment?

CONSIDER ANIMALS, PLANTS ETC.

Yes

No

Х 
Please justify this statement.

The potential ecological risk due to exposure to Escherichia coli JM109 or DH5 alpha is likely to be minimal.

3A.3 What would be the consequence of these hazards being realised?

FOR THE PURPOSE OF THIS ASSESSMENT, ASSUME THAT THERE ARE NO BARRIERS TO PREVENT EXPOSURE. PLEASE GIVE DETAILS OF THE EXPECTED CONSEQUENCES AND USE THE TERMS "SEVERE, MEDIUM, LOW OR NEGLIGIBLE"

A. On human health

Negligible

B. On the environment

Negligible

3A.4 Is it possible to substitute these GMM with a safer alternative?

Yes $\square$ No $\quad$ \

Please justify this statement.

Transformation of mitochondrial genes into $E$. coli are necessary for gene sequencing and storage of the clone sequences.

3A.5Likelihood of hazards associated with GMM being realised.

State the maximum culture volume to be used at any one time

$60 \mathrm{ml}$ (Three 90-mm Petri dishes)

$20 \mathrm{ml}$ of bacterial culture

Identify all types of operation with potential for dispersal (e.g. centrifugation, sonication, aspiration)

Plates and cultures will be inoculated on the bench close to a gas flame to protect samples from contamination.

Do any of these activities generate aerosols of splashes which could pose a risk to the worker? If so please provide details 
No

If so is a Microbiological safety cabinet used to control these risks? If yes, please provide details of cabinet and location.

No

Are the GMM's to be centrifuged?

Yes

If so will sealed rotors and buckets be used for this and where will these buckets be opened?

Open bench

Please describe the culture conditions for the GMMs. E.g. shacking incubator, static shelves, rotary platforms etc.

Static Shelves and shaking incubators.

3A.6 PLEASE DESCRIBE THE TYPE OF WASTE GENERATED AND ITS DISINFECTION AND DISPOSAL ROUTE.

Remember to include liquid waste, sharps, solid waste.

Solid media in Petri dishes, culture supernatant, tips, serological pipettes, and tubes.

What is the expected degree of kill

$100 \%$

How do you know that this degree of kill will be achieved

Autoclaving waste material for 40 minutes at $136{ }^{\circ} \mathrm{C}$ is more than sufficient to $E$. coli. Likewise, $2 \%$ biocleanse or $2 \%$ bleach for $12 \mathrm{~h}$ is enough to disinfect glassware and other labware. Waste will be autoclaved at 132 for 30 minutes. A designated autoclave for GMO organisms is located in the Wallace Building room 001. This autoclave is regularly (at least once a year) validated using a 12point thermocouple technique. Staff technicians keep records of the validation. Once autoclaved the waste will be placed in tiger bags and disposed into the autoclave skip situated in the car park between Margam and ILS1.

3A.7 Please describe the emergency procedures for dealing with spills of GMMs 
Microbial spill kits are available in lab 131A. This spill kit consists of paper towels, to absorb the bulk of the spill, concentrated biocleanse or suitable disinfectant, and disposable gloves, sharp container, and biohazard bags. In the event of a spill, the user will notify everybody in the lab. If any, the user will remove the sharps (broken glass) with tweezers or a spatula and dustpan and put them in the sharp container. Subsequently, the user will cover the spills with disinfectant to a final concentration of $2 \%$ and paper towels. The solution will be allowed to sit for 10 minutes before removing the paper towels, which will be disposed of in a biohazard bag. Surface will be cleaned down with a $2 \%$ disinfectant solution. Paper towels, and gloves will be placed in the biohazard bag, which will be sealed and disposed of appropriately. Utensils used to clean up the spill (e.g., tweezers, spatula, dustpan) will be disinfected with $2 \%$ biocleanse solution.

3A.8 Are animals to be infected with these GMOs?

IF YES PLEASE PROVIDE DETAILS.

No

3A.9 Are the GMM to be transported outside the laboratory to other areas of the university? IF SO PLEASE PROVIDE DETAILS.

No

3A.10 Are the GMM to be transported outside Singleton campus?

IF SO PLEASE PROVIDE DETAILS.

No

3A.11 Are any microorganism or nucleic acid derived from a microorganism which is listed under Schedule 5 of the Anti-terrorism crime and security act 2001 as amended?

\begin{tabular}{llll}
\hline Yes & $\square$ & No & \
\end{tabular}

If yes - please provide details....

3A.12 Estimation of risk magnitude - to human health and safety

Based on the likelihood of exposure to GMM (following the procedures described above) and the 
severity of the consequence of exposure, please select an estimation of risk magnitude from the matrix below.

\begin{tabular}{lllll}
\hline & & & Likelihood \\
& & & \\
Consequence & Probable & Possible & Unlikely & $\begin{array}{l}\text { Highly } \\
\text { improbable }\end{array}$ \\
& & & \\
\hline Severe & $\square$ High & $\square$ High & $\square$ Medium & $\square$ Effectively 0 \\
\hline Moderate & $\square$ High & $\square$ Medium & $\square$ Medium/low & $\square$ Effectively 0 \\
\hline Minor & $\square$ Medium/Low & $\square$ Low & $\square$ Low & $\square$ Effectively 0 \\
\hline Negligible & $\square$ Effectively 0 & $\square$ Effectively 0 & $\square$ Effectively 0 & 区Effectively 0 \\
\hline
\end{tabular}

IF NOT "EFFECTIVELY O" PLEASE DESCRIBE THE ADDITIONAL MEASURES REQUIRED TO CONTROL THE RISK.

N/A

3A.13 Estimation of risk magnitude - to the environment

Based on the likelihood of release of GMM (following the procedures described above) and the severity of the consequence of release, please select an estimation of risk magnitude from the matrix below.

\begin{tabular}{|c|c|c|c|c|}
\hline & \multicolumn{4}{|c|}{ Likelihood } \\
\hline Consequence & Probable & Possible & Unlikely & $\begin{array}{l}\text { Highly } \\
\text { improbable }\end{array}$ \\
\hline Severe & $\square$ High & $\square$ High & $\square$ Medium & $\square$ Effectively 0 \\
\hline Moderate & $\square$ High & $\square$ Medium & $\square$ Medium/low & $\square$ Effectively 0 \\
\hline Minor & $\square$ Medium/Low & $\square$ Low & $\square$ Low & $\square$ Effectively 0 \\
\hline Negligible & $\square$ Effectively 0 & $\square$ Effectively 0 & $\square$ Effectively 0 & 区Effectively 0 \\
\hline
\end{tabular}


IF NOT "EFFECTIVELY O" PLEASE DESCRIBE THE ADDITIONAL MEASURES REQUIRED TO CONTROL THE RISK.

N/A

3.A.14 Please state the proposed class of GM activity

(Class 1, 2 or 3)

Class 1

Section 3B: Working with Larger Genetically modified organisms

3B.1 IDENTIFY ALL POTENTIALLY HAZARDOUS PROPERTIES OF THE LGMOS TO HUMAN HEALTH AND SAFETY

Take into account any toxic or allergenic effects, new reservoir for pathogens etc.

3B.2 Identify persons who could be exposed to the hazard.

3B.3 What are the consequences of exposure of humans to these hazards?

3B.4 What are the measures put in place to prevent or control the risk?

3B.5 Identify all potentially hazardous properties of the IGMO's to the environment

ABILITY TO TRANSFER GENES TO OTHER ORGANISMS, COLONISE NEW ECOSYSTEMS, IMPROVED SURVIVAL ETC

3B.6 What would be the consequence of release of these LHMO's on the local environment

PLEASE GIVE DETAILS OF THE EXPECTED CONSEQUENCES AND USE THE TERMS "SEVERE, 
MEDIUM, LOW OR NEGLIGIBLE"

3B.7 Describe the likely routes of release of the GMHO

3B.8 Describe the physical control measures that will be in place to minimise or prevent such release and identify control measures required to manage the risks.

3B.9 Describe the waste routes for GMHO (contaminated) material

3B.10 Estimation of risk magnitude - to human health and safety

Based on the likelihood of exposure to LGMO (following the procedures described above) and the severity of the consequence of exposure please select an estimation of risk magnitude from the matrix below.

Likelihood

\begin{tabular}{lllll}
\hline Consequence & Probable & Possible & Unlikely & Highly \\
& & & improbable \\
\hline Severe & $\square$ High & $\square$ High & $\square$ Medium & $\square$ Effectively 0 \\
\hline Moderate & $\square$ High & $\square$ Medium & $\square$ Medium/low & $\square$ Effectively 0 \\
\hline Minor & $\square$ Medium/Low & $\square$ Low & $\square$ Low & $\square$ Effectively 0 \\
\hline Negligible & $\square$ Effectively 0 & $\square$ Effectively 0 & $\square$ Effectively 0 & $\square$ Effectively 0 \\
\hline If not "effectively 0" please describe the additional measures required to control the risk.
\end{tabular}

3B.11 Estimation of risk magnitude - to the environment

Based on the likelihood of release of LGMO (following the procedures described above) and the severity of the consequence of release please select an estimation of risk magnitude from the 


\begin{tabular}{|c|c|c|c|c|}
\hline \multicolumn{5}{|l|}{ matrix below. } \\
\hline \multirow{3}{*}{ Consequence } & \multicolumn{4}{|c|}{ Likelihood } \\
\hline & Probable & Possible & Unlikely & Highly \\
\hline & & & & improbable \\
\hline Severe & $\square$ High & $\square$ High & $\square$ Medium & $\square$ Effectively 0 \\
\hline Moderate & $\square$ High & $\square$ Medium & $\square$ Medium/low & $\square$ Effectively 0 \\
\hline Minor & $\square$ Medium/Low & $\square$ Low & $\square$ Low & $\square$ Effectively 0 \\
\hline Negligible & $\square$ Effectively 0 & $\square$ Effectively 0 & $\square$ Effectively 0 & $\square$ Effectively 0 \\
\hline \multicolumn{5}{|c|}{ If not "effectively 0" please describe the additional measures required to control the risk. } \\
\hline
\end{tabular}

3B.12 Please state the proposed class of GM activity

As safe as unmodified parental organism

Harmful - pose additional risk to humans than the unmodified parental organism

\section{Section 4: Administration}

\subsection{FACILITY DETAILS}

\begin{tabular}{l|l}
\hline Building & Wallace Building \\
\hline Laboratory number \\
\hline Containment level
\end{tabular}

3.2 Local contacts please provide details of your college

\begin{tabular}{ll}
\hline Health and Safety Coordinator & Dr Christopher Coates
\end{tabular}

GM /Biological safety Officer Dr Almudena Ortiz-Urquiza 


\section{Lone Working Risk Assessment Form}

\begin{tabular}{|l|l|l|}
\hline $\begin{array}{l}\text { Lone Workers Name: } \\
\text { Jessica Minett }\end{array}$ & Role of Lone Worker: PhD Student & Number of people exposed: 1 \\
\hline School/College: College of Science & Department: Bioscience & Review date: 04/03/2020 \\
\hline $\begin{array}{l}\text { Risk assessment carried out by: Jessica Minett } \\
\text { and Sofia Consuegra }\end{array}$ & Date completed:03/03/20 & \\
\hline $\begin{array}{l}\text { Description of work activity : Cloning DNA mitochondrial DNA } \\
\text { fragments that cannot be expressed from fish for sequencing }\end{array}$ & Assessor's signature: Sofia Consuegra & \\
\hline
\end{tabular}

\begin{tabular}{|c|c|c|c|c|}
\hline Hazard: & $\begin{array}{l}\text { Controls and precautions against the } \\
\text { hazards: }\end{array}$ & $\begin{array}{l}\text { Comments/ Action Required (including who } \\
\text { and when): }\end{array}$ & Action Party: & By when: \\
\hline \multicolumn{5}{|l|}{ Individual } \\
\hline $\begin{array}{l}\text { Medical fitness: Is the Lone } \\
\text { Worker subject to any } \\
\text { medical condition that may } \\
\text { place them at increased risk } \\
\text { when working alone. } \\
\text { [Where they may be in } \\
\text { doubt refer the Lone Worker } \\
\text { to Human Resources or } \\
\text { Student Support] }\end{array}$ & $\begin{array}{l}\text { The Lone Worker must ensure that any } \\
\text { medical conditions which might be } \\
\text { relevant to their working alone are fully } \\
\text { discussed with their line manager and, if } \\
\text { necessary, Occupational Health and own } \\
\text { GP. Individuals must not work alone if any } \\
\text { such condition is assessed as placing them } \\
\text { at increased risk. Any person who requires } \\
\text { assistance to get out of the building in an } \\
\text { emergency must not work alone. }\end{array}$ & $\begin{array}{l}\text { No known medical conditions that will increase } \\
\text { risk of working alone. }\end{array}$ & & \\
\hline
\end{tabular}




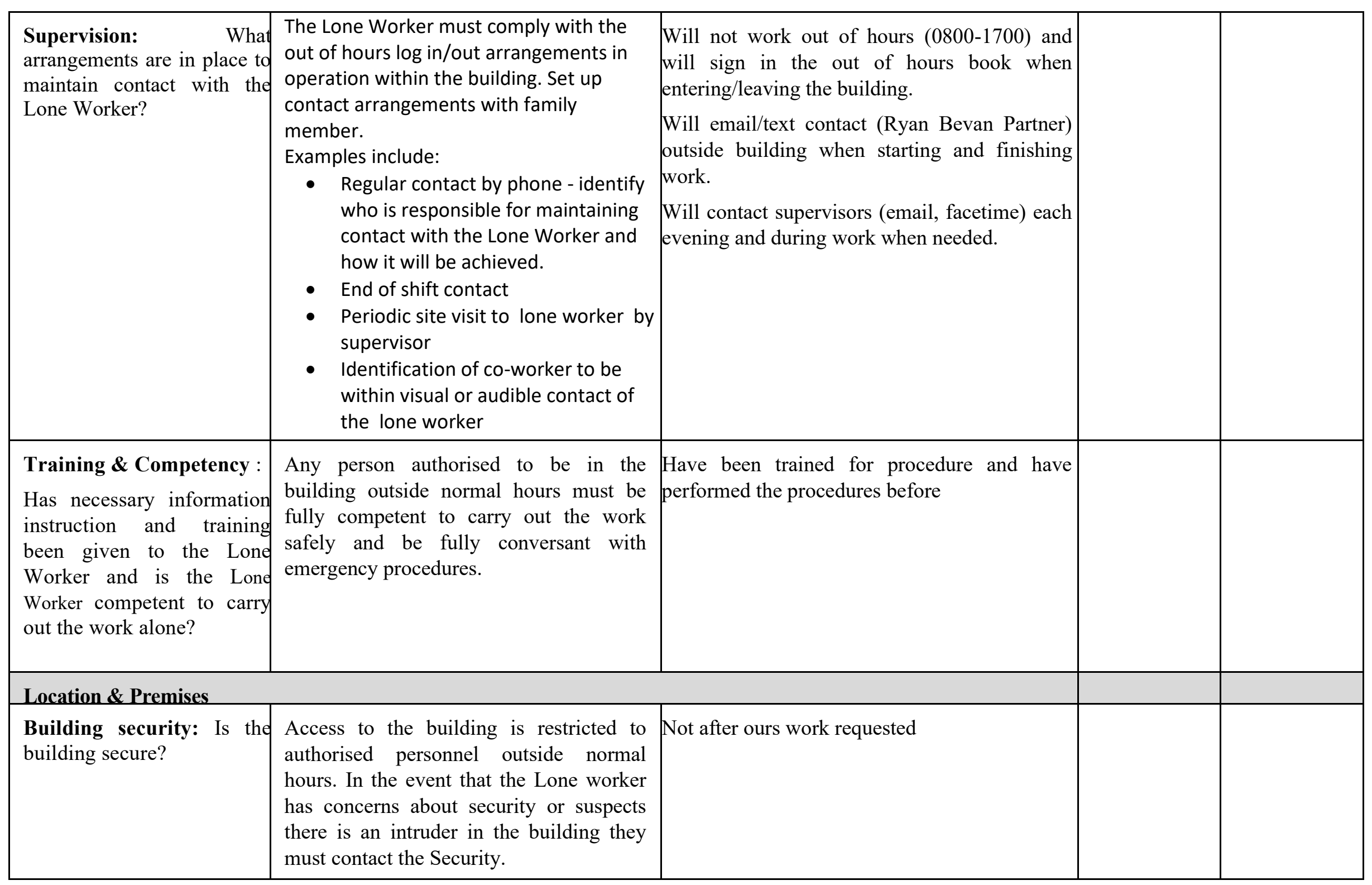




\begin{tabular}{|c|c|c|}
\hline $\begin{array}{l}\text { Access: Is there a safe } \\
\text { means of access/egress for } \\
\text { the lone worker (consider } \\
\text { lighting and personal } \\
\text { security issues and means } \\
\text { of escape in emergency) }\end{array}$ & $\begin{array}{l}\text { Entrances in the vicinity of the building and } \\
\text { car park are well lit. The Lone Worker } \\
\text { should plan how to get to car/public } \\
\text { transport after leaving, taking account of } \\
\text { potential personal safety issues. }\end{array}$ & Will aces building during the day only \\
\hline $\begin{array}{l}\text { Emergencies: Does the } \\
\text { Lone Worker have access to } \\
\text { emergency warning devices } \\
\text { to raise the alarm in event } \\
\text { of emergency e.g. fire } \\
\text { alarm, motion sensors } \\
\text { /manual device (panid } \\
\text { alarms). }\end{array}$ & $\begin{array}{l}\text { Lone Workers must know local } \\
\text { arrangements on how respond in event of } \\
\text { fire or other emergency. }\end{array}$ & Arranged \\
\hline $\begin{array}{l}\text { First aid: Are there } \\
\text { arrangements in place to } \\
\text { deal with a situation where } \\
\text { the Lone Worker becomes ill } \\
\text { or has an accident? (Access } \\
\text { to First aiders and facilities) }\end{array}$ & $\begin{array}{l}\text { First aiders are unlikely to be present. First } \\
\text { aid boxes are available and contents } \\
\text { checked regularly. In the event of a Lone } \\
\text { Worker feeling unwell they should if } \\
\text { possible return home or contact the } \\
\text { Security for assistance. }\end{array}$ & Arranged for emergencies with supervisors \\
\hline $\begin{array}{l}\text { Welfare facilities: Is } \\
\text { there adequate heating, } \\
\text { lighting, access to } \\
\text { drinking water and toilets. }\end{array}$ & $\begin{array}{l}\text { The Lone Worker should be aware that } \\
\text { heating/cooling in the area may be much } \\
\text { reduced unless the business need for after } \\
\text { hours working has been established. }\end{array}$ & Aware of lack of heating in the building \\
\hline
\end{tabular}






